\title{
Head and Neck Cancer Invasion: Contributions of Actin Regulatory Proteins and the Microenvironment
}

\author{
Elyse Lindsey Walk
}

Follow this and additional works at: https://researchrepository.wvu.edu/etd

\section{Recommended Citation}

Walk, Elyse Lindsey, "Head and Neck Cancer Invasion: Contributions of Actin Regulatory Proteins and the Microenvironment" (2014). Graduate Theses, Dissertations, and Problem Reports. 6887.

https://researchrepository.wvu.edu/etd/6887

This Dissertation is protected by copyright and/or related rights. It has been brought to you by the The Research Repository @ WVU with permission from the rights-holder(s). You are free to use this Dissertation in any way that is permitted by the copyright and related rights legislation that applies to your use. For other uses you must obtain permission from the rights-holder(s) directly, unless additional rights are indicated by a Creative Commons license in the record and/ or on the work itself. This Dissertation has been accepted for inclusion in WVU Graduate Theses, Dissertations, and Problem Reports collection by an authorized administrator of The Research Repository @ WVU.

For more information, please contact researchrepository@mail.wvu.edu. 


\title{
Head and Neck Cancer Invasion: Contributions of Actin Regulatory Proteins and the Microenvironment
}

\author{
Elyse Lindsey Walk
}

Dissertation Submitted to the School of Medicine at West Virginia University In Partial Fulfillment of the Requirements for the Degree of

Doctor of Philosophy in Cancer Cell Biology

\author{
Michael Schaller, Ph.D., Chair \\ John Hollander, Ph.D. \\ Karen Martin, Ph.D. \\ Elena Pugacheva, Ph.D. \\ Robert Wysolmerski, Ph.D. \\ Scott Weed, Ph.D., Mentor \\ Cancer Cell Biology Program \\ Morgantown, West Virginia \\ 2014
}

Keywords: HNSCC, Coronin 1B, Cortactin, High-frequency Ultrasound, Cervical Lymph Nodes 


\begin{abstract}
Head and Neck Cancer Invasion: Contributions of Actin Regulatory Proteins and the Microenvironment

Elyse L. Walk
\end{abstract}

\begin{abstract}
Metastasis of primary tumor lesions is the leading cause of cancer-related death. In head and neck cancer, a local-regional disease, metastasis is achieved mainly through invasion into surrounding tissue and spreads to cervical lymph nodes. Movement from the initial tumor site requires dynamic reorganization of the actin cytoskeleton, which utilizes the coordinated action of many actin regulatory proteins. However, there is increasing evidence that the tumor microenvironment is also a driver of invasion. This work aims to determine the contributions of proteins which regulate the actin cytoskeleton during head and neck cancer invasion both in vitro and in vivo, and provide details on how the HNSCC tumor microenvironment influences progression. This was accomplished, by the following Studies. In Study one, the actin binding protein coronin 1B is found to be amplified and overexpressed in invasive HNSCC patient samples, and a novel function in the regulation of protrusive membrane structures called invadopodia is described. Study two defines an in vivo role for the actin regulatory protein cortactin, which has been previously associated with more aggressive cancers in vitro and in patients. This work finds that cortactin expression is dispensable for tongue tumor invasion in a transgenic model of oral cancer, implicating the tumor microenvironment as being the major contributor to driving oral cancer invasion. Study three describes a technique for monitoring and biopsying cervical lymph nodes of mice using high frequency ultrasound. By using this technique, alterations in cervical lymph node size and blood flow were discovered in mice given the carcinogen 4-NQO to induce oral carcinogenesis. Collectively, these studies shed light on the importance of choosing comprehensive model systems for studying roles of actin binding proteins in cancer invasion.
\end{abstract}




\section{ACKNOWLEDGEMENTS}

This has been quite the journey for me, with lots of ups and downs, but l've finally managed to make it through to the end. Thank you to all of my friends and family who have helped me along the way.

l'd like to start with a big thank you to my parents, Jeff and Debi Walk, for always trying to help me out in whatever way possible, even if you had no idea what I was doing or what those "blue cells" were.

To my mentor, Dr. Scott Weed, thank you for your invaluable guidance and training which has helped me develop my skills as an independent researcher, and for your confidence in my abilities during good and bad science times. I have definitely learned a lot during my time in your lab and will take that with me in my future endeavors.

Thank you to my committee, you are truly a great group of people to work with. Whenever someone mentions how rough committee meetings are, I have always been able to honestly reply how helpful and supportive mine has been.

To past and present members of the Weed lab: You all are awesome. Thanks for getting me through the rough patches and laughing with me during the good. Mandy, thanks helping to create the single greatest memory I have of graduate school. You know what I'm talking about. Karen, don't worry, l'll still use your Audible credits for you. And Steve, thanks for being my buddy over the past few years. I will miss our wine and classic video game nights.

To Sarah M, a lot of this work couldn't have been done without you. Thank you for the many hours spent imaging mice in the dark, and for all your help with everything.

I also have to thank my study group: Bridget, Cat and Izzy. You made the last several months of grad school go by in such a fun way despite the stresses of it all. Thanks for getting me through it all and having a few beers along the way.

I can't forget my weightlifting crew as well. You guys rock and I'm seriously going to miss class and techno ab time. I could always count on you all to de-stress.

Lastly, I feel that it's only fitting that I conclude this with the same words of wisdom I used in my high school yearbook, from the great Homer Simpson: "I am so smart. I am so smart. I am so smart. S-M-R-T ... Uh, I mean S-M-A-R-T."

Ewok out. 


\section{TABLE OF CONTENTS}

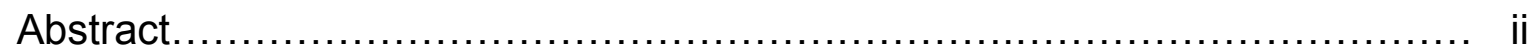

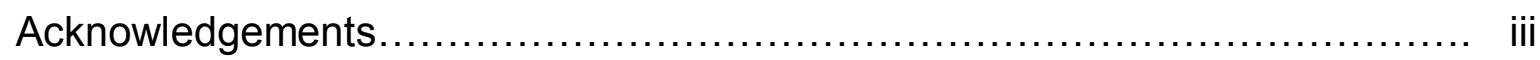

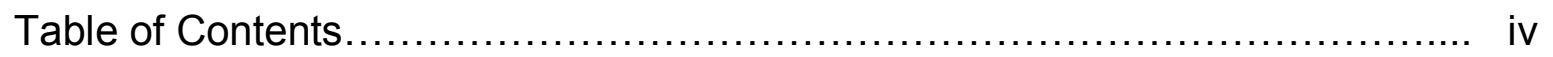

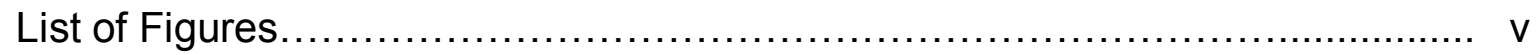

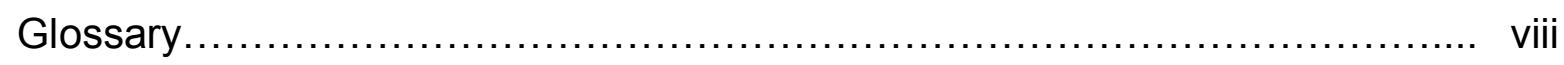

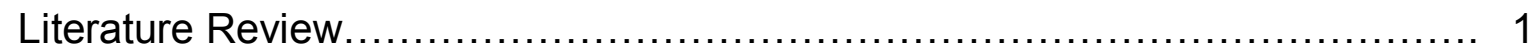

Head and neck squamous cell carcinoma Imaging HNSCC

Migratory modes during cancer cell invasion

The many faces of cortactin: Regulation of actin cytoskeletal dynamics in cancer cell motility and invasion

Coronin 1B promotes actin regulatory protein and network turnover

Study 1: Coronin 1B is Required for Invadopodia Function and Invasion in HNSCC.

Study 2: Cortactin is not required for carcinogen-induced head and neck squamous cell carcinoma invasion

Study 3: Use of High Frequency Ultrasound to Monitor Cervical Lymph Node Alterations in Mice.

General Discussion.

Appendix

Recently Validated Biomarkers That Promote Lymph Node Metastasis in Head and Neck Squamous Cell Carcinoma.

Quantitative Measurement of Invadopodia-mediated Extracellular Matrix Proteolysis in Single and Multicellular Contexts. ...

Detection and Biopsy of Cervical Lymph Node Alterations by High Frequency Ultrasound.

Curriculum Vitae. 


\section{LIST OF FIGURES AND TABLES}

\section{Literature Review}

Table

1. Common chromosomal alterations in HNSCC

Figures

1. Modes of migration.

2. Cortactin domain interactions and functions.

3. Domains of Coronin 1B.

4. Coronin $1 \mathrm{~B}$ antagonizes cortactin function.

\section{Study 1}

1. CORO1B is co-amplified and overexpressed with CTTN in HNSCC patient samples.

2. Coronin 1B is expressed in HNSCC cell lines and co-localizes with cortactin to mature invadopodia.

3. Coronin 1B depletion from HNSCC cells disrupts invadopodia function and reduces 3D spheroid invasion.

4. Coronin 1B knockdown alters cell spreading and FAK expression.

\section{Study 2}

1. Generation of mice with oral epithelium-specific cortactin knockout.

2. Cortactin knockout does not affect development of invasive tongue squamous cell carcinoma.

3. Cortactin knockout in HNSCC does not alter EMT.

4. Cortactin cKO tumors have increased collagen and CD31 positive vessels.

5. Cortactin knockout does not influence MMP14 expression in 4-NQO-induced HNSCC tumors.

\section{Supplemental Figures}

1. Cre recombination in $\mathrm{Cttn}^{\text {floxflox }}$ mice.

\section{Study 3}

1. Mapping of mouse cervical lymph nodes by high frequency ultrasound.

2. Image-guided fine needle biopsy of FasI mandibular lymph nodes.

3. 4-NQO exposure induces precancerous alterations in mouse mandibular lymph nodes.

4. 4-NQO treatment induces paracortical/T-cell zone hyperplasia in mandibular lymph nodes. 


\section{Supplemental Figures}

1. Visualization of regions within the mouse neck by high-frequency ultrasound.

2. 4-NQO exposure induces changes in mouse tongue epithelium similar to human HNSCC and results in cervical lymph node metastasis.

\section{Supplemental Videos}

1. Image-guided fine needle biopsy of Fasl mouse lymph node.

2. HF US and Power Doppler of age-matched control mouse cervical lymph node.

3. HF US and Power Doppler of 4-NQO-treated (28 wk) mouse cervical lymph node.

4. HF US and Power Doppler of Fasl mouse cervical lymph node. 


\section{GLOSSARY}

$\begin{array}{ll}\mu m & \text { micrometer } \\ \text { 18-FDG } & \text { 18-Fluorodeoxyglucose } \\ \text { 2D } & \text { 2 Dimentional } \\ \text { 3D } & \text { 3 Dimentional } \\ 4-N Q O & \text { 4-nitroquinoline-1-oxide } \\ \text { Abl } & \text { abelson tyrosine kinase } \\ \text { ADF } & \text { Actin depolymerizing factor } \\ \text { ADP } & \text { adenosine diphosphate } \\ \text { ADP }+ \text { Pi } & \text { adenosine diphophate }+ \text { inorganic phosphate } \\ \text { AJ } & \text { adherens junction } \\ \text { Akt } & \text { protein kinase B } \\ \text { AM } & \text { accessory mandibular } \\ \text { Arp2/3 } & \text { Actin related protein 2/3 } \\ \text { ATP } & \text { adenosine triphosphate } \\ \text { B6 } & \text { C57BL/6, black } 6 \text { mouse } \\ \text { BAC } & \text { bacterial artificial chromosome } \\ \text { B-mode } & \text { Brightness-mode } \\ \text { BSA } & \text { bovine serum albumin } \\ \text { CAD } & \text { coronary artery disease } \\ \text { CAF } & \text { cancer-associated fibroblast } \\ \text { CAM } & \text { cell adhesion molecule } \\ \text { CCL19 } & \text { chemokine (C-C motif) ligand 19 } \\ \text { CCL21 } & \text { chemokine (C-C motif) ligand 21 } \\ \text { CCND1 } & \text { cyclin D1 } \\ \text { CCR7 } & \text { chemokine (C-C motif) receptor 7 } \\ \text { CD31 } & \text { cluster of differentiation 31 } \\ \text { CD68 } & \text { cluster of differentiation 68 } \\ \text { Cdc42 } & \text { cell division cycle 42, GTP binding protein } \\ \text { CDKN2A } & \text { cyclin-dependent kinase inhibitor 2A } \\ \text { CE } & \text { C-terminal extension } \\ \text { CEP55 } & \text { centrosomal protein 55kDa } \\ \text { cFos } & \text { cellular Fos } \\ \text { cKO } & \text { conditional knockout } \\ \text { CORO1B } & \text { coronin 1B } \\ \text { CP } & \text { cheek pouch } \\ \text { CPC } & \text { chromosomal passenger complex } \\ \text { CXCL12 } & \text { chemokine (C-X-C motif) ligand 12 } \\ \text { C-Src } & \text { cellular sarcoma kinase } \\ \text { Ctl } & \text { control } \\ \text { CTTN } & \text { human cortactin gene } \\ \text { Cttn } & \text { murine cortactin gene } \\ & \end{array}$




$\begin{array}{ll}\text { CXCR4 } & \text { chemokine (C-X-C motif) receptor 4 } \\ \text { DAPI } & \text { 4', 6-diamidino-2-phenylindole } \\ \text { DDR1 } & \text { discoidin domain receptor tyrosine kinase 1 } \\ \text { DMBA } & \text { 7,12-Dimethylbenz(a)anthracene } \\ \text { DMSO } & \text { dimethyl sulfoxide } \\ \text { DNA } & \text { deoxyribonucleic acid } \\ \text { DOCK3 } & \text { dedicator of cytokinesis 3 } \\ \text { DT } & \text { dorsal tongue } \\ \text { E } & \text { esophagus } \\ \text { E-cadherin } & \text { epithelial-cadherin } \\ \text { ECG } & \text { echocardiograph } \\ \text { ECIS } & \text { electric cell-substrate Impedence sensing } \\ \text { ECM } & \text { extracellular matrix } \\ \text { EGF } & \text { epidermal growth factor } \\ \text { EGFR } & \text { epidermal growth factor receptor } \\ \text { eIF4B } & \text { eukaryotic translation initiation factor 4B } \\ \text { EMT } & \text { epithelial-mesenchymal transition } \\ \text { ERCC1 } & \text { excision repair cross-complementation group 1 } \\ \text { ERK1/2 } & \text { extracellular signal regulated kinase1/2 } \\ \text { ERT } & \text { estrogen receptor } \\ \text { ES cells } & \text { embryonic stem cells } \\ \text { FA } & \text { focal adhesion } \\ \text { FAK } & \text { focal adhesion kinase } \\ \text { Fasl } & \text { fas ligand } \\ \text { FDA } & \text { Federal Drug Administration } \\ \text { FFPE } & \text { formalin-fixed paraffin-embedded } \\ \text { FGF } & \text { fibroblast growth factor } \\ \text { FISH } & \text { fluorescent in situ hybridization } \\ \text { FITC } & \text { fluorescein isothiocyanate } \\ \text { FLPe } & \text { flippase } \\ \text { FNAC } & \text { fine needle aspiration cytology } \\ \text { FOXM1 } & \text { forkhead box protein M1 } \\ \text { FRT } & \text { flippase recognition target } \\ \text { G } & \text { globular } \\ \text { GAP-43 } & \text { growth associated protein 43 } \\ \text { GEMM } & \text { genetically engineered mouse model } \\ \text { GSK3 } & \text { glycogen synthase kinase 3 beta } \\ \text { GTP } & \text { guanosine-5'- triphosphate } \\ \text { H\&E } & \text { hematoxylin and eosin } \\ \text { HCl } & \text { hydrochloric acid } \\ \text { HF US } & \text { high frequency ultrasound } \\ \text { HGF } & \text { hepatocyte growth factor } \\ \text { Hif-1a } & \text { hypoxia-inducible factor } 1 \text {-alpha } \\ & \end{array}$




$\begin{array}{ll}\text { HNSCC } & \text { head and neck squamous cell carcinoma } \\ \text { HPV } & \text { human papilloma virus } \\ \text { IAP } & \text { inhibitor of apoptosis } \\ \text { IE } & \text { intact epithelium } \\ \text { IF } & \text { immunofluorescence } \\ \text { IHC } & \text { immunohistochemistry } \\ \text { IL-1/8 } & \text { interleukin-1/8 } \\ \text { K } & \text { kidney } \\ \text { K14 } & \text { cytokeratin 14 } \\ \text { KO } & \text { knockout } \\ \text { K-ras } & \text { Kirsten rat sarcoma viral oncogene homolog } \\ \text { L } & \text { lymphocyte } \\ \text { L/min } & \text { liters/minute } \\ \text { LB } & \text { lysogeny broth } \\ \text { loxP } & \text { locus of crossover P1 } \\ \text { LT } & \text { lymph tissue } \\ \text { M } & \text { mandibular } \\ \text { MAPK } & \text { mitogen-activated protein kinase } \\ \text { MDCK } & \text { Madin-Darby Canine Kidney Epithelial Cells } \\ \text { mDia1 } & \text { diaphanous-related formin-1 } \\ \text { MEF } & \text { mouse embryonic fibroblast } \\ \text { MET } & \text { hepatocyte growth factor receptor } \\ \text { MHz } & \text { Megahertz } \\ \text { mL } & \text { milliliter } \\ \text { MLC2 } & \text { myosin light chain 2 } \\ \text { mm } & \text { millimeter } \\ \text { MMP } & \text { matrix metalloproteinase } \\ \text { Mre11 } & \text { meiotic recombination 11 homolog A } \\ \text { MRI } & \text { magnetic resonance imaging } \\ \text { MRN Complex } & \text { Mre11, Rad50 and Nbs1 complex } \\ \text { mRNA } & \text { message RNA } \\ \text { MT1-MMP } & \text { membrane-type-1 matrix metalloproteinase } \\ \text { MYC } & \text { V-Myc Avian Myelocytomatosis Viral Oncogene Homolog } \\ \text { MYPT1 } & \text { myosin phosphatase 1 } \\ \text { NaBH4 } & \text { Sodium borohydride } \\ \text { NBS1 } & \text { Nijmegen breakage syndrome protein 1 } \\ \text { Nck } & \text { non-catalytic region of tyrosine kinase adaptor protein } \\ \text { NEDD9 } & \text { neural precursor cell expressed developmentally down-regulated } \\ \text { NFKB } & \text { protein 9 } \\ \text { NOD/SCID } & \text { nuclear factor kappa-light-chain-enhancer of activated B cells } \\ \text { NPF } & \text { nucleation promoting factor } \\ \text { NRG-1 } & \text { neuregulin-1 } \\ & \end{array}$




$\begin{array}{ll}\text { NS } & \text { Not Significant } \\ \text { NTA } & \text { N-terminal acidic } \\ \text { N-WASp } & \text { Neuronal-Wiskott-Aldrich Syndrome protein } \\ \text { OSCC } & \text { oral squamous cell carcinoma } \\ \text { p16INK4a } & \text { cyclin-dependent kinase inhibitor 2A } \\ \text { p21WAF1/Cip1 } & \text { cyclin-dependent kinase inhibitor 1 } \\ \text { p27Kip1 } & \text { Cyclin-dependent kinase inhibitor 1B } \\ \text { p65 } & \text { nuclear factor NF-kappa-B p65 subunit } \\ \text { PAK } & \text { p21-activated protein kinase } \\ \text { PBS } & \text { phospho-buffered saline } \\ \text { PCNA } & \text { Proliferating cell nuclear antigen } \\ \text { PCR } & \text { polymerase chain reaction } \\ \text { PDGF } & \text { platelet-derived growth factor } \\ \text { PDGFR } & \text { platelet-derived growth factor receptor } \\ \text { PDX } & \text { patient-derived xenografts } \\ \text { PET } & \text { positron emission tomography } \\ \text { PGK-neo } & \text { phosphoglycerate kinase-neomycin } \\ \text { PI3K } & \text { phosphoinositide 3-kinase } \\ \text { PIK3CA } & \text { phosphatidylinositol-4,5-Bisphosphate 3-Kinase, Catalytic Subunit } \\ \text { PIP2 } & \text { phosphatidylinositol-4,5-bisphosphate } \\ \text { PKC } & \text { protein kinase C } \\ \text { PLD2 } & \text { phospholipase D2 } \\ \text { PPARy } & \text { peroxisome proliferator-activated receptor gamma } \\ \text { PRR } & \text { proline rich region } \\ \text { Ptdlns(3,4)P2 } & \text { phosphatidylinositol-4,5-bisphosphate } \\ \text { PTEN } & \text { phosphatase and tensin homolog } \\ \text { R26R } & \text { rosa 26 reporter } \\ \text { Rac } & \text { Ras-related C3 botulinum toxin substrate 1 } \\ \text { Rad5 } & \text { Radiation sensitivity protein 5 } \\ \text { Rb } & \text { retinoblastoma protein } \\ \text { RF } & \text { reticular fibers } \\ \text { RhoA } & \text { Ras homolog family member A } \\ \text { RNAi } & \text { ribonucleic acid interference } \\ \text { ROCK1/2 } & \text { Rho-associated serine/threonine kinase 1/2 } \\ \text { ROI } & \text { region of interest } \\ \text { RSK2 } & \text { p90 ribosomal S6 kinase 2 } \\ \text { S } & \text { skin } \\ \text { S1P } & \text { sphingosine-1-phosphate } \\ \text { SCC } & \text { squamous cell carcinoma } \\ \text { SDF-1 } & \text { stromal cell-derived factor 1 } \\ \text { SH3 } & \text { Src homology 3 } \\ \text { shRNA } & \text { short hairpin ribnonucleic acid } \\ \text { siRNA } & \text { small interfering ribonucleic acid } \\ & \end{array}$




$\begin{array}{ll}\text { SMAD4 } & \text { Mothers against decapentaplegic homolog 4 } \\ \text { SP } & \text { superficial parotid } \\ \text { SrC } & \text { sarcoma kinase } \\ \text { SSH1L } & \text { slingshot homolog-1L } \\ \text { T } & \text { tongue } \\ \text { TAM } & \text { tumor-associated macrophage } \\ \text { TF } & \text { transcription factor } \\ \text { Tg } & \text { transgenic } \\ \text { TGF } 31 & \text { Transforming growth factor beta 1 } \\ \text { Th1/2 } & \text { T-helper cell 1/2 } \\ \text { TIFF } & \text { tagged image file format } \\ \text { TJ } & \text { tight junction } \\ \text { Tks5 } & \text { SH3 and PX domains 2A } \\ \text { TMA } & \text { tumor microarray } \\ \text { TNF- } \alpha & \text { Tumor necrosis factor alpha } \\ \text { TP53 } & \text { Tumor Protein P53 } \\ \text { TZDs } & \text { thiazolidinediones } \\ \text { US } & \text { ultrasound } \\ \text { VEGF-A } & \text { vascular endothelial growth factor-A } \\ \text { VT } & \text { ventral tongue } \\ \text { WASp } & \text { Wiskott-Aldrich Syndrome protein } \\ \text { WAVE2 } & \text { WASp family verprolin-homologous protein } \\ \text { WD40 repeats } & \text { beta-transducin repeats } \\ \text { WIP } & \text { WASP-interacting protein } \\ \text { Wt1 } & \text { Wilms' tumor-1 transcription factor } \\ \text { ZO } & \text { zonula occludens protein }\end{array}$




\section{Literature Review}

\section{Head and neck squamous cell carcinoma}

Head and neck squamous cell carcinoma (HNSCC) is a disease of the upper aerodigestive tract, arising from mucosal surfaces of the oral cavity, larynx, pharynx, and nasal cavity ${ }^{1,2}$. HNSCC can be categorized into two distinct subtypes based on the involvement of human papillomavirus (HPV): HPV-positive and HPV-negative ${ }^{1,2}$. HPVpositive tumors develop after infection with a high-risk HPV, which is almost exclusively HPV-16 $6^{3,4}$. The risk factors for HPV-negative tumors include prolonged tobacco and alcohol exposure ${ }^{2}$. Despite similar histology, HPV-negative HNSCC is more aggressive and has a worse prognosis, resulting in a 5-year survival rate of $\sim 60 \% 5$.

HPV-related HNSCC primarily arises in the oropharynx and tonsils and comprises approximately $60 \%$ of all oropharyngeal head and neck cancers ${ }^{3}$. The increased survival rates associated with HPV-positive HNSCC are likely due to the molecular pathology behind its progression. HPV consists of a small double-stranded circular DNA that encodes one group of "early" transcribed proteins (E1-7) and two "late" proteins (L1 and L2) ${ }^{4}$. Two early proteins, E6 and E7, are responsible for the transformation of epithelial cells by causing the degradation of tumor suppressor proteins p53 and Rb, respectively, leading to deregulated cell cycle progression ${ }^{4}$. Both $\mathrm{p} 53$ and $\mathrm{Rb}$ regulate the cell cycle by halting the G1/S transition in the event of DNA damage. Incidence of this subgroup of HNSCC has drastically increased over the past few decades in the United States, while HPV-negative tumor incidence has decreased, with estimates showing HPV-related tumors being the primary form of HNSCC by $2020^{6}$. 
Despite declining incidence in the USA, overall survival rates of patients with HPVnegative HNSCC have remained unchanged ${ }^{6}$. HPV-negative HNSCC is characterized by a higher frequency of genomic mutations and chromosomal losses and/or gains, resulting in a highly heterogeneous population of cells. A majority of these tumors harbor p53 mutations, unlike the p53 degradation which occurs with HPV-related carcinomas. Chromosomal losses have been frequently found to occur at 9p21, 10q23, 17p13 and $18 q 21^{2}$. Within these areas are genes with important tumor-suppressor functions, namely CDKN2A, PTEN, TP53 and SMAD4, respectively. Amplification of chromosome segments generally occurs at locations that encode genes important for growth, motility and survival. In HNSCC, these locations include 3q26, 7p11, 7q31, 8q24 and 11q132,7. These regions are home to the following genes: PIK3CA (3q26), EGFR (7p11), MET (7q31), MYC (8q24) and CCND1 and CTTN at 11q13. Table 1 describes each of the tumor suppressors and promoters in greater detail. The accumulation of these genetic alterations results in establishment of tumors with a propensity to locally invade and metastasize to cervical lymph nodes ${ }^{1,2}$. Though distant metastases to the lung and bone occur, mortality is generally due to growth of primary tumors and loco-regional recurrence ${ }^{8,9}$. Detection of primary tumor invasion and lymph node infiltration is therefore of utmost importance in accurately determining patient diagnosis and staging. Multiple types of imaging modalities have been employed by clinicians in order to identify primary tumor location and aid in improving patient diagnosis. 
Table 1: Common chromosomal alterations in HNSCC

\begin{tabular}{|c|c|c|c|}
\hline $\begin{array}{l}\text { Chromosomal } \\
\text { Location }\end{array}$ & Gene & Function & Reference \\
\hline \multicolumn{4}{|c|}{ Tumor Suppressors } \\
\hline $9 \mathrm{p} 21$ & CDKN2A & Encodes $\mathrm{p} 16$, regulator of CDK4 and cell cycle progression & 10,11 \\
\hline $10 q 23$ & PTEN & $\begin{array}{c}\text { Phosphatase for } \mathrm{PIP}_{2} \text {, resulting in inhibition of AKT } \\
\text { proliferation pathway }\end{array}$ & 12 \\
\hline $17 p 13$ & TP53 & $\begin{array}{c}\text { P53, activator of DNA damage repair, growth arrest and } \\
\text { apoptosis pathways }\end{array}$ & 13,14 \\
\hline $18 q 21$ & SMAD4 & $\begin{array}{c}\text { Transcription factor downstream of TGF- } \beta \text {, mediator of } \\
\text { many pathways including cell cycle, apoptosis and } \\
\text { differentiation }\end{array}$ & 11 \\
\hline \multicolumn{4}{|c|}{ Tumor Promoters } \\
\hline $3 q 26$ & PIK3CA & $\begin{array}{l}\text { Catalytic subunit of PI3-kinase, part of AKT pathway which } \\
\text { is involved in cellular growth, proliferation and survival }\end{array}$ & $11,15,16$ \\
\hline 7p11 & EGFR & $\begin{array}{l}\text { Epidermal growth factor receptor tyrosine kinase, signals as } \\
\text { part of growth and survival pathways }\end{array}$ & 17 \\
\hline $7 q 31$ & MET & $\begin{array}{l}\text { c-Met receptor tyrosine kinase for hepatocyte growth factor, } \\
\text { signals downstream leading to cell survival and motility, an } \\
\text { oncogene }\end{array}$ & 18 \\
\hline $8 q 24$ & MYC & $\begin{array}{c}\text { Transcription factor in mitogenic signaling, regulates cell } \\
\text { growth, an oncogene }\end{array}$ & 19 \\
\hline $11 q 13$ & CCND1 & $\begin{array}{c}\text { Cyclin D1, interacts with tumor suppressor Rb, promoting } \\
\text { cell cycle progression }\end{array}$ & $20-22$ \\
\hline $11 q 13$ & CTTN & $\begin{array}{c}\text { Cortactin, actin binding protein that regulates cell motility } \\
\text { and invasion }\end{array}$ & $21-24$ \\
\hline
\end{tabular}

\section{Imaging HNSCC}

The goals of imaging in head and neck cancer patients are to determine the degree of primary tumor infiltration, size and involvement of cervical lymph nodes. This information provides clinicians with the means necessary for an accurate diagnosis and prognosis. Detection of lymph node involvement is imperative, as it is important to both patient diagnosis and prognosis. Patients with regional nodal metastasis have a poorer prognosis and decreased survival rates ${ }^{25}$. The most common imaging modalities used for HNSCC visualization are computed tomography $(\mathrm{CT})$, positron emission tomography (PET), integrated PET/CT, magnetic resonance imaging (MRI) and ultrasound (US). The specific technique used depends on the suspected tumor location, as well as any additional necessary information for proper staging. 
CT requires the use of $\mathrm{x}$-rays to produce individual slices of scanned objects, giving detailed images of structures within the body due to the variation between tissue types in their ability to block $x$-rays ${ }^{26}$. Tumors generally appear as masses which distort the normal anatomy of the affected neck region ${ }^{27}$. In comparison to MRI, CT scans provide better spatial resolution and are faster to acquire; however, detection of lymph node metastases can prove difficult, as the main criteria used is size and appearance, which has been shown to be unreliable ${ }^{28}$.

PET imaging relies on administration of radionuclides that are taken up by metabolically active tissues ${ }^{27}$. The most frequently used radionuclide for diagnosing cancer is the glucose analog $18 \mathrm{~F}$-fluorodeoxyglucose (18-FDG). This type of imaging takes advantage of the exceptionally high metabolic rates of tumor cells and is especially useful in detection of metastases. The downside to this method is poor spatial resolution, making it difficult to determine the precise site of localized metabolic activity. For this reason, PET imaging is usually coupled with $\mathrm{CT}$ technology (PET/CT), giving a more accurate depiction of the anatomic location, enhancing the ability to detect nodal involvement ${ }^{29}$.

MR imaging (MRI) uses a magnetic field for acquisition of images, which gives enhanced visualization of tendons, ligaments and spinal cords when compared to $\mathrm{CT}^{27}$. For this reason, it is often used as a complementary system to PET/CT for detection of primary tumors and metastases, especially in the brain. Addition of contrast agents can improve the resolution of internal organs or provide more insight into responses to drug therapy and patient survival ${ }^{30,31}$. Another form of MRI, termed diffusion-weighted MRI, 
measures the diffusion of water molecules in various tissues ${ }^{32}$ and has also been shown useful in predicting patient response to therapies and overall outcome ${ }^{30,33}$.

Ultrasound (US) technology is mainly used for detecting lymph node metastases in combination with fine needle aspiration cytology $(\mathrm{FNAC})^{34,35}$. As a result, it is the least used imaging modality. In US, sound waves are used to image internal structures, generating a typical black and white image that is obtained using Brightness (B)-mode. The amount of black or white of an object is due to variations in tissue density. This determines the echogenicity of the specific tissue: dark areas are deemed "hypoechoic" while white areas are "hyperechoic". Some studies have attempted to use US alone or in conjunction with Power or Color Doppler sonography, which is used to image blood flow, in order to detect lymph node metastases ${ }^{36-38}$. However, it is not as sensitive alone and is generally combined with FNAC ${ }^{34,39}$. Despite this, studies repeatedly show that USguided FNAC is as good or better at determining nodal status when compared to PET/CT and $M R I^{34,35}$.

The combination of these imaging modalities in the clinic results in accurate detection of cancer growth and spread to local and distant sites. Locoregional spread is the result of multiple factors, one of the most important being the ability to move within the specific tumor microenvironment. The heterogeneous nature of HNSCC confers cellular plasticity, allowing it to adapt multiple migration modes in order to invade.

\section{Migratory modes during cancer cell invasion}

Depending on tumor type and specific microenvironment, cancer cells employ one or a combination of several modes of migration in order to facilitate tumor invasion ${ }^{40}$. Cells can migrate as single entities or in collective groups. Single cell migration occurs in the 
absence of cell-cell adhesions, and is broken into two distinct subtypes (amoeboid and mesenchymal), while collective invasion generally involves formation of invasive groups or protrusive strands ${ }^{40}$ (Figure 1). Which mode is used is dependent on the composition and interactions with various components of the extracellular matrix (ECM). The ECM is composed of the basement membrane (BM) and interstitial matrix ${ }^{41}$. The BM underlies epithelial and endothelial cells and is a dense network made up of mainly type IV collagen, glycoproteins laminin and entactin/nidogen, heparan sulfate proteoglycans and fibronectin ${ }^{42}$. On the other hand, the interstitial matrix is more loosely organized, made of fibrillar collagens, proteoglycans, glycoproteins and also fibronectin, giving tissue enhanced elasticity ${ }^{41}$. The combination of these provides a framework that requires dynamic interactions and network reorganization by cells for efficient stromal navigation.

Amoeboid motility is characterized by limited adhesions to the ECM and high actomyosin contractility ${ }^{43}$. The resulting cells are rounded in form, able to deform the cytoskeleton, and by producing membrane blebs, pseudopodia or filopodia, are able to squeeze through spaces within the ECM without employing extracellular proteolysis. The amoeboid mode requires high activity of the small GTPase RhoA, which signals through the serine(Ser)/threonine(Thr) kinase Rho-associated Kinase (ROCK) in order to generate the actomyosin-based forces necessary for membrane deformation ${ }^{44}$. ROCK activation increases contractility through inhibitory phosphorylation of myosin phosphatase (MYPT1) at Thr696, which increases myosin-II light chain (MLC2) phosphorylation at Thr18/Ser19. Inhibition of ROCK activity is responsible for driving the mesenchymal mode of motility ${ }^{45}$. 

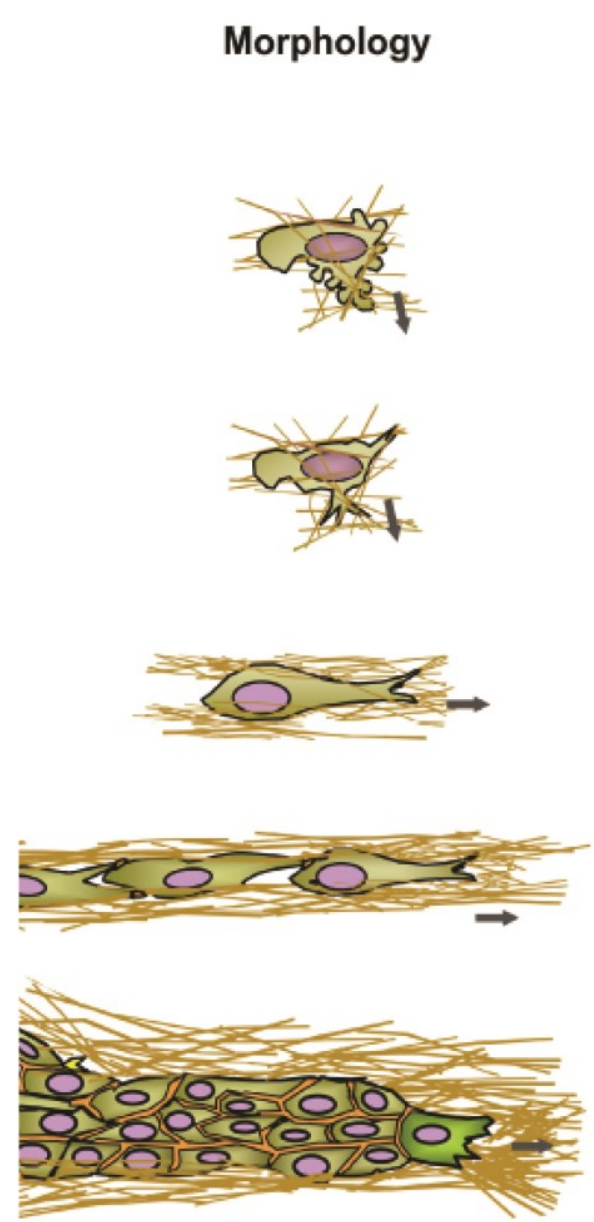

Mesenchymal migration requires formation of adhesions to the ECM and matrix proteolysis in order to move within the microenvironment ${ }^{40}$. Cells with the mesenchymal phenotype are elongated, producing lamellipodia and invadopodia to direct migration through and break down of the surrounding ECM. Mesenchymal migration is controlled by the small GTPase, Rac1, which signals through the actin binding protein WAVE2 following activation by a NEDD9/DOCK3 complex ${ }^{43}$. DOCK3 is a guanine nucleotide exchange factor (GEF) for Rac146 while NEDD9 is a scaffolding protein located in the cytoplasm $^{47}$. Loss of any of these factors in mesenchymal cells results in adaptation of amoeboid migration, since Rac1 is a potent negative regulator of actomyosin contractility ${ }^{43}$ 
In multicellular streaming, cells using one of the previously mentioned migratory modes form chains of cells, "streaming" one after the other through previously formed tracks, generated by leader cells or stromal fibroblasts, within the ECM. Cell streams are typically attracted by a chemotactic gradient ${ }^{48}$, provided by growth factors such as epidermal growth factor (EGF) or colony stimulating factor 1 (CSF1) ${ }^{48}$. Although termed a "stream" or "chain", cells move in a stream without forming cell-cell contacts, similar to single cell migration by retaining the ability to generate force for rapid movement. This migratory mode is utilized for the dissemination of breast cancer cells ${ }^{49,50}$.

In contrast to single cell migration, collective cell migration relies on maintenance of cell-cell contacts to form protrusive strands or groups capable of moving as a single entity ${ }^{48}$. Many cancer types are known to use this migratory mode for invasion, including HNSCC $^{51,52}$. Depending on the density and content of the microenvironment, cells can adopt different morphologies, organized as small clusters, or strands with a single or multiple leader cells. Leader cells are responsible for the pathway generation necessary for forward migration, and can be either tumor associated fibroblasts or carcinoma cells themselves ${ }^{53,54}$. Paths are generated by matrix remodeling through secretion of matrix metalloproteinases (MMPs). Tight spatiotemporal regulation of RhoA and ROCK activity is required for maintaining a cohesive cellular unit ${ }^{55,56}$. Actomyosin contractility is also necessary for this migratory mode, however in order to sustain the collective strands, there must be lower levels of contractility within the groups, at cell-cell junctions. At these junctions, there are decreased concentrations of MLC. Both RhoA and ROCK are necessary for MLC activation. Dysregulation of the activity of either leads to global actomyosin activation and decreased collective invasion in SCC cell lines ${ }^{55}$. Regulation 
A

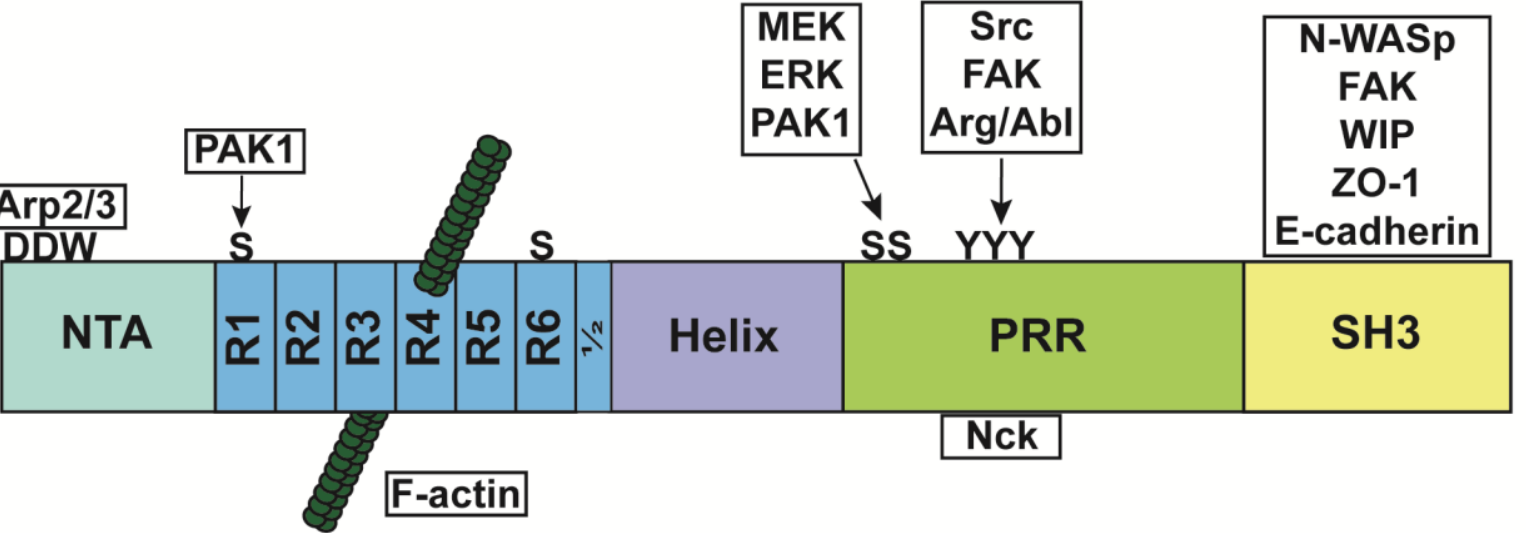

B

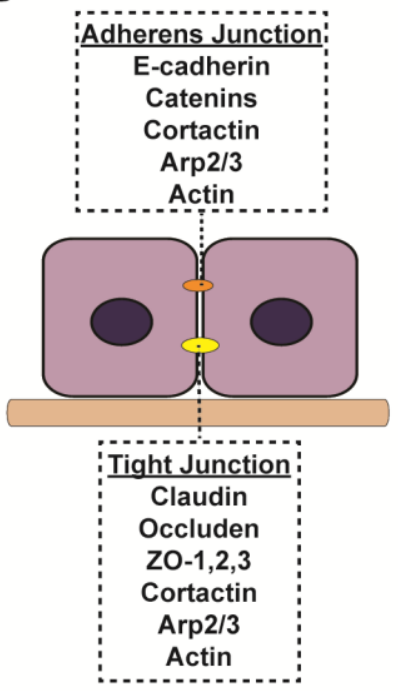

C

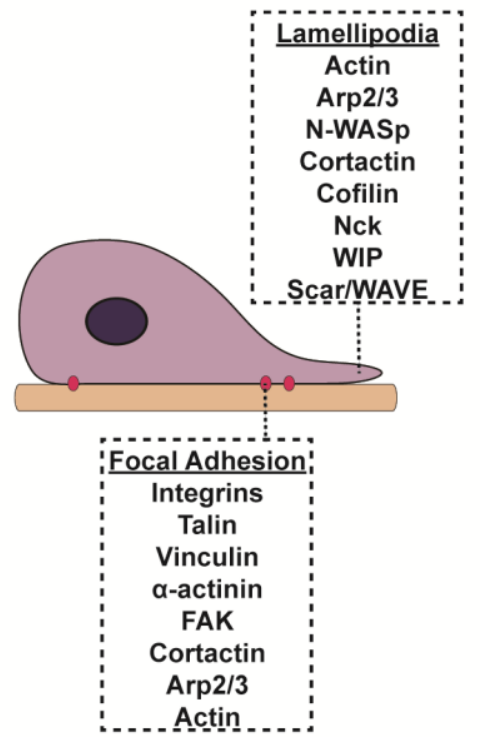

D

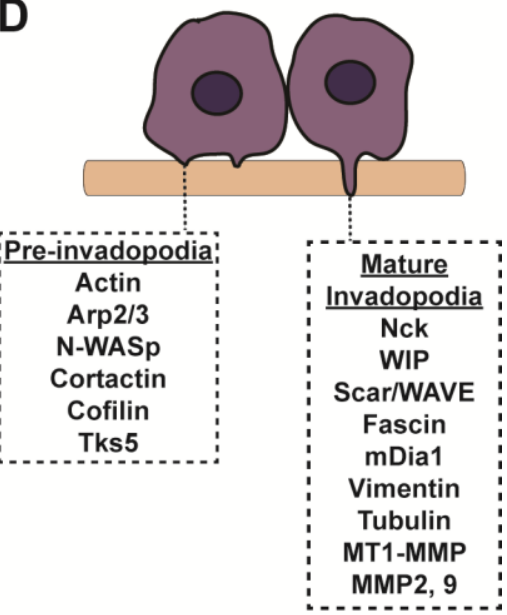

Figure 2. Cortactin domain interactions and functions. A. Cortactin Structure. Cortactin binds Arp2/3 via its N-terminal acidic (NTA) domain through a conserved DDW motif. Adjacent to this are six and half repeats $(R)$ which mediate F-actin binding, specifically through $R 4$. This is followed by a helical domain and proline rich region (PRR). The PRR contains serine and tyrosine residues that are phosphorylated by various kinases to increase cortactin activity. At the far $\mathrm{C}$-terminal location is an SH3 domain that interacts with several different kinases and adaptor proteins that link them to the actin cytoskeleton. Arrows denote phosphorylation events. B. Cell-cell adhesions and their associated proteins. Cortactin plays a role in both AJs and TJs. C. Proteins necessary for directed cell motility. Both Cell-ECM attachments and lamellipodia are necessary for forward migration. D. Invadopodia and matrix degradation. Cortactin is a core component of invadopodia, necessary for formation and function.

of MLC at points of cell-cell contact is carried out by discoidin domain receptor 1 (DDR1), a membrane-bound protein that interacts with fibrillar collagen and has an intracellular kinase domain ${ }^{55}$. Normally, engagement of DDR1 with collagen results in 
autophosphorylation and activation of the protein, which transmits extracellular signals inside the cell ${ }^{57}$. However in the context of collective migration, DDR1 instead interacts with cell polarity regulator Par3 which, together with Par6, regulates DDR1 and MLC localization at cell-cell junctions ${ }^{55}$. Loss of any of these components results in a loss of cohesive motility in vitro.

Each migratory mode requires dynamic reorganization of the actin cytoskeleton, leading to the formation of pseudopodia, filopodia, lamellipodia or invadopodia ${ }^{58}$. Production of these subcellular structures requires dynamic polymerization/depolymerization of actin filaments regulated by a variety of actin-binding proteins. Proteins involved in regulating actin polymerization kinetics govern the production, stabilization and turnover of resultant filamentous (F) actin networks. F-actin strands are composed of globular (G) actin monomers that contain a cleft for binding ATP. Filament growth occurs most rapidly using G-actin bound with ATP, where intrinsic hydrolysis of ATP occurs to form ADP+Pi intermediates. ATP hydrolysis within F-actin renders filaments more labile and subject to depolymerization. Depending on the specific protein(s), F-actin can be assembled into higher-order forms, including bundled strands or sheets ${ }^{59}$. Pseudopodia and filopodia are formed through bundling of actin strands, while invadopodia and lamellipodia contain actin networks organized into a branched orthogonal array ${ }^{60}$. Newly formed branched F-actin complexes are generated by the nucleation activity of the actin-related protein $2 / 3$ (Arp2/3) complex, which is activated by nucleation promoting factors (NPFs) including the Wiskott-Aldrich Syndrome protein (WASp) family ${ }^{61-63}$ and cortactin $^{64-67}$. 
The many faces of cortactin: Regulation of actin cytoskeletal dynamics in cancer cell motility and invasion

Cortactin is a multi-domain scaffolding protein (Figure 2) first identified as a substrate of Src kinase that localized to regions containing cortical F-actin ${ }^{68}$. Cortactin overexpression has been linked to increased invasion and metastasis in multiple cancer types, including breast ${ }^{69,70}$, colorectal ${ }^{71}$, hepatocellular ${ }^{72}$, esophageal ${ }^{73}$, melanoma ${ }^{74}$ and HNSCC $^{22,75-78}$. The gene encoding cortactin is located at chromosomal location $11 \mathrm{q} 13$, which is found amplified in approximately $30 \%$ of head and neck cancers and associated with a poor patient outcome $\mathrm{e}^{21,23,24,79,80}$. The association of cortactin with aggressive tumor progression is likely due to its role as an important regulator of actin cytoskeleton organization during cell motility and endocytosis ${ }^{81}$.

Cortactin activates Arp2/3 through association with a conserved DDW amino acid motif with the N-terminal acidic (NTA) domain. The amino terminus also contains a region with six and half tandem repeats responsible for binding to F-actin ${ }^{68}$. The C-terminal half of cortactin mediates signal transduction events, with an alpha-helical and a proline-rich region containing several tyrosine and serine residues that are conserved sites of phosphorylation for a variety of oncogenic protein kinases ${ }^{68}$. Phosphorylation of cortactin at these sites serves to regulate the ability of cortactin to activate Arp2/3 complex nucleation by direct and indirect mechanisms ${ }^{82}$. The extreme C-terminus contains a Src homology $(\mathrm{SH}) 3$ domain that interacts with multiple proline-rich binding partners. In addition to promoting Arp $2 / 3$ activity, cortactin simultaneously binds to Arp $2 / 3$ complex and F-actin branchpoints to help stabilize and protect $\mathrm{F}$-actin branches from spontaneous disassembly ${ }^{66}$. Collectively these cortactin functions contribute to different aspects of 
head and neck cancer cell dissemination, including regulation of cell-cell adhesion, motility, and ECM degradation.

Cell-cell and cell-matrix adhesions are important for maintaining tissue architecture. Altering adhesion is important in driving tumor progression. Contacts between epithelial cells are made through adherens junctions (AJ) and tight junctions $(T J)^{83}$. Initiation of AJs is the first step in intercellular contact formation. The major molecules responsible for the initial adhesion event are members of the cadherin family of transmembrane glycoproteins, with E-cadherin the most important member for maintaining epithelial cell-cell adhesion ${ }^{83}$. Following initial cell-cell contact, E-cadherin clustering occurs at membrane contact points, leading to recruitment of catenin family proteins ( $p 120-, \beta$ - and $\alpha$-catenin), which link E-cadherin clusters to the actin cytoskeleton ${ }^{84}$. In addition to catenins, E-cadherin ligation at the cell surface designates assembly sites for Arp2/3-mediated branched actin networks ${ }^{85}$. Arp2/3 activity is necessary for the maturation of E-cadherin contact points ${ }^{86}$. Cortactin associates with the adherin junction actin network to maintain stability of Arp2/3-F-actin branchpoints, thereby enabling extension of nascent contacts and adhesion maturation ${ }^{87,88}$. Loss of E-cadherin expression is a hallmark event in epithelial-mesenchymal transition (EMT), and is important for the acquisition of the invasive mesenchymal phenotype ${ }^{89,90}$. HNSCC tumors with low E-cadherin expression are consistently linked to lymph node metastasis, increased tumor stage and decreased patient survival ${ }^{91-94}$. AJ formation also leads to basolateral recruitment of the transmembrane proteins claudin and occludin, key proteins that comprise the core components needed for tight junction formation ${ }^{83}$. 
Tight junctions form a paracellular barrier between epithelia that regulates solute flow between cells while restricting diffusion of transmembrane proteins to apical and basolateral compartments ${ }^{83}$. The cytoskeleton is connected to TJs through zonula occludens (ZO) 1, 2 and 3, members of a scaffolding protein family that bind claudin and/or occludin as well as F-actin ${ }^{83}$. ZO-1 and ZO-3 directly bind F-actin ${ }^{95,96}$, while ZO-1 and ZO-2 are important for maintaining TJ barrier function ${ }^{97}$. Cortactin may also play a role in regulating $\mathrm{TJ}$ function, as it has been shown to directly interact with ZO-1 in Drosophila $^{98}$. In support of this, mice with Cttn knockout display increased endothelial and intestinal cell permeability ${ }^{99,100}$, while binding of cortactin to ZO-1 promotes colorectal cancer progression ${ }^{71}$.

Cell motility requires cell-matrix adhesion formation and coordinated adhesion turnover to generate the force necessary to propel the cell forward and maintain motility. One type of cell-ECM interaction is the focal adhesion (FA). FA initiation begins when members of the integrin family of integral membrane matrix receptors engage insoluble protein components of the extracellular matrix ${ }^{101}$. Integrins are composed of $\alpha$ and $\beta$ subunits that heterodimerize in order to transmit cellular signals, leading to growth and motility ${ }^{102}$. Engagement of integrins with the ECM causes them to adopt an active conformation that leads to intracellular signaling, while interactions with cytoskeletal proteins triggers a change in affinity for ECM ligands. A major activator of integrins is the cytoplasmic adaptor protein talin, which provides a direct link by binding to the $\beta$-integrin subunit and to actin filaments ${ }^{103}$. Recruitment of talin initiates formation of nascent cellular adhesions, which are stabilized following subsequent recruitment of the adaptor proteins vinculin and $\alpha$-actinin, as well as focal adhesion kinase $(F A K)^{104}$. Both vinculin and $\alpha-$ 
actinin provide additional links to the actin cytoskeleton by simultaneously interacting with talin and F-actin ${ }^{103}$. Additionally, vinculin is thought to play an important role in further recruitment of FA core proteins and transmission of external mechanical stimuli ${ }^{105}$. FAK is important in governing the turnover of FAs during cell movement, since genetic deletion of FAK expression in fibroblasts results in increased FA stablity ${ }^{106}$. Cortactin is also found in FAs, where it functions to regulate adhesion turnover by serving as a mediator between F-actin and FAs. Tyrosine phosphorylation of cortactin by FAK following integrinstimulated FAK activation regulates this activity ${ }^{107,108}$. Signaling between $\beta_{1}$ integrin, FAK and cortactin has been implicated in the acquisition of radioresistance in HNSCC, where inhibiting $\beta_{1}$ integrin activity led to dissociation from FAK and cortactin, increasing radiation-induced cell death ${ }^{109}$.

Directional mesenchymal migration requires formation of protrusions termed lamellipodia, which are generated through Arp2/3-mediated actin polymerization and assembly of a cortical branched F-actin network. Initiation of lamellipodia formation occurs through stimulation by growth factors, including as EGF ${ }^{110}$. Lamellipodia appear as thin, sheet-like protrusions in $2 \mathrm{D}$ that are maintained and elongated through Arp2/3driven actin nucleation. F-actin elongation in lamellipodia is accelerated by the additional and rapid generation of F-actin barbed-ends. Actin subunits are organized into filaments facing the same direction, which creates "barbed" and "pointed" ends. While addition of G-actin monomers can occur at both sides, polymerization is much more favorable at the barbed end ${ }^{59}$. Barbed end production is increased in lamellipodia by the actin filamentsevering activity of ADF/cofilin proteins ${ }^{111,112}$. Arp2/3 complex has relatively low ability to activate actin polymerization on its own, requiring activation by different groups of 
nucleation promoting factors (NPFs) through direct binding ${ }^{113}$. Arp2/3 NPFs include the Wiskott-Aldrich syndrome protein (WASP) family members WASP and N-WASp, related WAVE/Scar proteins and cortactin ${ }^{113}$. Cortactin is a weak NPF on its own, but is able to synergize with N-WASp to enhance NPF activity and promote robust actin polymerization ${ }^{64}$. Localization of cortactin to sites of actin assembly in lamellipodia requires its interaction with both F-actin and Arp2/3114. Cortactin-mediated Arp2/3 activation is further enhanced by binding to the adaptor protein Nck1 $1^{115}$ and WASpInteracting Protein (WIP) ${ }^{65,82}$. Cortactin tyrosine phosphorylation by several different nonreceptor tyrosine kinases, including Src family kinases, FAK and Abl family kinases, are also necessary for promoting its Arp2/3 complex and F-actin interactions ${ }^{81}$. Src phosphorylation of cortactin at tyrosines (Tyr) 421/466 augments its interaction with Nck1, which enhances actin assembly ${ }^{82,116}$. In addition to tyrosine phosphorylation, serine/threonine phosphorylation of cortactin by Rac1/Cdc42 activated kinases PAK1 or PAK3, or Erk1/2 enhance binding of the cortactin SH3 domain to N-WASp ${ }^{81}$. Cortactin SH3 domain binding relieves N-WASp autoinhibition, promoting Arp2/3 activation that results in increased lamellipodia persistence and enhanced motility in HNSCC cells ${ }^{117}$.

While cortactin directly influences Arp2/3-F-actin network stability, cortactin is not required for lamellipodia formation ${ }^{64,118}$ but is necessary for lamellipodia persistence ${ }^{118}$. For this reason, cortactin is required for directed cell migration, evidenced by increased random motility in cortactin-null mouse embryonic fibroblasts ${ }^{119}$. Conversely cortactin overexpression enhances migration in HNSCC cell lines ${ }^{120}$, fibroblasts ${ }^{121}$ and mammary epithelial cells ${ }^{67}$. 
Mesenchymal cancer cells invade into surrounding tissue by proteolysis of the basement membrane and underlying ECM. The main cellular mechanism for invasionbased proteolysis is accomplished through formation of actin-rich membrane protrusions called invadopodia ${ }^{122}$. Invadopodia were first identified in Src-transformed fibroblasts, to sites of focalized proteolytic activity ${ }^{123}$. Invadopodia formation requires coordination of several cytoskeletal networks and regulatory proteins ${ }^{124}$. These structures function through recruitment of matrix metalloproteases (MMPs), which facilitate ECM proteolysis ${ }^{125,126}$. Similar to lamellipodia, invadopodia formation is initiated upon ligandinduced activation of growth factor receptors, including EGFR, triggering a downstream signaling cascade that activates $\mathrm{Src}, \mathrm{PKC}$ and ERK ${ }^{122,123,127-129}$. This in turn results in activation of Arp2/3, cortactin, N-WASp and cofilin ${ }^{122,127,130}$. Recruitment of these core components initiates formation of pre-invadopodia that lack MMP activity ${ }^{131}$. Deletion of Arp2/3, cortactin or N-WASp in cancer cells results in a loss of invadopodia formation. Following recruitment of the precursor core components, the adaptor protein Tks 5 binds Ptdlns $(3,4) \mathrm{P}_{2}$ (PIP2) at the plasma membrane, stabilizing newly-formed invadopodia precursors ${ }^{132}$. Tks5 interacts with Nck1, enhancing N-WASp activity within invadopodia ${ }^{127,133}$. Invadopodia maturation (defined by the acquisition of ECM degradation capability) occurs following recruitment of MT1-MMP (MMP14), a membrane-bound matrix metalloproteinase ${ }^{131}$ that leads to focalized activation of MMP 2 and 9 that are secreted from invadopodia ${ }^{125}$. Invadopodia maturation requires cortactin tyrosine phosphorylation, which releases bound cofilin from cortactin, allowing cofilin to enhance F-actin barbed end formation and subsequent invadopodia elongation ${ }^{130}$. Secreted and membrane-bound MMPs are trafficked to elongated invadopodia through 
caveolae-mediated endocytosis ${ }^{134-136}$ and exocytic reinsertion ${ }^{137-139}$ in a cortactindependent manner ${ }^{125}$. Invadopodia elongation requires additional actin nucleation, promoted through cofilin-mediated severing and diaphanous-related formin mDia1 unbranched F-actin polymerization. F-actin in invadopodia is stabilized by the F-actin bundling activity of the crosslinking protein fascin ${ }^{140}$. In addition to F-actin, vimentinenriched intermediate filaments and microtubules contribute to the processes of invadopodia elongation and MMP trafficking ${ }^{124}$. Without the activity of these downstream components utilized in invadopodia elongation and maturation, invadopodia-mediated ECM matrix degradation is dramatically reduced. Cortactin therefore plays important roles in tumor invasion through manifold roles in invadopodia biogenesis.

Coronin 1B promotes actin regulatory protein and network turnover

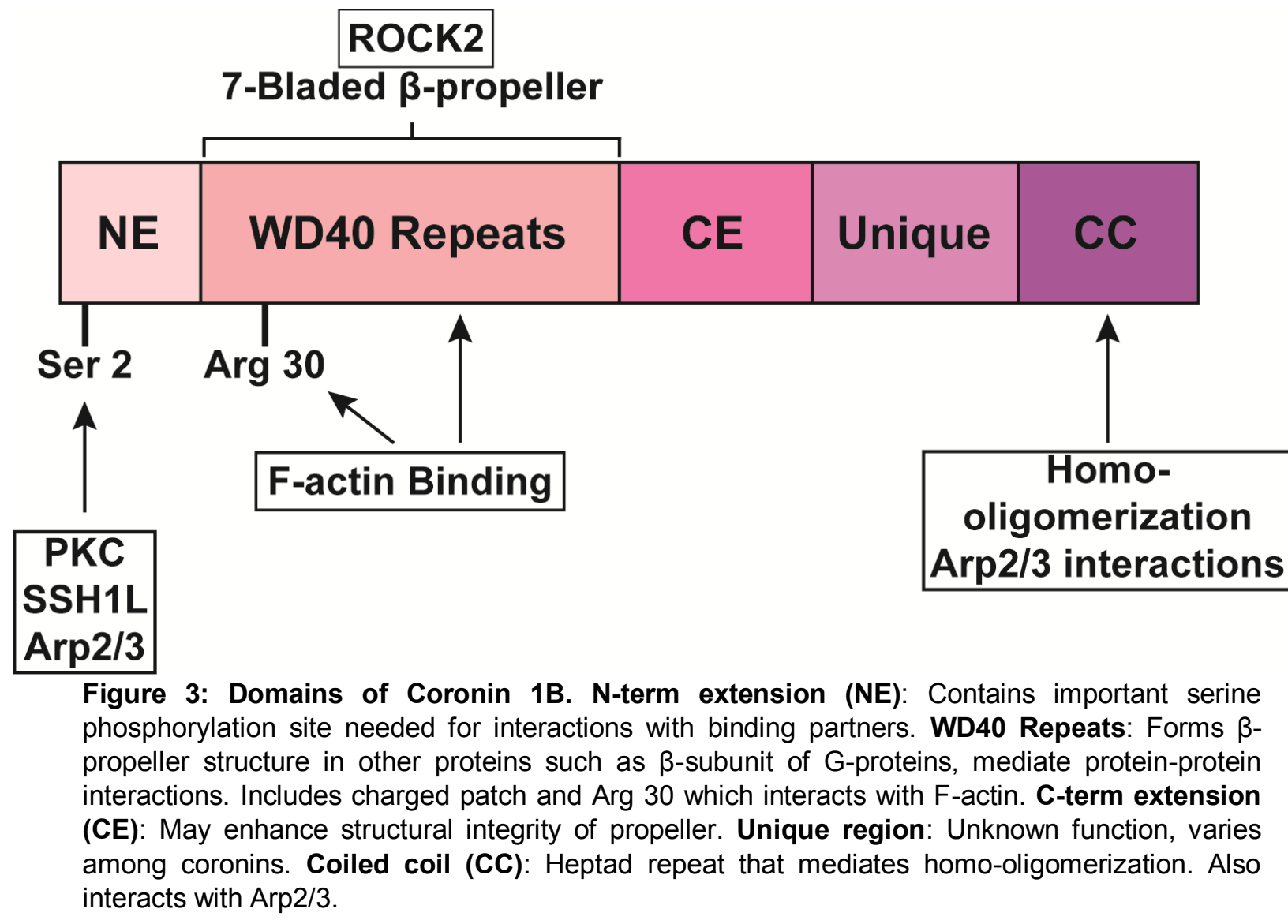


The coronin protein family are conserved regulators of cell motility ${ }^{141}$. They were first discovered in the slime mold Dictyostelium discoideum, where they localized to "crown-like" structures on the dorsal surface and were found as a component of contracted myosin-actin preparations ${ }^{142}$. Subsequent studies in $D$. discoideium and yeast found that coronin has multiple functional roles in motility, cytokinesis, phagocytosis and actin filament disassembly ${ }^{143-147}$. There are three classes of mammalian coronins; all have a similar basic structure consisting of WD40 repeats that form a $\beta$-propeller, short conserved $\mathrm{N}$ - and $\mathrm{C}$ - terminal regions around the propeller and a unique region connecting the propeller to a coiled-coil domain (Figure 3$)^{148}$. However, each specific type has different functions within the cell ${ }^{149}$. Type I coronins are regulators of actin network assembly, with the ability to bind both F-actin and Arp2/3 complex. Type II coronins have been implicated in the regulation of focal adhesions and nuclear co-repression. Finally, a third type of "long" coronin (Coro7), which contains two $\beta$-propeller regions and lacks a coiled-coil domain, has more distinct functions that vary in mammals and lower organisms despite having a conserved structure. In humans, Coro7 localizes to the Golgi apparatus, where it is important for maintaining morphology and membrane trafficking, and has no apparent interactions with the actin cytoskeleton. Non-mammalian Coro7, on the other hand, still influences actin-dependent processes, and plays roles in phagocytosis and vesicle trafficking ${ }^{149}$. This section will focus on the ubiquitously expressed Type I coronin, coronin 1B, which is investigated in Study 1. 
1. Cortactin-stabilized Arp2/3 actin networks
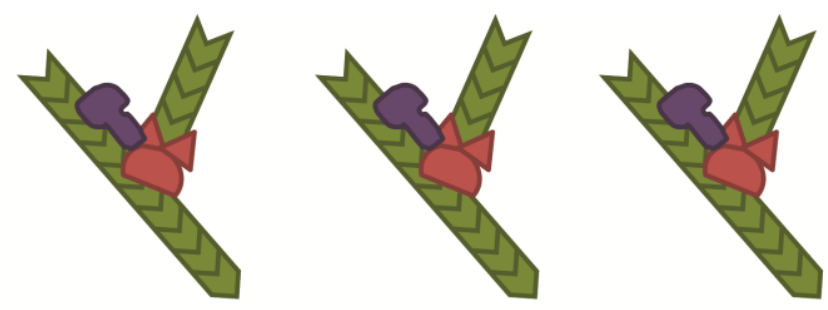

2. Coronin $1 \mathrm{~B}$ activation, Arp2/3 and cortactin displacement

3. Coronin $1 \mathrm{~B}$ inactivation, displacement and F-actin network breakdown

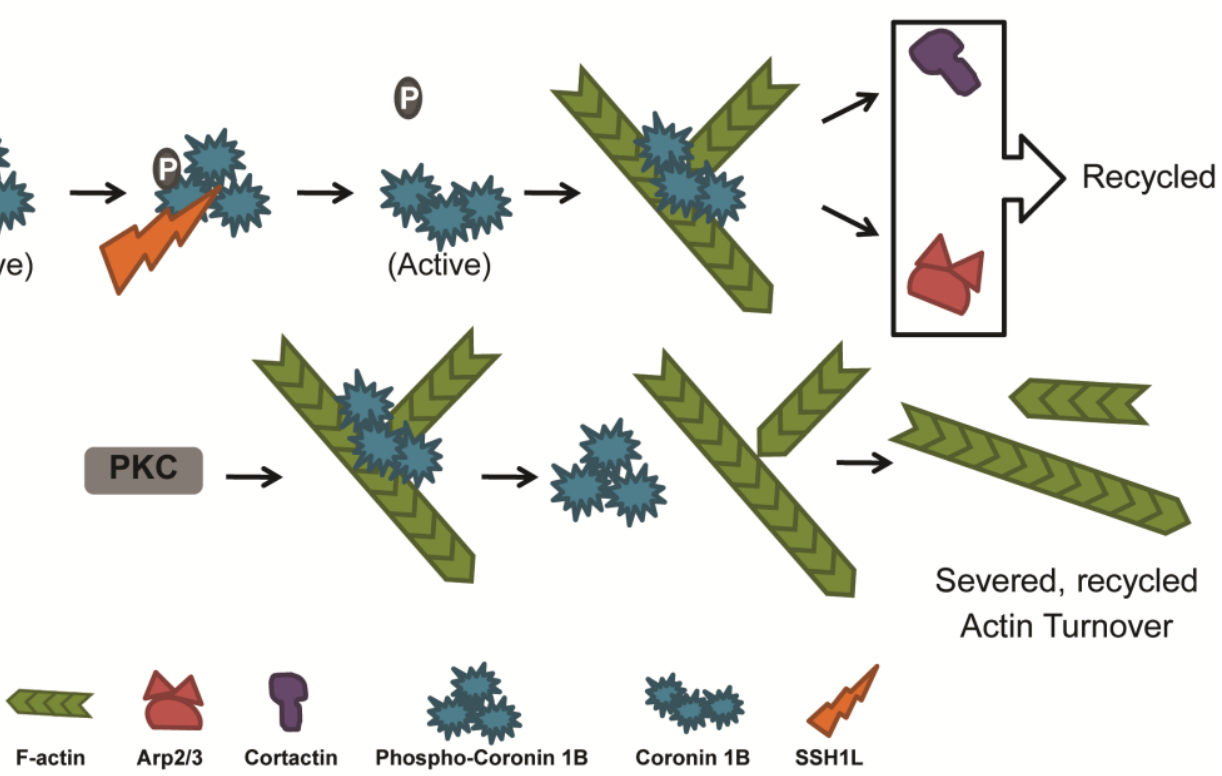

Figure 4: Coronin 1B antagonizes cortactin function. Cortactin is responsible for stabilizing Arp2/3 branched actin networks, preventing their spontaneous disassembly. Upon activation of coronin 1B through dephosphorylation of serine 2 by SSH1L, the coronin 1B trimer displaces cortactin and Arp2/3 at F-actin branches, leading less stable branch points and recycling of cortactin and Arp2/3. PKC phosphorylation at serine 2 inactivates coronin $1 \mathrm{~B}$, causing it to lose its affinity for ADP+Pi/ATP actin and dissociate. This allows for cofilin-mediated severing and turnover of actin.

Coronin 1B is important in regulating branched actin network turnover. It localizes to the leading edge of fibroblast lamellipodia, where it interacts with both F-actin and Arp2/3 complex ${ }^{150}$. Studies from the Bear laboratory at University of North Carolina, Chapel Hill have led to a proposed mechanism of coronin 1B's function in regulating actin network turnover in lamellipodia (Figure 4) ${ }^{151}$. Branched actin networks formed by Arp2/3 complex and stabilized by cortactin are necessary for lamellipodia function. However, forward migration requires turnover of these components, where coronin $1 \mathrm{~B}$ participates in network breakdown. Coronin 1B interacts with and inhibits Arp2/3-mediated actin 
nucleation, a function that also requires binding to $\mathrm{F}$-actin ${ }^{152,153}$. The interaction with Factin is achieved through the interaction of a charged patch within the $\beta$-propeller region centered at residue $\mathrm{Arg}^{153}$. Coronin 1B activation is achieved by slingshot (SSH1L) phosphatase-mediated dephosphorylation at serine $2^{152}$. Localization of coronin 1B to the leading edge is needed for proper SSH1L recruitment, since this phosphatase is also required for local activation of cofilin, stimulating F-actin severing activity following dephosphorlyation at serine 3. Coronin 1B there may play an additional role in coordinating regional cofilin activity. Following corinin 1B activation, activated coronin 1B displaces Arp2/3 and cortactin in the branched cortical actin network, destabilizing cortical actin branch points ${ }^{151}$. Coronin $1 \mathrm{~B}$ activity is downregulated by protein kinase $\mathrm{C}$ phosphorylation at serine $2^{150}$, resulting in coronin $1 \mathrm{~B}$ dissociation from F-actin branches. The resulting F-actin serves as a substrate for cofilin, where cofilin-mediated F-actin severing deconstructs the network to drive lamellipodia actin turnover ${ }^{151}$. In addition, coronin 1B regulates proper actin filament elongation by preventing cofilin binding to newly polymerized actin filaments that contain high ATP/ADP+Pi, due to an increased affinity of coronin 1B for newly polymerized actin monomers within F-actin ${ }^{152,153}$. Coronin 1B knockdown in fibroblasts alters lamellipodia dynamics, enhancing the frequency of protrusions that are shorter and less persistent than in control cells, supporting the idea that proper recycling of actin network components is important for efficient lamellipodia migration $^{152}$.

Coronin 1B also plays additional roles in promoting the mesenchymal mode of cell migration. Recently coronin 1B was found to interact and negatively regulate the activities of Rho kinase 2 (ROCK2) ${ }^{154}$, a serine/theronine kinase important for driving amoeboid 
motility by stimulating actomyosin contractility. Attenuation of ROCK signaling is required for neuregulin-1 (NRG-1)-induced cell scattering of breast carcinoma cells ${ }^{154}$. Downregulation of coronin $1 \mathrm{~B}$ enhances phosphorylation of the downstream ROCK targets myosin phosphatase 1 (MYPT1) and myosin light chain (MLC) ${ }^{154}$. Translocation of coronin 1B to endothelial cell lamellipodia occurs following sphingosine-1-phosphate (S1P) stimulation ${ }^{155}$. This response requires phospholipase D2 (PLD2) and Rac1, again showing a link to the mesenchymal phenotype.

Despite the fact that mice with genetic deletion of coronin $1 \mathrm{~B}$ are viable and fertile ${ }^{156}$, there is evidence of coronin 1B playing important roles in the heart, brain and nervous system. During mouse heart development, coronin 1B is expressed in the atrioventricular cushion, where cardiac EMT takes place, as well as in the endocardium and epicardium ${ }^{157}$. The Wilms' tumor-1 (Wt1) transcription factor influences coronin 1B expression in vitro and cardiac-specific deletion of $\mathrm{Wt} 1$ decreases coronin $1 \mathrm{~B}$ expression in the epicardium ${ }^{157}$. Another study investigating changes in platelets from patients with coronary artery disease (CAD) found them to have decreased coronin 1B expression ${ }^{158}$. Platelet activation has been shown to contribute to plaque development that leads to CAD. Arp2/3 contributes to the cytoskeletal rearrangements needed for this process ${ }^{159}$, therefore it is likely that coronin 1B-mediated actin cytoskeleton reorganization is involved in circulatory pathology. In vascular smooth muscle cells, platelet-derived growth factor (PDGF)-induced migration requires down-regulation of coronin 1 $\mathrm{B}^{160}$, which is in line with reduced coronin 1B expression during platelet activation. Contrary to fibroblast lamellipodia, knockdown of coronin 1B in vascular smooth muscle cells increased lamellipodia protraction rate and protrusion distance. Inactivation of coronin 1B by 
phosphorylation at serine 2 occurs in response to vessel injury ${ }^{160}$. Decreased coronin 1B activity in components of the circulatory system appears necessary for effective migration and vessel remodeling, however more studies are needed to confirm this.

Coronin 1B expression has also been shown to be important for neurite outgrowth ${ }^{161,162}$, and is up-regulated during an experimental system of spinal cord injury in rats ${ }^{163}$. Neurite extensions from primary neurons and neuroblastoma cells increase following coronin $1 \mathrm{~B}$ overexpression, and coronin 1B co-localizes with the neuronal regeneration marker GAP-43 in growth cones and extended neurite terminals ${ }^{163}$. Following spinal cord injury, similar increases of coronin 1B expression are also observed in neurons. This up-regulation is mediated by the transcription factor $p 53^{162}$. Additionally, coronin $1 \mathrm{~B}$ has been identified as a binding partner for importin $\mathrm{a} 5$ in adult mouse brain, and is located in the nucleus of hippocampal neurons ${ }^{164}$. While the role of coronin 1B in the nucleus remains to be elucidated, it is likely related to intra-nuclear actin-dependent functions ${ }^{165}$.

There have been no reported studies to date that define a role for coronin $1 \mathrm{~B}$ in any cancer type. However, its location near cortactin in the chromosome 11q13 amplicon ${ }^{166}$ suggests it may play important roles in enhancing motility and invasion in carcinoma tumor cells harboring 11q13 amplification, including breast and head and neck cancers $^{167}$.

This review has detailed different aspects of HNSCC relevant to the dissertation work presented herein. These include the genetic alterations leading to progression, modes of imaging important for diagnosis of primary tumors and lymph node involvement, and the 
various migratory modes and actin cytoskeletal proteins involved in tumor invasion. Amplification of the chromosomal region $11 \mathrm{q} 13$ results in cortactin overexpression, which has been repeatedly shown to drive invasion and metastasis detected through imaging modalities such as PET/CT, MRI and ultrasound. The following studies touch on each of these different components to tumor growth and detection. Study 1 identifies coronin 1B as a potential co-mediator of invasion along with cortactin in cases with $11 \mathrm{q} 13$ amplification, and reveals for the first time expression of coronin 1B in HNSCC and in invadopodia. In Study 2, we investigate the role of cortactin in a transgenic mouse model of oral tumorigenesis. We determine that contrary to in vitro and xenograft model data, cortactin is dispensable for tongue cancer invasion, demonstrating the importance of using complete microenvironments in mouse models of cancer. Finally in Study 3, we apply high frequency ultrasound (HF US) to a mouse model of oral cancer. We map mouse cervical lymph nodes by HF US and histology and show the utility of image-guided fine needle biopsy on mice similar to that used in the clinic. We use this technique to show early cervical lymph node changes that occur prior to carcinogen-induced tumor formation, and how these changes are the result of hyperproliferation of the paracortical T-cell zone within the nodes. Collectively, these studies provide an enhanced understanding of actin regulatory proteins in HNSCC and their roles both in vitro and in vivo, as well as emphasizes the importance of utilizing the best models for accurate analysis of their functions in human cancers. 


\section{References}

1 Rothenberg SM, Ellisen LW. The molecular pathogenesis of head and neck squamous cell carcinoma. J Clin Invest 2012; 122: 1951-1957.

2 Leemans $\mathrm{CR}$, Braakhuis BJM, Brakenhoff $\mathrm{RH}$. The molecular biology of head and neck cancer. Nat Rev Cancer 2010; 11: 9-22.

3 Benson E, Li R, Eisele D, Fakhry C. The clinical impact of HPV tumor status upon head and neck squamous cell carcinomas. Oral Oncol 2013.

4 Rampias T, Sasaki C, Psyrri A. Molecular mechanisms of HPV induced carcinogenesis in head and neck. Oral Oncol 2013.

5 O'Rorke MA, Ellison M V, Murray LJ, Moran M, James J, Anderson LA. Human papillomavirus related head and neck cancer survival: a systematic review and meta-analysis. Oral Oncol 2012; 48: 1191-1201.

6 Chaturvedi AK, Engels EA, Pfeiffer RM, Hernandez BY, Xiao W, Kim E et al. Human papillomavirus and rising oropharyngeal cancer incidence in the United States. $J$ Clin Oncol 2011; 29: 4294-4301.

$7 \quad$ Lin M, Smith LT, Smiraglia DJ, Kazhiyur-Mannar R, Lang JC, Schuller DE et al. DNA copy number gains in head and neck squamous cell carcinoma. Oncogene 2006; 25: 1424-1433.

8 Kotwall C, Sako K, Razack MS, Rao U, Bakamjian V, Shedd DP. Metastatic patterns in squamous cell cancer of the head and neck. Am J Surg 1987; 154: 439442.

9 Calhoun $\mathrm{KH}$, Fulmer P, Weiss R, Hokanson JA. Distant metastases from head and neck squamous cell carcinomas. Laryngoscope 1994; 104: 1199-1205.

10 Reed AL, Califano J, Cairns $\mathrm{P}$, Westra $\mathrm{WH}$, Jones RM, Koch $\mathrm{W}$ et al. High frequency of p16 (CDKN2/MTS-1/INK4A) inactivation in head and neck squamous cell carcinoma. Cancer Res 1996; 56: 3630-3633.

11 Li H, Wawrose JS, Gooding WE, Garraway LA, Lui VW, Peyser ND et al. Molecular Profiling of HNSCC Cells and Tumors Reveals a Rational Approach to Preclinical Model Selection. Mol Cancer Res 2014. doi:10.1158/1541-7786.MCR-13-0396.

12 Okami K, Wu L, Riggins G, Cairns P, Goggins M, Evron E et al. Analysis of PTEN/MMAC1 alterations in aerodigestive tract tumors. Cancer Res 1998; 58: 509-511. 
13 Gonzalez M V, Pello MF, Lopez-Larrea C, Suarez C, Menendez MJ, Coto E. Loss of heterozygosity and mutation analysis of the p16 (9p21) and p53 (17p13) genes in squamous cell carcinoma of the head and neck. Clin Cancer Res 1995; 1: 10431049.

14 Somers KD, Merrick MA, Lopez ME, Incognito LS, Schechter GL, Casey G. Frequent p53 mutations in head and neck cancer. Cancer Res 1992; 52: 59976000.

15 Redon R, Muller D, Caulee K, Wanherdrick K, Abecassis J, du Manoir S. A simple specific pattern of chromosomal aberrations at early stages of head and neck squamous cell carcinomas: PIK3CA but not p63 gene as a likely target of 3q26-qter gains. Cancer Res 2001; 61: 4122-4129.

16 Murugan AK, Hong NT, Fukui Y, Munirajan AK, Tsuchida N. Oncogenic mutations of the PIK3CA gene in head and neck squamous cell carcinomas. Int J Oncol 2008; 32: 101-111.

17 Sheu JJ, Hua CH, Wan L, Lin YJ, Lai MT, Tseng HC et al. Functional genomic analysis identified epidermal growth factor receptor activation as the most common genetic event in oral squamous cell carcinoma. Cancer Res 2009; 69: 2568-2576.

18 Seiwert TY, Jagadeeswaran R, Faoro L, Janamanchi V, Nallasura V, El Dinali M et al. The MET receptor tyrosine kinase is a potential novel therapeutic target for head and neck squamous cell carcinoma. Cancer Res 2009; 69: 3021-3031.

19 Rodrigo JP, Lazo PS, Ramos S, Alvarez I, Suarez C. MYC amplification in squamous cell carcinomas of the head and neck. Arch Otolaryngol Head Neck Surg 1996; 122: 504-507.

20 Williams ME, Gaffey MJ, Weiss LM, Wilczynski SP, Schuuring E, Levine PA. Chromosome 11Q13 amplification in head and neck squamous cell carcinoma. Arch Otolaryngol Head Neck Surg 1993; 119: 1238-1243.

21 Meredith SD, Levine PA, Burns JA, Gaffey MJ, Boyd JC, Weiss LM et al. Chromosome 11q13 amplification in head and neck squamous cell carcinoma. Association with poor prognosis. Arch Otolaryngol Head Neck Surg 1995; 121: 790-794.

22 Greer Jr RO, Said S, Shroyer KR, Marileila VG, Weed SA. Overexpression of cyclin D1 and cortactin is primarily independent of gene amplification in salivary gland adenoid cystic carcinoma. Oral Oncol 2007; 43: 735-741.

23 Rodrigo JP, Garcia LA, Ramos S, Lazo PS, Suarez C. EMS1 gene amplification correlates with poor prognosis in squamous cell carcinomas of the head and neck. Clin Cancer Res 2000; 6: 3177-3182. 
24 Rodrigo JP, Garcia-Carracedo D, Garcia LA, Menendez S, Allonca E, Gonzalez M $\mathrm{V}$ et al. Distinctive clinicopathological associations of amplification of the cortactin gene at 11q13 in head and neck squamous cell carcinomas. J Pathol 2009; 217: 516-523.

25 Layland MK, Sessions DG, Lenox J. The influence of lymph node metastasis in the treatment of squamous cell carcinoma of the oral cavity, oropharynx, larynx, and hypopharynx: N0 versus N+. Laryngoscope 2005; 115: 629-39.

26 Seeram E. Computed tomography: physical principles, clinical applications, and quality control. Elsevier Health Sciences, 2013.

27 Poon C, Stenson K. Overview of the diagnosis and staging of head and neck cancer. 2014; 2014.

28 Don DM, Calcaterra TC, Anzai Y, Lufkin RB, Fu Y. Evaluation of cervical lymph node metastases in squamous cell carcinoma of the head and neck. Laryngoscope 1995; 105: 669-674.

29 Escott EJ. Role of Positron Emission Tomography/Computed Tomography (PET/CT) in Head and Neck Cancer. Radiol Clin North Am 2013; 51: 881-893.

30 Chawla S, Kim S, Dougherty L, Wang S, Loevner LA, Quon H et al. Pretreatment diffusion-weighted and dynamic contrast-enhanced MRI for prediction of local treatment response in squamous cell carcinomas of the head and neck. AJRAmerican J Roentgenol 2013; 200: 35-43.

31 Shukla-Dave A, Lee NY, Jansen JFA, Thaler HT, Stambuk HE, Fury MG et al. Dynamic contrast-enhanced magnetic resonance imaging as a predictor of outcome in head-and-neck squamous cell carcinoma patients with nodal metastases. Int J Radiat Oncol Biol Phys 2012; 82: 1837-1844.

32 Herneth AM, Guccione S, Bednarski M. Apparent diffusion coefficient: a quantitative parameter for in vivo tumor characterization. Eur J Radiol 2003; 45: 208-213.

33 Kim S, Loevner L, Quon H, Sherman E, Weinstein G, Kilger A et al. Diffusionweighted magnetic resonance imaging for predicting and detecting early response to chemoradiation therapy of squamous cell carcinomas of the head and neck. Clin Cancer Res 2009; 15: 986-994.

34 De Bondt RBJ, Nelemans PJ, Hofman PAM, Casselman JW, Kremer B, van Engelshoven JMA et al. Detection of lymph node metastases in head and neck cancer: a meta-analysis comparing US, USgFNAC, CT and MR imaging. Eur $J$ Radiol 2007; 64: 266-272. 
35 Stoeckli SJ, Haerle SK, Strobel K, Haile SR, Hany TF, Schuknecht B. Initial staging of the neck in head and neck squamous cell carcinoma: A comparison of CT, PET/CT, and ultrasound-guided fine-needle aspiration cytology. Head Neck 2012; 34: 469-476.

36 Ahuja AT, Ying M, Ho SY, Antonio G, Lee YP, King AD et al. Ultrasound of malignant cervical lymph nodes. Cancer Imaging 2008; 8: 48.

37 Chang DB, Yuan A, Yu CJ, Luh KT, Kuo SH, Yang PC. Differentiation of benign and malignant cervical lymph nodes with color Doppler sonography. Am J Roentgenol 1994; 162: 965-968.

38 Dangore-Khasbage S, Degwekar SS, Bhowate RR, Banode PJ, Bhake A, Choudhary MS et al. Utility of color Doppler ultrasound in evaluating the status of cervical lymph nodes in oral cancer. Oral Surgery, Oral Med Oral Pathol Oral Radiol Endodontology 2009; 108: 255-263.

39 Liao L-J, Lo W-C, Hsu W-L, Wang C-T, Lai M-S. Detection of cervical lymph node metastasis in head and neck cancer patients with clinically NO neck-a metaanalysis comparing different imaging modalities. BMC Cancer 2012; 12: 236.

40 Friedl P, Alexander S. Cancer invasion and the microenvironment: plasticity and reciprocity. Cell 2011; 147: 992-1009.

41 Lu P, Weaver VM, Werb Z. The extracellular matrix: a dynamic niche in cancer progression. J Cell Biol 2012; 196: 395-406.

42 LeBleu VS, Macdonald B, Kalluri R. Structure and function of basement membranes. Exp Biol Med (Maywood) 2007; 232: 1121-9.

43 Sanz-Moreno V, Gadea G, Ahn J, Paterson H, Marra P, Pinner S et al. Rac activation and inactivation control plasticity of tumor cell movement. Cell 2008; 135 : 510-523.

44 Sahai E, Marshall CJ. Differing modes of tumour cell invasion have distinct requirements for Rho/ROCK signalling and extracellular proteolysis. Nat Cell Biol 2003; 5: 711-719.

45 Wilkinson S, Paterson HF, Marshall CJ. Cdc42-MRCK and Rho-ROCK signalling cooperate in myosin phosphorylation and cell invasion. Nat Cell Biol 2005; 7: 255261.

46 Namekata K, Enokido Y, Iwasawa K, Kimura H. MOCA induces membrane spreading by activating Rac1. J Biol Chem 2004; 279: 14331-14337. 
47 O'Neill GM, Seo S, Serebriiskii IG, Lessin SR, Golemis EA. A new central scaffold for metastasis: parsing HEF1/Cas-L/NEDD9. Cancer Res 2007; 67: 8975-8979.

48 Friedl P, Locker J, Sahai E, Segall JE. Classifying collective cancer cell invasion. Nat Cell Biol 2012; 14: 777-783.

49 Roussos ET, Balsamo M, Alford SK, Wyckoff JB, Gligorijevic B, Wang Y et al. Mena invasive (MenaINV) promotes multicellular streaming motility and transendothelial migration in a mouse model of breast cancer. J Cell Sci 2011; 124: 2120-2131.

50 Patsialou A, Bravo-Cordero JJ, Wang Y, Entenberg D, Liu H, Clarke $\mathrm{M}$ et al. Intravital multiphoton imaging reveals multicellular streaming as a crucial component of in vivo cell migration in human breast tumors. Intravital 2013; 2: e25294.

51 Yamamoto E, Kohama G, Sunakawa H, Iwai M, Hiratsuka H. Mode of invasion, bleomycin sensitivity, and clinical course in squamous cell carcinoma of the oral cavity. Cancer 1983; 51: 2175-2180.

52 DiCostanzo D, Rosen PP, Gareen I, Franklin S, Lesser M. Prognosis in infiltrating lobular carcinoma: an analysis of" classical" and variant tumors. Am J Surg Pathol 1990; 14: 12-23.

53 Gaggioli C, Hooper S, Hidalgo-Carcedo C, Grosse R, Marshall JF, Harrington K et al. Fibroblast-led collective invasion of carcinoma cells with differing roles for RhoGTPases in leading and following cells. Nat Cell Biol 2007; 9: 1392-1400.

54 Scott RW, Hooper S, Crighton D, Li A, Konig I, Munro J et al. LIM kinases are required for invasive path generation by tumor and tumor-associated stromal cells. J Cell Biol 2010; 191: 169-185.

55 Hidalgo-Carcedo C, Hooper S, Chaudhry SI, Williamson P, Harrington K, Leitinger $\mathrm{B}$ et al. Collective cell migration requires suppression of actomyosin at cell-cell contacts mediated by DDR1 and the cell polarity regulators Par3 and Par6. Nat Cell Biol 2011; 13.

56 Reffay M, Parrini MC, Cochet-Escartin O, Ladoux B, Buguin A, Coscoy S et al. Interplay of RhoA and mechanical forces in collective cell migration driven by leader cells. Nat Cell Biol 2014; 16: 217-223.

57 Vogel W, Gish GD, Alves F, Pawson T. The Discoidin Domain Receptor Tyrosine Kinases Are Activated by Collagen. Mol Cell 1997; 1: 13-23.

58 Yamaguchi $\mathrm{H}$, Condeelis J. Regulation of the actin cytoskeleton in cancer cell migration and invasion. Biochim Biophys Acta 2007; 1773: 642-652. 
59 Chhabra ES, Higgs HN. The many faces of actin: matching assembly factors with cellular structures. Nat Cell Biol 2007; 9: 1110-1121.

60 Pollard TD, Borisy GG. Cellular motility driven by assembly and disassembly of actin filaments. Cell 2003; 112: 453-465.

61 Prehoda KE, Scott JA, Mullins RD, Lim WA. Integration of multiple signals through cooperative regulation of the N-WASP-Arp2/3 complex. Science 2000; 290: 801806.

62 Rohatgi R, Ma L, Miki H, Lopez M, Kirchhausen T, Takenawa T et al. The interaction between N-WASP and the Arp2/3 complex links Cdc42-dependent signals to actin assembly. Cell 1999; 97: 221-231.

63 Machesky LM, Insall RH. Scar1 and the related Wiskott-Aldrich syndrome protein, WASP, regulate the actin cytoskeleton through the Arp2/3 complex. Curr Biol 1998; 8: 1347-1356.

64 Kempiak SJ, Yamaguchi H, Sarmiento C, Sidani M, Ghosh M, Eddy RJ et al. A neural Wiskott-Aldrich Syndrome protein-mediated pathway for localized activation of actin polymerization that is regulated by cortactin. J Biol Chem 2005; 280: 58365842.

65 Kinley AW, Weed SA, Weaver AM, Karginov A V, Bissonette E, Cooper JA et al. Cortactin interacts with WIP in regulating Arp2/3 activation and membrane protrusion. Curr Biol 2003; 13: 384-393.

66 Weaver AM, Karginov A V, Kinley AW, Weed SA, Li Y, Parsons JT et al. Cortactin promotes and stabilizes Arp2/3-induced actin filament network formation. Curr Biol 2001; 11: 370-374.

67 Kowalski JR, Egile C, Gil S, Snapper SB, Li R, Thomas SM. Cortactin regulates cell migration through activation of N-WASP. J Cell Sci 2005; 118: 79-87.

$68 \mathrm{Wu} \mathrm{H}$, Reynolds AB, Kanner SB, Vines RR, Parsons JT. Identification and characterization of a novel cytoskeleton-associated pp60src substrate. Mol Cell Biol 1991; 11: 5113-5124.

69 Dedes KJ, Lopez-Garcia MA, Geyer FC, Lambros MB, Savage K, Vatcheva R et al. Cortactin gene amplification and expression in breast cancer: a chromogenic in situ hybridisation and immunohistochemical study. Breast Cancer Res Treat 2010. doi:10.1007/s10549-010-0816-0.

70 Li Y, Tondravi M, Liu J, Smith E, Haudenschild CC, Kaczmarek M et al. Cortactin potentiates bone metastasis of breast cancer cells. Cancer Res 2001; 61: 69066911. 
71 Hirakawa H, Shibata K, Nakayama T. Localization of cortactin is associated with colorectal cancer development. Int J Oncol 2009; 35: 1271-1276.

72 Yuan B-Z, Zhou X, Zimonjic DB, Durkin ME, Popescu NC. Amplification and overexpression of the EMS 1 oncogene, a possible prognostic marker, in human hepatocellular carcinoma. $J$ Mol diagnostics 2003; 5: 48-53.

73 Luo ML, Shen XM, Zhang Y, Wei $F, X u X$, Cai $Y$ et al. Amplification and overexpression of CTTN (EMS1) contribute to the metastasis of esophageal squamous cell carcinoma by promoting cell migration and anoikis resistance. Cancer Res 2006; 66: 11690-11699.

74 Gao HW, Yu CP, Lee HS, Nieh S, Chiang CP, Wang WM et al. Fascin, cortactin and survivin expression of melanocytic neoplasms and association with clinicopathological parameters and anatomic locations in Chinese people. Eur $J$ Dermatol 2010; 20: 293-301.

75 Ambrosio EP, Rosa FE, Domingues MAC, Villacis RAR, Coudry R de A, Tagliarini $\mathrm{JV}$ et al. Cortactin is associated with perineural invasion in the deep invasive front area of laryngeal carcinomas. Hum Pathol 2011; 42: 1221-1229.

76 Clark ES, Brown B, Whigham AS, Kochaishvili A, Yarbrough WG, Weaver AM. Aggressiveness of HNSCC tumors depends on expression levels of cortactin, a gene in the 11q13 amplicon. Oncogene 2009; 28: 431-444.

77 Gibcus JH, Mastik MF, Menkema L, de Bock GH, Kluin PM, Schuuring E et al. Cortactin expression predicts poor survival in laryngeal carcinoma. $\mathrm{Br} \mathrm{J}$ Cancer 2008; 98: 950-955.

78 Hofman P, Butori C, Havet K, Hofman V, Selva E, Guevara N et al. Prognostic significance of cortactin levels in head and neck squamous cell carcinoma: comparison with epidermal growth factor receptor status. Br J Cancer 2008; 98: 956-964.

79 Alavi S, Namazie A, Calcaterra TC, Wang MB, Srivatsan ES. Clinical application of fluorescence in situ hybridization for chromosome 11q13 analysis in head and neck cancer. Laryngoscope 1999; 109: 874-879.

80 Jin C, Jin Y, Gisselsson D, Wennerberg J, Wah TS, Stromback B et al. Molecular cytogenetic characterization of the $11 \mathrm{q} 13$ amplicon in head and neck squamous cell carcinoma. Cytogenet Genome Res 2006; 115: 99-106.

81 Ammer AG, Weed SA. Cortactin branches out: roles in regulating protrusive actin dynamics. Cell Motil Cytoskeleton 2008; 65: 687-707. 
82 Tehrani S, Tomasevic N, Weed S, Sakowicz R, Cooper JA. Src phosphorylation of cortactin enhances actin assembly. Proc Natl Acad Sci U S A 2007; 104: 1193311938.

83 Hartsock A, Nelson WJ. Adherens and tight junctions: structure, function and connections to the actin cytoskeleton. Biochim Biophys Acta (BBA)-Biomembranes 2008; 1778: 660-669.

84 Baum B, Georgiou M. Dynamics of adherens junctions in epithelial establishment, maintenance, and remodeling. J Cell Biol 2011; 192: 907-917.

85 Kovacs EM, Goodwin M, Ali RG, Paterson AD, Yap AS. Cadherin-directed actin assembly: E-cadherin physically associates with the Arp2/3 complex to direct actin assembly in nascent adhesive contacts. Curr Biol 2002; 12: 379-382.

86 Verma S, Shewan AM, Scott JA, Helwani FM, den Elzen NR, Miki H et al. Arp2/3 activity is necessary for efficient formation of E-cadherin adhesive contacts. $J$ Biol Chem 2004; 279: 34062-34070.

87 Helwani FM, Kovacs EM, Paterson AD, Verma S, Ali RG, Fanning AS et al. Cortactin is necessary for E-cadherin-mediated contact formation and actin reorganization. J Cell Biol 2004; 164: 899-910.

88 Han SP, Gambin Y, Gomez GA, Verma S, Giles N, Michael M et al. Cortactin Scaffolds Arp2/3 and WAVE2 at the Epithelial Zonula Adherens. J Biol Chem 2014; 289: $7764-7775$.

89 Hanahan D, Weinberg RA. Hallmarks of cancer: the next generation. Cell 2011; 144: 646-74.

90 Lamouille S, Xu J, Derynck R. Molecular mechanisms of epithelial-mesenchymal transition. Nat Rev Mol Cell Biol 2014; 15: 178-196.

91 Eriksen JG, Steiniche T, Søgaard H, Overgaard J. Expression of integrins and Ecadherin in squamous cell carcinomas of the head and neck. Apmis 2004; 112: 560-568.

92 Kurtz KA, Hoffman HT, Zimmerman MB, Robinson RA. Decreased E-cadherin but not beta-catenin expression is associated with vascular invasion and decreased survival in head and neck squamous carcinomas. Otolaryngol Head Neck Surg 2006; 134: 142-146.

93 Rodrigo JP, Domınguez F, Alvarez C, Manrique C, Herrero A, Suárez C. Expression of E-cadherin in squamous cell carcinomas of the supraglottic larynx with correlations to clinicopathological features. Eur J Cancer 2002; 38: 1059-1064. 
94 Yang T-L, Wu C-T, Ko J-Y, Wang C-P, Lou P-J, Chang Y-L. Significance of tumor satellite variables in reflecting the epithelial-mesenchymal transition of tongue cancer. Oral Oncol 2011; 47: 720-724.

95 Fanning AS, Jameson BJ, Jesaitis LA, Anderson JM. The tight junction protein ZO1 establishes a link between the transmembrane protein occludin and the actin cytoskeleton. J Biol Chem 1998; 273: 29745-29753.

96 Wittchen ES, Haskins J, Stevenson BR. Protein interactions at the tight junction. Actin has multiple binding partners, and ZO-1 forms independent complexes with ZO-2 and ZO-3. J Biol Chem 1999; 274: 35179-35185.

97 Furuse M, Itoh M, Hirase T, Nagafuchi A, Yonemura S, Tsukita S. Direct association of occludin with ZO-1 and its possible involvement in the localization of occludin at tight junctions. J Cell Biol 1994; 127: 1617-1626.

98 Katsube T, Takahisa M, Ueda R, Hashimoto N, Kobayashi M, Togashi S. Cortactin associates with the cell-cell junction protein ZO-1 in both Drosophila and mouse. $J$ Biol Chem 1998; 273: 29672-29677.

99 Schnoor M, Lai FP, Zarbock A, Klaver R, Polaschegg C, Schulte D et al. Cortactin deficiency is associated with reduced neutrophil recruitment but increased vascular permeability in vivo. J Exp Med 2011; 208: 1721-1735.

100 Citaln-Madrid A, Garca-Ponce A, Vargas-Robles H, Betanzos A, Rottner K, Mennigen $\mathrm{R}$ et al. Cortactin regulates intestinal epithelial permeability by stabilizing tight junctions (650.6). FASEB J 2014; 28: 650.6.

101 Berrier AL, Yamada KM. Cell-matrix adhesion. J Cell Physiol 2007; 213: 565-573.

102 Harburger DS, Calderwood DA. Integrin signalling at a glance. J Cell Sci 2009; 122 : 159-163.

103 Morse EM, Brahme NN, Calderwood DA. Integrin Cytoplasmic Tail Interactions. Biochemistry 2014.

104 Nagano M, Hoshino D, Koshikawa N, Akizawa T, Seiki M. Turnover of focal adhesions and cancer cell migration. Int J Cell Biol 2012; 2012.

105 Carisey A, Tsang R, Greiner AM, Nijenhuis N, Heath N, Nazgiewicz A et al. Vinculin regulates the recruitment and release of core focal adhesion proteins in a forcedependent manner. Curr Biol 2013; 23: 271-281.

106 Ren XD, Kiosses WB, Sieg DJ, Otey CA, Schlaepfer DD, Schwartz MA. Focal adhesion kinase suppresses Rho activity to promote focal adhesion turnover. $J$ Cell Sci 2000; 113 (Pt 2: 3673-3678. 
107 Wang W, Liu Y, Liao K. Tyrosine phosphorylation of cortactin by the FAK-Src complex at focal adhesions regulates cell motility. BMC Cell Biol 2011; 12: 49.

108 Tomar A, Lawson C, Ghassemian M, Schlaepfer DD. Cortactin as a Target for FAK in the Regulation of Focal Adhesion Dynamics. PLoS One 2012; 7: e44041.

109 Eke I, Deuse Y, Hehlgans S, Gurtner K, Krause M, Baumann M et al. beta(1)Integrin/FAK/cortactin signaling is essential for human head and neck cancer resistance to radiotherapy. J Clin Invest 2012; 122: 1529-1540.

110 Chan AY, Raft S, Bailly M, Wyckoff JB, Segall JE, Condeelis JS. EGF stimulates an increase in actin nucleation and filament number at the leading edge of the lamellipod in mammary adenocarcinoma cells. J Cell Sci 1998; 111 ( Pt 2: 199_ 211.

111 Ichetovkin I, Grant W, Condeelis J. Cofilin produces newly polymerized actin filaments that are preferred for dendritic nucleation by the Arp2/3 complex. Curr Biol 2002; 12: 79-84.

112 Mullins RD, Heuser JA, Pollard TD. The interaction of Arp2/3 complex with actin: nucleation, high affinity pointed end capping, and formation of branching networks of filaments. Proc Natl Acad Sci U S A 1998; 95: 6181-6186.

113 Campellone KG, Welch MD. A nucleator arms race: cellular control of actin assembly. Nat Rev cell Biol 2010; 11: 237-251.

114 Weed SA, Karginov A V, Schafer DA, Weaver AM, Kinley AW, Cooper JA et al. Cortactin localization to sites of actin assembly in lamellipodia requires interactions with F-actin and the Arp2/3 complex. J Cell Biol 2000; 151: 29-40.

115 Rohatgi R, Nollau P, Ho HY, Kirschner MW, Mayer BJ. Nck and phosphatidylinositol 4,5-bisphosphate synergistically activate actin polymerization through the $\mathrm{N}$ WASP-Arp2/3 pathway. J Biol Chem 2001; 276: 26448-26452.

116 Oser M, Mader CC, Gil-Henn H, Magalhaes M, Bravo-Cordero JJ, Koleske AJ et al. Specific tyrosine phosphorylation sites on cortactin regulate Nck1-dependent actin polymerization in invadopodia. J Cell Sci 2010; 123: 3662-73.

117 Kelley LC, Hayes KE, Ammer AG, Martin KH, Weed SA. Cortactin phosphorylated by ERK1/2 localizes to sites of dynamic actin regulation and is required for carcinoma lamellipodia persistence. . PLoS One 2010; 5: e13847.

118 Bryce NS, Clark ES, Leysath JL, Currie JD, Webb DJ, Weaver AM. Cortactin promotes cell motility by enhancing lamellipodial persistence. Curr Biol 2005; 15: 1276-1285. 
119 Lai FP, Szczodrak M, Oelkers JM, Ladwein M, Acconcia F, Benesch S et al. Cortactin promotes migration and platelet-derived growth factor-induced actin reorganization by signaling to Rho-GTPases. Mol Biol Cell 2009; 20: 3209-3223.

120 Rothschild BL, Shim AH, Ammer AG, Kelley LC, Irby KB, Head JA et al. Cortactin overexpression regulates actin-related protein $2 / 3$ complex activity, motility, and invasion in carcinomas with chromosome 11q13 amplification. Cancer Res 2006; 66: 8017-8025.

121 Patel AS, Schechter GL, Wasilenko WJ, Somers KD. Overexpression of EMS1/cortactin in NIH3T3 fibroblasts causes increased cell motility and invasion in vitro. Oncogene 1998; 16.

122 Ayala I, Baldassarre M, Giacchetti G, Caldieri G, Tete S, Luini A et al. Multiple regulatory inputs converge on cortactin to control invadopodia biogenesis and extracellular matrix degradation. J Cell Sci 2008; 121: 369-378.

123 Chen W-T, Chen J-M, Parsons SJ, Parsons JT. Local degradation of fibronectin at sites of expression of the transforming gene product pp60src. 1985.

124 Schoumacher M, Goldman RD, Louvard D, Vignjevic DM. Actin, microtubules, and vimentin intermediate filaments cooperate for elongation of invadopodia. $\mathrm{J} \mathrm{Cell} \mathrm{Biol}$ 2010; 189: 541-556.

125 Clark ES, Whigham AS, Yarbrough WG, Weaver AM. Cortactin is an essential regulator of matrix metalloproteinase secretion and extracellular matrix degradation in invadopodia. Cancer Res 2007; 67: 4227-4235.

126 Nakahara H, Howard L, Thompson EW, Sato H, Seiki M, Yeh $\mathrm{Y}$ et al. Transmembrane/cytoplasmic domain-mediated membrane type 1-matrix metalloprotease docking to invadopodia is required for cell invasion. Proc Natl Acad Sci U S A 1997; 94: 7959-7964.

127 Yamaguchi H, Lorenz M, Kempiak S, Sarmiento C, Coniglio S, Symons M et al. Molecular mechanisms of invadopodium formation: the role of the N-WASP-Arp2/3 complex pathway and cofilin. J Cell Biol 2005; 168: 441-452.

128 Mader CC, Oser M, Magalhaes MA, Bravo-Cordero JJ, Condeelis J, Koleske AJ et al. An EGFR-Src-Arg-cortactin pathway mediates functional maturation of invadopodia and breast cancer cell invasion. Cancer Res 2011; 71: 1730-1741.

129 Bowden ET, Barth M, Thomas D, Glazer RI, Mueller SC. An invasion-related complex of cortactin, paxillin and PKCmu associates with invadopodia at sites of extracellular matrix degradation. Oncogene 1999; 18: 4440-4449. 
130 Oser M, Yamaguchi H, Mader CC, Bravo-Cordero JJ, Arias M, Chen X et al. Cortactin regulates cofilin and N-WASp activities to control the stages of invadopodium assembly and maturation. J Cell Biol 2009; 186: 571-587.

131 Artym V V, Zhang Y, Seillier-Moiseiwitsch F, Yamada KM, Mueller SC. Dynamic interactions of cortactin and membrane type 1 matrix metalloproteinase at invadopodia: defining the stages of invadopodia formation and function. Cancer Res 2006; 66: 3034-3043.

132 Sharma VP, Eddy R, Entenberg D, Kai M, Gertler FB, Condeelis J. Tks5 and SHIP2 Regulate Invadopodium Maturation, but Not Initiation, in Breast Carcinoma Cells. Curr Biol 2013; 23: 2079-2089.

133 Stylli SS, Stacey TT, Verhagen AM, Xu SS, Pass I, Courtneidge SA et al. Nck adaptor proteins link Tks5 to invadopodia actin regulation and ECM degradation. $J$ Cell Sci 2009; 122: 2727-2740.

134 Albrechtsen R, Stautz D, Sanjay A, Kveiborg M, Wewer UM. Extracellular engagement of ADAM12 induces clusters of invadopodia with localized ectodomain shedding activity. Exp Cell Res 2011; 317: 195-209.

135 Caldieri G, Giacchetti G, Beznoussenko G, Attanasio F, Ayala I, Buccione R. Invadopodia biogenesis is regulated by caveolin-mediated modulation of membrane cholesterol levels. J Cell Mol Med 2009; 13: 1728-1740.

136 Yamaguchi H, Takeo Y, Yoshida S, Kouchi Z, Nakamura Y, Fukami K. Lipid rafts and caveolin-1 are required for invadopodia formation and extracellular matrix degradation by human breast cancer cells. Cancer Res 2009; 69: 8594-8602.

137 Bravo-Cordero JJ, Marrero-Diaz R, Megías D, Genís L, García-Grande A, García MA et al. MT1-MMP proinvasive activity is regulated by a novel Rab8-dependent exocytic pathway. EMBO J 2007; 26: 1499-1510.

138 Sakurai-Yageta M, Recchi C, Le Dez G, Sibarita J-B, Daviet L, Camonis J et al. The interaction of IQGAP1 with the exocyst complex is required for tumor cell invasion downstream of Cdc42 and RhoA. J Cell Biol 2008; 181: 985-998.

139 Yu X, Zech T, McDonald L, Gonzalez EG, Li A, Macpherson I et al. N-WASP coordinates the delivery and F-actin-mediated capture of MT1-MMP at invasive pseudopods. J Cell Biol 2012; 199: 527-544.

140 Li A, Dawson JC, Forero-Vargas M, Spence HJ, Yu X, Konig I et al. The actinbundling protein fascin stabilizes actin in invadopodia and potentiates protrusive invasion. Curr Biol 2010; 20: 339-345. 
141 Morgan RO, Fernandez MP. Molecular phylogeny and evolution of the coronin gene family. In: The Coronin Family of Proteins. Springer, 2008, pp 41-55.

142 De Hostos EL, Bradtke B, Lottspeich F, Guggenheim R, Gerisch G. Coronin, an actin binding protein of Dictyostelium discoideum localized to cell surface projections, has sequence similarities to $\mathrm{G}$ protein beta subunits. EMBO J 1991; 10: 4097-4104.

143 De Hostos EL, Rehfuess C, Bradtke B, Waddell DR, Albrecht R, Murphy J et al. Dictyostelium mutants lacking the cytoskeletal protein coronin are defective in cytokinesis and cell motility. J Cell Biol 1993; 120: 163-173.

144 Humphries CL, Balcer HI, D’Agostino JL, Winsor B, Drubin DG, Barnes G et al. Direct regulation of Arp2/3 complex activity and function by the actin binding protein coronin. J Cell Biol 2002; 159: 993-1004.

145 Gandhi M, Achard V, Blanchoin L, Goode BL. Coronin switches roles in actin disassembly depending on the nucleotide state of actin. Mol Cell 2009; 34: 364374.

146 Goode BL, Wong JJ, Butty AC, Peter M, McCormack AL, Yates JR et al. Coronin promotes the rapid assembly and cross-linking of actin filaments and may link the actin and microtubule cytoskeletons in yeast. J Cell Biol 1999; 144: 83-98.

147 Maniak M, Rauchenberger R, Albrecht R, Murphy J, Gerisch G. Coronin involved in phagocytosis: dynamics of particle-induced relocalization visualized by a green fluorescent protein Tag. Cell 1995; 83: 915-924.

148 Appleton BA, Wu P, Wiesmann C. The crystal structure of murine coronin-1: a regulator of actin cytoskeletal dynamics in lymphocytes. Structure 2006; 14: 87-96.

149 Chan KT, Creed SJ, Bear JE. Unraveling the enigma: progress towards understanding the coronin family of actin regulators. Trends Cell Biol 2011; 21: 481-488.

150 Cai L, Holoweckyj N, Schaller MD, Bear JE. Phosphorylation of coronin 1B by protein kinase $C$ regulates interaction with Arp2/3 and cell motility. $J$ Biol Chem 2005; 280: 31913-31923.

151 Cai L, Makhov AM, Schafer DA, Bear JE. Coronin 1B antagonizes cortactin and remodels Arp2/3-containing actin branches in lamellipodia. Cell 2008; 134: 828842.

152 Cai L, Marshall TW, Uetrecht AC, Schafer DA, Bear JE. Coronin 1B coordinates Arp2/3 complex and cofilin activities at the leading edge. Cell 2007; 128: 915-929. 
153 Cai L, Makhov AM, Bear JE. F-actin binding is essential for coronin 1B function in vivo. J Cell Sci 2007; 120: 1779-1790.

154 Rana MK, Worthylake RA. Novel mechanism for negatively regulating Rho-kinase (ROCK) signaling through Coronin1B protein in neuregulin 1 (NRG-1)-induced tumor cell motility. J Biol Chem 2012; 287: 21836-21845.

155 Usatyuk P V, Burns M, Mohan V, Pendyala S, He D, Ebenezer DL et al. Coronin 1B Regulates S1P-Induced Human Lung Endothelial Cell Chemotaxis: Role of PLD2, Protein Kinase C and Rac1 Signal Transduction. PLoS One 2013; 8: e63007.

156 Foger N, Jenckel A, Orinska Z, Lee KH, Chan AC, Bulfone-Paus S. Differential regulation of mast cell degranulation versus cytokine secretion by the actin regulatory proteins Coronin1a and Coronin1b . J Exp Med 2011; 208: 1777-1787.

157 Hsu W-H, Yu Y-R, Hsu S-H, Yu W-C, Chu Y-H, Chen Y-J et al. The Wilms' tumor suppressor Wt1 regulates Coronin 1B expression in the epicardium. Exp Cell Res 2013; 319: 1365-1381.

158 Banfi C, Brioschi M, Marenzi G, De Metrio M, Camera M, Mussoni L et al. Proteome of platelets in patients with coronary artery disease. Exp Hematol 2010; 38: 341350.

$159 \mathrm{Li}$ Z, Kim ES, Bearer EL. Arp2/3 complex is required for actin polymerization during platelet shape change. Blood 2002; 99: 4466-4474.

160 Williams HC, San Martin A, Adamo CM, Seidel-Rogol B, Pounkova L, Datla SR et al. Role of coronin 1B in PDGF-induced migration of vascular smooth muscle cells. Circ Res 2012; 111: 56-65.

161 Ma X, Fei E, Fu C, Ren H, Wang G. Dysbindin-1, a schizophrenia-related protein, facilitates neurite outgrowth by promoting the transcriptional activity of p53. Mol Psychiatry 2011; 16: 1105-1116.

162 Di Giovanni S, Knights CD, Rao M, Yakovlev A, Beers J, Catania J et al. The tumor suppressor protein p53 is required for neurite outgrowth and axon regeneration. EMBO J 2006; 25: 4084-4096.

163 Di Giovanni S, De Biase A, Yakovlev A, Finn T, Beers J, Hoffman EP et al. In vivo and in vitro characterization of novel neuronal plasticity factors identified following spinal cord injury. J Biol Chem 2005; 280: 2084-2091.

164 Fukumoto M, Sekimoto T, Yoneda Y. Proteomic analysis of importin alphainteracting proteins in adult mouse brain . Cell Struct Funct 2011; 36: 57-67. 
165 Dingová H, Fukalová J, Maninová M, Philimonenko V V, Hozák P. Ultrastructural localization of actin and actin-binding proteins in the nucleus. Histochem Cell Biol 2009; 131: 425-434.

166 Kelley LC, Shahab S, Weed SA. Actin cytoskeletal mediators of motility and invasion amplified and overexpressed in head and neck cancer. Clin Exp Metastasis 2008; 25: 289-304.

167 Wilkerson PM, Reis-Filho JS. The 11q13-q14 amplicon: clinicopathological correlations and potential drivers. Genes Chromosomes Cancer 2013; 52: 333-55. 


\section{Study 1: Coronin 1B is Required for Invadopodia Function and Invasion in HNSCC}

Elyse L. Walk ${ }^{1}$, Colleen Beatty ${ }^{1}$, Hong Wu ${ }^{2}$, Marielia Varella-Garcia ${ }^{3}$, James E. Bear ${ }^{4}$ and Scott A. Weed ${ }^{1}$

${ }^{1}$ Department of Neuroscience and Anatomy, Program in Cancer Cell Biology, Mary Babb Randolph Cancer Center, West Virginia University, Morgantown, West Virginia, 265069300, '2Department of Pathology, Fox Chase Cancer Center, Philadelphia, PA 19111, ${ }^{3}$ Departments of Medicine and Pathology, University of Colorado-Denver, Anschutz Medical Center, University of Colorado Cancer Center, Aurora, CO 80045, ${ }^{4}$ Lineberger Comprehensive Cancer Center, Department of Cell and Developmental Biology, Howard Hughes Medical Center, University North Carolina at Chapel Hill, North Carolina, 275997295 


\section{Abstract}

Amplification of chromosome $11 \mathrm{q} 13$ in head and neck squamous cell carcinoma (HNSCC) is a common late-stage occurrence associated with poor patient prognosis. Within the core amplified region is the gene that encodes cortactin (CTTN), a filamentous (F-) actin binding protein and Src kinase substrate that stabilizes Arp2/3-F-actin branchpoints in dynamic cortical F-actin structures. CTTN gene amplification results in increased lymph node metastases and decreased survival rates in HNSCC patients. CTTN amplification in HNSCC cell lines enhances tumor cell motility and invasion. Regions flanking the core 11q13 amplicon are often amplified in HNSCC, and contain several genes with the potential to cooperate with CTTN in regulating tumor invasion. One such gene within the $11 \mathrm{q} 13$ region is coronin 1B (CORO1B), an actin-binding protein that antagonizes cortactin function by promoting the breakdown of F-actin branches, impairing cell motility. Here, we show that coronin $1 \mathrm{~B}$ is a potential mediator of HNSCC invasion. CORO1B amplification and overexpression occurs in a subset of HNSCC patients with CTTN amplification. Coronin 1B localizes with cortactin within HNSCC invadopodia, ventral membranous protrusions responsible for degrading extracellular matrix $(\mathrm{ECM})$ to facilitate loco-regional tumor invasion. RNAi-mediated coronin 1B knockdown decreases the number of invadopodia per cell, enhances cell spreading and reduces ECM degradation and 3D spheroid collagen invasion. These results collectively point to a potential role for coronin $1 \mathrm{~B}$ is in regulating HNSCC tumor cell invasion through modulating invadopodia function, and supports a potential prognostic role for CORO1B amplification in identifying a previously unidentified HNSCC subset that may display increased invasiveness in HNSCC cases with 11q13 amplification. 


\section{Introduction}

Head and neck squamous cell carcinoma (HNSCC) is a heterogeneous disease that results from distinct molecular changes of the squamous epithelia in the upper aerodigestive tract ${ }^{1}$. Amplification of the chromosomal region $11 \mathrm{q} 13$ is a late-stage genetic event associated with poor clinical outcome ${ }^{2-5}$. The amplicon typically spans from $11 \mathrm{q} 13.1$ to $11 \mathrm{q} 13.4$, and has been identified in $30 \%$ of HNSCC patients ${ }^{6}$. The most frequently amplified subregion, located at $11 \mathrm{q} 13.3^{6}$, encodes several genes important in cell cycle and actin regulation, including CCND1 (cyclin D1) and CTTN (cortactin). Cortactin is a multi-domain scaffolding protein with important roles in actin cytoskeleton organization, including cell motility and vesicular trafficking ${ }^{7-9}$. Cortactin gene amplification and overexpression in HNSCC is associated with lymph node metastasis, recurrence, and decreased disease-free survival due to more aggressive and invasive tumors $^{2-5,10,11}$. HNSCC cell lines with $11 \mathrm{q} 13$ amplification and cortactin overexpression are more motile and invasive than lines without amplification ${ }^{11}$, and overexpression of cortactin in non-invasive lines results in an invasive phenotype ${ }^{12}$.

While the core region amplified within the $11 q 13$ amplicon is at $11 q 13.3$; the flanking regions from 11q13.1-11q13.4 are frequently co-amplified, thus are considered part of the amplicon ${ }^{6}$. Genes located within this region therefore have the potential to function in a cooperative manner with core amplicon products in HNSCC and augment tumor progression. Coronin 1B (CORO1B) was previously identified by our laboratory in a gene mining study to discover potential actin regulators of motility and invasion amplified in $\mathrm{HNSCC}^{13}$. CORO1B is located at the border of 11q13.1/.2, making it a possible candidate for co-amplification with CTTN. Coronin 1B is an Arp2/3 complex- 
and actin-binding protein that regulates cell motility ${ }^{14}$. In fibroblast lamellipodia, it colocalizes with Arp2/3, actin and cortactin, where it promotes turnover of Arp2/3-cortactin F-actin networks. Coronin 1B is phosphorylated at serine 2 by protein kinase C (PKC $)^{15,16}$, and remains inactive until recruitment of slingshot $1 \mathrm{~L}(\mathrm{SSH} 1 \mathrm{~L})$ to the cell membrane and subsequent dephosphorylation ${ }^{14}$. Following activation, coronin $1 \mathrm{~B}$ binds to F-actin branchpoints, displacing Arp2/3 and cortactin, resulting in a less stable F-actin branch with altered geometry ${ }^{15}$. SSH1L recruitment also results in activation of cofilin, which facilitates F-actin severing and filament disassembly. PKC phosphorylation of coronin 1B at serine 2 inactivates coronin $1 \mathrm{~B}$, where it is subsequently recycled to the leading edge $\mathrm{e}^{15}$. The antagonistic activities of cortactin and coronin 1B on Arp2/3-F-actin branchpoints has been proposed to be necessary for dendritic F-actin network turnover within lamellipodia and efficient cell migration ${ }^{15}$. A role for coronin 1B in regulating motile events in HNSCC or other cancer types has not been reported.

Tumor cell migration and invasion requires dynamic reorganization of the actin cytoskeleton, resulting in the formation of lamellipodia, filopodia and invadopodia in response to extracellular signals ${ }^{17}$. While lamellipodia and filopodia are necessary for motility, invasion through the basement membrane and stroma is thought to require invadopodia activity. Invadopodia are F-actin-rich membrane protrusions produced in cancer cells and Src-transformed fibroblasts that actively degrade the extracellular matrix $(E C M)$ through the action of matrix membrane metalloproteinases $(M M P s)^{18}$. Cortactin is a critical component of the F-actin invadopodia "core" that regulates invadopodia formation and function. RNAi-mediated knockdown of cortactin in HNSCC and other tumor cell lines results in reduced ECM degradation, defective matrix metalloproteinase 
(MMP) localization and secretion ${ }^{12}$. Invadopodia biogenesis has been divided into distinct stages to determine the key steps required for tumor cells to acquire the ability to degrade ${ }^{18}$. Initial events involve the accumulation of F-actin, cortactin, Arp2/3 and NWASp to form invadopodial precursors ("pre-invadopodia") that are incapable of degrading ECM. Invadopodia mature by subsequent actin polymerization and recruitment of various MMPs, with MT1-MMP (MMP14) localization the key event in triggering initiation of ECM degradation. While the role of cortactin in invadopodia formation and activity has been well studied ${ }^{19-21}$, a role for coronin $1 \mathrm{~B}$ in regulating invadopodia function has not been established.

In this study, we determine that coronin $1 \mathrm{~B}$ is overexpressed with cortactin in a subset of $\mathrm{HNSCC}$ with $11 \mathrm{q} 13$ amplification. We show that coronin 1B is a component of the invadopodia F-actin core, where it localizes with cortactin in mature invadopodia. RNAi-mediated inhibition of CORO1B expression results in decreased ECM invadopodia degradation activity in 2D and suppresses HNSCC invasion in 3D collagen matrices. Coronin 1B knockdown reduced expression of focal adhesion kinase (FAK), resulting in enhanced tumor cell spreading and adhesion. Taken together, these data suggest that coronin $1 \mathrm{~B}$ is essential for invadopodia function and tumor cell invasion, where coamplification with cortactin may cooperatively accelerate ECM matrix degradation to promote aggressive tumor progression in a subset of HNSCC with $11 \mathrm{q} 13$ amplification. 


\section{Materials and Methods}

\section{Cell culture and lentiviral infection}

HNSCC cell lines 584, HN4, OSC19, FaDu, UMSCC1, UMSCC2, 1483 and MSK921 were cultured as described previously ${ }^{22}$. PLKO.1 lentiviral vectors (ThermoScientific, Pittsburgh, PA) with shRNA targeting Coro1B (shRNA1B 4, 5' ATGCAGTTTGTAGAACCGGGC - $3^{\prime}$ and shRNA $1 \mathrm{~B} \quad 6,5^{\prime}$ ACATTCCAGATGAGTACCACG - 3') were used for stable knockdown in UMSCC1 and OSC19 cells. Lentiviral particles (Santa Cruz Biotechnology, Dallas, TX) containing nontargeting shRNA were used as a control. Stable lines expressing non-targeting shRNA or shCoro1B KD were generated by puromycin selection following standard methods ${ }^{23}$.

\section{Western blotting and antibodies}

Western blotting was performed using standard techniques ${ }^{24}$. Antibodies used were: anticortactin clone 4F11 (1 $\left.\mathrm{\mu g} / \mathrm{ml}^{11}\right)$, anti- $\beta$-actin (1:10,000; EMD Millipore, Billerica, MA), and anti-coronin-2 (1:2000, Bethyl Laboratories, Montgomery, TX).

\section{Immunohistochemistry}

Human HNSCC cases were obtained from the West Virginia Tissue Bank and used under the approval of West Virginia University Institutional Review Board. Five-micrometer sections from human HNSCC tissue blocks were processed and stained using a Discovery XT automated staining system (Ventana Medical Systems, Tucson, AZ, USA).Primary antibodies used were: rabbit polyclonal anti-coronin1B (1:250, generous gift from James Bear $\left.{ }^{15}\right)$ and anti-cortactin clone $4 \mathrm{~F} 11\left(1 \mu \mathrm{g} / \mathrm{ml}^{11}\right)$. Primary antibodies were detected using the Omnimap antibody horseradish peroxidase kit (Ventana) and slides were counterstained with hematoxylin. 


\section{Preparation and labeling of CTTN and CORO1B FISH probes}

Proper bacterial artificial chromosome (BAC) clones for the areas of interest were selected using www.ensembl.org. Two BAC clones, RP11-347/13 encompassing the CTTN gene and RP11-249K11 encompassing the CORO1B gene, were obtained from CHORI (Oakland, CA) and cultured overnight in LB Broth with chloramphenicol. Resulting cultures were streaked on LB agar plates and cultured overnight. Five single colonies were chosen for each clone and expanded in LB Broth overnight for DNA verification. Touchdown PCR was performed to validate BACs using the following set of primers for CTTN: Forward 5'-GGTGTGGAACAAGACCGAATGGAT-3' and Reverse 5'CAGGCATTGACAGTGATGACACCT-3'; and the following set of primers for CORO1B: Forward 5'-GAGGGACCCTGGGAATAAAGTGAA-3' and Reverse 5'GTGTTCAGGAAGTGGATGTAGGGA-3'. One verified single colony per clone was cultured overnight for DNA extraction using the Qiagen QIAamp DNA Mini Kit (Valencia, CA) and the Repli-G Kit (Qiagen, Valencia, CA) was used as per manufacturer's instructions for whole genome amplification. Concentrations were estimated by gel electrophoresis and $1 \mu \mathrm{g}$ of DNA for each clone was then labeled with the use of Vysis

Nick Translation Kit (Des Plaines, IL) with SpectrumRed (RP11-347I13) or SpectrumGreen (RP11-249K11) conjugated dUTPs, according to manufacturer's protocol. Labeled DNA was ethanol precipitated with herring sperm and human Cot-1, and the DNA pellet was re-suspended in $10 \mu \mathrm{l}$ of t-DenHyb (Insitus Biotechnologies, Albuquerque, NM). 


\section{FISH of HNSCC Tissue Microarrays}

A duplicate core HNSCC tissue microarray (TMAs) was constructed from archival paraffin blocks of 39 patients seen at Fox Chase Cancer Center using a MTA-1 manual tissue arrayer (Beecher Instruments, Sun Prairie, WI). Five $\mu \mathrm{m}$ array sections were subjected to dual-color FISH performed according to standard protocol using reagents from the SpotLight Tissue Pre-Treatment Kit (Zymed). Briefly, the slides were incubated in CitriSolv twice for 5 min each and then in 100\% ethanol twice for 1 min each for paraffin removal. Slides were incubated in Pretreatment Solution for $18 \mathrm{~min}$, followed by three two minute PBS, Enzyme Reagent at $37^{\circ} \mathrm{C}$ for $20 \mathrm{~min}$, then three additional two minute PBS washes. Slides were then dehydrated in a graded ethanol series. A mixture of 100ng of CTTN SpectrumRed probe and 300ng of CORO1B SpectrumGreen probe per $113 \mathrm{~mm}^{2}$ of hybridization area was diluted in t-DenHyb (Insitus Technologies, Albuquerque, NM) and applied to the selected area on each slide. Hybridized cores were covered with a glass coverslip in mounting media and sealed with rubber cement. Codenaturation of probe and target DNAs was performed in the Hybridizer DAKO at $85^{\circ} \mathrm{C}$ for $5 \mathrm{~min}$ and hybridized at $37^{\circ} \mathrm{C}$ for $36 \mathrm{hr}$. Post-hybridization washes were performed with 2 XSSC $/ 0.3 \% N P-40$ at $72^{\circ} \mathrm{C}$, followed by washing with $2 x S S C$ for two min at room temperature. The hybridized slide was dehydrated in a graded ethanol series. Chromatin was visualized by counterstaining with DAPI $(0.3 \mu \mathrm{g} / \mathrm{ml}$ in Vectashield Mounting Medium, Vector Laboratories).

Visual analysis of CTTN and CORO1B gene levels was performed on a Zeiss Axioimager M1 epifluorescence microscope using single interference filter sets for green (FITC), red (Texas red), and blue (DAPI), as well as dual (red/green) and triple (blue, red, 
green) band pass filters. A minimum of thirty tumor cell nuclei were analyzed per TMA core. Images were captured using CytoVision software (Applied Imaging Inc., San Jose, $\mathrm{CA})$.

\section{Gelatin degradation assay}

Gelatin degradation assays to evaluate invadopodia function were performed as described ${ }^{25}$. Briefly, HNSCC cell lines OSC19 and UMSCC1 were plated on Oregon Green 488-conjugated gelatin (Life Technologies, Grand Island, NY) coated coverslips, allowed to degrade for 6 and 8 hours, respectively, rinsed in PBS and fixed with fresh $4 \%$ paraformaldehyde (Electron Microscopy Sciences, Hatfield, PA). Cells were permeabilized with $0.4 \%$ Triton-X/PBS in preparation for immunofluorescence labeling.

\section{Immunofluorescence staining and confocal microscopy}

Primary antibodies were diluted in 5\% BSA/PBS. F-actin was labeled with rhodamineconjugated phalloidin (Life Technologies). Primary antibodies used were: mouse monoclonal anti-coronin 1B (1:500, Abnova, Taipei, Taiwan), rabbit polyclonal anticoronin 1B (1:500) and anti-cortactin clone 4F11 $(1 \mu \mathrm{g} / \mathrm{ml})$. Primary antibodies were visualized using Alexa Fluor 405 and 647 conjugated goat anti-rabbit or anti-mouse secondary antibodies (1:2000; Life Technologies). Cells were mounted with ProLong Gold (Life Technologies) and images were acquired with a Zeiss LSM510 confocal

microscope using AIM software (Carl Zeiss Microlmaging, Thornwood, NY). Gelatin degradation and cell area quantification was performed as described ${ }^{25}$ using ImageJ software. Cell volumes were measured using the Countess ${ }^{\circledR}$ Automated Cell Counter (Life Technologies) and selecting "more data" to display cell volumes. 


\section{D spheroid invasion assay}

96 well plates were coated with $100 \mu \mathrm{L}$ of $1.5 \%$ noble agar (BD Biosciences, Sparks, MD) in Dulbecco's PBS. $1 \times 10^{3}$ (OSC19) or $5 \times 10^{3}$ (UMSCC1) cells were plated into individual wells for $48 \mathrm{~h}$ to form spheroids. 24 well plates were coated with $400 \mu \mathrm{L}$ of $2 \mathrm{mg} / \mathrm{mL}$ rat tail collagen I (BD) and allowed to polymerize. Three spheroids from individual wells were transferred to a microcentrifuge tube and centrifuged at $1000 \mathrm{xg}$ for $1 \mathrm{~min}$. The media was aspirated and replaced with $500 \mu \mathrm{L}$ of $2 \mathrm{mg} / \mathrm{mL}$ rat tail collagen I (BD). The spheroid mixture was transferred to an individual well of the pre-coated 24 -well plate. Plates were incubated for $1 \mathrm{~h}$ at $37^{\circ} \mathrm{C}$, then overlayed with $1 \mathrm{~mL}$ of complete media. Spheroid invasion was imaged at 0 and $48 \mathrm{~h}$ by phase contrast microscopy (Zeiss, Axiovert 200M). Maximal radial distances for invaded cells were calculated using Axiovision 4.6 software (Zeiss).

\section{Electric cell-substrate impedence sensing of cell adhesion}

$5 \times 10^{5}$ cells were plated into 8 -well $8 \mathrm{~W} 10 \mathrm{E}$ electric cell-substrate impedance sensing (ECIS) dishes (Applied Biophysics, Troy, NY). Measurements were taken at $45 \mathrm{kHz}$ immediately upon addition of cells, and continuously recorded every minute for $24 \mathrm{~h}$.

\section{Statistical analysis}

Differences in mean values between groups were evaluated using Students t-test, with significance determined at $\mathrm{P}<0.05$ 


\section{Results}

Cortactin and coronin 1B gene amplification correlates with increased protein expression in HNSCC

Expression of coronin 1B has not been evaluated in HNSCC or any other cancer type. To determine the genomic and protein expression status of CORO1B and CTTN in HNSCC, an HNSCC TMA representing 42 cases was screened by FISH using genomic probes specific for CORO1B and CTTN. Eleven cases contained CTTN amplification, with two patients containing co-amplification of CORO1B (Figure 1A). The lower incidence of CORO1B amplification can be explained by the location of CORO1B within the 11q13 region, lying outside the core amplicon including CTTN ${ }^{6}$. Subsequent analysis of over 100 HNSCC cases increased co-amplification event to $\sim 14.5 \%$ (data not shown). In addition, five cases with CTTN amplification also have 3-4 gene copies of CORO1B, providing the potential for upregulated protein expression. TMAs subsequently screened by IHC with antibodies to coronin 1B or cortactin showed protein overexpression in all cases with gene amplification (Figure 1B), indicating that CORO1B and CTTN co-amplification occurs in a subset of HNSCC patients.

\section{Coronin 1B is expressed in HNSCC cell lines and co-localizes with cortactin in mature invadopodia}

Co-expression and co-amplification of coronin 1B and cortactin in HNSCC suggests that elevated coronin 1B expression may cooperate with cortactin to enhance invasion and metastasis. Protein expression in multiple HNSCC cell lines was analyzed, with coronin 1B overexpression found in the OSC19 and UMSCC1 (lacking 11q13 amplification), as 
well as the 11q13 amplified lines FaDu, and UMSCC2 (Figure 2A). UMSCC1 and OSC19 cells spontaneously form invadopodia, and were used to determine the subcellular localization of coronin 1B in invasive HNSCC using gelatin degradation assays. Confocal immunofluorescence microscopy (IF) showed coronin 1B colocalization with cortactin in the invadopodia F-actin core, coincident with sites of gelatin degradation (Figure 2B). These data indicate that coronin $1 \mathrm{~B}$ is a component of invadopodia, and suggests a potential function for coronin $1 \mathrm{~B}$ in invadopodia similar regulation of Arp2/3 and cortactin function in lamellipodia ${ }^{15}$.

\section{Coronin 1B is required for HNSCC invadopodia function and 3D invasion}

To determine if coronin $1 \mathrm{~B}$ is required for invadopodia formation and/or function, UMSCC1 and OSC19 cells were infected with lentivirus encoding two different shRNA sequences specific to human CORO1B. Stable clones obtained by puromycin selection displayed $>90 \%$ knockdown of coronin 1B compared to stable non-silencing shRNA control lines (Figure 3A). Gelatin degradation assays using control and coronin 1B knockdown cells indicated that the amount of gelation degradation per cell was decreased by 40 (sh1B 4) and 60\% (sh 1B 6) in UMSCC1 cells, and 30 (sh1B 6) and 50\% (sh1B 4) in OSC19 cells (Figure 3B-C). To determine if decreased invadopodia activity in coronin 1B cells correlates with decreased invasive behavior, 3D spheroid collagen invasion assays were performed using control and sh1B 6 lines. Knockdown of coronin 1B decreased invasion in both HNSCC cell lines, with an average reduction in invasive area of $163 \mu \mathrm{m}$ in UMSCC1 and $116 \mu \mathrm{m}$ in OSC19 coronin 1B knockdown cells compared to shRNA controls (Figure 3D-E). Taken together, these data indicate that coronin 1B 
regulates invadopodia-mediated $\mathrm{ECM}$ degradation activity in $2 \mathrm{D}$, as well as cell motility and invasion through collagen I in 3D.

\section{Coronin 1B knockdown alters cell attachments through modulation of FAK expression}

A striking observation in cells lacking coronin 1B expression was that individual tumor cells appeared larger, which is most apparent in the UMSCC1 line (Figure 3B). Measurements of cell area revealed significant increases in cell area in both UMSCC1 and OSC19 lines expressing either of the two coronin 1B shRNAs (Figure 4A). UMSCC1 cell area increased from an average of $3019.33 \mu \mathrm{m}^{2}$ in shCtl cells to $7103.37 \mu \mathrm{m}^{2}$ in sh1B 4 and $4122.08 \mu \mathrm{m}^{2}$ in sh1B 6 cells. The increase in OSC19 cells was less but still significant, with the average area of $5482.83 \mu \mathrm{m}^{2}$ in shCtl cells increased to $7197.32 \mu \mathrm{m}^{2}$ in sh1B 4 and $6531.59 \mu \mathrm{m}^{2}$ in sh1B 6 cells. It is important to note that the pre-existing larger control cell area in OSC19 cells may be near the maximal spread volume limit for this line, thus restricting additional volume increases induced by coronin 1B knockdown. The increase in cell area resulting from coronin 1B knockdown is most likely due to enhanced cell spreading, since the volume of knockown cells for each HNSCC line in suspension compared to control is unchanged (Figure 4B). Since cellular spreading requires formation of integrin-based ECM attachments, we conducted ECIS assays to determine the effects of coronin 1B knockdown on cell adhesion. While the rate of attachment was not altered, cells with decreased coronin 1B expression had increased average electrical resistance compared to control cells (Figure 4C). This is likely due to elevated rates of cell spreading, resulting in increased cell area. To determine the 
mechanism responsible for increasing cell spreading, we investigated the expression level of potential focal adhesion modulators, focusing on FAK. FAK is a cytoplasmic tyrosine kinase that regulates focal adhesion dynamics governing cell spreading and motility $^{26}$. FAK expression was downregulated in UMSCC1 and OSC19 coronin 1B knockdown cells compared to controls (Figure 4D). These results suggest that FAK expression in HNSCC cells is dependent on coronin 1B, where reduction of coronin 1B expression enhances cell spreading by preventing efficient FAK-medicated focal adhesion turnover. 


\section{Discussion}

In this study, we demonstrate that CORO1B is amplified and overexpressed in a subset of HNSCC cases along with CTTN upon 11q13 amplification. We also show coronin 1B localizes to HNSCC invadopodia, where it is required for efficient ECM degradation and 3D collagen invasion. We have revealed a role for coronin $1 \mathrm{~B}$ in cell adhesion, as decreased coronin 1B expression leads to enhanced cell adhesion and a reduction in total FAK expression. Overall, these results point to an important role for coronin 1B in regulating multiple aspects of the actin cytoskeletal dynamics utilized during HNSCC tumor cell invasion and metastasis.

The 11q13 amplicon has been well-established as being associated with poor clinical outcome in $\mathrm{HNSCC}^{27,28}$. The region spanning $11 \mathrm{q} 13.1-11 \mathrm{q} 13.4$ is a gene-rich area, with the most common region of amplification located at $11 \mathrm{q} 13.3^{6}$. This location contains several core genes, including CTTN. CTTN amplification and protein overexpression is linked to increased tumor aggressiveness, lymph node metastasis and poor prognosis. While other genes have been associated with HNSCC at this location ${ }^{29,30}$, none have been shown to cooperate with CTTN in enhancing tumor invasion. Coronin 1B is a functional antagonist of cortactin and Arp2/3 complex function at F-actin branchpoints in lamellipodia, displacing both proteins to promote actin machinery turnover ${ }^{15}$. Additionally, the CORO1B locus found at $11 \mathrm{q} 13.1 / .2$ and is co-amplified with CTTN in some cases (Figure 1). These data suggests that coronin 1B amplification may serve as a potential prognostic marker in select HNSCC cases to identify potentially aggressive or invasive tumors in patients containing co-amplification of both genes, which may drive increased invadopodia activity and matrix degradation. 
Similar to fibroblast lamellipodia ${ }^{15}$, coronin 1B co-localizes with cortactin in HNSCC invadopodia (Figure 2B). While coronin 1B does not affect invadopodia formation, optimal invadopodia function requires coronin 1B expression (Figure 3B-C). Coronin 1B has been previously shown to be necessary for actin network turnover at the leading edge of motile cells, through the recruitment of SSH1L and subsequent activation of the actin severing protein cofilin ${ }^{14}$. Cofilin function is necessary for the development of mature invadopodia. In breast cancer lines, cofilin is sequestered by cortactin through direct binding. Cortactin tyrosine phosphorylation due to upstream signaling pathway activation releases cofilin, allowing increased F-actin severing and turnover needed for invadopodia maturation and elongation $^{20}$. Since coronin 1B binds the cofilin-activating phosphatase SSH1L, it is possible that coronin $1 \mathrm{~B}$ is responsible for recruitment of $\mathrm{SSH} 1 \mathrm{~L}$ to invadopodia, which in turn would dephosphorylate cofilin to initiate F-actin severing activity. Turnover of actin and other invadopodia-associated proteins is likely important for invadopodia maturation and activity, since loss of cofilin expression results in reduced gelatin degradation levels ${ }^{31}$, similar to coronin 1B knockdown.

Loss of coronin 1B and invadopodia-mediated ECM degradation ability correlates with decreased 3D collagen invasion (Figure 3D-E). The effect of 1B knockdown in 3D resulted in different invasive modes for UMSCC1 and OSC19 cell lines. Recent studies in cancer cell motility lead to the classification of different types of cell movement. Tumor cells are thought to move individually, as single cells with no intercellular attachments, or as multicellular groups that maintain cell-cell attachments ${ }^{32}$. Single-cell migration is categorized as being either mesenchymal or ameboid, with mesenchymal cells having an elongated shape that utilizes MMPs to facilitate ECM breakdown. Amoeboid motility 
utilizes a rounded cell state characterized by a lack of adhesions and increased actomyosin contractility to cause cellular deformation, allowing cells to fit through permissive spaces within connective tissue ${ }^{32}$. Mesenchymal motility relies on the expression of the small GTPase Rac1, while amoeboid migration involves signaling through another GTPase RhoA and the Rho kinase, $\mathrm{ROCK}^{33}$. In addition to single cell migration, cancer cells are also capable of multicellular migration, where cell-cell adhesions remain intact, and cells invade using collective strands or groups ${ }^{34}$; this migratory mode is thought to require a combination of proteolysis and force-generation for matrix remodeling. Several different cancer types rely on collective migration in order to invade, including HNSCC (personal observations). Both OSC19 and UMSCC1 lines invade collectively in collagen I: OSC19 move as several invasive strands, while UMSCC1 grow expansively outward, as one large collective group of cells. We note that coronin 1B knockdown results in a complete loss of collective invasive strands in OSC19 cells and a partial loss in the UMSCC1 line (Figure 3D). The UMSCC1 line seem to rely more on expansive growth in 3D collagen, whereas OSC19s lose their ability to produce strands and instead rely on this mode only upon loss of coronin 1B. Formation of collective invasive strands requires controlled RhoA activation and subsequent actomyosin-based activity ${ }^{35,36}$. Coronin 1B was recently shown to be a negative regulator of $\mathrm{ROCK} 2{ }^{37}$; therefore it is possible that loss of coronin 1B may lead to unregulated ROCK2 activity, promoting increased global actomyosin contraction and a switch from collective strands to expansive growth in invasion. Verification of a role for coronin $1 \mathrm{~B}$ in regulating different modes of collective invasion utilized in HNSCC is planned for future studies. 
Another important regulator of RhoA activity is $\mathrm{FAK}^{38}$. Knockdown of coronin $1 \mathrm{~B}$ expression leads to increased cell spreading and adhesion, presumably due to decreased FAK expression levels (Figure 4). Rho activity is elevated in FAK-null fibroblasts and keratinocytes, resulting in stable focal adhesions ${ }^{38,39}$. While the mechanism used by coronin $1 \mathrm{~B}$ to regulate FAK expression is unknown, it is most likely indirect since FAK mRNA and protein stability appear unaffected (data not shown). Given the results of from our 3D collagen invasion assays, it is possible that coronin 1B is affecting HNSCC invasive capabilities through multiple pathways. Perturbation of FAK in cells disrupts $\beta 1$ integrin signaling, which is necessary for radiotherapy resistance in HNSCC ${ }^{40}$. FAK is also needed for proper activation of Src, another important tyrosine kinase that regulates cancer cell invasion ${ }^{41}$. Downregulation of both of these has been implicated in a loss of E-cadherin-dependent collective migration ${ }^{42}$.

This study points to a role for coronin 1B in several important aspects of cancer cell migration and collective invasion. Cells must be able to adhere to, degrade and move through the matrix during invasion and metastasis. Maintaining a proper balance of actomyosin contractility and protease secretion is critical for effective collective invasion and tumor spread. Loss of coronin 1B disrupts this balance at multiple levels, highlighting the need for efficient turnover mechanisms of the different components utilized in tumor cell motility and invasion. 


\section{References}

1. Pai SI, Westra WH. Molecular pathology of head and neck cancer: implications for diagnosis, prognosis, and treatment. Annu Rev Pathol. 2009;4:49-70. doi:10.1146/annurev.pathol.4.110807.092158.

2. Gibcus JH, Mastik MF, Menkema L, et al. Cortactin expression predicts poor survival in laryngeal carcinoma. $\mathrm{Br} J$ Cancer. 2008;98(5):950-955. doi:10.1038/sj.bjc.6604246.

3. Hofman $\mathrm{P}$, Butori $\mathrm{C}$, Havet $\mathrm{K}$, et al. Prognostic significance of cortactin levels in head and neck squamous cell carcinoma: comparison with epidermal growth factor receptor status. Br J Cancer. 2008;98(5):956-964. doi:10.1038/sj.bjc.6604245.

4. Rodrigo JP, Garcia-Carracedo D, Garcia LA, et al. Distinctive clinicopathological associations of amplification of the cortactin gene at 11q13 in head and neck squamous cell carcinomas. J Pathol. 2009;217(4):516-523. doi:10.1002/path.2462.

5. Yamada SI, Yanamoto S, Kawasaki G, Mizuno A, Nemoto TK. Overexpression of Cortactin Increases Invasion Potential in Oral Squamous Cell Carcinoma. Pathol Oncol Res. 2010;4:523. doi:10.1007/s12253-009-9245-y.

6. Jin C, Jin Y, Gisselsson D, et al. Molecular cytogenetic characterization of the $11 \mathrm{q} 13$ amplicon in head and neck squamous cell carcinoma. Cytogenet Genome Res. 2006;115(2):99-106. doi:10.1159/000095228.

7. Ammer AG, Weed SA. Cortactin branches out: roles in regulating protrusive actin dynamics. Cell Motil Cytoskeleton. 2008;65(9):687-707. doi:10.1002/cm.20296.

8. Weed SA, Karginov A V, Schafer DA, et al. Cortactin localization to sites of actin assembly in lamellipodia requires interactions with F-actin and the Arp2/3 complex. J Cell Biol. 2000;151(1):29-40.

9. Weaver AM, Karginov A V, Kinley AW, et al. Cortactin promotes and stabilizes Arp2/3-induced actin filament network formation. Curr Biol. 2001;11(5):370-374.

10. Clark ES, Brown B, Whigham AS, Kochaishvili A, Yarbrough WG, Weaver AM. Aggressiveness of HNSCC tumors depends on expression levels of cortactin, a gene in the 11q13 amplicon. Oncogene. 2009;28(3):431-444. doi:10.1038/onc.2008.389.

11. Rothschild $B \mathrm{~L}$, Shim $\mathrm{AH}, \mathrm{Ammer} A \mathrm{G}$, et al. Cortactin overexpression regulates actin-related protein $2 / 3$ complex activity, motility, and invasion in carcinomas with chromosome 11q13 amplification. Cancer Res. 2006;66(16):8017-8025. doi:10.1158/0008-5472.CAN-05-4490. 
12. Clark ES, Whigham AS, Yarbrough WG, Weaver AM. Cortactin is an essential regulator of matrix metalloproteinase secretion and extracellular matrix degradation in invadopodia. Cancer Res. 2007;67(9):4227-4235. doi:10.1158/0008-5472.CAN06-3928.

13. Kelley LC, Shahab S, Weed SA. Actin cytoskeletal mediators of motility and invasion amplified and overexpressed in head and neck cancer. Clin Exp Metastasis. 2008;25(4):289-304. doi:10.1007/s10585-008-9154-6.

14. Cai L, Marshall TW, Uetrecht AC, Schafer DA, Bear JE. Coronin 1B coordinates Arp2/3 complex and cofilin activities at the leading edge. Cell. 2007;128(5):915929. doi:10.1016/j.cell.2007.01.031.

15. Cai L, Makhov AM, Schafer DA, Bear JE. Coronin 1B antagonizes cortactin and remodels Arp2/3-containing actin branches in lamellipodia. Cell. 2008;134(5):828842. doi:10.1016/j.cell.2008.06.054.

16. Cai L, Holoweckyj N, Schaller MD, Bear JE. Phosphorylation of coronin 1B by protein kinase $\mathrm{C}$ regulates interaction with Arp2/3 and cell motility. J Biol Chem. 2005;280(36):31913-31923. doi:10.1074/jbc.M504146200.

17. Chhabra ES, Higgs HN. The many faces of actin: matching assembly factors with cellular structures. Nat Cell Biol. 2007;9(10):1110-1121. doi:10.1038/ncb10071110.

18. Hoshino D, Branch KM, Weaver AM. Signaling inputs to invadopodia and podosomes. J Cell Sci. 2013;126(Pt 14):2979-2989. doi:10.1242/jcs.079475; 10.1242/jcs.079475.

19. Artym V V, Zhang Y, Seillier-Moiseiwitsch F, Yamada KM, Mueller SC. Dynamic interactions of cortactin and membrane type 1 matrix metalloproteinase at invadopodia: defining the stages of invadopodia formation and function. Cancer Res. 2006;66(6):3034-3043. doi:10.1158/0008-5472.CAN-05-2177.

20. Oser M, Yamaguchi $\mathrm{H}$, Mader $\mathrm{CC}$, et al. Cortactin regulates cofilin and N-WASp activities to control the stages of invadopodium assembly and maturation. $J$ Cell Biol. 2009;186(4):571-587. doi:10.1083/jcb.200812176.

21. Ayala I, Baldassarre M, Giacchetti G, et al. Multiple regulatory inputs converge on cortactin to control invadopodia biogenesis and extracellular matrix degradation. $J$ Cell Sci. 2008;121(Pt 3):369-378. doi:10.1242/jcs.008037.

22. Kelley LC, Ammer AG, Hayes KE, et al. Oncogenic Src requires a wild-type counterpart to regulate invadopodia maturation. J Cell Sci. 2010;123(Pt 22):39233932. doi:10.1242/jcs.075200; 10.1242/jcs.075200. 
23. Gatesman Ammer A, Hayes KE, Martin KH, Zhang L, Spirou GA, Weed SA. Multiphoton imaging of tumor cell invasion in an orthotopic mouse model of oral squamous cell carcinoma. J Vis Exp. 2011;(53). doi:10.3791/2941.

24. Evans J V, Ammer AG, Jett JE, et al. Src binds cortactin through an SH2 domain cystine-mediated linkage. J Cell Sci. 2012;125(Pt 24):6185-97. doi:10.1242/jcs.121046.

25. Martin KH, Hayes KE, Walk EL, Ammer AG, Markwell SM, Weed SA. Quantitative measurement of invadopodia-mediated extracellular matrix proteolysis in single and multicellular contexts. J Vis Exp. 2012;(66):e4119(66):e4119. doi:10.3791/4119; 10.3791/4119.

26. Hall JE, Fu W, Schaller MD. Focal adhesion kinase: exploring Fak structure to gain insight into function. Int Rev Cell Mol Biol. 2011;288:185-225. doi:10.1016/B978-012-386041-5.00005-4; 10.1016/B978-0-12-386041-5.00005-4.

27. Meredith SD, Levine PA, Burns JA, et al. Chromosome 11q13 amplification in head and neck squamous cell carcinoma. Association with poor prognosis. Arch Otolaryngol Head Neck Surg. 1995;121(7):790-794.

28. Alavi S, Namazie A, Calcaterra TC, Wang MB, Srivatsan ES. Clinical application of fluorescence in situ hybridization for chromosome 11q13 analysis in head and neck cancer. Laryngoscope. 1999;109(6):874-879.

29. Ayoub C, Wasylyk C, Li Y, et al. ANO1 amplification and expression in HNSCC with a high propensity for future distant metastasis and its functions in HNSCC cell lines. Br J Cancer. 2010;103(5):715-726.

30. Miyamoto R, Uzawa N, Nagaoka S, Hirata Y, Amagasa T. Prognostic significance of cyclin D1 amplification and overexpression in oral squamous cell carcinomas. Oral Oncol. 2003;39(6):610-618.

31. Yamaguchi H, Lorenz M, Kempiak S, et al. Molecular mechanisms of invadopodium formation: the role of the N-WASP-Arp2/3 complex pathway and cofilin. $J$ Cell Biol. 2005;168(3):441-452. doi:10.1083/jcb.200407076.

32. Friedl $\mathrm{P}$, Alexander $\mathrm{S}$. Cancer invasion and the microenvironment: plasticity and reciprocity. Cell. 2011;147(5):992-1009.

33. Sanz-Moreno V, Gadea G, Ahn J, et al. Rac activation and inactivation control plasticity of tumor cell movement. Cell. 2008;135(3):510-523.

34. Friedl P, Locker J, Sahai E, Segall JE. Classifying collective cancer cell invasion. Nat Cell Biol. 2012;14(8):777-783. 
35. Hidalgo-Carcedo C, Hooper S, Chaudhry SI, et al. Collective cell migration requires suppression of actomyosin at cell-cell contacts mediated by DDR1 and the cell polarity regulators Par3 and Par6. Nat Cell Biol. 2011;13(1).

36. Reffay M, Parrini MC, Cochet-Escartin O, et al. Interplay of RhoA and mechanical forces in collective cell migration driven by leader cells. Nat Cell Biol. 2014;16(3):217-223.

37. Rana MK, Worthylake RA. Novel mechanism for negatively regulating Rho-kinase (ROCK) signaling through Coronin1B protein in neuregulin 1 (NRG-1)-induced tumor cell motility. J Biol Chem. 2012;287(26):21836-21845. doi:10.1074/jbc.M112.346114; 10.1074/jbc.M112.346114.

38. Ren XD, Kiosses WB, Sieg DJ, Otey CA, Schlaepfer DD, Schwartz MA. Focal adhesion kinase suppresses Rho activity to promote focal adhesion turnover. $J$ Cell Sci. 2000;113 ( Pt 2(Pt 20):3673-3678.

39. Schober M, Raghavan S, Nikolova M, et al. Focal adhesion kinase modulates tension signaling to control actin and focal adhesion dynamics. J Cell Biol. 2007;176(5):667-680. doi:10.1083/jcb.200608010.

40. Eke I, Deuse $Y$, Hehlgans $S$, et al. beta(1)Integrin/FAK/cortactin signaling is essential for human head and neck cancer resistance to radiotherapy. $J$ Clin Invest. 2012;122(4):1529-1540. doi:10.1172/JCl61350 [doi].

41. Mitra SK, Schlaepfer DD. Integrin-regulated FAK-Src signaling in normal and cancer cells. Curr Opin Cell Biol. 2006;18(5):516-23. doi:10.1016/j.ceb.2006.08.011.

42. Canel M, Serrels A, Miller D, et al. Quantitative in vivo imaging of the effects of inhibiting integrin signaling via Src and FAK on cancer cell movement: effects on E-cadherin dynamics. Cancer Res. 2010;70(22):9413-9422. doi:10.1158/00085472.CAN-10-1454; 10.1158/0008-5472.CAN-10-1454. 


\section{Figure Legends}

Figure 1. CORO1B is co-amplified and overexpressed with CTTN in HNSCC patient samples. A. An HNSCC TMA containing 42 patient tumor samples was analyzed for gene copy number with genomic probes for CTTN (Spectrum Red) and CORO1B (Spectrum Green). Gene amplification (GA) is defined as $>5$ gene signals per cell nucleus. Additional information regarding CTTN and CORO1B genomic status is listed to the right of the graph. B. Representative FISH and IHC images for listed patients from $\mathbf{A}$. Examples shown: Disomic gene copy number for CTTN and CORO1B with low protein expression (Patient 10), GA for CTTN, disomic CORO1B (Patient 16) and GA and high protein expression (Patients 8 and 37). Coronin 1B and cortactin protein expression is consistent with gene amplification in these representative examples.

Figure 2. Coronin 1B is expressed in HNSCC cell lines and co-localizes with cortactin in mature invadopodia. A. HNSCC lines were analyzed by Western blotting with antibodies against cortactin, coronin 1B and $\beta$-actin. B. UMSCC1 cells plated on 488gelatin coated coverslips were fixed and immunostained with anti-cortactin and coronin 1B antibodies. Rhodamine-labeled phalloidin was used for visualizing F-actin. Coronin 1B co-localizes with cortactin and actin to active invadopodia. Scale bar $=10 \mu \mathrm{m}$

Figure 3. Coronin 1B depletion from HNSCC cells disrupts invadopodia function and reduces 3D spheroid invasion. A. Western blot analysis demonstrating stable coronin 1B depletion from UMSCC1 and OSC19 cells. B. UMSCC1 and OSC19 cells stably expressing control or CORO1B shRNA were plated on 488-gelatin and immunostained as in Fig 2B. Scale bar $=10 \mu \mathrm{m}$. C. Quantitative analysis of coronin 1B depletion on HNSCC invadopodia function. Degradation per cell is shown from experiments quantified as displayed in panel B. D. Phase contrast images of 3D collagen spheroid invasion assay performed over 48 hours. Control OSC19 cells invade as several collective groups of strands, while control UMSCC1 cells expansively grow as one large strand. E. Quantitation of invasive distance of spheroids into collagen. $p<0.05$ for each experimental parameter in all assays.

Figure 4. Coronin 1B knockdown alters cell spreading and FAK expression. A. Area analysis of cells used in invadopodia assay in Figure 3. The actin area of each cell was measured in ImageJ. B. Measurement of cell volumes in suspension. C. Adhesion assay dynamics for UMSCC1 and OSC19 cells with and without coronin 1B knockdown. Data is displayed as changes in resistance over 4 (UMSCC1) or 8 (OSC19) hours. D. Western blot analysis of coronin $1 \mathrm{~B}$ and FAK expression in HNSCC lines stably expressing control or CORO1B shRNAs. 
A

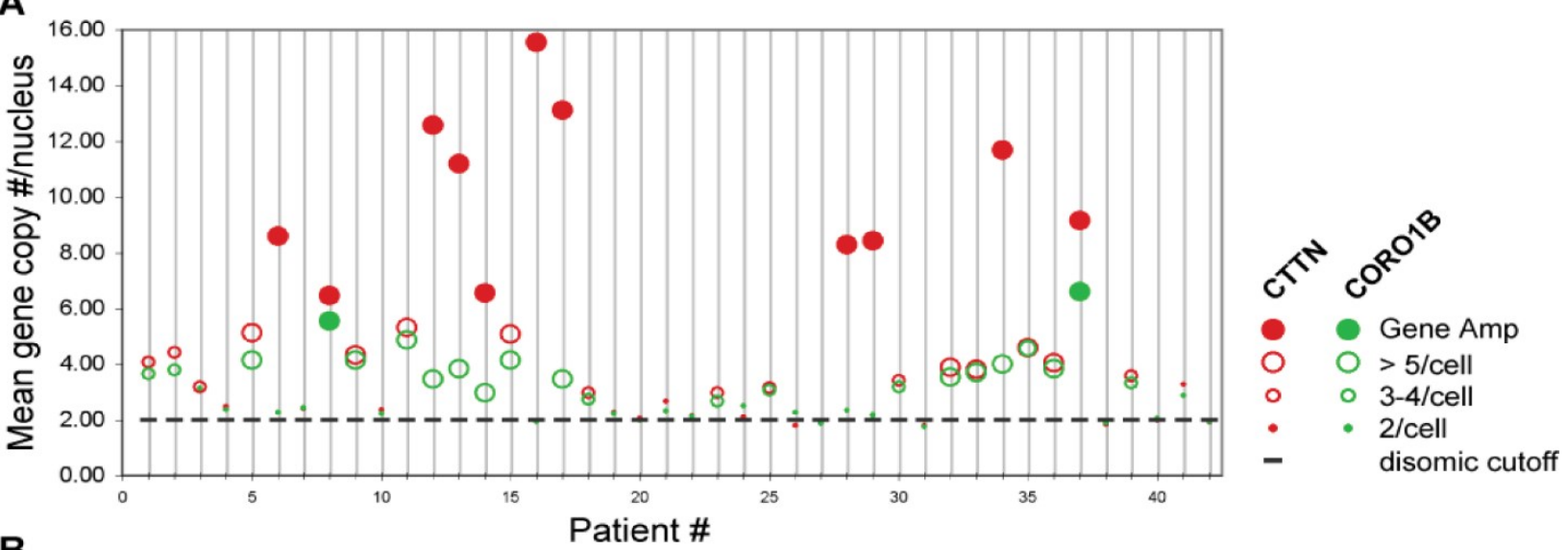

B

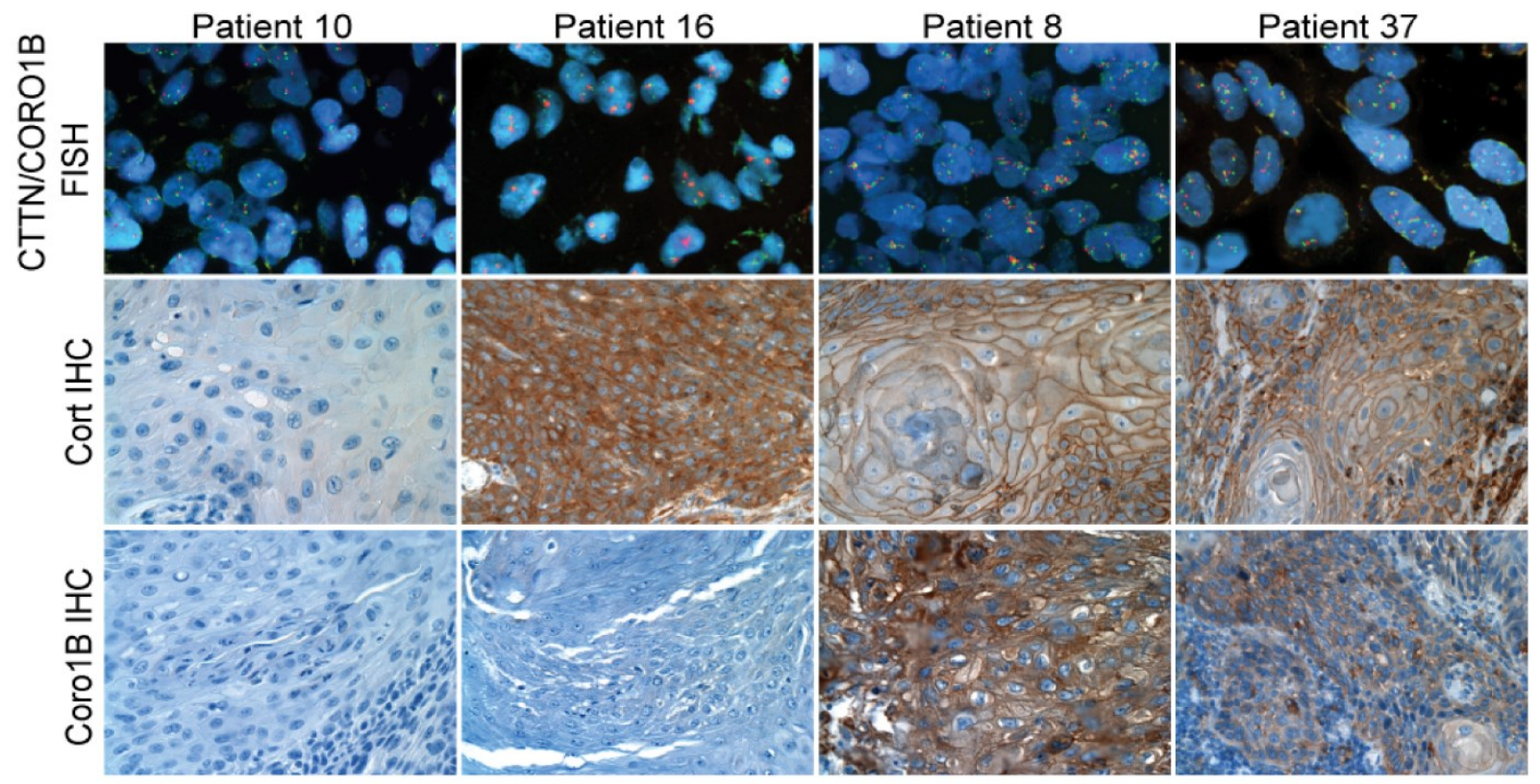

Figure 1 Walk et al. 


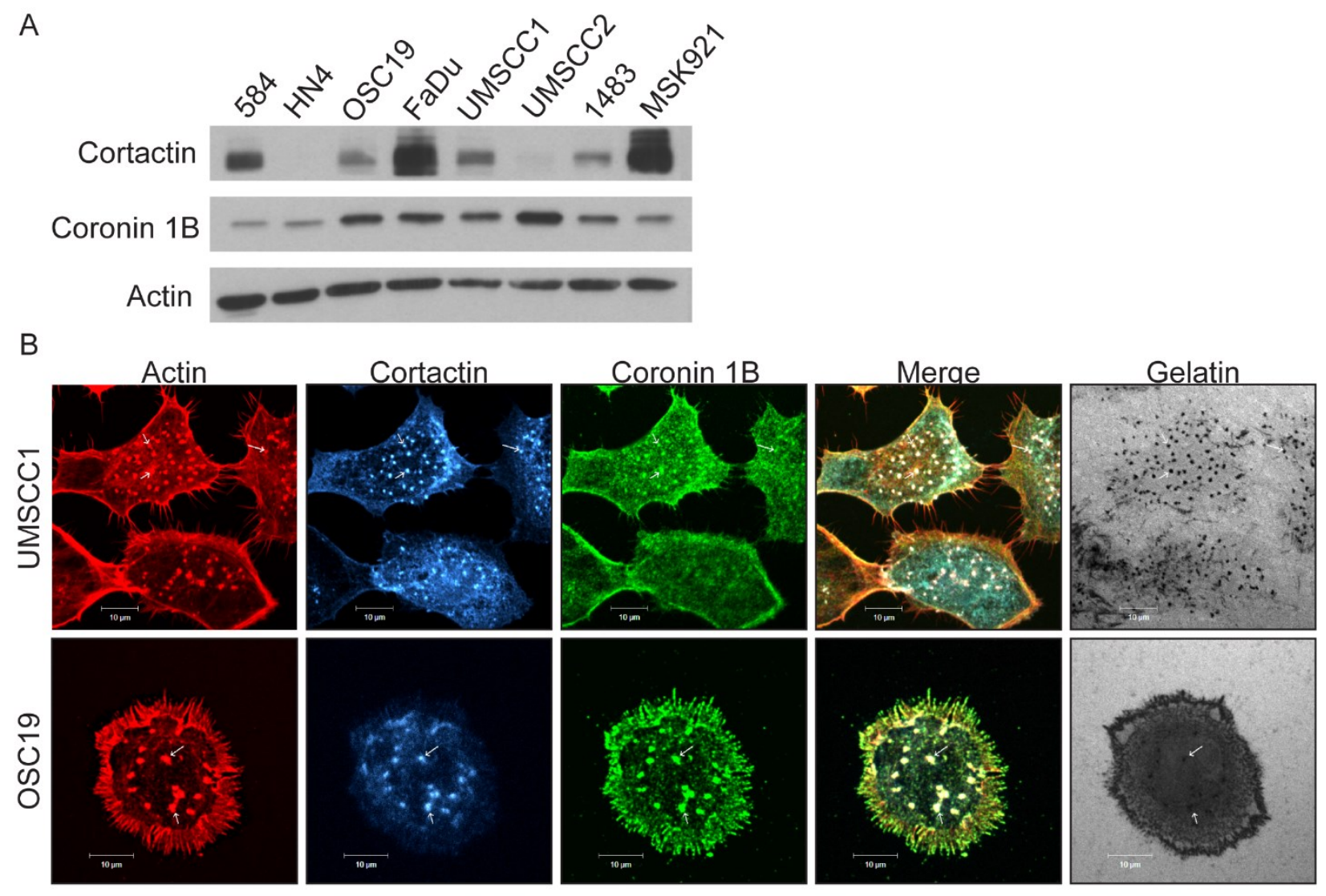

Figure 2 Walk et al. 


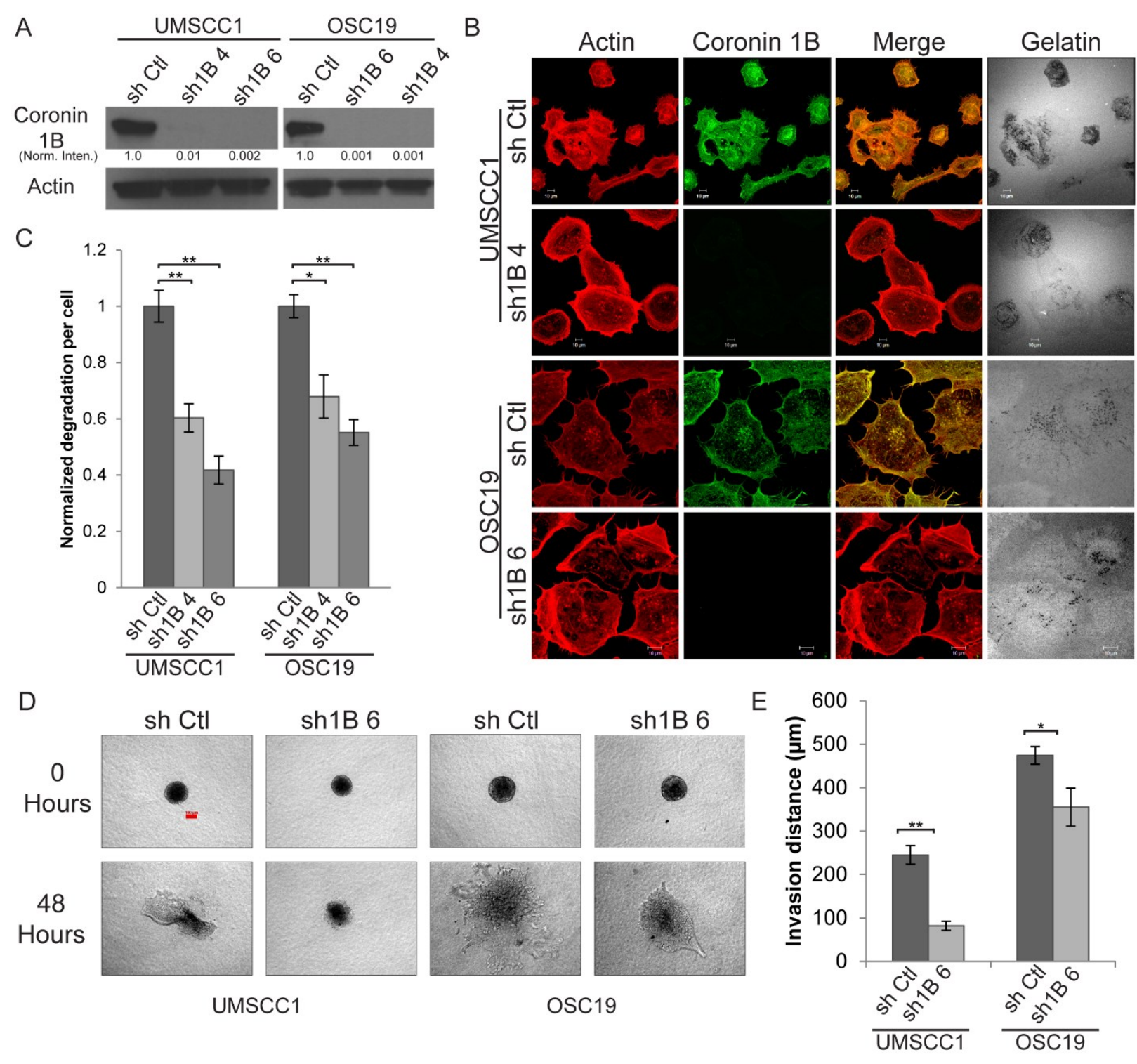

Figure 3 Walk et al. 
A

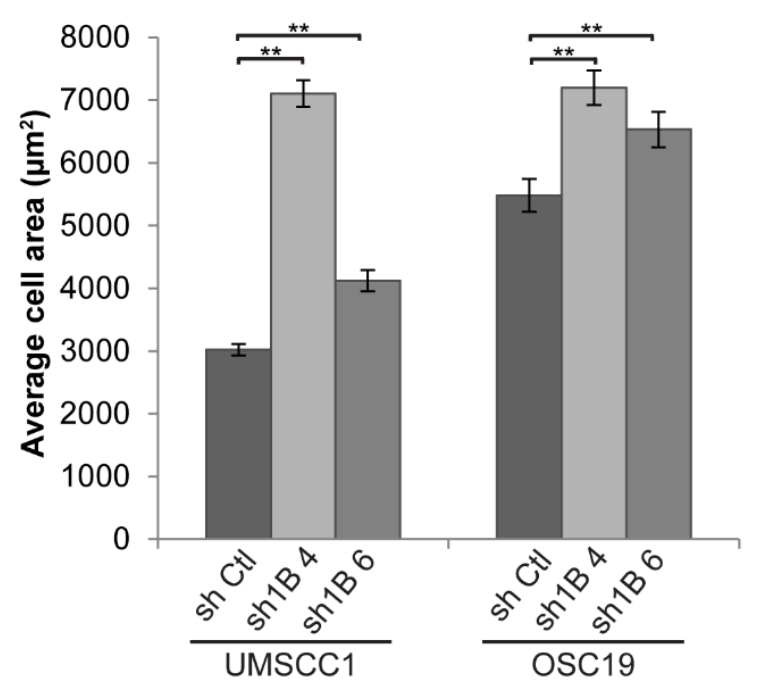

C

UMSCC1

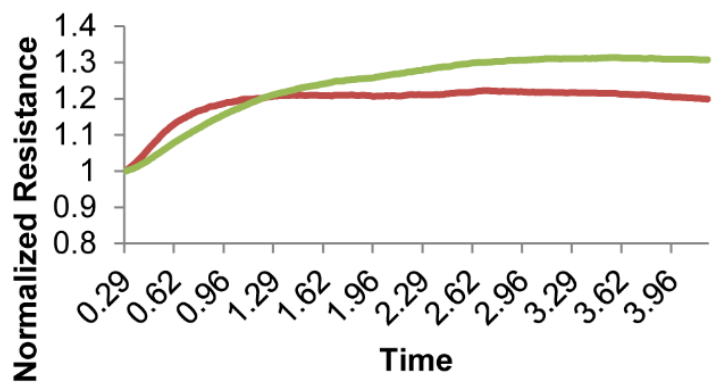

D

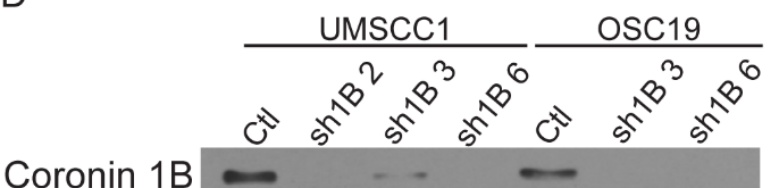
FAK

Actin

Figure 4 Walk et al.
B

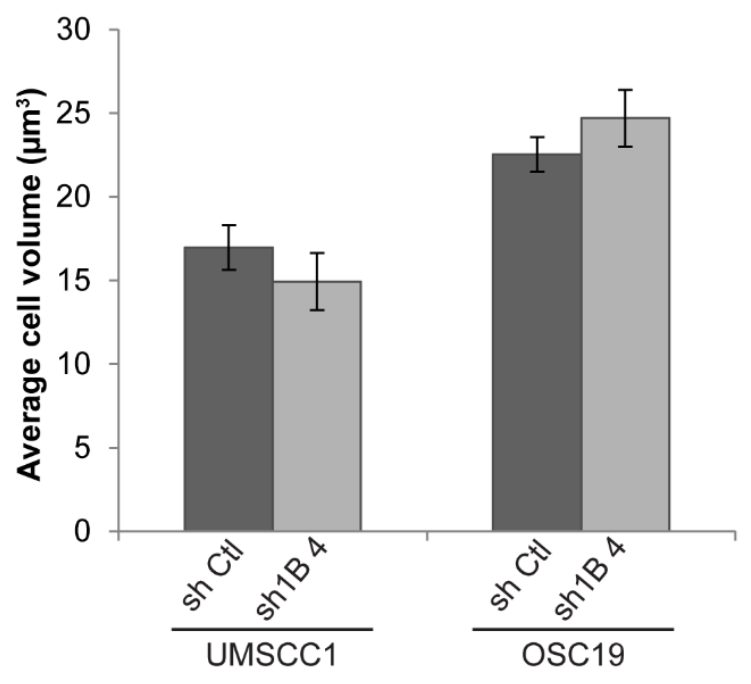

osc19

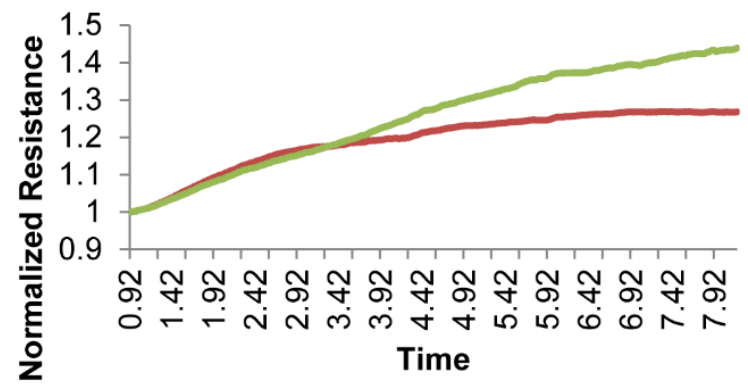

$-\mathrm{Ctl}$ Avg $\longrightarrow$ KD Avg 


\title{
Study 2: Cortactin is not required for carcinogen-induced head and neck squamous cell carcinoma invasion
}

\author{
Elyse L. Walk ${ }^{1}$ and Scott A. Weed ${ }^{1 *}$ \\ ${ }^{1}$ Department of Neurobiology and Anatomy, Program in Cancer Cell Biology, Mary Babb \\ Randolph Cancer Center, West Virginia University, Morgantown, West Virginia, 26506- \\ 9300, United States of America
}

${ }^{*}$ Corresponding author:

Scott A. Weed

West Virginia University

Mary Babb Randolph Cancer Center

Morgantown, WV 26506-9300

Phone: 304-293-3016

Fax: 304-293-4667

Email: scweed@hsc.wvu.edu 


\section{Abstract}

Head and neck squamous cell carcinoma (HNSCC) is characterized by aggressive tumors that invade loco-regionally. Genetic alterations resulting in increased cytoskeletal protein expression enables tumor motility and invasion. Cortactin overexpression as a result of chromosome $11 \mathrm{q} 13$ amplification is found in $30 \%$ of HNSCC cases, where it is associated with enhanced tumor aggressiveness, invasion and poor outcome. While utilization of in vitro cell line and xenograft models has shown that cortactin loss decreases these neoplastic characteristics in HNSCC and other tumor types, the consequential effects of deleting the cortactin locus on tumor behavior using transgenic models has not been reported for any cancer type. Here we determine the impact of cortactin deletion on oral cancer tumorigenesis and progression in carcinogen-induced mouse tumors with oral cavity-specific cortactin knockout. Cortacin-null mice produced 4nitroquinoline-1-oxide (4-NQO)-induced invasive tongue tumors that are phenotypically indistinguishable from tumors generated in control animals. Expression patterns of the epithelial to mesenchymal transition (EMT) markers E-cadhern and vimentin were the same in tumors with and without cortactin deletion, indicating cortactin does not influence HNSCC EMT in HNSCC. Surprisingly, carcinoma cells in control and cortactin knockout tumors do not express the invadopodia proteinase MMP14, with expression restricted to cells in the invasive tumor microenvironment. Cortactin knockout tumors had increased collagen and vascular content, potentially compensating for loss of cortactin expression during invasion. Invasive tumors in control and cortactin knockout animals had fibroblasts and macrophages enriched at the invasive front. These results collectively indicate that cortactin is not involved in driving HNSCC invasion in this system, with the tumor 
microenvironment potentially playing a causative role in promoting carcinogen-induced oral cancer invasion. 


\section{Introduction}

Head and neck squamous cell carcinoma (HNSCC) is a group of cancers arising in the upper aerodigestive tract. Tobacco and alcohol-related HNSCC frequently occur due to the accumulation of genetic alterations, resulting in aggressive and locally invasive tumors with a high propensity for cervical lymph node metastasis ${ }^{1}$. Gene amplification and overexpression of the actin regulatory protein cortactin is found in approximately $30 \%$ of HNSCC patients, and is frequently associated with higher grade tumors, lymph node metastasis and decreased survival rates ${ }^{2-5}$. Cortactin is responsible for regulating actin related protein (Arp) 2/3 complex-mediated filamentous $(F)$-actin branchpoints in leading edge lamellipodia of motile cells $\mathbf{s}^{6,7}$. Cortactin is also a core component of invadopodia, actin-based protrusive structures enriched in matrix metalloproteinases (MMPs) that confer tumor cells with the ability to breach basement membrane (BM) and stromal extracellular matrix $(E C M)^{7-9}$. Degradation of the ECM by invadopodia has been proposed to enable tumor cell invasion and metastatic dissemination ${ }^{9,10}$. Cortactin is essential for invadopodia formation and function in HNSCC and other tumor cell types, where loss of expression ablates the ability of tumor cells to degrade ECM and decreases tumor aggressiveness in xenograft models ${ }^{3,11}$.

Several mouse models of HNSCC have emerged that rely on tissue-specific knockout or activation of tumor suppressor or dominant-positive oncogenic proteins in the oral epithelium to drive tumorigenesis. Alternatively, exposure of oral tissues in wild-type animals to cancer-inducing carcinogens is also a potent method to induce oral tumors that recapitulate most stages of human $\mathrm{HNSCC}^{12,13}$ Many recent transgenic models exploit the specific activity of the cytokeratin 14 (K14) promoter, with restricted expression 
in mitotically active cells in the squamous basal layers of skin, oral epithelia and esophagus $^{14}$. Crossing of tamoxifen-inducible K14-Cre mice (K14-CreERT; ${ }^{14}$ ) with animals harboring flanking loxP (floxed) loci for transforming growth factor beta 1 (Tgfbr1) results in oral squamous cell carcinomas in animals exposed to DMBA $(7,12-$ Dimethylbenz(a)anthracene $)^{15}$. Another HNSCC model using the K14-CreERT system mimicks a two-hit model by simultaneously activating oncogenic K-ras and deleting p53 to drive oral tumor formation ${ }^{16}$. In addition to DMBA, 4-nitroquinoline-1-oxide (4-NQO) has also been extensively used in multiple studies as a model for mimicking tobaccorelated oral cancer ${ }^{17-19}$. Immunocompetent C57BL/6 (B6) mice exposed to 4-NQO in drinking water in dose and time-dependent studies reliably form oral tumors that closely mimic the etiology and progression of human HNSCC at the phenotypic and genetic levels ${ }^{13}$. These model systems have tremendously aided in advancing the understanding of the key steps involved in HNSCC tumorigenesis ${ }^{18,20}$.

There have been few mouse models describing transgenic manipulation of Cttn expression reported to date. Cttn overexpression driven by the MMTV promoter in breast tissues did not enhance breast cancer tumorigenesis or invasion, in spite of the frequent occurrence of cortactin gene amplification and overexpression in human breast tumors ${ }^{21-}$ 23. Studies investigating Cttn-null mouse embryonic fibroblasts (MEFs) determined that cortactin was not required for lamellipodia formation or clathrin-mediated endocytosis, but demonstrated a role for Cttn in governing Rac and Cdc42-mediated signaling and reduced cell speed ${ }^{24}$. A second study that produced Cttn-null MEFs observed no changes in cellular F-actin and actin-binding protein distribution ${ }^{25}$. Non-inducible gene trapping of the Cttn locus indicated that $\mathrm{Cttn}^{-/-}$offspring were not born due to embryonic lethality after 
fertilization ${ }^{26}$. However, a later study producing complete Cttn knockout by conventional targeting resulted in viable, fertile mice, with enhanced endothelial cell permeability and reduced neutrophil recruitment as the only reported defects ${ }^{27}$. These results suggest that cortactin plays a crucial role during early mouse development necessitating the use of a conditional knockout approach to evaluate potential roles for cortactin in HNSCC and other model tumor systems.

Given the evidence supporting a critical role for cortactin in HNSCC invasive progression, we generated a conditional knockout (cKO) mouse model of cortactin deletion using the K14-CreERT inducible system for targeted removal of cortactin from oral cavity epithelium. Surprisingly, 4-NQO-induced tumors in mice lacking cortactin expression in the oral cavity resulted in collective oral squamous cell carcinoma invasion, with no apparent differences in onset or progression compared to oral tumors in wild-type mice. Cortactin-null tumors did not contain altered EMT or levels of MMP14 expression. However, cortactin-null oral tumors had elevated collagen I deposition and increased vasculature, potential compensatory measures to maintain invasion. Cortactin-null and wild-type tumors had abundant vimentin and CD68 positive staining at the invasive front, indicating fibroblast and macrophage involvement in promoting the collective invasion phenotype. Our results suggest that cortactin expression is dispensable for tongue tumor invasion in this system, indicating that cortactin influences HNSCC clinical outcome through mechanisms other than driving tumor cell loco-regional invasion. 


\section{Results}

\section{Generation of mice with oral epithelium-specific cortactin knockout}

$\mathrm{Cttn}^{\text {floxfllox }}$ mice were engineered with loxP sites flanking Cttn exon 4 . This exon is responsible for encoding part of the Arp2/3 complex binding domain in $\operatorname{cortactin}^{28}$, a region important for lamellipodia and invadopodia function ${ }^{7,29}$. Cre-mediated removal of exon 4 creates a frameshift upon exon 3 and 5 splicing ensuring ablation of Arp2/3 binding after Cre-mediated excision. Mouse genotyping utilized two different primer sets to verify germline transgene incorporation. One set encompassed the entire transgene external to the loxP sites, where the second set utilized a 5' primer homologous to a portion of the first loxP site, and a reverse primer complementary to genomic sequence between exons 3 and 4 (Figure 1a). This strategy allowed for homozygous floxed animals to be clearly identified, since amplification of the entire transgene was difficult due to the large size (> 3.5kb). Genotyping of cortactin ${ }^{\text {wtflox }}$ or cortactin flox/flox mice gave the expected banding patterns and intensities indicative of the presence of heterozygous or homozygous transgene alleles (Figure 1b). Following congenic backcrossing of K14Cre-ERT mice into the B6 strain, retention of the K14Cre-ERT allele was validated by PCR (Figure 1b). Crossing of K14Cre-ERT B6 mice with the Rosa26 reporter strain verified tissue-specific K14Cre-ERT activity following tamoxifen treatment and $\beta$-galactosidase activity assays in skin, buccal mucosa and tongue (Supplementary Figure 1a). $\beta$-galactosidase activity patterns in B6 K14Cre-ERT mice were similar to those previously reported for the same tissues in other strains ${ }^{16,30}$.

$\mathrm{Ctth}^{\text {floxfllox }}$ and $\mathrm{K} 14 \mathrm{Cre}-\mathrm{ERT}$ mice were crossed to produce double transgenic mice with floxed Cttn and inducible Cre activity (Cttn ${ }^{\text {floxflox; }}$ K14Cre-ERT). The model was tested 
by orally applying tamoxifen treatment for $5 \mathrm{~d}$, then assaying tissues for cortactin knockout by IHC 10 days and 1 mo following tamoxifen-induced Cre activity. Cortactin knockout in the tongue and buccal mucosa was evident at the $10 \mathrm{~d}$ (Figure 1c) and one month (data not shown) time points, displaying similar reductions in cortactin staining. Cortactin knock out was more efficient on the ventral tongue surface (Figure 1c, second panel), whereas the dorsal surface displayed a mosaic knockout pattern (Figure 2b, second panel), similar to that seen in buccal mucosa (Figure 1c, fourth panel) and with other genes that utilize a similar strategy ${ }^{15}$. Tissues where the epithelium contained cortactin knockout did not display any overt abnormalities or phenotypic changes compared to homozygous floxed controls (Figure 1c). This was expected based on the largely benign phenotype observed in mice with complete cortactin knockout ${ }^{27}$. These data demonstrate successful construction of an inducible conditional cortactin knockout mouse model targeting the oral cavity epithelium.

Cortactin knockout does not affect development of invasive tongue squamous cell carcinoma

To determine the consequence of cortactin knockout on HNSCC initiation and

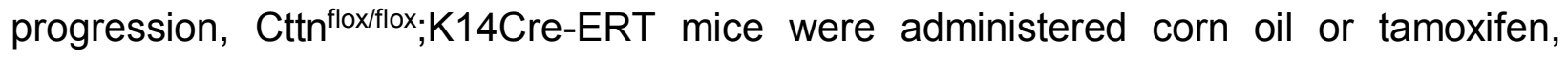
followed by 8 wk exposure to either DMSO or 4-NQO and subsequent monitoring of tumor formation for 28 wks (see Materials and Methods). Genotyping of tongues from tamoxifentreated mice showed a 285 bp PCR-generated DNA band, indicating genomic Cttn knockout not present in mice that did not receive tamoxifen (Figure 2a, "T" lanes). The majority of tamoxifen treated and untreated mice also had a band corresponding to the floxed Cttn allele, possibly due to the mosaic nature of the Cttn knockout in epithelia 
tissues and/or genomic DNA contamination from non-epithelial stromal cells. Cttn knockout was not evident in the kidneys from any group, confirming that tissue-specific K14CreTAM expression was limited to squamous epithelia (Figure 2a, "K" lanes). Unexpectedly, all mice had cortactin knockout in skin samples from the ear independent of tamoxifen exposure (Figure 2a, "S" lanes). Since ear skin samples were used for the initial genotyping, a PCR comparison of skin samples from 6 week old mice and the same animals at 28 weeks of age was conducted to verify knockout status. K14-CreERT demonstrated spontaneous activation in the skin following weaning, resulting in cortactin knockout within the skin in all animals used in the study (Supplementary Figure 1b). Similar leakiness of K14-CreERT activity has been reported by others ${ }^{31,32}$, and was restricted to the skin in our study.

No differences in tumor incidence or progression was observed between the Cttn floxflox and Cttn cKO groups during the 28 wk monitoring period. Mouse tongues at the end of the study were analyzed for cortactin knockout and presence of invasive SCC (Figure 2a): $78 \%$ of $\mathrm{Cttn}^{\text {floxflox }}$ mice and $67 \%$ of Cttn cKO mice had developed invasive SCC, with the remainder containing hyperplastic alterations of the epithelial layer as previously reported ${ }^{13,17}$. Four cortactin-deficient tumors from Cttn cKO mice displayed stromal and intramuscular invasion similar to tumors in tongues of $\mathrm{Cttn}^{\text {floxflox }}$ mice (Figure $2 \mathrm{~b}, 4^{\text {th }}$ column) and cortactin-expressing tumors from Cttn cKO mice (data not shown). This was surprising given the established role for cortactin expression in HNSCC invadopodia formation ${ }^{8-10,29}$ and aggressive tumor progression in head and neck and esophageal SCC xenograft models ${ }^{3,33}$. Careful inspection of the invasive fronts in Cttn cKo tumors indicated no cortactin expression in any squamous tumor cell, including 
leader cells at the invasive front (Figure 2c). Cttn cKo and Cttn floxflox tumors did have extensive cortactin labeling of muscle and other stromal cell types as seen before ${ }^{2,34}$. These results indicate that cortactin expression is not required for the development or invasion of oral SCC.

\section{Cortactin knockout in HNSCC does not alter EMT}

Changes in EMT status have been shown to be involved in initiating and maintaining collective HNSCC invasion ${ }^{35}$. To determine if cortactin knockout altered EMT in HNSCC as a compensatory mechanism to drive invasion, tumor sections from $\mathrm{Cttn}{ }^{\text {floxflox }}$ and $\mathrm{Cttn}$ cKO mice were evaluated by IHC for changes in the classical EMT marker proteins Ecadherin and vimentin. In HNSCC, decreased E-cadherin and increased vimentin expression are associated with poor prognosis and increased invasiveness ${ }^{35-37}$. In addition, cortactin expression is required for actin-based E-cadherin localization and adherens junction formation in epithelial monolayers ${ }^{38}$, implying a functional role in maintaining cell-cell adhesion during collective movement. E-cadherin expression and cortical localization in associated normal tongue epithelium was unaltered in tumors from Cttn floxflox and Cttn cKo mice (Figure 3a, "IE", boxed areas). E-cadherin expression was decreased in invasive tumor regions, as seen in the traditional EMT phenotype (Figure 3a, "T" and 3b). Little to no vimentin expression was evident in invasive tumor cells from $\mathrm{Cttn}^{\text {flox/flox }}$ and Cttn cKo mice. However, vimentin-positive cells were present within the tumor microenvironment, where they outlined invasive tumor cell strands (Figure 3c). These results are similar to what have been reported for patient oral SCC samples ${ }^{37}$. Levels of E-cadherin and vimentin expression in cortactin ${ }^{\text {floxfllox }}$ and cortactin cKO tumors were quantified, with no significant changes observed for either protein (Figures $3 d$ and 
e). These results suggest cortactin expression levels do not govern the global HNSCC EMT program during tumor progression, and indicate that vimentin-positive cells closely associate with invasive tumor strands in 4-NQO-induced tongue SCC.

\section{Cortactin cKO tumors have increased collagen and CD31 positive vessels}

While many reports support a role for cortactin in Arp2/3-mediated lamellipodia extension, conflicting studies have shown cortactin expression is not essential for lamellipodial protrusion ${ }^{24}$. Recently, lamellipodial defects resulting from cortactin knockdown in fibrosarcoma cells have been shown to be rescued by plating cortactin-deficient cells on high levels of ECM proteins, including collagen $\mathrm{I}^{39}$. To determine if cortactin deletion in HNSCC alters tumor collagen levels, collagen composition in invasive tumors from $\mathrm{Cttn}^{\text {floxflox }}$ and Cttn cKO mice were stained with Masson's Trichrome (Figure 4a-b). Tumors form Cttn cKO mice contained an average of $53 \%$ more collagen than tumors from Cttn flox/flox animals (Figure 4c).

In addition to ECM levels, tumor vascularity has previously been shown to be influenced by cortactin knockdown in a semi-orthotopic HNSCC xenografts ${ }^{3}$. To determine the amount of vascular content, tumors from Cttn floxflox and Cttn cKO mice were analyzed for changes in angiogenesis by IHC for the endothelial cell marker CD31 (Figure 4d). Tumors from Cttn cKO mice had a $64 \%$ increase in vessel density compared to tumors from Cttn floxfllox animals (Figure 4e). The observed increase in collagen in Cttn cKo tumors may be due to increased collagen deposition associated with increased angiogenesis. These data suggest that the tumor microenvironment is responsible for rescuing motility defects typically associated with loss of cortactin expression in in vitro and xenograft HNSCC experimental systems. 


\section{Cortactin knockout does not influence MMP14 expression in 4-NQO-induced HNSCC tumors}

In vitro studies have shown that cortactin expression levels regulate HNSCC invadopodia ECM degradation activity through recruitment of MMP14 and subsequent activation of secreted MMP2 and MMP99,10,40. We therefore evaluated the levels of MMP14 in tongue tumors from Cttn ${ }^{\text {floxfllox }}$ and Cttn cKO mice. Surprisingly, MMP14 expression was not detected in $\mathrm{Cttn}^{\text {floxflox }}$ or Cttn cKO tumor cells. (Figure 5a). MMP14 expression was seen in the stroma between tumor cell groups and at the invasive front (Figure 5a, arrows). MMP14 expression levels did not significantly vary between $\mathrm{Cttn}{ }^{\text {flox/flox }}$ or $\mathrm{Cttn}$ cKO tumors (Figure 5b).

Finally, the observation that MMP14 expression is found in the stroma surrounding invasive tumor strands, and not the tumor cells per se, suggests that non-tumor cells in the microenvironment are responsible for stromal ECM degradation. Cancer-associated fibroblasts and macrophages have both been implicated in promoting invasion in HNSCC $^{41,42}$ and other tumor types ${ }^{43-45}$. Labeling of invasive tongue tumor sections from Cttn floxflox and Cttn cKO animals with the monocyte-specific marker CD68 identified macrophages in close apposition to the invasive front of $\mathrm{Cttn}^{\text {floxfllox }}$ and $\mathrm{Cttn}$ cKO tumors (Figure 5c, arrows). No significant differences in the number of CD68-positive cells were observed between $\mathrm{Cttn}^{\text {floxflox }}$ and cortactin cKO tumors $(2.49 \%$ vs $2.62 \%$, Figure $5 \mathrm{~d}$ ). Given the presence of vimentin-positive cells in these same stroma regions (Figure 3c), these results suggest that macrophages and fibroblasts are the sources of MMP14 expression within the invasive microenvironment, where they potentially contribute to 
stromal proteolysis to enable invasion and migration of HNSCC tumors that lack cortactin expression. 


\section{Discussion}

Cortactin has been traditionally identified as a driver of tumor invasion, where it is required for formation and function of invadopodia-mediated ECM breakdown, enabling tumor cells to move through the basement membrane into surrounding tissues. These past studies have evaluated the effects of cortactin loss using 2D and 3D in vitro and xenograft models, but no studies have investigated the impact of cortactin knockout in a genetically engineered mouse model with an intact immune system in the appropriate anatomic site. Here we describe the first genetic mouse model of cortactin deletion in any cancer type, evaluating the role of cortactin in carcinogen-induced tongue SCC development and invasion. Surprisingly, we show that cortactin plays a non-essential role in tongue SCC invasion. Tumors lacking cortactin were still able to breach the basement membrane and invade between muscle strands within the tongue. Cortactin-deficient tumors had increased collagen and $\mathrm{CD} 31^{+}$vessels, which provide a means to compensate for cortactin loss to promote and maintain invasion. Additionally, although loss of E-cadherin expression traditionally seen during EMT remained unchanged in cortactin cKO tumors, tumor cells did not have concomitant upregulation of vimentin expression. Instead, vimentin was found in cells within the tumor microenvironment near the invasive front. Another atypical finding was the lack of MMP14 in control Cttn floxflox and Cttn cKO tumors, with expression also restricted to cells within the microenvironment stroma, along with tumor-associated macrophages identified by anti-CD68 labeling. The lack of invadopodia MMP14 in tongue SCC, combined with the presence of multiple cell types in the tumor stroma that possess the ability to degrade matrix, indicates that the tongue SCC 
microenvironment and not the carcinoma cells are responsible for driving SCC invasion in our model system.

The effect of complete knockout of cortactin in mice has been somewhat controversial. Despite the contribution of cortactin to actin branchpoint stability and cell motility, studies using Cttn-null MEFs failed to show any major migratory defects ${ }^{24,25}$. Additionally, viable Cttn-KO mice have been generated that only display minor defects related to endothelial cell leakiness and the ability of neutrophils to form attachments within vessels ${ }^{27}$. These results imply cortactin is expendable during mouse development and for fibroblast cell motility. However, a gene trap model of cortactin deletion failed to produce homozygous mice due to incomplete asymmetric division oocytes during meiotic metaphase II, leading to a lethal phenotype ${ }^{26}$. Given these inconsistent findings, we chose to develop a conditional mouse model of cortactin knockout in order to specifically remove cortactin from squamous epithelium of mature animals. By combining our floxed cortactin model with K14-CreERT-inducible mice, we were able to conditionally delete cortactin from epithelial tissue in the oral cavity and skin (Figure 1c, 2b). The main caveats with this system were that it resulted in an incomplete knockout, leading to a mosaic pattern of cortactin expression in some instances (Figure 1c), as well as the inherent leakiness of K14-CreERT activity within the skin in older animals (Supplementary Figure 1b). In spite of these potential pitfalls, neither issue detracted from the results obtained in the rest of the study.

There is an abundance of information linking cortactin to tumor cell invasion and metastasis. The cortactin gene is located within chromosomal region $11 \mathrm{q} 13$, an area amplified in breast, head and neck cancers and other cancer types ${ }^{46}$. Due to its 
amplification and overexpression in HNSCC, cortactin is frequently associated with more aggressive tumors and cervical lymph node metastasis in patients ${ }^{5,33} .2 \mathrm{D}$ and $3 \mathrm{D}$ in HNSCC in vitro lead to the conclusion that cortactin is important for the organization of many associated proteins necessary for efficient migration and ECM degradation. In vivo models of cortactin in head and neck cancer have mainly been limited to xenografts, where cortactin expression leads to larger, well-vascularized tumors ${ }^{3}$. Contrary to these data, we find that cortactin is expendable for HNSCC tumor invasion. Tumors lacking cortactin are as competent of invading the surround stroma as tumors with normal cortactin expression, suggesting that they are also capable of degrading basement membrane to enable stromal spread (Figure $2 b, c)$. These results are corroborated by studies in breast cancer. Transgenic mice with mammary-targeted cortactin overexpression do not develop pre-malignant lesions or enhance cyclin D1-induced breast carcinoma ${ }^{21}$. Additionally, the actin bundling protein, fascin, a vital invadopodia protein in breast cancer and melanoma in $2 \mathrm{D}$ and $3 \mathrm{D}$ invasion assays ${ }^{47}$, does not drive invasion in a transgenic knockout model of pancreatic cancer ${ }^{48}$. Collectively, these results suggest in vivo transgenic models may be more faithful of the human disease than in vitro or orthotopic systems.

The EMT program is thought to facilitate invasion, where epithelial cells suppress expression of cell-cell and cell-matrix adhesion genes in favor of genes that drive motility and the mesenchymal phenotype ${ }^{49}$. Traditionally, EMT results in the loss of the adherens junction protein E-cadherin and increased expression of the intermediate filament protein vimentin. Consistent with this, E-cadherin levels decreased when tumors became invasive, with intact normal epithelial retaining the typical peripheral membrane 
expression pattern. However, no vimentin expression was found in any tumor; instead vimentin positivity was found in cells between tumor strands and in cells lining the invasive front. These results suggest that cancer-associated fibroblasts (CAFs) or myofibroblasts are the source of vimentin expression. In HNSCC, the presence of CAFs are linked to poor prognosis ${ }^{50,51}$. In addition, fibroblast expression of MMPs confer growth and invasion advantages in 2D, 3D and orthotopic SCC models ${ }^{52-54}$. These studies are in agreement with our data, where cells with MMP14 expression are interspersed between tumors and at the tips of invasive strands. MMP14, in spite of its presence in cultured HNSCC cells $^{9,10}$, was not found in tumor cells in our model system, regardless of cortactin expression. Instead, evidence from our study supports a role for microenvironment MMP14 in enabling invasion.

We also identified tumor-associated macrophages (TAMs) as another potential source of MMP14 within the stroma at the invasive front. TAMs secrete many factors that influence both the tumor itself and other cells in the surrounding tissue, and have been connected with enhanced vascularization in $\mathrm{HNSCC}^{41,55}$. While we found no difference in macrophage levels in Cttn ${ }^{\text {floxflox }}$ and Cttn cKO tumors, TAM localization occurred in a pattern reminiscent to vimentin and MMP14. While MMP expression has generally been thought of as an activity of tumor cells to promote matrix reorganization and efficient invasion, the majority of this supporting work was performed in vitro, using cancer cell lines that have long been removed from extracellular influences ${ }^{9,10,40}$. Our study uses in vivo carcinogen-induced oral tumors that have developed within in a natural environment, allowing for the tumor-microenvironment crosstalk which normally occurs in patients. The role of cortactin in promoting MMP14 localization to invadopodia may 
therefore be an artifact of culturing in a $2 \mathrm{D}$ environment. In the in vivo setting, CAFs and/or TAMs are likely responsible for matrix-degrading proteinase activity in the stroma. Fibroblasts and macrophages remodel ECM during as a function of normal tissue maintenance; these systems are hijacked by the developing tumor through secretion of various cytokines which alter their functions to become pro-tumorigenic ${ }^{56}$.

One area we did see a difference was in the amount of CD31-staining blood vessels. Though there were no differences in macrophage expression, we saw higher levels of CD31 within cortactin-negative tumors, suggesting these tumors are compensating for cortactin knockdown. How these tumors enhance vessel formation is unknown; however, why cortactin cKO cancer cells require increased vascularity may be related to the amount of collagen within the tumor. We also noted increased collagen within microenvironment of cortactin-deficient tumors. Endothelial cells utilize collagen as support for maintaining vessel structure. Cortactin functions as a regulator of ECM secretion in vitro; this activity is thought to be important in regulating cell motility ${ }^{39}$. High amounts of collagen rescues cortactin motility defects ${ }^{39}$. It is possible cortactin-deficient tumors are less motile; however compensation by the microenvironment may negate this defect. Alternative pathways are used for secretion of angiogenic factors (e.g. through diffusion ${ }^{57}$ ), giving the tumor another mechanism for rescue of motility defects. High VEGF expression in HNSCC enhances metastatic dissemination and is associated with poor outcomes ${ }^{58}$. This combination of enhanced vascularity and collagen deposition may serve to provide a mechanism for non-cortactin-expressing tumors retain migratory functions. 
We describe here the first oral cancer model of cortactin knockout, where we have determined that it is dispensable for HNSCC invasion. Our data suggests that microenvironment contributions are likely more important for early tongue tumor invasion, and are able to compensate for the loss of cortactin. Both cancer-associated fibroblasts and macrophages may play synergistic roles through secretion of growth signals and ECM reorganization. Additionally, cortactin-deficient tumors display plasticity in their ability to counter the effects of cortactin deletion. These results emphasize the importance of accurate in vivo modeling of head and neck cancer when studying the actin cytoskeleton. 


\section{Materials and Methods}

\section{Generation of $\mathrm{Cttn}^{\text {flox/flox }}$ mice}

All animal procedures were conducted under institutional protocols (08-0502 and 110412) approved by animal care and use committees. Cttn ${ }^{\text {wt/flox }}$ B6 mice engineered with loxP sites flanking exon 4 were generated by Ozgene (Bentley DC, WA, Australia). A targeting vector was designed to replace exon 4 of murine Cttn through homologous recombination. PCR amplification of B6 genomic DNA produced 2 homology arms and a loxP fragment that were ligated into the FLSniper vector backbone (Ozgene). The final targeting vector sequentially contained a $5^{\prime}$ ' homologous arm, followed by a 5' loxP site upstream of exon 4, the exon 4 sequence, a PGK (Phosphoglycerate kinase)-Neo selection cassette site flanked by Flippase Recognition Target (FRT) sites, an additional loxP site located after the cassette and a 3' homologous arm. The complete vector was linearized and electroporated into B6 embryonic stem (ES) cells and after confirmation of the targeting vector by PCR. ES cells containing the genomically incorporated targeting vector were expanded in culture, injected into blastocysts and implanted into 129 pseudopregnant females to produce chimeric offspring. Chimeras were mated to B6 or albino B6 (AlbB6) mice to obtain germline transmission of the transgene. Confirmation of transgene incorporation was determined by Southern blotting using probes corresponding to the $5^{\prime}$ or $3^{\prime}$ homology arms or the middle of the construct. Resulting Cttn ${ }^{\text {wtflox }}$ breeding pairs were crossed to produce $\mathrm{Cttn}^{\text {floxflox }}$ mice.

\section{Generation of B6 K14Cre-ERT mice}

$\operatorname{Tg}(\mathrm{KRT} 14-\mathrm{cre} / \mathrm{ERT}) 20 \mathrm{Efu} / \mathrm{J}$ (K14Cre-ERT) CD-1 mice were purchased from The Jackson Laboratories (Bar Harbor, ME). K14Cre-ERT mice were backcrossed with wild- 
type B6 mice for five successive generations to achieve B6 congenic synchrony before breeding with Cttn floxed mice for experimentation.

\section{Tamoxifen application}

Tamoxifen (Sigma, St Louis, MO) was dissolved at $20 \mathrm{mg} / \mathrm{mL}$ concentration in corn oil (Sigma) by constantly rocking overnight at $37^{\circ} \mathrm{C}$ and dissolved stocks stored at $4^{\circ} \mathrm{C}$. For induction of K14Cre-ERT activity, 200 uL of tamoxifen stock or corn oil was administered into the oral cavity with a feeding needle. In some instances, mice had either tamoxifen or corn oil painted onto the dorsal surface of the anterior tongue as well as had water withheld for an hour after application to increase potency of K14Cre-ERT activity. Mice were dosed once a day for 5 consecutive days.

\section{Evaluation of Cre activity in B6 K14-CreERT mice}

B6.129S4-Gt(ROSA)26 ${ }^{\text {Sortm1 }}$ Sor/J (R26R) mice ${ }^{59}$ were a generous gift from J. Michael Ruppert (West Virginia University). R26R mice were crossed with B6 K14-CreERT mice and Cre expression was induced by oral cavity tamoxifen application. One month after induction, oral cavity tissues dissected from euthanized mice were fixed in $4 \%$ paraformaldehyde (Electron Microscopy Sciences, Hatfield, PA) and analyzed for $\beta$ galactosidase activity after overnight incubation with X-gal (Life Technologies, Grand Island, NY).

\section{DNA isolation and genotyping}

DNA was isolated from ear notch samples by boiling for 20 minutes at $95^{\circ} \mathrm{C}$ in $\mathrm{NaOH}$ buffer followed by neutralization with $\mathrm{HCl}$. PCR primers used for identifying $\mathrm{Cttn}^{\text {floxflox }}$ mice were synthesized by Integrated DNA Technologies (Coralville, IA) and used as follows: full-length cortactin exon 4 forward (Cttn-F) 5'-TGCCAGGTGTACTGTTTAGGTCTC-3' 
and reverse (Cttn-R) 5'- TCCAAGTTACTCAAAGCCATCCCACA-3'; for the 5' loxP (loxP1) site, forward (Ip1F) 5'- CGCGCCATCGATAACTTCGTATAGCATACA-3' and reverse (Ip1R) 5'-TCTACCCTGGAAGAGCCAGTGG-3'. Primer sequences for identifying Cre expressing mice were obtained from The Jackson Laboratories website: forward (Cre-F) 5'- GCGGTCTGGCAGTAAAAACTATC-3' and reverse (Cre-R) 5'GTGAAACAGCATTGCTGTCACTT-3'. Genomic DNA was isolated from dissected kidney, skin and tongue tissues (Qiagen DNeasy; Qiagen, Germantown, MD).

\section{Carcinogenic induction of oral tumors}

A total of 79 mice with were divided into 4 study arms: Oil + DMSO, Tamoxifen + DMSO, Oil + 4-NQO and Tamoxifen + DMSO. Mice selected for the 4-NQO groups were given $100 \mu \mathrm{g} / \mathrm{mL}$ 4-NQO (Sigma) in their drinking water ad libitum for eight weeks, with water changed at weekly intervals. Normal drinking water was resumed at the end of the eightweek treatment. Tumor formation was monitored for the following 28 weeks. Mice were weighed and oral cavity examinations were performed starting at the end of 4-NQO application and conducted out monthly until 17 weeks, then weekly afterwards. Upon visual confirmation of tumor, individual mice were given a soft transgenic dough diet (BioServ, Flemington, $\mathrm{NJ}$ ) along with moistened dry food and were monitored daily. Mice were euthanized according to Institutional Animal Care and Use Committee guidelines. Two of mice in each study arm were analyzed by H\&E and IHC at the end of the 4-NQO application and 14 weeks later. DNA from kidney, skin, and tongue tissue was isolated from two mouse per group at 3 weeks following the end of 4-NQO treatment. 


\section{Immunohistochemistry}

Tongues from control and tumor-bearing mice were dissected, rinsed in PBS, fixed in $10 \%$ neutral buffered formalin (Fisher, Pittsburgh, PA) and embedded in paraffin. Fivemicrometer sections from tissue blocks were stained with hematoxylin and eosin (H\&E), Masson's Trichrome or immunolabeled with prediluted cytokeratin 14 antibody (Abcam, Cambridge, MA), cortactin (Novus Biologicals, Littleton, CO), E-cadherin (Cell Signaling Technology, Danvers, MA), vimentin (Cell Signaling Technology), CD31, MMP14 (GeneTex, Irvine, CA) and CD68 (Abcam) using a Discovery XT automated staining system (Ventana Medical Systems, Tucson, AZ). Tissues analyzed for $\beta$-galactosidase activity were counterstained with nuclear fast red.

\section{Microscopy}

Histological images were obtained using an Olympus AX70 Provis microscope (Center Valley, PA) as previously described ${ }^{2}$. 5-12 images per tumor were analyzed for expression per tumor field. Images were subjected to color deconvolution and analyzed in Image J and Adobe Photoshop C6.

\section{Statistical analysis}

Differences between groups were evaluated using student's $t$-test with significance determined at $p \leq 0.05$. 


\section{$\underline{\text { References }}$}

1 Leemans CR, Braakhuis BJM, Brakenhoff RH. The molecular biology of head and neck cancer. Nat Rev Cancer 2010; 11: 9-22.

2 Rothschild BL, Shim AH, Ammer AG, Kelley LC, Irby KB, Head JA et al. Cortactin overexpression regulates actin-related protein $2 / 3$ complex activity, motility, and invasion in carcinomas with chromosome 11q13 amplification. Cancer Res 2006; 66: 8017-8025.

3 Clark ES, Brown B, Whigham AS, Kochaishvili A, Yarbrough WG, Weaver AM. Aggressiveness of HNSCC tumors depends on expression levels of cortactin, a gene in the 11q13 amplicon. Oncogene 2009; 28: 431-444.

$4 \quad$ Rodrigo JP, Garcia LA, Ramos S, Lazo PS, Suarez C. EMS1 gene amplification correlates with poor prognosis in squamous cell carcinomas of the head and neck. Clin Cancer Res 2000; 6: 3177-3182.

5 Rodrigo JP, Garcia-Carracedo D, Garcia LA, Menendez S, Allonca E, Gonzalez M $V$ et al. Distinctive clinicopathological associations of amplification of the cortactin gene at 11q13 in head and neck squamous cell carcinomas. J Pathol 2009; 217: 516-523.

6 Weed SA, Karginov A V, Schafer DA, Weaver AM, Kinley AW, Cooper JA et al. Cortactin localization to sites of actin assembly in lamellipodia requires interactions with F-actin and the Arp2/3 complex. J Cell Biol 2000; 151: 29-40.

7 Weaver AM, Karginov A V, Kinley AW, Weed SA, Li Y, Parsons JT et al. Cortactin promotes and stabilizes Arp2/3-induced actin filament network formation. Curr Biol 2001; 11: 370-374.

8 Ayala I, Baldassarre M, Giacchetti G, Caldieri G, Tete S, Luini A et al. Multiple regulatory inputs converge on cortactin to control invadopodia biogenesis and extracellular matrix degradation. J Cell Sci 2008; 121: 369-378.

9 Clark ES, Whigham AS, Yarbrough WG, Weaver AM. Cortactin is an essential regulator of matrix metalloproteinase secretion and extracellular matrix degradation in invadopodia. Cancer Res 2007; 67: 4227-4235.

10 Artym V V, Zhang Y, Seillier-Moiseiwitsch F, Yamada KM, Mueller SC. Dynamic interactions of cortactin and membrane type 1 matrix metalloproteinase at invadopodia: defining the stages of invadopodia formation and function. Cancer Res 2006; 66: 3034-3043. 
11 Evans J V, Ammer AG, Jett JE, Bolcato CA, Breaux JC, Martin KH et al. Src binds cortactin through an SH2 domain cystine-mediated linkage. J Cell Sci 2012; 125: 6185-97.

12 Vitale-Cross L, Molinolo AA, Martin D, Younis RH, Maruyama T, Patel $\vee$ et al. Metformin prevents the development of oral squamous cell carcinomas from carcinogen-induced premalignant lesions. Cancer Prev Res 2012; 5: 562-573.

13 Tang XH, Knudsen B, Bemis D, Tickoo S, Gudas LJ. Oral cavity and esophageal carcinogenesis modeled in carcinogen-treated mice. Clin Cancer Res 2004; 10: 301-313.

14 Vasioukhin V, Degenstein L, Wise B, Fuchs E. The magical touch: genome targeting in epidermal stem cells induced by tamoxifen application to mouse skin. Proc Natl Acad Sci U S A 1999; 96: 8551-8556.

15 Bian Y, Terse A, Du J, Hall B, Molinolo A, Zhang $P$ et al. Progressive tumor formation in mice with conditional deletion of TGF-beta signaling in head and neck epithelia is associated with activation of the PI3K/Akt pathway. Cancer Res 2009; 69: 5918-5926.

16 Raimondi AR, Molinolo A, Gutkind JS. Rapamycin prevents early onset of tumorigenesis in an oral-specific K-ras and p53 two-hit carcinogenesis model. Cancer Res 2009; 69: 4159-4166.

17 Hasina R, Martin LE, Kasza K, Jones CL, Jalil A, Lingen MW. ABT-510 is an effective chemopreventive agent in the mouse 4-nitroquinoline 1-oxide model of oral carcinogenesis. Cancer Prev Res 2009; 2: 385-393.

18 Kanojia D, Vaidya MM. 4-Nitroquinoline-1-oxide induced experimental oral carcinogenesis. Oral Oncol 2006; 42: 655-667.

19 Zhou G, Hasina R, Wroblewski K, Mankame TP, Doçi CL, Lingen MW. Dual Inhibition of Vascular Endothelial Growth Factor Receptor and Epidermal Growth Factor Receptor is an Effective Chemopreventive Strategy in the Mouse 4-NQO Model of Oral Carcinogenesis. Cancer Prev Res 2010; 3: 1493-1502.

20 Bindels EMJ, van den Brekel MWM. Development of a conditional mouse model for head and neck squamous cell carcinoma. Adv Otorhinolaryngol 2005; 62: 1-11.

21 Van Rossum AGSH, van Bragt MPA, Schuuring-Scholtes E, van der Ploeg JCM, van Krieken JHJM, Kluin PM et al. Transgenic mice with mammary gland targeted expression of human cortactin do not develop (pre-malignant) breast tumors: studies in MMTV-cortactin and MMTV-cortactin/-cyclin D1 bitransgenic mice. BMC Cancer 2006; 6: 58. 
22 Ormandy CJ, Musgrove EA, Hui R, Daly RJ, Sutherland RL. Cyclin D1, EMS1 and $11 q 13$ amplification in breast cancer. Breast Cancer Res Treat 2003; 78: 323-35.

23 Hui R, Ball JR, Macmillan RD, Kenny FS, Prall OW, Campbell DH et al. EMS1 gene expression in primary breast cancer: relationship to cyclin D1 and oestrogen receptor expression and patient survival. Oncogene 1998; 17: 1053-9.

24 Lai FP, Szczodrak M, Oelkers JM, Ladwein M, Acconcia F, Benesch S et al. Cortactin promotes migration and platelet-derived growth factor-induced actin reorganization by signaling to Rho-GTPases. Mol Biol Cell 2009; 20: 3209-3223.

25 Tanaka S, Kunii M, Harada A, Okabe S. Generation of cortactin floxed mice and cellular analysis of motility in fibroblasts. Genes (New York, NY 2000) 2009; 47: 638-646.

26 Yu D, Zhang H, Blanpied TA, Smith E, Zhan X. Cortactin is implicated in murine zygotic development. Exp Cell Res 2010; 316: 848-858.

27 Schnoor M, Lai FP, Zarbock A, Klaver R, Polaschegg C, Schulte D et al. Cortactin deficiency is associated with reduced neutrophil recruitment but increased vascular permeability in vivo. J Exp Med 2011; 208: 1721-1735.

28 Van Rossum AG, Schuuring-Scholtes E, van Buuren-van Seggelen V, Kluin PM, Schuuring E. Comparative genome analysis of cortactin and HS1: the significance of the F-actin binding repeat domain. BMC Genomics 2005; 6: 15.

29 Oser M, Yamaguchi H, Mader CC, Bravo-Cordero JJ, Arias M, Chen X et al. Cortactin regulates cofilin and N-WASp activities to control the stages of invadopodium assembly and maturation. J Cell Biol 2009; 186: 571-587.

30 Caulin C, Nguyen T, Longley MA, Zhou Z, Wang XJ, Roop DR. Inducible activation of oncogenic K-ras results in tumor formation in the oral cavity. Cancer Res 2004; 64: 5054-5058.

31 Sayama K, Kajiya K, Sugawara K, Sato S, Hirakawa S, Shirakata Y et al. Inflammatory mediator TAK1 regulates hair follicle morphogenesis and anagen induction shown by using keratinocyte-specific TAK1-deficient mice. PLoS One 2010; 5: e11275.

32 Nenci A, Huth M, Funteh A, Schmidt-Supprian M, Bloch W, Metzger D et al. Skin lesion development in a mouse model of incontinentia pigmenti is triggered by NEMO deficiency in epidermal keratinocytes and requires TNF signaling. Hum $\mathrm{Mol}$ Genet 2006; 15: 531-542.

33 Luo ML, Shen XM, Zhang Y, Wei $F, X u X$, Cai $Y$ et al. Amplification and overexpression of CTTN (EMS1) contribute to the metastasis of esophageal 
squamous cell carcinoma by promoting cell migration and anoikis resistance. Cancer Res 2006; 66: 11690-11699.

34 Ammer AG, Kelley LC, Hayes KE, Evans J V, Lopez-Skinner LA, Martin KH et al. Saracatinib Impairs Head and Neck Squamous Cell Carcinoma Invasion by Disrupting Invadopodia Function. J Cancer Sci Ther 2009; 1: 52-61.

35 Basu D, Bewley AF, Sperry SM, Montone KT, Gimotty PA, Rasanen K et al. EGFR inhibition promotes an aggressive invasion pattern mediated by mesenchymal-like tumor cells within squamous cell carcinomas. Mol Cancer Ther 2013; 12: 2176 2186.

36 Bosch FX, Andl C, Abel U, Kartenbeck J. E-cadherin is a selective and strongly dominant prognostic factor in squamous cell carcinoma: A comparison of $E$ cadherin with desmosomal components. Int J cancer 2005; 114: 779-790.

37 Chaw SY, Abdul Majeed A, Dalley AJ, Chan A, Stein S, Farah CS. Epithelial to mesenchymal transition (EMT) biomarkers-E-cadherin, beta-catenin, APC and Vimentin-in oral squamous cell carcinogenesis and transformation. Oral Oncol 2012; 48: 997-1006.

38 Han SP, Gambin Y, Gomez GA, Verma S, Giles N, Michael M et al. Cortactin Scaffolds Arp2/3 and WAVE2 at the Epithelial Zonula Adherens. J Biol Chem 2014; 289: 7764-7775.

39 Sung $\mathrm{BH}$, Zhu X, Kaverina I, Weaver AM. Cortactin controls cell motility and lamellipodial dynamics by regulating ECM secretion. Curr Biol 2011; 21: 14601469.

40 Clark ES, Weaver AM. A new role for cortactin in invadopodia: regulation of protease secretion. Eur J Cell Biol 2008; 87: 581-590.

41 Liss C, Fekete MJ, Hasina R, Lam CD, Lingen MW. Paracrine angiogenic loop between head-and-neck squamous-cell carcinomas and macrophages. Int $J$ Cancer 2001; 93: 781-5.

42 Tsujikawa T, Yaguchi T, Ohmura G, Ohta S, Kobayashi A, Kawamura N et al. Autocrine and paracrine loops between cancer cells and macrophages promote lymph node metastasis via CCR4/CCL22 in head and neck squamous cell carcinoma. Int J Cancer 2013; 132: 2755-66.

43 Wyckoff J, Wang W, Lin EY, Wang Y, Pixley F, Stanley ER et al. A paracrine loop between tumor cells and macrophages is required for tumor cell migration in mammary tumors. Cancer Res 2004; 64: 7022-9. 
44 Wyckoff JB, Wang Y, Lin EY, Li J, Goswami S, Stanley ER et al. Direct visualization of macrophage-assisted tumor cell intravasation in mammary tumors. Cancer Res 2007; 67: 2649-56.

45 Qian B-Z, Pollard JW. Macrophage diversity enhances tumor progression and metastasis. Cell 2010; 141: 39-51.

46 Wilkerson PM, Reis-Filho JS. The 11q13-q14 amplicon: clinicopathological correlations and potential drivers. Genes Chromosomes Cancer 2013; 52: 333-55.

47 Li A, Dawson JC, Forero-Vargas M, Spence HJ, Yu X, Konig I et al. The actinbundling protein fascin stabilizes actin in invadopodia and potentiates protrusive invasion. Curr Biol 2010; 20: 339-345.

48 Li A, Morton JP, Ma Y, Karim SA, Zhou Y, Faller WJ et al. Fascin is regulated by slug, promotes progression of pancreatic cancer in mice, and is associated with patient outcomes. Gastroenterology 2014; 146: 1386-96.e1-17.

49 Lamouille S, Xu J, Derynck R. Molecular mechanisms of epithelial-mesenchymal transition. Nat Rev Mol Cell Biol 2014; 15: 178-196.

50 Lim KP, Cirillo N, Hassona Y, Wei W, Thurlow JK, Cheong SC et al. Fibroblast gene expression profile reflects the stage of tumour progression in oral squamous cell carcinoma. J Pathol 2011; 223: 459-69.

51 Marsh D, Suchak K, Moutasim KA, Vallath S, Hopper C, Jerjes W et al. Stromal features are predictive of disease mortality in oral cancer patients. J Pathol 2011; 223: 470-81.

52 Johansson A-C, Ansell A, Jerhammar F, Lindh MB, Grénman R, Munck-Wikland E et al. Cancer-associated fibroblasts induce matrix metalloproteinase-mediated cetuximab resistance in head and neck squamous cell carcinoma cells. Mol Cancer Res 2012; 10: 1158-68.

53 Zhang W, Matrisian LM, Holmbeck K, Vick CC, Rosenthal EL. Fibroblast-derived MT1-MMP promotes tumor progression in vitro and in vivo. BMC Cancer 2006; 6: 52.

54 Gaggioli C, Hooper S, Hidalgo-Carcedo C, Grosse R, Marshall JF, Harrington K et al. Fibroblast-led collective invasion of carcinoma cells with differing roles for RhoGTPases in leading and following cells. Nat Cell Biol 2007; 9: 1392-1400.

55 Liss C, Fekete MJ, Hasina R, Lingen MW. Retinoic acid modulates the ability of macrophages to participate in the induction of the angiogenic phenotype in head and neck squamous cell carcinoma. Int J Cancer 2002; 100: 283-9. 
56 Hanahan D, Coussens LM. Accessories to the crime: functions of cells recruited to the tumor microenvironment. Cancer Cell 2012; 21: 309-22.

57 Park JE, Keller GA, Ferrara N. The vascular endothelial growth factor (VEGF) isoforms: differential deposition into the subepithelial extracellular matrix and bioactivity of extracellular matrix-bound VEGF. Mol Biol Cell 1993; 4: 1317-1326.

58 Walk EL, Weed SA. Recently identified biomarkers that promote lymph node metastasis in head and neck squamous cell carcinoma. Cancers (Basel) 2011; 3: 747-772.

59 Soriano P. Generalized lacZ expression with the ROSA26 Cre reporter strain. Nat Genet 1999; 21: 70-1. 


\section{Figure Legends}

Figure 1. Generation of mice with oral epithelium-specific cortactin knockout. (a) PCR genotyping strategy for identifying $\mathrm{Cttn}^{\text {flox/flox }}$ mice. Two primer sets were used to determine presence of floxed or deleted exon 4 (red half-arrows) and loxP site (black halfarrows). (b) Sample results for each primer set in a, including primers to detect presence of cre gene. Typical genotyping results are shown, with a $100 \mathrm{bp}$ band for the cre fragment, a $691 \mathrm{bp}$ band for the WT Cttn fragment, and a $320 \mathrm{bp}$ fragment that demonstrates the presence of loxP site. The $2973 \mathrm{bp}$ fragment representing the entire selection cassette is not shown. (c) Histology and IHC of tongue and buccal mucosa of $\mathrm{Cttn}^{\text {floxflox }}$ and cKO mice. Tongues and mucosa were stained for cortactin, cytokeratin 14 (CK 14) and H\&E. Loss of cortactin staining demonstrates cortactin knockout in the second and fourth panels of the top row. Cytokeratin 14 and H\&E stains display normal tongue and buccal epithelium, despite cortactin knockout. Scale $=50 \mu \mathrm{m}$

Figure 2. Cortactin knockout does not affect development of invasive tongue squamous cell carcinoma. (a) Tongue, skin and kidney DNA samples from $\mathrm{Cttn} \mathrm{f}^{\text {flox/flox }}$ and cKO mice were genotyped using primers described in figure 1a (red half-arrows). Mice given oil in their oral cavity displayed the $2973 \mathrm{bp}$ fragment representing the selection cassette in the tongue and kidney samples. Application of tamoxifen in the oral cavity resulted in the appearance of the $285 \mathrm{bp}$ knockout fragment in the tongue. This fragment also was seen in skin in both floxed and cKO mice, implying active cre in this tissue. Kidney samples from Cttn cKO mice had the expected floxed fragment. (b) Representative IHC and H\&E images from cortactin ${ }^{\text {floxflox }}$ and $\mathrm{cKO}$ animals given either DMSO or 4-NQO in the oral cavity. Normal cortactin expression was seen in cortactin $^{\text {floxflox }}$ mice with oral tumors ( $3^{\text {rd }}$ panel). Mice in the 4-NQO/cKO group still developed invasive SCC, despite lacking cortactin $\left(4^{\text {th }}\right.$ panel). Scale $=100 \mu \mathrm{m}$ (c) Higher magnification of invasive tumors with and without cortactin expression. Tumor strands invaded collectively between tongue muscle fibers. Dotted yellow lines outline tumor strands. Scales $=100 \mu \mathrm{m}$ (low magnification) and $50 \mu \mathrm{m}$ (high magnification).

Figure 3. Cortactin knockout in HNSCC does not alter EMT (a) Representative images of E-cadherin staining of tumors (T) next to intact epithelium (IE). Intact epithelium displayed traditional E-cadherin staining at cell membranes (box, zoomed image), while tumors expressed little to no E-cadherin. No differences were seen between mice with or without cortactin expression. Scales $=100 \mu \mathrm{m}$ (low magnification) and $50 \mu \mathrm{m}$ (high magnification). (b\&c) High magnification of e-cadherin expression in tumor strands at invasive front. Both floxed and cKO tumors expressed low levels of E-cadherin (b) while vimentin (c) stained around strands and in between tumors in the microenvironment. Dotted yellow lines outline tumor regions. Scale $=25 \mu \mathrm{m}$ (d\&e) Quantitation of e-cadherin (d) and vimentin (e) levels within tumors. 5-12 images per tumor were analyzed for expression per tumor field. NS = not significant.

Figure 4. Cortactin cKO tumors have increased collagen and CD31 positive vessels. Masson's trichrome stain of cortactin-expressing (a) and cortactin cKO (b) 
tumors. Top images are entire tumors, with box highlighting area displayed in zoomed image. Scales $=250 \mu \mathrm{m}$ (low magnification) and $100 \mu \mathrm{m}$ (high magnification). Percentage of tumor area with collagen was quantitated in (c). (d) Representative images of CD31 staining of cortactin-expressing and cKO tumors. Scale bar $=100 \mu \mathrm{m}$ (e) Quantitation of CD31 in tumors revealed cortactin cKO tumors had increased amounts of CD31-positive vessels. ${ }^{* *} p<0.01$

Figure 5. Cortactin knockout does not influence MMP14 expression in 4-NQOinduced HNSCC tumors. (a) Cortactin-expressing and cKO tumors were stained by IHC using anti-MMP14. Arrows denote cells within the microenvironment positive for MMP14. Percentage of tumor area with MMP14 expression was quantitated in (b).(c) Serial sections of tongue tumors were analyzed for macrophage-specific marker CD68. Arrows point to CD68+ macrophages within and at the front of invasive strands, (d). Quantitation of CD68 expression per tumor field. Scale $=100 \mu \mathrm{m}$. NS = not significant. 


\section{Supplemental Figure Legends}

Supplementary Figure 1. Confirmation of cre activity. (a) K14-Cre ${ }^{E R T}$ mice were crossed with R26R mice that express $\beta$-galactosidase when cre recombinase is active.Tongue, buccal mucosa and skin tissue were stained with $\mathrm{X}$-gal (blue) to detect the presence of $\beta$-galactosidase, and counterstained with nuclear fast red for contrast, 1 month after induction of cre activity using tamoxifen. Recombination occurred as seen in previous studies in each of these tissues, with the highest activity in the skin. Scale $=100$ $\mu \mathrm{m}$ (b) PCR analysis of DNA from tongue (T), kidney (K), skin from when the mouse was weaned (Sy) and skin from the same mouse 8 months later, in Cttn flox/flox and cKO mice. Primers used were described in Figure 1a (red half-arrows). Cre recombination can be detected in the cKO mice, but also in older mice, suggesting cre activity becomes leaky as the mice age. 


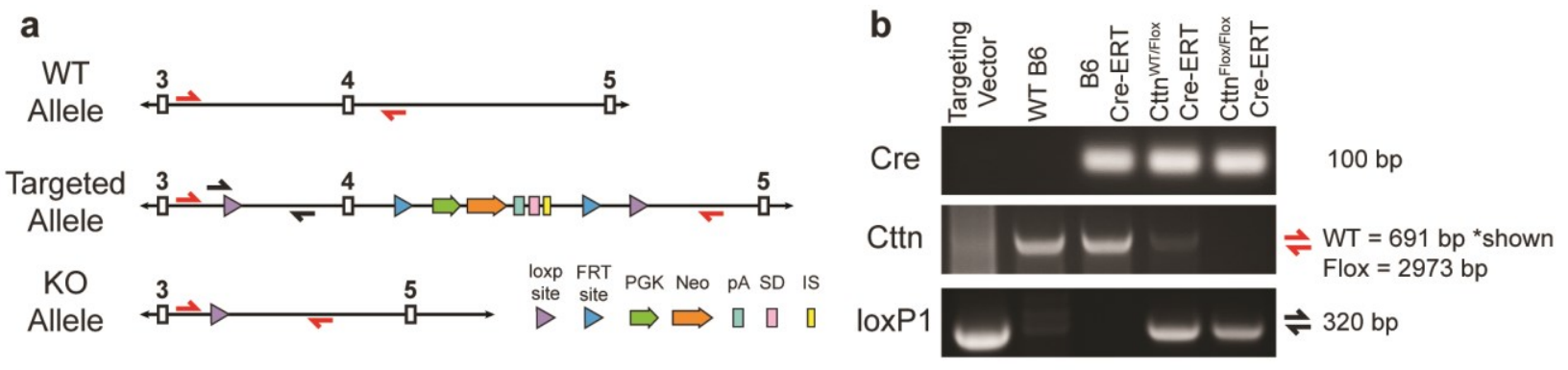

C
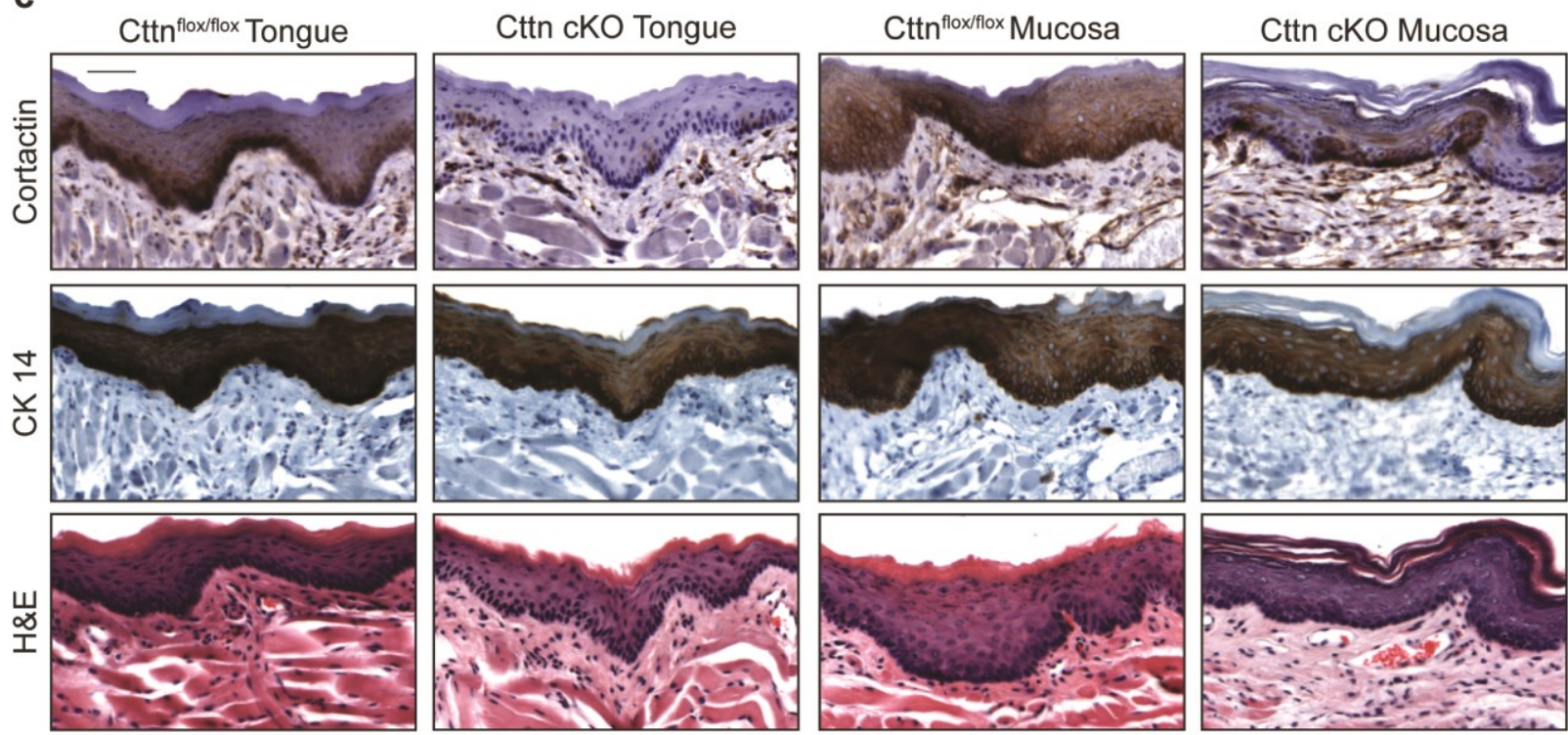

Figure 1 Walk et al.
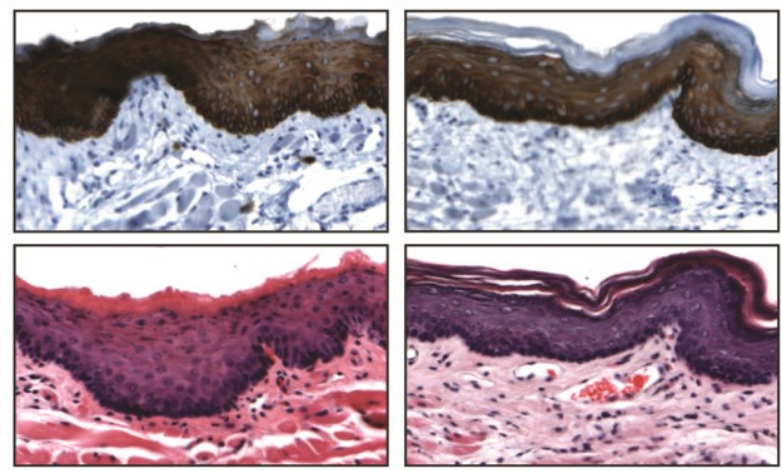
a
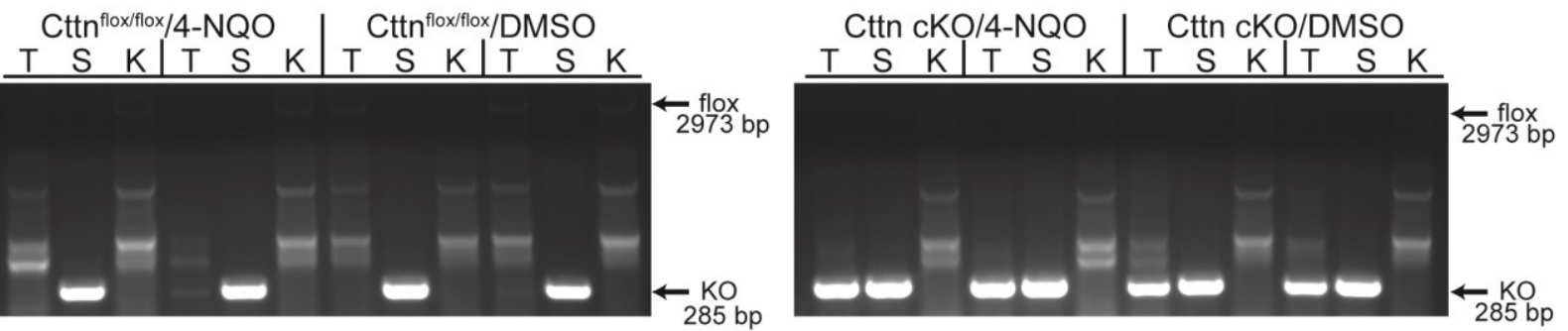

b
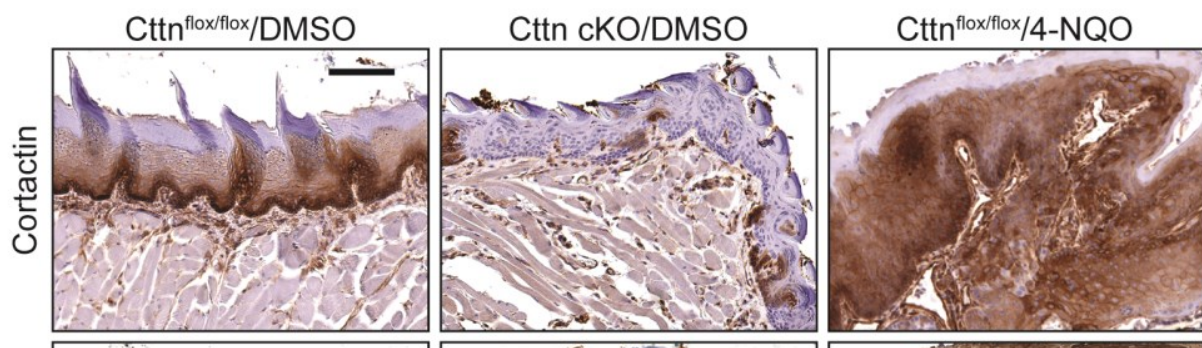

Cttn cKO/4-NQO
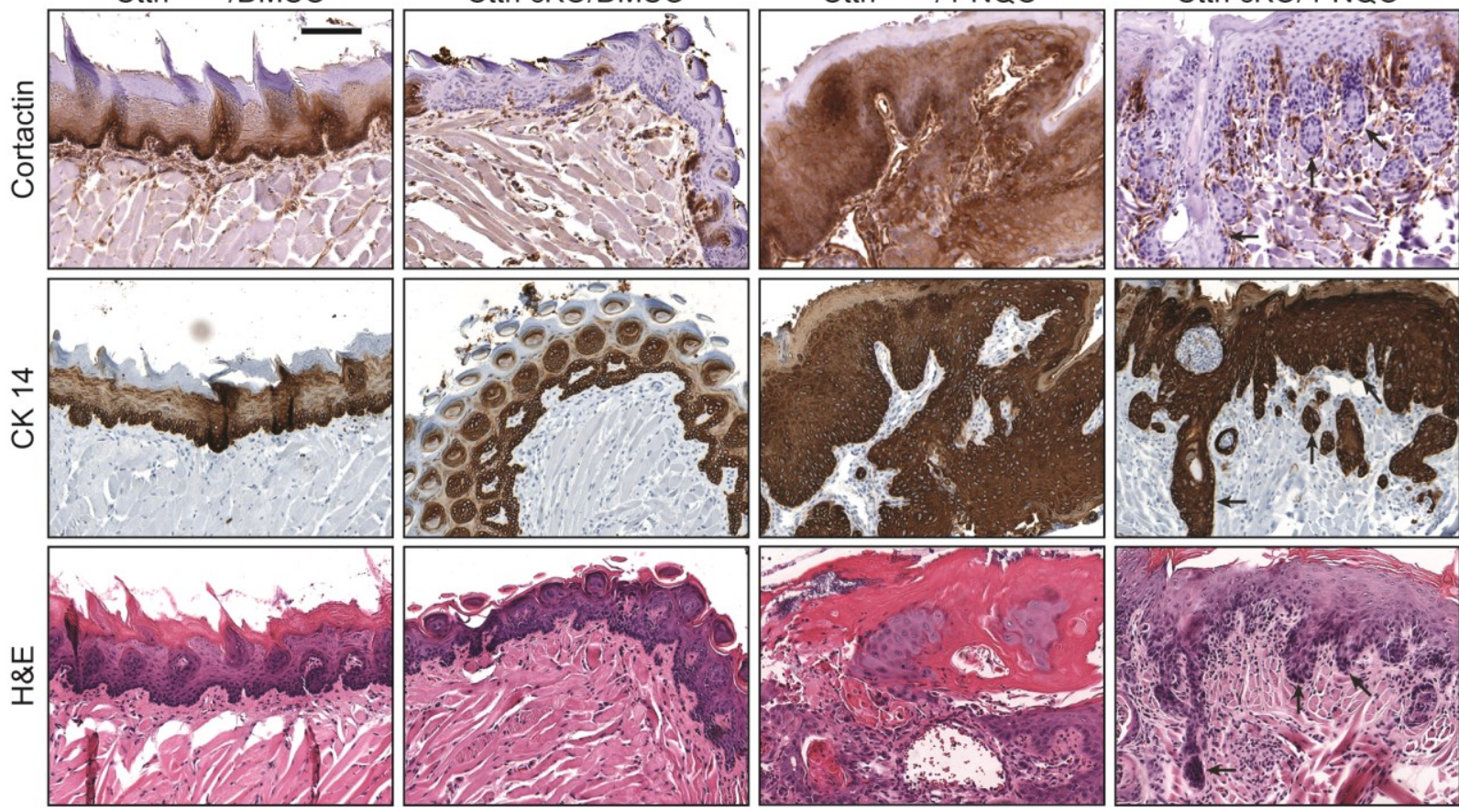

c

Cttn ${ }^{\text {flox/flox} / 4-N Q O ~}$
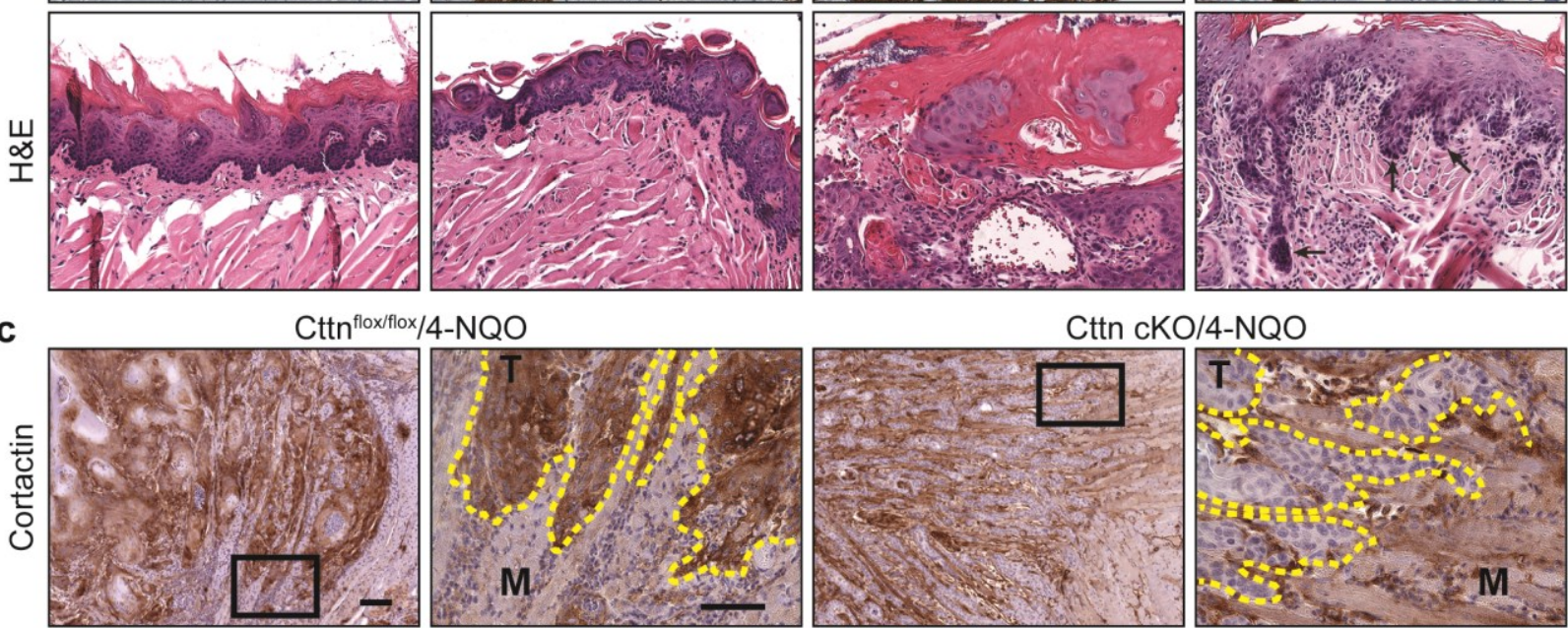

Cttn cKO/4-NQO

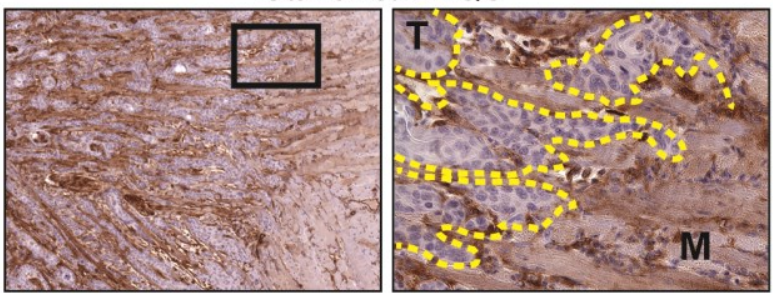

Figure 2 Walk et al. 
a
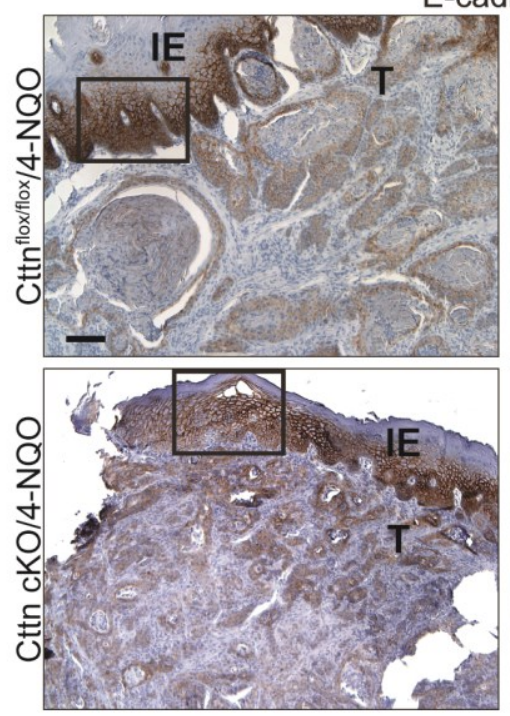

b
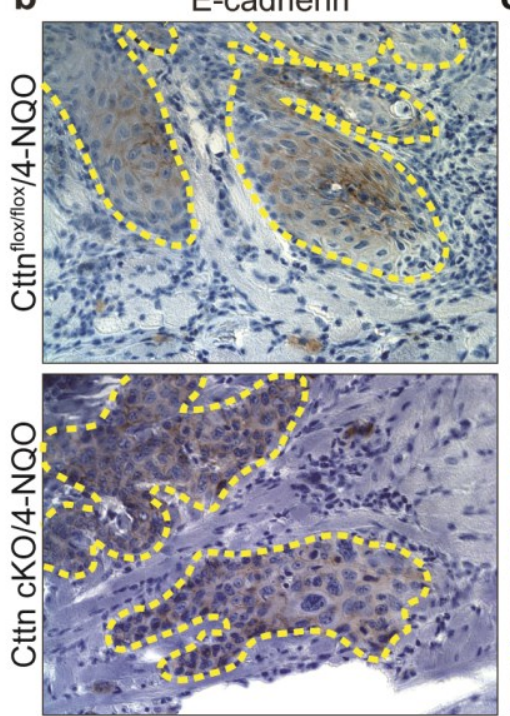

Figure 3 Walk et al. d

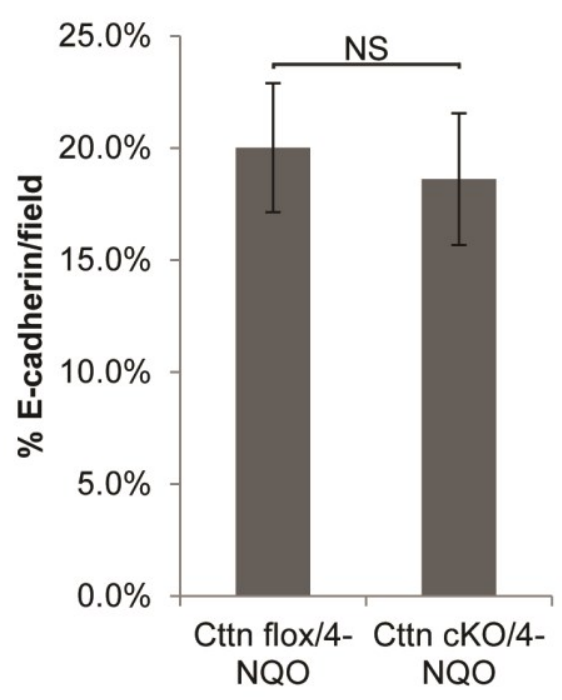

c

Vimentin

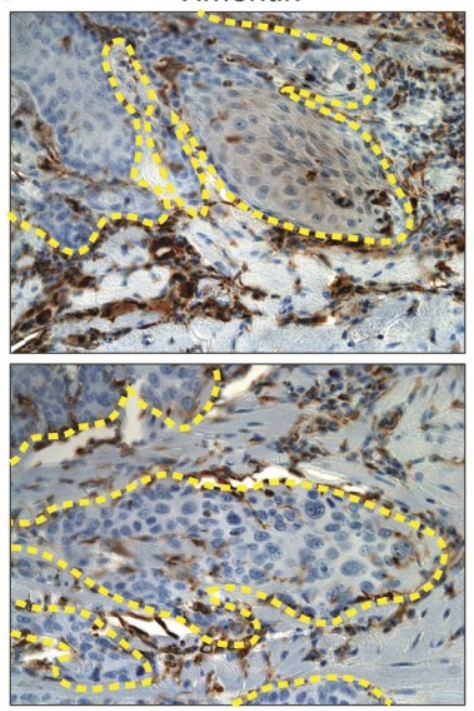

e

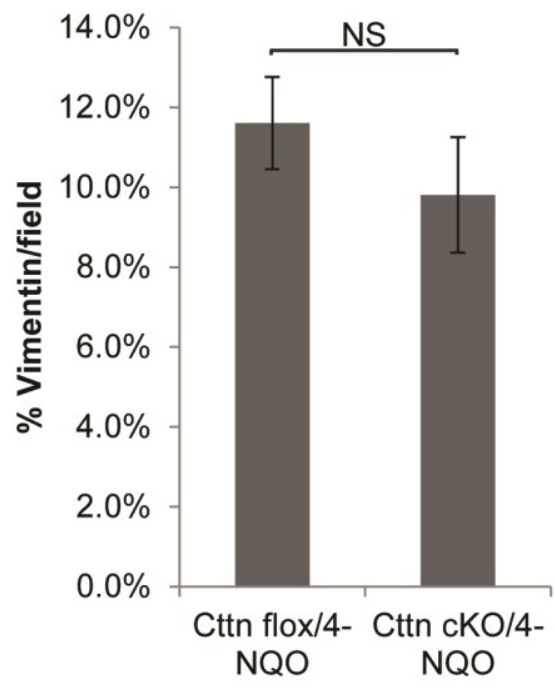



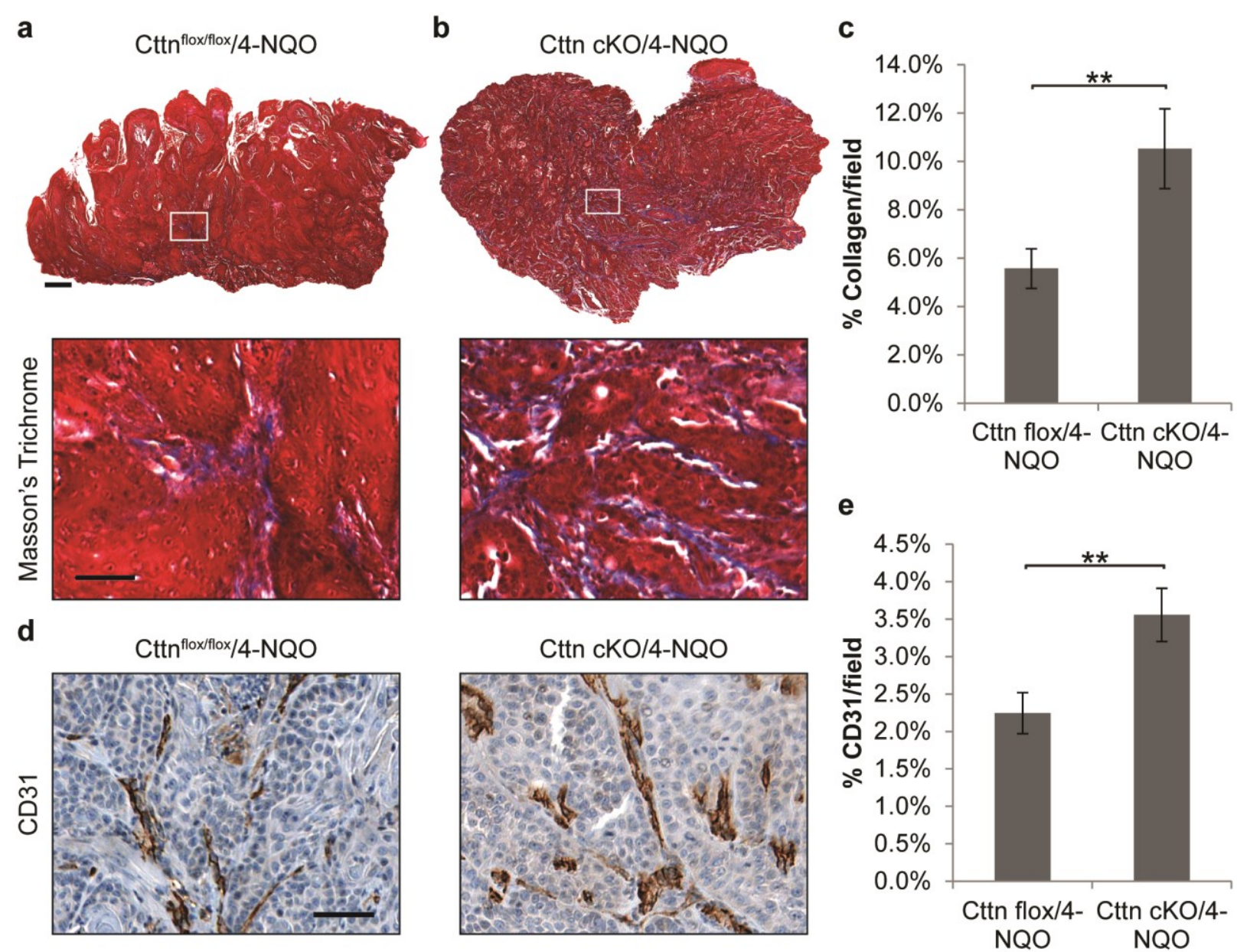

Figure 4 Walk et al.

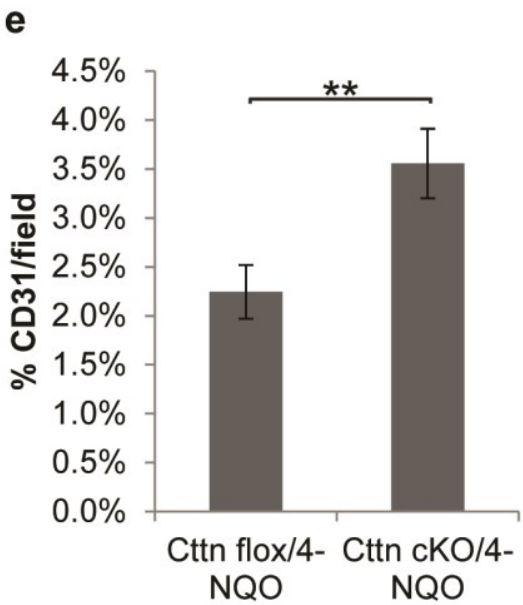


a

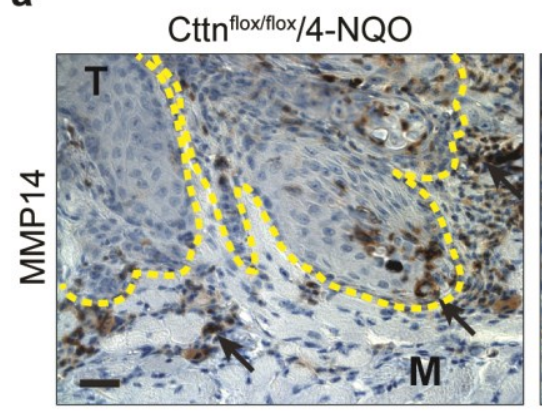

c

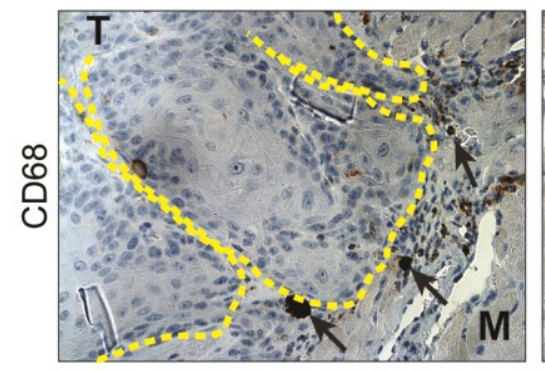

Figure 5 Walk et al. b
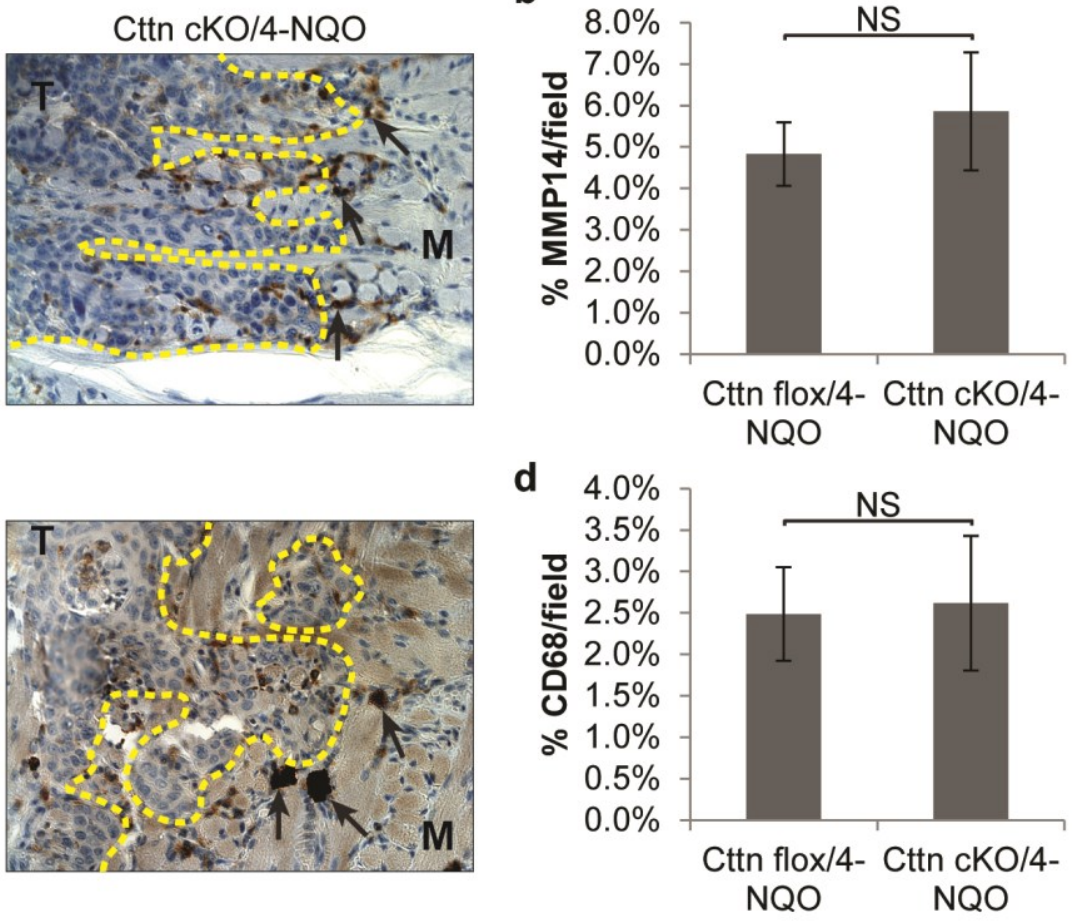


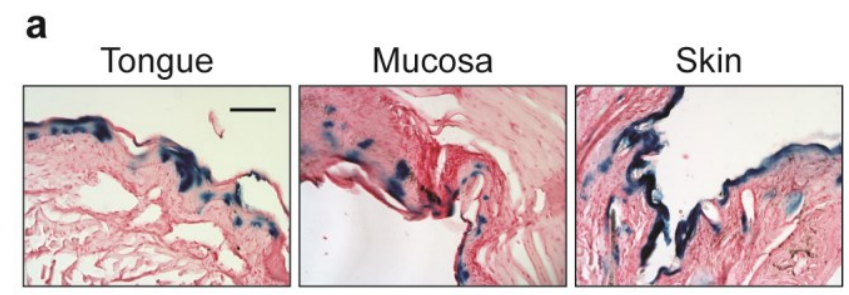

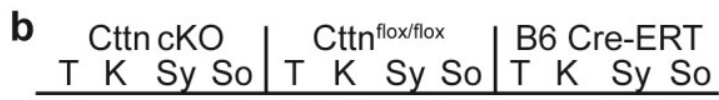

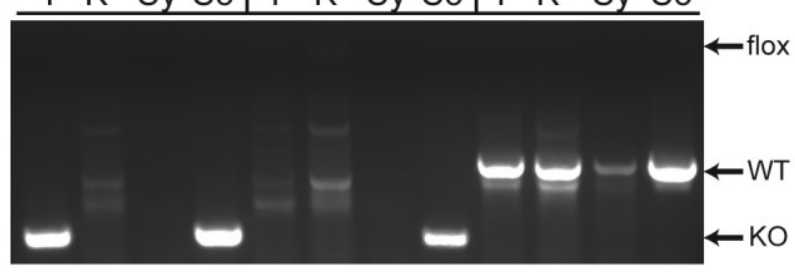

Supplementary Figure 1 Walk et al. 


\section{Study 3: Use of High Frequency Ultrasound to Monitor Cervical Lymph Node Alterations in Mice}

Elyse L. Walk ${ }^{1,3,5}$, Sarah McLaughlin ${ }^{4,5}$, James Coad $^{2}$ and Scott A. Weed ${ }^{*, 1,3,5}$

${ }^{1}$ Department of Neurobiology and Anatomy, ${ }^{2}$ Department of Pathology, ${ }^{3}$ Program in Cancer Cell Biology, ${ }^{4}$ Animal Models and Imaging Facility, ${ }^{5}$ Mary Babb Randolph Cancer Center, West Virginia University, Morgantown, West Virginia, 26506-9300, United States of America

"Corresponding author:

Scott A. Weed

West Virginia University

Mary Babb Randolph Cancer Center

Morgantown, WV 26506-9300

Phone: 304-293-3016

Fax: 304-293-4667

Email: scweed@hsc.wvu.edu 


\section{Abstract}

Cervical lymph node evaluation by clinical ultrasound is a non-invasive procedure used in diagnosing nodal status, and when combined with fine-needle aspiration cytology (FNAC), provides an effective method to assess nodal pathologies. Development of highfrequency ultrasound (HF US) allows real-time monitoring of lymph node alterations in animal models. While HF US is frequently used in animal models of tumor biology, use of HF US for studying cervical lymph node alterations associated with murine models of head and neck cancer, or any other model of lymphadenopathy, is lacking. Here we utilize HF US to monitor cervical lymph node changes in mice following exposure to the oral cancer-inducing carcinogen 4-nitroquinoline-1-oxide (4-NQO) and in mice with systemic autoimmunity. 4-NQO induces tumors within the mouse oral cavity as early as 19 wks that recapitulate HNSCC. Monitoring of cervical (mandibular) lymph nodes by gray scale and power Doppler sonography revealed changes in lymph node size eight weeks after 4-NQO treatment, prior to tumor formation. 4-NQO causes changes in cervical node blood flow resulting from oral tumor progression. Histological evaluation indicated that the early 4-NQO induced changes in lymph node volume were due to specific hyperproliferation of T-cell enriched zones in the paracortex. We also show that HF US can be used to perform image-guided fine needle aspirate (FNA) biopsies on mice with enlarged mandibular lymph nodes due to genetic mutation of Fas ligand (Fasl). Collectively these studies indicate that HF US is an effective technique for the noninvasive study of cervical lymph node alterations in live mouse models of oral cancer and other mouse models containing cervical lymphadenopathy. 


\section{Introduction}

The most common route of dissemination for head and neck cancers is via the local lymphatic system, where patient prognosis relies heavily on the ability to detect cervical lymph node involvement [1-3]. Several different imaging modalities are currently used to enhance pretreatment staging of patients with head and neck squamous cell carcinoma (HNSCC), including computed tomography (CT), positron emission tomography (PET)$\mathrm{CT}$, magnetic resonance imaging (MRI) and ultrasonography [4-7]. Of these, ultrasound has greater clinic availability and is easiest to employ [6]. When combined with FNAC, ultrasound provides a highly accurate, sensitive and selective means to assess lymph node alterations in patients, including tumor cell metastasis $[4,6,8]$.

The development of high-frequency ultrasound (HF US) technology has allowed sonography to be performed on rodent and other small animal disease models. HF US is a noninvasive, real-time technique that allows imaging of internal structures down to 30 microns using gray scale or brightness (B)-mode [9]. This resolution allows for real-time monitoring of tumor formation and progression in vivo in a variety of animal model systems. 3D reconstructions of HF US 2D images allows for the calculation of highly accurate tumor and lymph node volumes. In addition, power Doppler sonography is commonly used to assess and quantify blood flow velocities in tumors and lymph nodes. The combination of these two modalities is useful in quantifying tumor-induced alterations of circulatory flow [10-13].

Several mouse models of HNSCC have been generated that recapitulate important aspects of the human disease. These include orthotopic xenografts, genetically engineered mouse models and carcinogen-initiated tumors [14,15]. Common 
carcinogens used to spontaneously generate rodent HNSCC include 7,12dimethylbenz(a)anthracene or 9,10-dimethyl-1,2-benzanthracene (DMBA) and 4nitroquinoline-1-oxide (4-NQO) [16]. The 4-NQO oral cancer model is a prevalent method to induce HNSCC in mice, as it closely mimics the oncogenic effect of tobacco carcinogens and copies many key molecular alterations that occur during human HNSCC development $[17,18]$, including lymph node metastasis [19]. Tumor induction is achieved by the addition of 4-NQO to the drinking water of immunocompetent mice, with tumor development followed over a period of several weeks to months. The degree and swiftness of carcinogenesis is dependent on the exposure time and 4-NQO dosage [2022]. While many studies have investigated the effects of 4-NQO on multiple aspects of rodent oral cancer $[20,21,23-28]$, reports examining the impact of 4-NQO exposure on murine lymph node biology are lacking [19].

While diagnostic ultrasound affords practical utility in evaluating pre- and cancerous changes within patient cervical lymph nodes, adapting HF US to evaluate cervical nodal alterations in mouse HNSCC or other model systems has not been reported. Here we show that HF US can be utilized for monitoring changes in cervical lymph nodes in 4NQO-treated mice during the course of oral cancer progression. C57BL/6 (B6) mice treated with 4-NQO for eight weeks displayed increased lymph node volume and vascular flow prior to oral tumor development. Histological evaluation determined that precancerous elevation of lymph node volume was specifically due to increased proliferation of intranodal T-cell zones. Furthermore, we show that HF US can be utilized to obtain image-guided FNA biopsy material from Fasl mice that contain chronically enlarged cervical nodes. The ability of HF US to conduct real time monitoring of murine cervical 
lymph node dynamics allows for the practical detection of neck node changes in mice that cannot be accomplished by conventional histology. This technique ultimately provides increased utility and accuracy for studies involving live rodent models of HNSCC and other rodent systems that model cervical node lymphadenopathy. 


\section{Materials and Methods}

\section{Mice}

B6 and CPt.C3-Fas/gld/J (Fasl) mice were purchased from the Jackson Laboratory (Bar Harbor, ME). FVB mice were a generous gift from John Hollander (West Virginia University). All animal studies were approved by the WVU Institutional Animal Care and Use Committee (protocol 11-0412) and conducted in accordance with the principles and procedures outlined in the NIH Guide for the Care and Use of Animals.

\section{4-NQO administration}

22-24 week old B6 mice were given 50-100 $\mu \mathrm{g} / \mathrm{mL}$ 4-NQO (Sigma, St Louis, MO) in their drinking water ad libitum for eight weeks, with water changed at weekly intervals. Normal drinking water was resumed at the end of the eight-week treatment.

\section{High-frequency ultrasonography and image analysis}

Ultrasound imaging was performed using a VisualSonics Vevo 2100 micro-ultrasound system (Toronto, Ontario, Canada) on control $(n=4)$ and 4-NQO-treated $(n=3)$ mice. Mice were initially anesthetized with $3 \%$ isoflurane with oxygen and maintained at $1-2 \%$ isoflurane with oxygen during imaging. Anesthetized mice were positioned in dorsal recumbancy on a heated imaging platform and paws taped to electrocardiograph (ECG) leads to monitor heart and respiration rates. Body temperature was maintained at $37^{\circ} \mathrm{C}$ and monitored with a rectal probe thermometer. Hair was removed from the neck region using a chemical depilatory (Nair, Church \& Dwight, NJ). A $40 \mathrm{MHz}$ transducer was used for lower resolution overview imaging of the neck region from the thyroid gland through to the posterior tongue. All other images were acquired using a $50 \mathrm{MHz}$ transducer. Images were taken in 3D-mode using combined B- and power Doppler mode. Lymph node volume and percent blood flow were determined using Vevo 2100 software after 
drawing regions of interest within each sequential 2D image. On average, each mouse took approximately 15 minutes to prepare and image.

\section{Image-guided fine needle biopsy}

Enlarged mandibular cervical nodes in anesthetized Fasl mice were identified using the $50 \mathrm{MHz}$ transducer focused at the lymph node center. A $271 / 2$ gauge needle attached to a $1 \mathrm{ml}$ syringe was inserted into the micro-injector, consisting of an adjustable needle holder with micro-manipulation controls. The needle was positioned bevel side up and inserted through the skin into the mandibular node. After $\sim 100 \mu \mathrm{l}$ of lymph tissue was extracted, the needle was removed and the syringe placed in a $2 \mu \mathrm{L}$ microcentrifuge tube. The syringe was filled with $1 \mathrm{~mL}$ of ThinPrep media and reattached to the needle. The media was dispensed for rinsing and processed by Cytospin using a blue filter in a Thinprep 2000 processor (Cytyc, Marlborough, MA).

\section{Immunohistochemical analysis}

Whole necks, cervical lymph nodes and tongues were dissected, rinsed in PBS, fixed in $10 \%$ neutral buffered formalin (Fisher, Pittsburgh, PA) and embedded in paraffin. Whole neck sections required decalcification using Rapid-Cal•Immuno decalcification solution (BBC Biochemical, Seattle, WA) after fixation. Five-micrometer sections from tissue blocks were stained with hematoxylin and eosin (H\&E) or immunolabeled with prediluted cytokeratin 14 antibody (Abcam, Cambridge, MA) using a Discovery XT automated staining system (Ventana Medical Systems, Tucson, AZ). Lymph node paracortical Tcell zone expansion analysis was performed by pathological evaluation on H\&E stained sections after grouping nodes by right or left side. Individual nodes were scored as having 
none, moderate or robust enlargement. Histological images were obtained using an Olympus AX70 Provis microscope (Center Valley, PA).

\section{Statistical analysis}

Differences between groups were evaluated using Student's $t$-test with significance determined at $p \leq 0.05$. 


\section{Results}

\section{High-frequency ultrasound detection of mouse cervical lymph nodes}

Cervical ultrasound is a commonly utilized tool for non-invasive imaging of lymph nodes in the patient neck, where it is frequently combined with MRI and PET/CT to determine patient staging in HNSCC and other diseases. While several publications describe the features of benign and malignant cervical lymph nodes in humans [29-33], studies detailing the suitability and use of US to image normal or diseased mouse cervical nodes are lacking. We initially conducted HF US on untreated B6 mice to identify and map the three supraclavicular (mandibular, accessory mandibular and superficial parotid [34]) cervical lymph nodes in the murine neck that drain the oral cavity tissues. Anesthetized mice were imaged on a heated platform with the Vevo 3D-mode scanner in order to automate the process (Figure 1A). For point of reference, the transducer was first focused on the thyroid gland, where it is well-defined as a hyperechoic solid structure when imaged by gray scale sonography (Figure 1B and C) [35-38]. Subsequent serial HF US images were taken of the entire neck region, starting at the jaw base and moving proximally to the thyroid (diagramed in Figure 1B). Corresponding HF US images identified each cervical node as hypoechoic oval structures within dense hyperechoic regions (Figure $1 \mathrm{C}$ ). These hyperechoic areas primarily contain adipose, salivary gland and skeletal muscle tissue adjacent to the cervical lymph nodes, with the nodes positioned just below the integument when identified by histological analysis of parallel tissue sections (Figure 1D). The superficial nature of the cervical nodes increased their mobility due to the pressure placed by the transducer on the neck, resulting in equivalent right and left nodes appearing in different imaging planes. This was countered by making compensatory adjustments to the imaging stand while maintaining the transducer in a 
stationary position. Insertion of a metal feeder needle into the oral cavity during imaging ablated the ultrasound signal, allowing additional imaging of buccal regions and esophagus to provide a more comprehensive sonographic depiction of the murine oral cavity (Figure S1).

Since FNAC of lymph nodes is used to determine patient tumor staging and for other diagnostic purposes, we determined the feasibility of conducting HF US image-guided FNAC analysis on live mice. The cervical nodes in B6 mice proved too small and mobile obtain a FNA. We therefore used Fasl mice that contain enlarged lymph nodes due to systemic autoimmunity $[39,40]$ that mimic the size of human lymph nodes (Figure $2 \mathrm{~A}$ ). FNAC of Fasl cervical mandibular nodes was performed using an image-guided microinjection system with the $50 \mathrm{MHz}$ transducer focused at the presumed lymph node center (Figure 2B; Video S1). The entire biopsy can be seen in Video S1. Analysis of the aspirated material following Cytospin concentration exclusively revealed cellular and extracellular lymph node components, including large clumps of lymph tissue, individual lymphocytes and reticular fibers (Figure 2C). These results indicate that HF US can be successfully adapted for FNA analysis on enlarged cervical lymph nodes in mice.

\section{4-NQO induces pre-cancerous enlargement of mouse submandibular lymph nodes}

We next used HF US to monitor cervical lymph node changes in mice following oral 4NQO exposure designed to induce tumorigenesis. B6 mice were selected since this strain exhibits near complete penetrance and predictable oral tumor course in response to 4-NQO treatment $[28,29]$. Mice were given 4-NQO continuously for eight weeks as 
previously reported [20-22]. For clarity, the end of the eight week treatment period is denoted as the zero week time point in the study. Mice formed oral lesions similar to those reported in previous studies, starting as early as 19 weeks post-treatment $[20,22]$ (Figure S2A). The neck region in control and 4-NQO treated mice was imaged every four weeks by HF US for an additional 28 weeks after the zero week time point. B-mode imaging of the mandibular and accessory mandibular lymph nodes in 4-NQO treated mice at the end of the entire 36 week study period indicated slight increases in lymph node size compared to nodes from age-matched control animals (Figure 3A and B, Videos S2S3). In a separate study, 4-NQO-treated B6 mice developed lymph node metastasis by 33 weeks post-4-NQO treatment (41 weeks total), demonstrating that 4-NQO-induced tumors are capable of undergoing lymph node metastasis during the later stages of oral cancer progression (Figure S2B).

The increased mandibular node size in 4-NQO treated mice at the end of 36 weeks was comparable to the mandibular node size in Fasl mice in many instances (Figure 3C, Video S4). Three dimensional volume measurements revealed median mandibular nodal volumes of $3.1 \mathrm{~mm}^{3}$ in control mice and $4.4 \mathrm{~mm}^{3}$ in 4-NQO treated mice 28 weeks after cessation of 4-NQO treatment (Figure 3D). Interestingly, mandibular node volume measured by HF US at the end of the initial eight-week 4-NQO treatment period (prior to tumor onset) was significantly greater than nodes in control mice (Figure 3D; $1.3 \mathrm{~mm}^{3} \mathrm{vs}$ $4.9 \mathrm{~mm}^{3}$, respectively). This finding was surprising since there was no evidence of tumor onset in 4-NQO treated mice at this time, suggesting an early inflammatory response in these nodes, potentially due to hyperkeratosis present on the tongues of these animals 
(Figure S2A, 0 weeks post-4-NQO). Power Doppler analysis of the mandibular nodes indicated that while intranodal median vascular flow rates were comparable within nodes in age-matched control and 4-NQO treated mice immediately following 4-NQO treatment, median vascular flow in 4-NQO exposed nodes was increased by close to $15 \%$ in mice 28 weeks after the end of 4-NQO exposure (Figure 3E). Although median blood flow percentages were largely different between age-matched control and 4-NQO treated mice at 28 weeks ( $7.4 \%$ vs $17.83 \%$, Figure $3 \mathrm{E})$, the overall change did not reach statistical significance. Blood flow between age-matched non-treated controls at 0 and 28 weeks also did not increase significantly. The increased nodal blood flow in $28 \mathrm{wk}$ animals was not due to the increase in lymph node volume in these mice, since the amount of vascular flow in Fasl mandibular nodes was comparable to the flow percentages in control and 4NQO treated mice at the zero week time point (Figure 3E). Collectively these results suggest that 4-NQO treatment in B6 mice results in precancerous mandibular lymph node enlargement accompanied by increased intranodal blood flow during tumor onset and progression.

\section{Acute 4-NQO exposure in B6 mice enhances expansion of the mandibular lymph node paracortical/T-cell zone}

Mandibular lymph nodes from 4-NQO exposed mice 28 weeks post-treatment displayed areas of increased lymphocyte density compared to age-matched controls (Figure 3B versus Figure $3 \mathrm{~A}$ ), suggesting that lymphocyte proliferation could be responsible for the

increased submandibular nodal volume observed by HF US. Pathological evaluation of H\&E-stained sections containing all cervical lymph nodes from both sides of the neck 
revealed varying degrees of enlargement of the T-cell enriched paracortical zones in control and 4-NQO exposed mice (Figure 4A and 4B). However, lymph nodes in 4-NQO exposed mice had a greater degree of paracortical T-cell enlargement, with over $80 \%$ of the nodes scored as containing robust expansion of this region (Figure 4C). In contrast, none of the paracortical regions in control nodes displayed more than moderate T-cell expansion (Figure 4C). These results suggest that 4-NQO exposure induces increased cervical lymph node volume attributable to specific hyperproliferation of the nodal T-cell population. 


\section{Discussion}

Clinical sonography has emerged as an important means of monitoring cervical lymph node changes in HNSCC and other oral diseases. In this study, we show that cervical lymph nodes in mouse can be effectively identified and imaged by HF US. Combined gray scale and power Doppler sonography revealed increased nodal volume and blood flow in mice treated with 4-NQO prior to tumor formation. The increase in overall precancerous cervical node size in 4-NQO exposed mice can be attributed to expansion of the paracortical/T-cell zone within the node. We also demonstrate that HF US imageguided biopsies can be successfully conducted on live mice using a mutant Fasl strain that displays chronic cervical lymphadenopathy. Collectively these results support the application and utility of HF US for the minimally invasive study of cervical lymph nodes in mouse models of HNSCC and other diseases.

Examination of the mouse cervical region by HF US provides an in vivo map of cervical lymph node position that closely matches node location in histological sections. This mapping is in agreement with previous studies of the thyroid and tongue that charted these regions on a more limited level $[36,41]$. Due to their inherent small size, an accurate, comprehensive in situ portrayal of mouse cervical lymph nodes is useful not only to mouse models of HNSCC, but other systems pertaining to illness causing cervical lymphadenopathy, including thyroid cancer $[37,38]$ and bacterial infection [42]. HF US can also be applied to study cervical organs other than lymph nodes. Salivary gland diseases such as salivary gland tumors, sialolithiasis, sialodenitis and Sjogren's syndrome [43] all have the potential to have organ-induced alterations visualized by HF US in rodent models. 
FNAC is an important technique used to aid in diagnosing nodal involvement in HNSCC and other diseases. Here we demonstrate that image-guided FNAC can be successfully utilized to obtain biopsy material from FasI mice with systemic lymphadenopathy. These mice have lymph node sizes similar to humans $[44,45]$, with volumes comparable to enlarged cervical nodes due to 4-NQO exposure and subsequent HNSCC tumor progression (Figure 3D). This implies that successful biopsies can be performed on any enlarged mouse lymph with similar volume. HF US-guided FNAC therefore has the potential to detect lymph node metastases in HNSCC mouse models, and is planned for future studies where longer term HF US monitoring of animals from pre-cancerous stages through tumor development and progression is achieved. The ability to conduct imageguided FNAC on cervical lymph nodes imparts translational impact on such mouse model studies, where tumor staging is typically based on the degree of nodal metastases $[46,47]$.

Mice orally treated with 4-NQO displayed several different changes in cervical lymph node biology unrelated to metastatic involvement that can be overlooked if not for the real-time capabilities of ultrasonography. 4-NQO-treated mice develop enlarged lymph nodes that correspond with early alterations to the tongue epithelium, where enlargement is maintained during tumor onset and progression. While enlarged nodes can be expected in response to neoplastic development, growth and/or metastasis, our findings indicate that significant lymph node enlargement occurs before tumor formation occurs in the oral cavity. The increased node size can be explained by paracortical/T-cell zone hyperplasia 
within the cervical nodes (Figure 4). Similar findings of paracorticial T-cell expansion have been observed in patients with oral cavity or oropharynx tumors $[48,49]$, but the underlying mechanism for this is unclear. Patient intranodal paracortical expansion is more pronounced in nodes without tumor infiltration $[48,49]$, in agreement with our data, as we did not observe metastasis in any analyzed cervical lymph node in this study (Figure 4). However, since 4-NQO-treated mice develop cervical node metastases at time points later than what were monitored in the present study (Figure S2B), it is conceivable that HF US can be employed to analyze volume changes in cervical nodes containing tumor metastases, as noted above.

In addition to increased cervical lymph node volume, power Doppler HF US demonstrated that 4-NQO treated mice have greater median blood flow in their mandibular node after tumor onset (Figure 3E). Primary tumors have been shown to induce vasculature reorganization within downstream lymph nodes, preparing the nodal microenvironment ("soil") prior to tumor cell arrival ("seed") in order to better support metastatic colonization [50]. This is achieved by angiogenic induction of microvasculature, including high endothelial venules, within lymph nodes before tumor cell arrival [50-52]. However, we did not observe changes in cervical node microvessel density or size in 4-NQO treated mice (data not shown). The systemic cause for the 4-NQO-mediated increase in cervical nodal blood flow is currently under investigation.

In summary, we demonstrate the benefits of using HF US technology to monitor cervical lymph node alterations in a mouse model of oral cancer. Real-time monitoring of lymph 
node biological responses is an important aspect in therapeutic and biomarker development. Detection of lymph node metastasis without the need for immediate sacrifice allows for more comprehensive and long-term study of animal disease models. In addition to HNSCC, other disease models that induce murine cervical lymphadenopathy may benefit from the application of HF US, allowing improved evaluation of cervical nodes in a variety of experimental prognostic and diagnostic settings. 


\section{Acknowledgements}

We thank John Hollander (Department of Exercise Physiology, West Virginia University) for providing FVB mice. Ultrasound imaging and analysis were performed in the West Virginia University Animal Models \& Imaging Facility, Mary Babb Randolph Cancer. Tissue processing, staining and analysis were performed in the Pathology Laboratory for Translational Medicine (Department of Pathology, West Virginia University). Additional image acquisition was performed in the West Virginia University Microscope Imaging Facility, Mary Babb Randolph Cancer Center. 


\section{$\underline{\text { References }}$}

1. Noguti J, De Moura, Carolina Foot Gomes, De Jesus, Gustavo Protasio Pacheco, Da Silva, Victor Hugo Pereira, Hossaka TA, et al (2012) Metastasis from oral cancer: An overview. Cancer Genomics-Proteomics 9: 329-335.

2. Argiris A, Karamouzis MV, Raben D, Ferris RL (2008) Head and neck cancer. The Lancet 371 : 1695-1709.

3. Leemans CR, Tiwari R, Nauta JJ, van der Waal I, Snow GB (1993) Regional lymph node involvement and its significance in the development of distant metastases in head and neck carcinoma. Cancer 71: 452-456.

4. De Bondt R, Nelemans P, Hofman P, Casselman J, Kremer B, et al (2007) Detection of lymph node metastases in head and neck cancer: A meta-analysis comparing US, USgFNAC, CT and MR imaging. Eur J Radiol 64: 266-272.

5. Liao L, Lo W, Hsu W, Wang C, Lai M (2012) Detection of cervical lymph node metastasis in head and neck cancer patients with clinically NO neck-a meta-analysis comparing different imaging modalities. BMC Cancer 12: 236.

6. Ng S, Ko S, Toh C, Chen Y (2006) Imaging of neck metastases. Chang Gung Med J 29: 119.

7. Van den Brekel, Michiel WM, Castelijns JA, Snow GB (1994) Detection of lymph node metastases in the neck: Radiologic criteria. RADIOLOGY-OAK BROOK IL- 192: 617-617.

8. Stoeckli SJ, Haerle SK, Strobel K, Haile SR, Hany TF, et al (2012) Initial staging of the neck in head and neck squamous cell carcinoma: A comparison of CT, PET/CT, and ultrasoundguided fine-needle aspiration cytology. Head Neck 34: 469-476.

9. Greco A, Mancini M, Gargiulo S, Gramanzini M, Claudio P, et al (2011) Ultrasound biomicroscopy in small animal research: Applications in molecular and preclinical imaging. Journal of Biomedicine and Biotechnology 2012.

10. Jugold M, Palmowski M, Huppert J, Woenne EC, Mueller MM, et al (2008) Volumetric highfrequency doppler ultrasound enables the assessment of early antiangiogenic therapy effects on tumor xenografts in nude mice. Eur Radiol 18: 753-758.

11. Kodama T, Tomita N, Yagishita Y, Horie S, Funamoto K, et al (2011) Volumetric and angiogenic evaluation of antitumor effects with acoustic liposome and high-frequency ultrasound. Cancer Res 71: 6957-6964.

12. Loveless ME, Li X, Huamani J, Lyshchik A, Dawant B, et al (2008) A method for assessing the microvasculature in a murine tumor model using contrast-enhanced ultrasonography. Journal of Ultrasound in Medicine 27: 1699-1709.

13. Snyder CS, Kaushal S, Kono Y, Cao HST, Hoffman RM, et al (2009) Complementarity of ultrasound and fluorescence imaging in an orthotopic mouse model of pancreatic cancer. BMC Cancer 9: 106. 
14. Sano D, Myers JN (2009) Xenograft models of head and neck cancers. Head Neck Oncol 1: 32-3284-1-32. 10.1186/1758-3284-1-32; 10.1186/1758-3284-1-32.

15. Kim S (2009) Animal models of cancer in the head and neck region. Clinical and experimental otorhinolaryngology 2: 55-60.

16. Lu S, Herrington $\mathrm{H}$, Wang $X(2006)$ Mouse models for human head and neck squamous cell carcinomas. Head Neck 28: 945-954.

17. Kanojia D, Vaidya MM (2006) 4-nitroquinoline-1-oxide induced experimental oral carcinogenesis. Oral Oncol 42: 655-667.

18. Vitale-Cross L, Czerninski R, Amornphimoltham P, Patel V, Molinolo AA, et al (2009) Chemical carcinogenesis models for evaluating molecular-targeted prevention and treatment of oral cancer. Cancer Prevention Research 2: 419-422.

19. Li J, Liang F, Yu D, Qing H, Yang Y (2012) Development of a 4-nitroquinoline-1-oxide model of lymph node metastasis in oral squamous cell carcinoma. Oral Oncol .

20. Hasina R, Martin LE, Kasza K, Jones CL, Jalil A, et al (2009) ABT-510 is an effective chemopreventive agent in the mouse 4-nitroquinoline 1-oxide model of oral carcinogenesis. Cancer Prevention Research 2: 385-393.

21. Tang XH, Knudsen B, Bemis D, Tickoo S, Gudas LJ (2004) Oral cavity and esophageal carcinogenesis modeled in carcinogen-treated mice. Clin Cancer Res 10: 301-313.

22. Vitale-Cross L, Molinolo AA, Martin D, Younis RH, Maruyama T, et al (2012) Metformin prevents the development of oral squamous cell carcinomas from carcinogen-induced premalignant lesions. Cancer Prevention Research 5: 562-573.

23. Czerninski R, Amornphimoltham P, Patel V, Molinolo AA, Gutkind JS (2009) Targeting mammalian target of rapamycin by rapamycin prevents tumor progression in an oral-specific chemical carcinogenesis model. Cancer Prevention Research 2: 27-36.

24. Zhou G, Hasina R, Wroblewski K, Mankame TP, Doçi CL, et al (2010) Dual inhibition of vascular endothelial growth factor receptor and epidermal growth factor receptor is an effective chemopreventive strategy in the mouse 4-NQO model of oral carcinogenesis. Cancer Prevention Research 3: 1493-1502.

25. Vered M, Allon I, Buchner A, Dayan D (2007) Stromal myofibroblasts and malignant transformation in a 4NQO rat tongue carcinogenesis model. Oral Oncol 43: 999-1006.

26. Wilkey JF, Buchberger G, Saucier K, Patel SM, Eisenberg E, et al (2009) Cyclin D1 overexpression increases susceptibility to 4-nitroquinoline-1-oxide-induced dysplasia and neoplasia in murine squamous oral epithelium. Mol Carcinog 48: 853-861.

27. Leeman-Neill RJ, Seethala RR, Singh SV, Freilino ML, Bednash JS, et al (2011) Inhibition of EGFR-STAT3 signaling with erlotinib prevents carcinogenesis in a chemically-induced mouse model of oral squamous cell carcinoma. Cancer Prevention Research 4: 230-237. 
28. Yuan B, Oechsli MN, Hendler FJ (1997) A region within murine chromosome 7F4, syntenic to the human 11q13 amplicon, is frequently amplified in 4NQO-induced oral cavity tumors. Oncogene 15: 1161-1170. 10.1038/sj.onc.1201269.

29. Chang DB, Yuan A, Yu CJ, Luh KT, Kuo SH, et al (1994) Differentiation of benign and malignant cervical lymph nodes with color doppler sonography. Am J Roentgenol 162: 965968.

30. Ahuja A, Ying M, Ho S, Antonio G, Lee Y, et al (2008) Ultrasound of malignant cervical lymph nodes. Cancer Imaging 8: 48.

31. Rubaltelli L, Khadivi Y, Tregnaghi A, Stramare R, Ferro F, et al (2004) Evaluation of lymph node perfusion using continuous mode harmonic ultrasonography with a second-generation contrast agent. Journal of ultrasound in medicine 23: 829-836.

32. Ying M, Ahuja AT (2006) Ultrasound of neck lymph nodes: How to do it and how do they look? Radiography 12: 105-117.

33. Zenk J, Bozzato A, Steinhart H, Greess H, Iro H (2005) Metastatic and inflammatory cervical lymph nodes as analyzed by contrast-enhanced color-coded doppler ultrasonography: Quantitative dynamic perfusion patterns and histopathologic correlation. Ann Otol Rhinol Laryngol 114: 43.

34. Van den Broeck W, Derore A, Simoens P (2006) Anatomy and nomenclature of murine lymph nodes: Descriptive study and nomenclatory standardization in BALB/cAnNCrl mice. J Immunol Methods 312: 12-19.

35. Bosisio MR, Maisonneuve C, Gregoire S, Kettaneh A, Mueller CG, et al (2009) Ultrasound biomicroscopy: A powerful tool probing murine lymph node size $<\mathrm{i}>$ in vivo. Ultrasound Med Biol 35: 1209-1216.

36. Mancini M, Vergara E, Salvatore G, Greco A, Troncone G, et al (2009) Morphological ultrasound microimaging of thyroid in living mice. Endocrinology 150: 4810-4815.

37. Charles R, lezza G, Amendola E, Dankort D, McMahon M (2011) Mutationally activated BRAFV600E elicits papillary thyroid cancer in the adult mouse. Cancer Res 71: 3863-3871.

38. Diallo-Krou E, Yu J, Colby LA, Inoki K, Wilkinson JE, et al (2009) Paired box gene 8peroxisome proliferator-activated receptor-y fusion protein and loss of phosphatase and tensin homolog synergistically cause thyroid hyperplasia in transgenic mice. Endocrinology 150: 5181-5190.

39. Roths JB, Murphy ED, Eicher E (1984) A new mutation, gld, that produces lymphoproliferation and autoimmunity in $\mathrm{C} 3 \mathrm{H} / \mathrm{HeJ}$ mice. J Exp Med 159: 1-20.

40. Takahashi T, Tanaka M, Brannan Cl, Jenkins NA, Copeland NG, et al (1994) Generalized lymphoproliferative disease in mice, caused by a point mutation in the fas ligand. Cell 76 : 969-976. 
41. Pezold JC, Zinn K, Talbert MA, Desmond R, Rosenthal EL (2006) Validation of ultrasonography to evaluate murine orthotopic oral cavity tumors. ORL 68: 159-163.

42. Ehlers S, Hölscher C, Scheu S, Tertilt C, Hehlgans T, et al (2003) The lymphotoxin $\beta$ receptor is critically involved in controlling infections with the intracellular pathogens mycobacterium tuberculosis and listeria monocytogenes. The Journal of Immunology 170: 5210-5218.

43. Alyas F, Lewis K, Williams M, Moody A, Wong K, et al (2005) Diseases of the submandibular gland as demonstrated using high resolution ultrasound. Br J Radiol 78: 362-369.

44. Li L, Mori S, Kodama M, Sakamoto M, Takahashi S, et al (2013) Enhanced sonographic imaging to diagnose lymph node metastasis: Importance of blood vessel volume and density. Cancer Res .

45. Li L, Mori S, Sakamoto M, Takahashi S, Kodama T (2013) Mouse model of lymph node metastasis via afferent lymphatic vessels for development of imaging modalities. PloS one 8: e55797.

46. Sapino A, Cassoni P, Zanon E, Fraire F, Croce S, et al (2003) Ultrasonographically-guided fine-needle aspiration of axillary lymph nodes: Role in breast cancer management. $\mathrm{Br} \mathrm{J}$ Cancer 88: 702-706.

47. Zagorianakou P, Fiaccavento S, Zagorianakou N, Makrydimas G, Stefanou D, et al (2005) FNAC: Its role, limitations and perspective in the preoperative diagnosis of breast cancer. Eur J Gynaecol Oncol 26: 143-149.

48. van Herpen CM, van der Laak, Jeroen AWM, de Vries, I Jolanda M, van Krieken JH, de Wilde PC, et al (2005) Intratumoral recombinant human interleukin-12 administration in head and neck squamous cell carcinoma patients modifies locoregional lymph node architecture and induces natural killer cell infiltration in the primary tumor. Clinical cancer research 11: 18991909.

49. Woolgar JA, Triantafyllou A, Lewis Jr JS, Hunt J, Williams MD, et al (2012) Prognostic biological features in neck dissection specimens. European Archives of Oto-RhinoLaryngology : 1-12.

50. Qian C, Berghuis B, Tsarfaty G, Bruch M, Kort EJ, et al (2006) Preparing the "soil": The primary tumor induces vasculature reorganization in the sentinel lymph node before the arrival of metastatic cancer cells. Cancer Res 66: 10365-10376.

51. Lee SY, Chao-Nan Q, Seng OA, Peiyi C, Bernice WHM, et al (2012) Changes in specialized blood vessels in lymph nodes and their role in cancer metastasis. Journal of Translational Medicine 10: 206.

52. Chung MK, Jung E (2012) Lymphatic vessels and high endothelial venules are increased in the sentinel lymph nodes of patients with oral squamous cell carcinoma before the arrival of tumor cells. Annals of surgical oncology 19: 1595-1601. 


\section{Figure Legends}

Figure 1. Mapping of mouse cervical lymph nodes by high frequency ultrasound.

A. Overview image of the HF US platform for cervical lymph node evaluation. An anesthetized B6 mouse is shown positioned on the Vevo 2100 heated imaging platform with the ventral side exposed. Each paw is tapped to a monitoring electrode and the rectal probe (blue) secured to the stage. The transducer (white) is positioned over the ventral neck area. B. Diagram showing relative locations of murine cervical lymph nodes. Individual neck sections visualized by HF US imaging and histology are indicated by dashed lines. Arrows denote specific positions of each mapped section relative to corresponding ultrasound and histology images. Each imaged anatomical location is numbered. M, mandibular node. AM, accessory mandibular node. SP, superficial parotid node. C. Serial transverse sections of the mouse neck imaged by HF US corresponding to the indicated anatomic regions in (B). D. Transverse cervical H\&E stained histological sections corresponding to the HF US sections in (C). Arrows labeled " 2 " denote mandibular node as diagrammed in B. Scale bar $=1 \mathrm{~mm}$. CP, cheek pouch. VT, ventral tongue. DT, dorsal tongue. E, esophagus.

Figure 2. Image-guided fine needle biopsy of FasI mandibular lymph nodes. A. Transverse section of a Fasl mouse neck imaged with HF US. The enlarged cervical mandibular node is evident as an oval hypoechoic region near the skin surface (circumscribed in yellow). Scale bar $=1 \mathrm{~mm}$. B. Frames from fine needle biopsy of a Fasl mandibular node guided by HF US. Images show the position of the sampling hyperechoic needle tip prior to cervical skin penetration (left), position of the needle during tissue removal (middle), and following needle withdrawal (right). Note the break in the 
skin following needle withdrawal (arrow). The angle and trajectory of the dorsal needle surface is denoted by the yellow dotted line. Scale bar $=1 \mathrm{~mm}$. The entire procedure is shown in Video S1. C. Examples of lymph tissue obtained by HF US guided FNA of a Fasl cervical mandibular node following staining and processing by cytospin. Scale bar = $100 \mu \mathrm{m}$. LT; lymph tissue, RF; reticular fibers, L; individual lymphocytes.

Figure 3. 4-NQO exposure induces precancerous alterations in mouse mandibular lymph nodes. A-C. Images of dissected H\&E and whole animal HF US (ultrasound) mandibular lymph nodes from representative age-matched (AM) control (A), 4-NQOtreated (28wk) (B) and Fasl (C) mice. Lymph node borders in the HF US images are indicated in yellow. Vascular flow identified by power Doppler imaging is shown in red. Power Doppler flow dynamics for each condition are visualized in Video S2-S4. H\&E scale bar $=250 \mu \mathrm{m}$, ultrasound scale bar $=1 \mathrm{~mm}$. CP, Cheek Pouch. D\&E. Analysis of lymph nodes by HF US. 4-NQO treated mice at 0 and 28 wk were imaged after 8 week 4-NQO treatment and study end point. B6 age-matched (AM) Ctl 0 and 28 wk mice were imaged at the same age as 4-NQO treated mice. The Fasl lymph node data is included for comparison. D. 4-NQO exposure induces increased mandibular lymph node volume. E. 4-NQO exposure increases vascular flow in mandibular nodes. $\mathrm{N}=6$ lymph nodes from 3 mice per group, except for the controls, where $\mathrm{N}=8$ lymph nodes were analyzed from 4 mice. Box and whisker plots show minimum, $25^{\text {th }}$, median, $75^{\text {th }}$ and maximum values, respectively. ${ }^{*}, p \leq 0.05$.

Figure 4. 4-NQO treatment induces paracortical/T-cell zone hyperplasia in mandibular lymph nodes. Representative examples of H\&E stained, dissected mandibular lymph nodes from age-matched (A) control and (B) 4-NQO-treated (28 wk) 
mice. T-cell zone expansions in each node are circumscribed in yellow. Scale bar $=250$ $\mu \mathrm{m}$. C. Distribution of nodal paracortical/T-cell zone hyperplasia. Mandibular lymph nodes were pathologically scored and grouped according to relative scale of T-cell zone involvement, using the following scale: None, absent to focal limited expansion; Modest, multifocal or focal up to moderate expansion; Robust, multifocal moderate expansion and/or confluence of paracortical subregions 


\section{Supplemental Figure Legends}

Figure S1. Visualization of regions within the mouse neck by high-frequency ultrasound. HF US imaging of the mouse oral cavity following placement of an oral gavage needle in mouth to dampen the US signal, aiding with identification of different sections during imaging. Arrows point to area probed with needle, which can be seen in each image blocking ultrasound signal. Scale bar $=1 \mathrm{~mm}$.

Figure S2. 4-NQO exposure induces changes in mouse tongue epithelium similar to human HNSCC and results in cervical lymph node metastasis. A. H\&E and cytokeratin 14 staining of representative mouse tongues: control untreated, after 8 weeks of treatment, and after termination at 19 weeks due to tumor burden as an example to validate the ability of 4-NQO to induce oral tumors. Scale bar $=100 \mu \mathrm{m}$. B. Cytokeratin 14 staining of mouse mandibular node from 4-NQO-treated animal 33 weeks after the end of 4-NQO treatment. Inset demonstrates cytokeratin 14-positive cells indicating epithelial origin, confirming tumor metastasis.

Video S1. Image-guided fine needle biopsy of FasI mouse lymph node.

Video S2. HF US and Power Doppler of age-matched control mouse cervical lymph node. Representative video of 3D scan of control mandibular node using combined Bmode and power Doppler imaging modalities. The red areas within the video represent blood flow.

Video S3. HF US and Power Doppler of 4-NQO-treated (28 wk) mouse cervical lymph node. Representative video of 3D scan of 4-NQO-treated mandibular node using 
combined B-mode and power Doppler imaging modalities. The red areas within the video represent blood flow.

Video S4. HF US and Power Doppler of Fasl mouse cervical lymph node. Representative video of 3D scan of Fasl mandibular node using combined B-mode and power Doppler imaging modalities. The red areas within the video represent blood flow. 

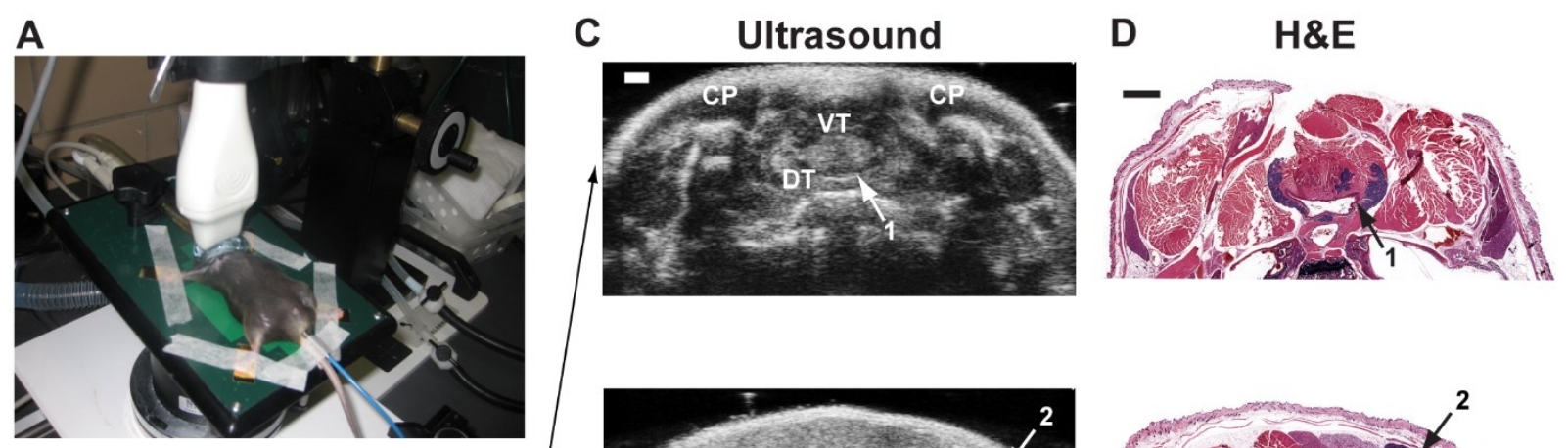

B
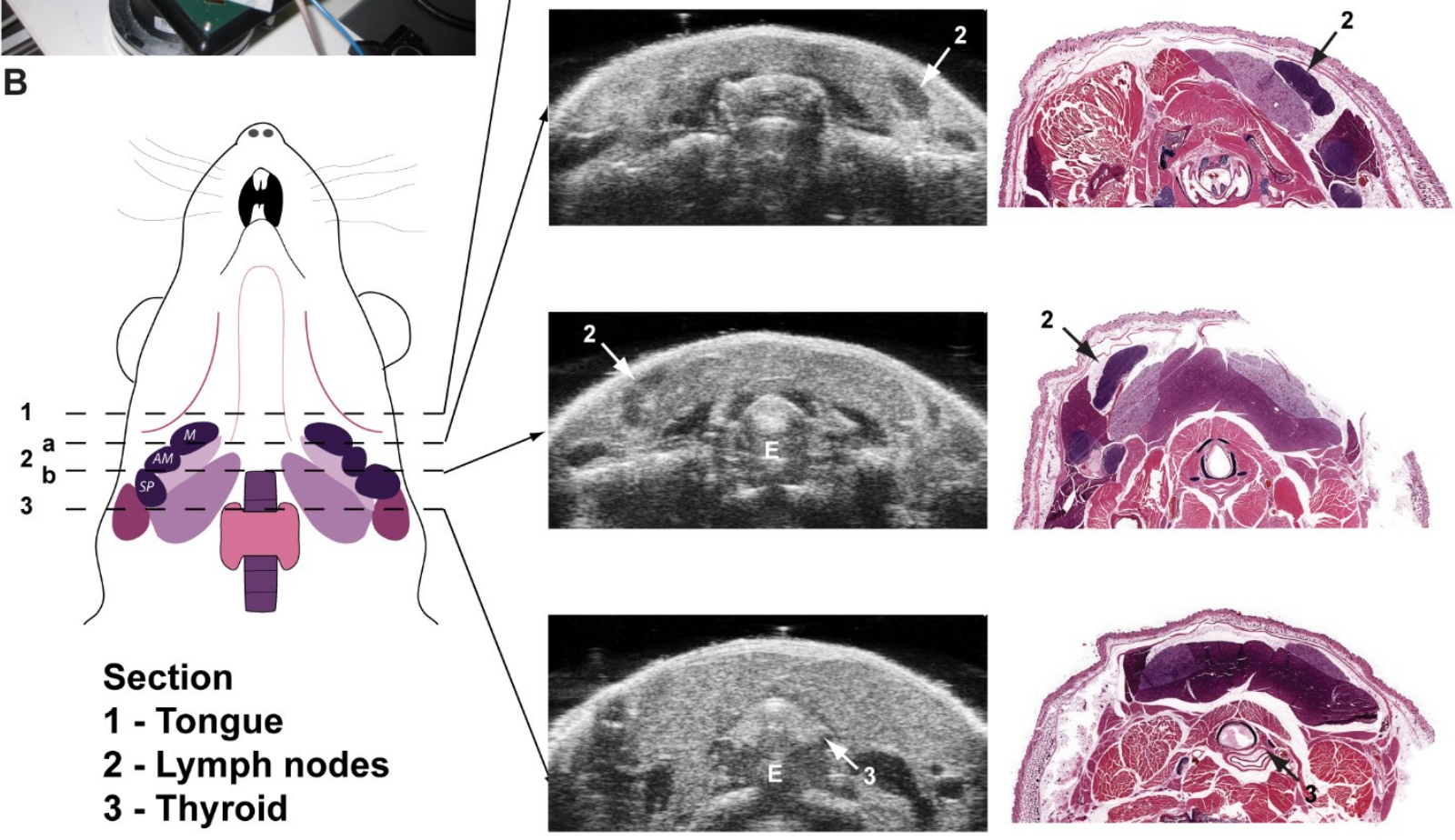

Figure 1 Walk et al. 
A

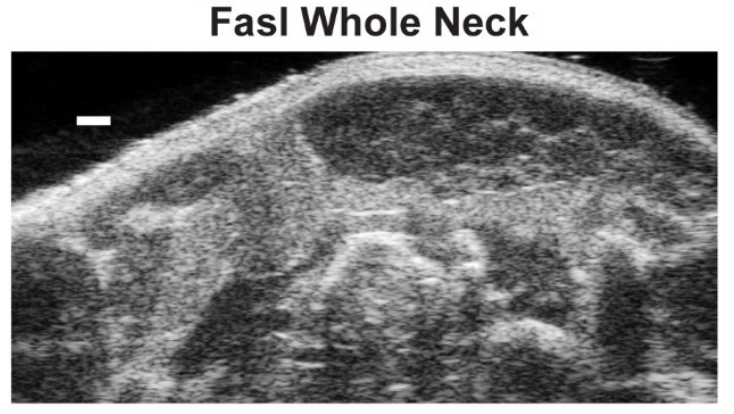

C

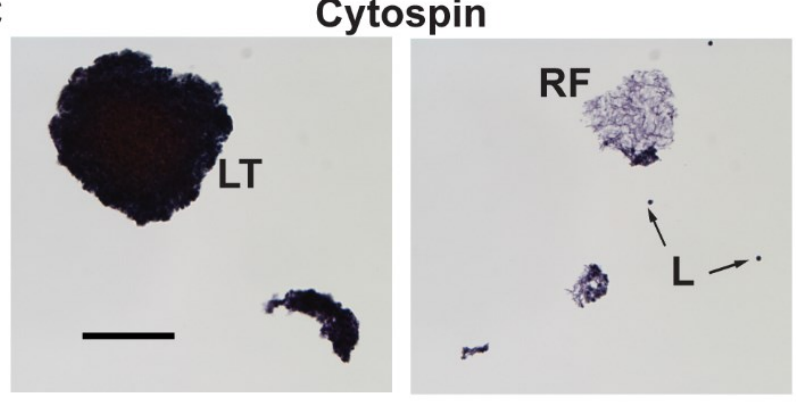

B

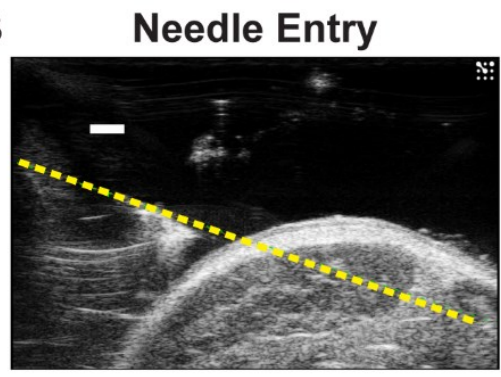

Biopsy

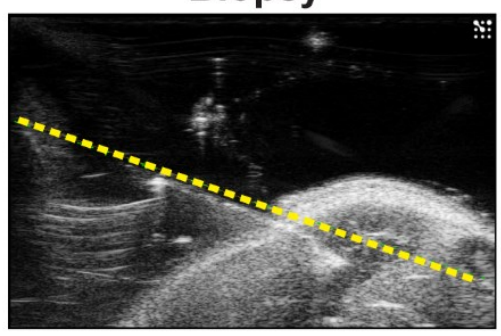

Needle Withdrawal

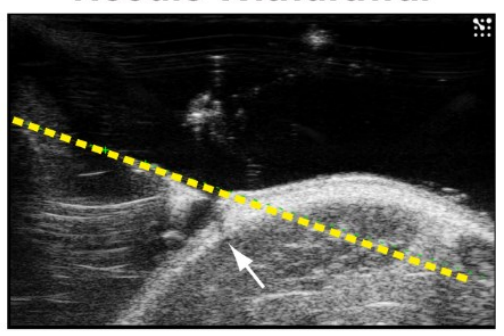

Figure 2 Walk et al. 

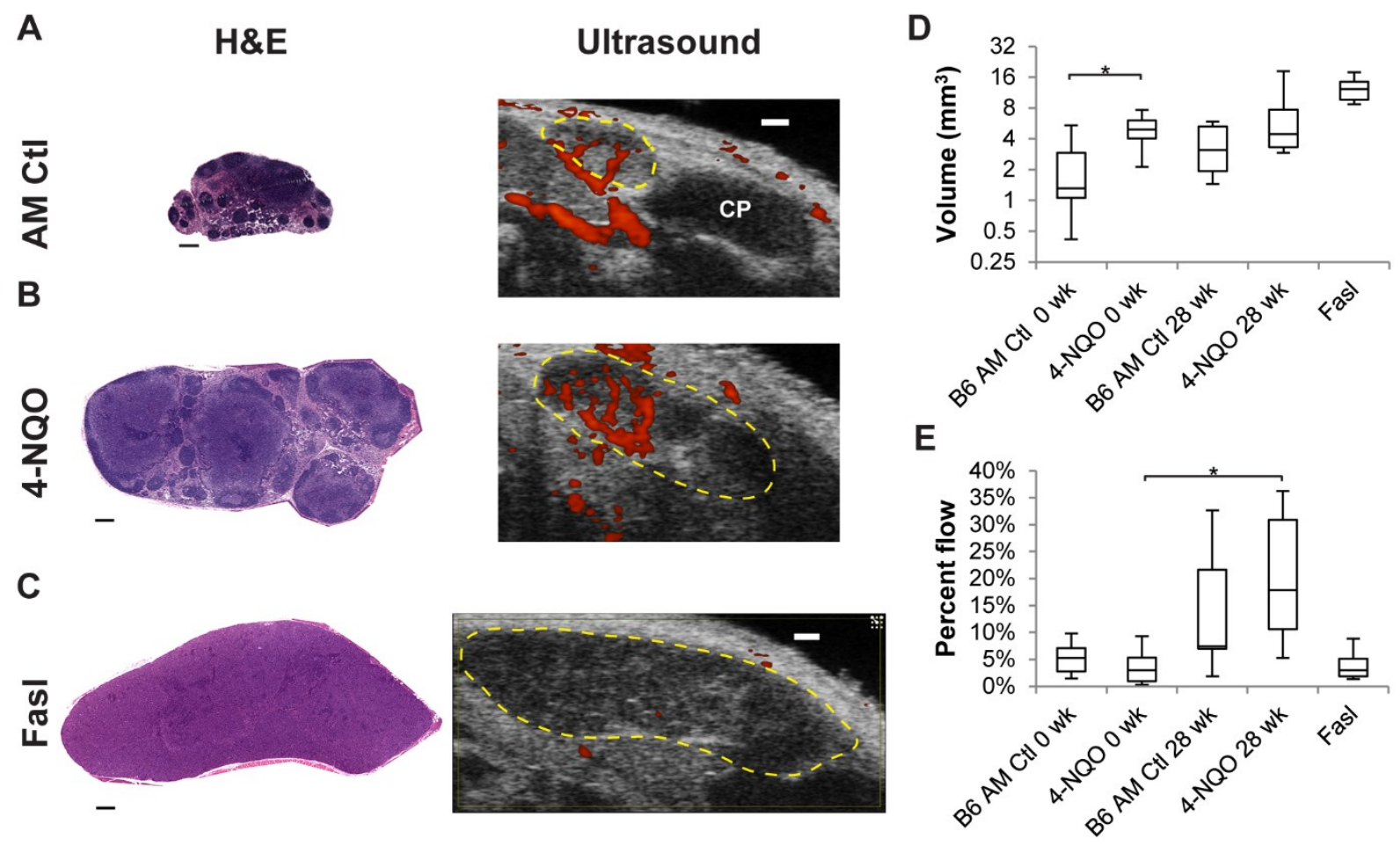

Figure 3 Walk et al.

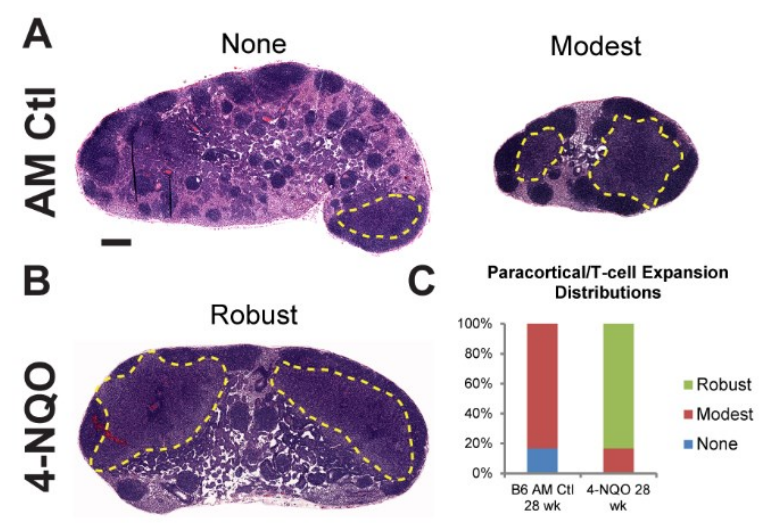

Figure 4 Walk et al. 

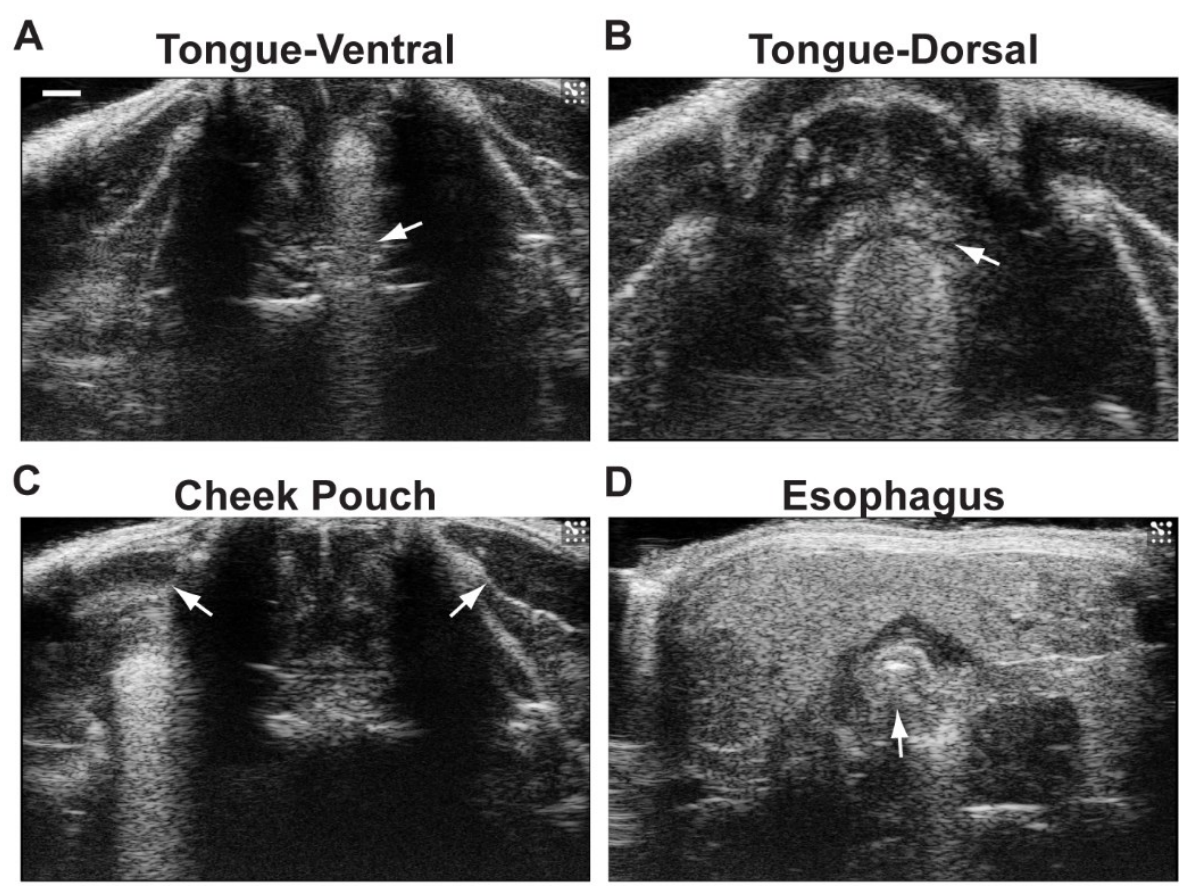

Figure S1 Walk et al. 


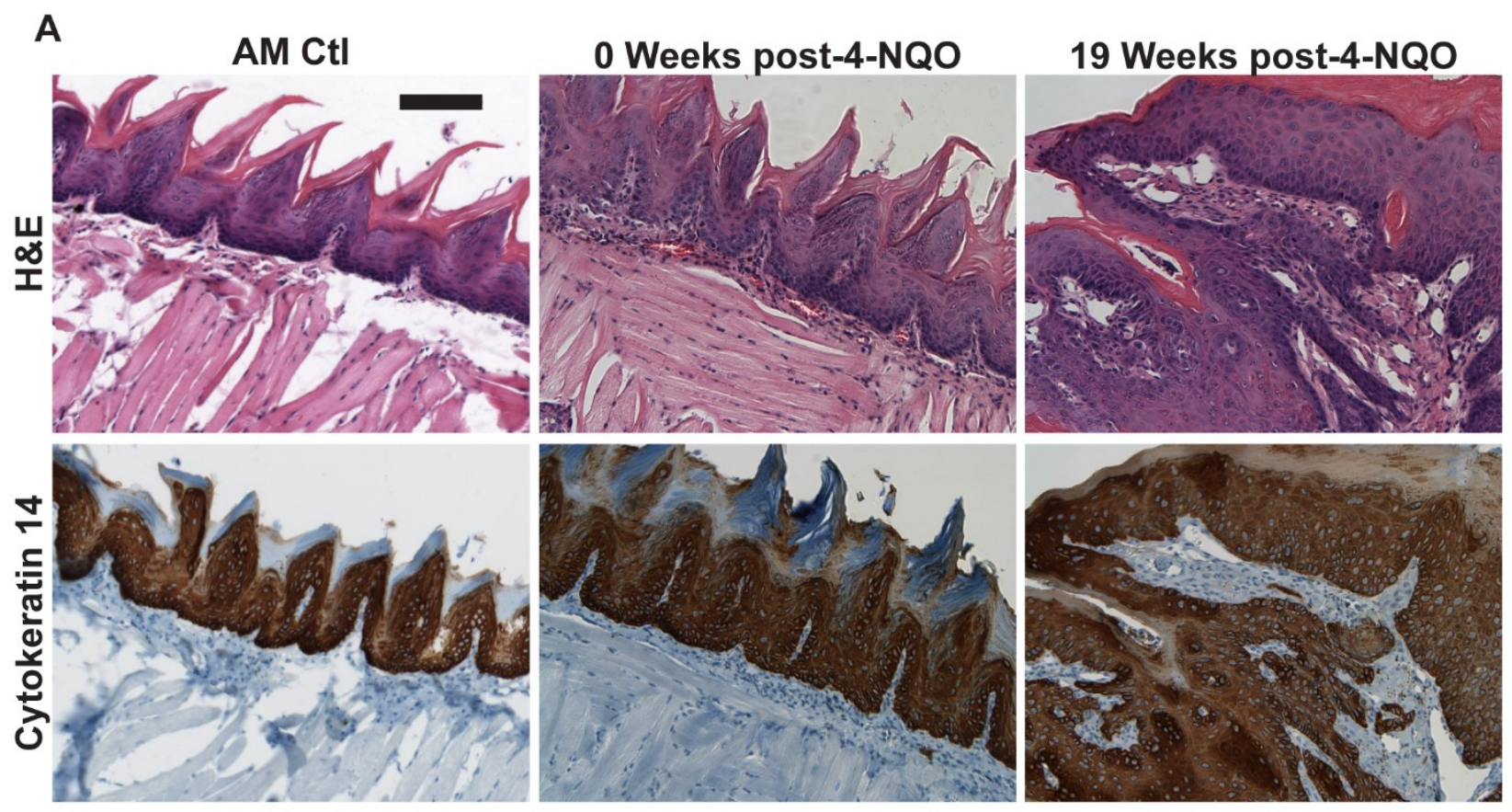

B

\section{Mandibular Lymph Node}
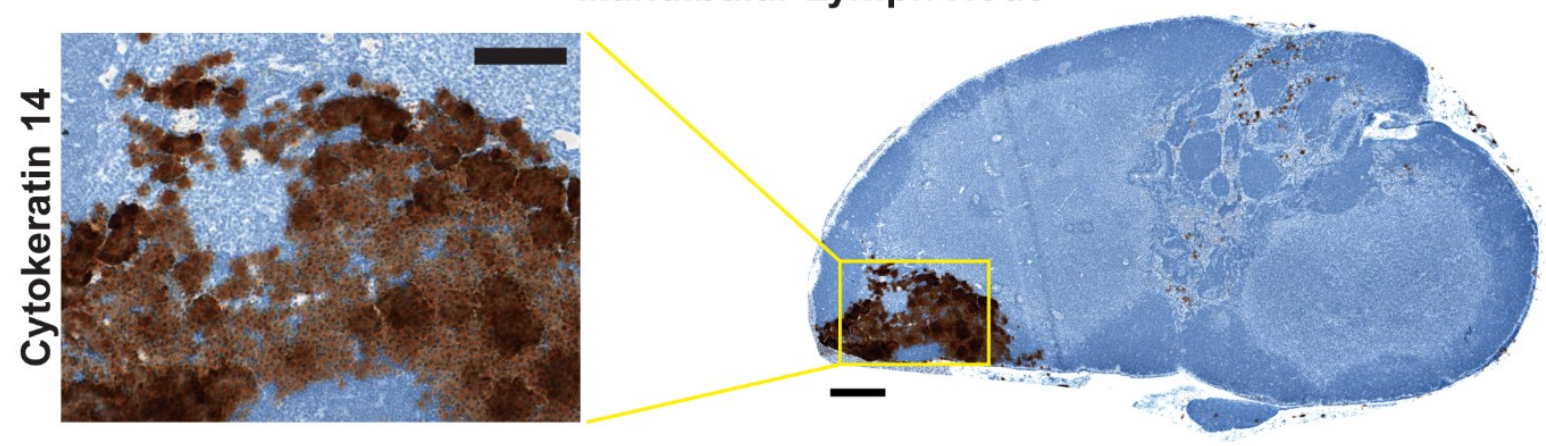

Figure S2 Walk et al. 


\section{GENERAL DISCUSSION}

This dissertation describes studies that use both $2 \mathrm{D} / 3 \mathrm{D}$ in vitro modeling and transgenic mouse models to determine the contributions of different actin binding proteins to HNSCC invasion, and describes efforts to produce more physiologically relevant oral cancer models and techniques for studying HNSCC progression in mice. Collectively, these studies give insight into another potential actin cytoskeleton regulator of HNSCC and shed light on how microenvironment alterations can contribute to tumor development and invasion. Additionally, we present surprising data relating to the role of cortactin during oral tongue cancer invasion, which challenges current dogma that cortactin functions as a driver of HNSCC invasion, highlighting the critical role of the tumor microenvironment in promoting and supporting collective carcinoma invasion.

Traditionally, solid tumors have been viewed as a collection of cells that have accumulated genetic alterations, resulting in defects in growth arrest and the ability to move from the primary site of origin. This has resulted in drug development efforts to focus only on the tumor itself, without taking into consideration the contributions of the surrounding stroma. In recent years, this view has altered, with the realization that not only do the cells comprising the tumor contribute to progression, but the extracellular environment in which the tumor resides also plays a major role in tumor development ${ }^{1}$. The tumor microenvironment is made up of a host of other elements, including fibroblasts, myofibroblasts, smooth muscle cells, endothelial cells, pericytes, mast cells, B and T lymphocytes, natural killer cells, macrophages, dendritic cells and numerous extracellular matrix components ${ }^{2}$. A number of these cell and matrix components have been found to promote carcinogenesis in HNSCC and other cancer types. 
The earliest evidence of microenvironmental influence on tumor progression comes from the inflammation field ${ }^{3}$. Dr. Rudolf Virchow first noted the presence of leukocytes in neoplastic tissue in 1863, and theorized they were the cause of cancer at sites of chronic inflammation ${ }^{3}$. Since then, there is considerable evidence that the innate and adaptive immune systems play a contributing role in many cancer types, including HNSCC. Inflammatory reactions occur prior to the onset of tumor formation, as we describe in Study $3^{4}$, which showed that lymph node enlargement in mice given 4-NQO is due to a paracortical/T-cell zone hyperproliferation prior to tumor onset. The effects of immune cells on tumors is somewhat paradoxical. Anti-tumor immunity is provided by cytotoxic CD8+ T cells and CD4+ Th1 cells activated by type M1 macrophages. M2 macrophages can stimulate differentiation of Th2 and T regulatory cells, responsible for secreting cytokines that suppress CD8+ T cells and CD4+ Th1 cells, as well as promote angiogenesis and stromal reorganization ${ }^{5}$. Indeed, high levels of M2 macrophages have been associated with the metastatic phenotype and decreased survival in patients with oral SCC $\mathrm{SC}^{6}$ In Study 2, we provide evidence that macrophages associate with tongue SCC invasion in mice, based on aggregated cells expressing the macrophage marker CD68 found with invasive tumors and at the tumor invasive front. Additionally, evidence of macrophage stimulation of angiogenesis in HNSCC was shown in a study involving paracrine signaling to macrophages by HNSCC cells ${ }^{7}$. Secretion of monocyte chemotactic protein-1 and TGF- $\beta 1$ by tumor cells resulted in macrophage activation, causing secretion of TNF- $\alpha$ and IL-1. This signals to HNSCC cells to produce IL-8 and VEGF, increasing neovascularization in a rat corneal angiogenesis assay ${ }^{7}$. 
Tumor vascularization is another important factor in driving neoplasia. As described above, stimulation of immune components can lead to secretion of proangiogenic factors such as VEGF. Growing tumors require an adequate blood supply to provide the necessary nutrients and waste removal required for continued proliferation and eventual metastasis. Hypoxia within larger tumor masses triggers cells to release a number of factors that encourage angiogenesis ${ }^{8}$. The primary factors are VEGF/VEGFA, however other proangiogenic factors include fibroblast growth factor (FGF), plateletderived growth factor (PDGF) and EGF ${ }^{8,9}$. VEGF expression has been associated with tumor progression and documented as a predictor of poor outcomes in several HNSCC studies $^{10-13}$. Increased microvessel density within tumors, as measured by markers such as CD31, CD34 or CD105 has also been linked to more aggressive tumors in humans ${ }^{10,14-16}$. Our own results in mice imply a compensatory role for angiogenesis in tumors lacking cortactin, as evidenced by the increased intratumoral CD31 staining (Study 2).

A third increasingly important mediator of invasion in the tumor microenvironment are cancer-associated fibroblasts (CAFs) $)^{9,17}$. Co-culture experiments with mammary carcinoma cells and fibroblasts first showed their impact by demonstrating that senescent or irradiated fibroblasts could stimulate normal mammary cell proliferation and induce tumors in mice ${ }^{18,19}$. 3D organotypic modeling of SCC showed that collective invasion, a common invasion mode utilized by HNSCC, required path generation by CAFs in order to efficiently migrate within the collagen ${ }^{20}$. CAFs are responsible for reorganization of the ECM, through physical engagement and secretion of $\mathrm{MMPs}^{20}$. They can be identified by markers such as $\alpha$-smooth muscle actin (SMA), S100A4, vimentin, MMP2 and PDGFR 
$\alpha / \beta$; however most of these markers are also expressed by other cell types ${ }^{21-23}$. In one study profiling fibroblast gene expression in oral cancer, fibroblasts were found to express $\alpha$-SMA and integrin $\beta 6$, and high levels of these genes correlated to shortened survival rates $^{24}$. Another study found high stromal expression of $\alpha-S M A$ to be the best predictor of decreased survival in OSCC patients ${ }^{25}$. We provide evidence of the contribution of fibroblasts to invasion in a mouse model of oral cancer in Study 2, where we show expression of vimentin between tumor cells and at the invasive front, similar to both MMP14 and CD68 expression. Fibroblasts evolve into cancer-associated fibroblasts as tumor progression occurs, and are known to secrete various cytokines and other growth factors that contribute to invasion ${ }^{26}$. Preclinical models of oral cancer demonstrated enhancement of HNSCC invasion with CAF-conditioned media and in an orthotopic floorof-mouth model ${ }^{27}$. 2D/3D invasion assays provided evidence of CAF-secreted interleukin33 contributing to invasion, through promotion of EMT in HNSCC cell lines ${ }^{28}$.

The cost to bring a new drug to market is substantial, with approximately $90 \%$ of compounds failing to reach FDA (Federal Drug Administration) approval ${ }^{29}$. In fact, when comparing the success rates of oncology drugs from phase I trials to drugs for all other diseases, the likelihood of approval is cut in half for cancer-related therapeutics, with the majority of failures due to lack of efficacy ${ }^{29,30}$. Clearly, in order to develop drugs with a higher chance of success in clinical trials, improved cancer models need to be developed that more accurately reflect human tumors, and which includes allowing for the influence of the tumor microenvironment. 
Mouse models are generally employed to validate the in vitro effects of potential tumor suppressors or promoters in vivo. The simplest way to do this is by using a xenograft transplant, whereby human cancer cell lines are subcutaneously or orthotopically implanted into immunodeficient mice. While xenograft studies have some predictive value ${ }^{31}$, and may be useful for predicting clinical outcomes of cytotoxic drugs, they may not be as informative when investigating the effects of targeted agents, especially those that directly influence the microenvironment. The main issues with xenografts are that they use cell lines, which give only a "snapshot" of a tumor in time, rather than its heterogeneous nature, and that the lack of a complete immune system in nude or NOD/SCID mice leaves out important regulators such at T-cells (nude) or macrophages (NOD/SCID). One way to compensate for the lack of heterogeneity in tumor lines is to use patient-derived xenografts (PDX), which are taken directly from patients and cultured in mice ${ }^{32}$. However, this model still omits a fully functional immune system. The next step in modeling involves the creation of mice harboring genetic alterations that predispose them to cancer. This solves the problem of the incomplete microenvironment, although differences still arise due to variations between mouse and human biology. These models can be engineered to have genetic instability and result in tumors that are much more heterogeneous in nature than cell line xenografts, especially with the addition of carcinogens. Carcinogen-induced tumor models may even be more relevant, as a model for tobacco-related cancers, such as HNSCC and lung cancer or for modeling sunexposure-induced skin cancers.

There are numerous instances of xenograft models failing to predict drug outcomes in humans. One interesting example involves activity of thiazolidinediones 
(TZDs), which bind to the peroxisome proliferator-activated receptor-y (PPARY). These agonists were shown to inhibit growth in colon cancer cells and transplanted tumors ${ }^{33}$; however a phase II study found progressive disease as the best outcome for patients treated with the drug ${ }^{34}$. Testing of this drug using a GEM model confirmed the phase II trial results ${ }^{35}$. A second important example of inconsistencies between preclinical and clinical trials are MMP inhibitors. Broad-spectrum MMP inhibitors were found to reduce metastasis and prevent regrowth in surgically resected mouse mammary tumors ${ }^{36}$, but once moved to the clinic, the results were disappointing ${ }^{36}$. It was later found that different MMPs played different roles during tumor progression, and are more important during early stages; this is not easily tested in humans, who are usually diagnosed and treated at later stages ${ }^{36}$. Additionally, there are a multitude of MMPs expressed by numerous cell types, and they are responsible for more than just degrading matrix ${ }^{37}$. These are just two examples where more rigorous testing in early preclinical models may have avoided the costs involved with late stage drug failures.

As for actin regulatory proteins, how do they fit in as therapeutic targets? Their contributions to cancer cell invasion are largely due to their roles in regulating cell motility and their association with invadopodia. Many studies in multiple cancer types have focused on the tumor cells themselves, relying on 2D, 3D and xenograft models to extrapolate the contributions of these proteins to invasion. While this has been acceptable in the past, it has become apparent, especially from work described in this dissertation, that better models are needed for more accurate determination of their function in humans. There has been substantial evidence for the importance of these 
proteins in vitro and xenograft models ${ }^{38-42}$, including our characterization of a novel function for the actin binding protein coronin 1B (Study 1), but how well does this hold up in GEM models? In Study 2, we describe the first instance of a transgenic model of cortactin knockout during carcinogen-induced tumorigenesis, and we found cortactin to be unnecessary for tongue cancer invasion, despite the extensive studies describing its importance in HNSCC invasion in vitro and in vivo ${ }^{38,43,44}$. The actin bundling protein fascin was found to be dispensable for pancreatic invasion and loss was only responsible for delaying onset in a GEM model ${ }^{45}$, even though its needed for proper invadopodia function ${ }^{42}$. Therefore, it would not be surprising to see future studies that determine other actin binding proteins thought to be critical to cancer invasion end up having little or no impact on tumor invasion as more specific GEM models are tested. Given that the main purpose of actin-binding proteins are to direct cells to interact with the microenvironment, using cancer models without a proper and complete stroma context may be contributing to inaccurate conclusions within the field.

However, the study of actin regulatory proteins as contributors to metastasis is still likely to be highly relevant. There has been little headway made in the production of antimetastatic drugs. Considering metastasis is the main cause of patient death, finding acceptable druggable targets that blunt or ablate metastasis should continue to be a priority. There is increasing evidence that cortactin plays a role in metastatic colonization $^{46-48}$, which is an aspect of metastasis we were unable to study in our own oral cancer model. Similiarly, expression of fascin is associated with vascular invasion in patient pancreatic cancer samples, and is needed for peritoneal metastasis in a mouse model of PDAC ${ }^{45}$. As better cancer models involving metastasis are generated, it will be 
interesting to see how many actin-associated proteins become important targets for prevention of metastasis.

In the future, studies should be designed to take into account tumor heterogeneity, the cell and site of origin, and the many different cellular and matrix components of the microenvironment in order to resolve whether certain proteins are truly important targets in cancer progression. Initial studies in 2D would benefit from further confirmation using genetically engineered and carcinogen-induced tumor models, especially in the case of actin regulatory proteins. The use of GEM models in drug development would allow mice to be treated more like patients, especially once more advanced stage modeling becomes available. Techniques such as those described in Study 3, where HF US is implemented to study lymph node alterations in mice with tongue cancer, will become increasingly useful in such model systems. Combining the use of a metastatic GEM models of cancer, which faithfully recapitulate human disease, with small animal imaging for tracking tumor progression and drug efficacy would create a powerful tool for better drug development and ultimately patient treatment. 


\section{$\underline{\text { References }}$}

1 Jain RK. Normalizing tumor microenvironment to treat cancer: bench to bedside to biomarkers. J Clin Oncol 2013; 31: 2205-18.

2 Koontongkaew S. The tumor microenvironment contribution to development, growth, invasion and metastasis of head and neck squamous cell carcinomas. $J$ Cancer 2013; 4: 66-83.

3 Balkwill F, Mantovani A. Inflammation and cancer: back to Virchow? Lancet 2001; 357: 539-45.

$4 \quad$ Walk EL, McLaughlin S, Coad J, Weed SA. Use of high frequency ultrasound to monitor cervical lymph node alterations in mice. PLoS One 2014; 9: e100185.

5 Duray A, Demoulin S, Hubert P, Delvenne P, Saussez S. Immune suppression in head and neck cancers: a review. Clin Dev Immunol 2010; 2010: 701657.

6 Costa NL, Valadares MC, Souza PPC, Mendonça EF, Oliveira JC, Silva TA et al. Tumor-associated macrophages and the profile of inflammatory cytokines in oral squamous cell carcinoma. Oral Oncol 2013; 49: 216-23.

7 Liss C, Fekete MJ, Hasina R, Lam CD, Lingen MW. Paracrine angiogenic loop between head-and-neck squamous-cell carcinomas and macrophages. Int $J$ Cancer 2001; 93: 781-5.

8 Fang $\mathrm{H}$, Declerck YA. Targeting the tumor microenvironment: from understanding pathways to effective clinical trials. Cancer Res 2013; 73: 4965-4977.

9 Junttila MR, de Sauvage FJ. Influence of tumour micro-environment heterogeneity on therapeutic response. Nature 2013; 501: 346-54.

10 Shao Z, Zhang WF, Chen XM, Shang ZJ. Expression of EphA2 and VEGF in squamous cell carcinoma of the tongue: correlation with the angiogenesis and clinical outcome. Oral Oncol 2008; 44: 1110-1117.

11 J. Eisma R, D. Spiro J, L. Kreutzer D. Vascular endothelial growth factor expression in head and neck squamous cell carcinoma. Am J Surg 1997; 174: 513-517.

12 Gandolfo M, Keszler A, Lanfranchi H, Itoiz ME. Increased subepithelial vascularization and VEGF expression reveal potentially malignant changes in human oral mucosa lesions. Oral Surgery, Oral Med Oral Pathol Oral Radiol Endodontology 2011; 111: 486-493. 
13 Johnstone S, Logan RM. Expression of vascular endothelial growth factor (VEGF) in normal oral mucosa, oral dysplasia and oral squamous cell carcinoma. Int $J$ Oral Maxillofac Surg 2007; 36: 263-6.

14 Martone T, Rosso P, Albera R, Migliaretti G, Fraire F, Pignataro L et al. Prognostic relevance of CD105+ microvessel density in HNSCC patient outcome. Oral Oncol 2005; 41: 147-55.

15 Joo YH, Jung CK, Kim MS, Sun DI. Relationship between vascular endothelial growth factor and Notch1 expression and lymphatic metastasis in tongue cancer. Otolaryngol Head Neck Surg 2009; 140: 512-518.

16 Bolzoni Villaret A, Schreiber A, Facchetti F, Fisogni S, Lonardi S, Lombardi D et al. Immunostaining patterns of CD31 and podoplanin in previously untreated advanced oral/oropharyngeal cancer: prognostic implications. Head Neck 2010; 32: 786-92.

17 Lim YZ, South AP. Tumour-stroma crosstalk in the development of squamous cell carcinoma. Int J Biochem Cell Biol 2014; 53: 450-8.

18 Barcellos-Hoff MH, Ravani SA. Irradiated mammary gland stroma promotes the expression of tumorigenic potential by unirradiated epithelial cells. Cancer Res 2000; 60: 1254-60.

19 Krtolica A, Parrinello S, Lockett S, Desprez PY, Campisi J. Senescent fibroblasts promote epithelial cell growth and tumorigenesis: a link between cancer and aging. Proc Natl Acad Sci U S A 2001; 98: 12072-7.

20 Gaggioli C, Hooper S, Hidalgo-Carcedo C, Grosse R, Marshall JF, Harrington K et al. Fibroblast-led collective invasion of carcinoma cells with differing roles for RhoGTPases in leading and following cells. Nat Cell Biol 2007; 9: 1392-1400.

21 Kalluri R, Zeisberg M. Fibroblasts in cancer. Nat Rev Cancer 2006; 6: 392-401.

22 Liu Y, Hu T, Shen J, Li SF, Lin JW, Zheng XH et al. Separation, cultivation and biological characteristics of oral carcinoma-associated fibroblasts. Oral Dis 2006; 12: $375-80$.

23 Sugimoto $\mathrm{H}$, Mundel TM, Kieran MW, Kalluri R. Identification of fibroblast heterogeneity in the tumor microenvironment. Cancer Biol Ther 2006; 5: 1640-6.

24 Lim KP, Cirillo N, Hassona Y, Wei W, Thurlow JK, Cheong SC et al. Fibroblast gene expression profile reflects the stage of tumour progression in oral squamous cell carcinoma. J Pathol 2011; 223: 459-69. 
25 Marsh D, Suchak K, Moutasim KA, Vallath S, Hopper C, Jerjes W et al. Stromal features are predictive of disease mortality in oral cancer patients. J Pathol 2011; 223: 470-81.

26 Curry JM, Sprandio J, Cognetti D, Luginbuhl A, Bar-ad V, Pribitkin E et al. Tumor microenvironment in head and neck squamous cell carcinoma. Semin Oncol 2014; 41: 217-34.

27 Wheeler SE, Shi H, Lin F, Dasari S, Bednash J, Thorne S et al. Enhancement of head and neck squamous cell carcinoma proliferation, invasion, and metastasis by tumor-associated fibroblasts in preclinical models. Head Neck 2014; 36: 385-92.

28 Johansson A-C, Ansell A, Jerhammar F, Lindh MB, Grénman R, Munck-Wikland E et al. Cancer-associated fibroblasts induce matrix metalloproteinase-mediated cetuximab resistance in head and neck squamous cell carcinoma cells. Mol Cancer Res 2012; 10: 1158-68.

29 Hay M, Thomas DW, Craighead JL, Economides C, Rosenthal J. Clinical development success rates for investigational drugs. Nat Biotechnol 2014; 32: 40 51 .

30 Sharpless NE, Depinho RA. The mighty mouse: genetically engineered mouse models in cancer drug development. Nat Rev Drug Discov 2006; 5: 741-754.

31 Voskoglou-Nomikos T, Pater JL, Seymour L. Clinical predictive value of the in vitro cell line, human xenograft, and mouse allograft preclinical cancer models. Clin Cancer Res 2003; 9: 4227-4239.

32 Tentler JJ, Tan AC, Weekes CD, Jimeno A, Leong S, Pitts TM et al. Patient-derived tumour xenografts as models for oncology drug development. Nat Rev Clin Oncol 2012; 9: 338-50.

33 Sarraf P, Mueller E, Jones D, King FJ, DeAngelo DJ, Partridge JB et al. Differentiation and reversal of malignant changes in colon cancer through PPARgamma. Nat Med 1998; 4: 1046-52.

34 Kulke MH, Demetri GD, Sharpless NE, Ryan DP, Shivdasani R, Clark JS et al. A phase II study of troglitazone, an activator of the PPARgamma receptor, in patients with chemotherapy-resistant metastatic colorectal cancer. Cancer J; 8: 395-9.

35 Saez E, Tontonoz P, Nelson MC, Alvarez JG, Ming UT, Baird SM et al. Activators of the nuclear receptor PPARgamma enhance colon polyp formation. Nat Med 1998; 4: 1058-61.

36 Coussens LM, Fingleton B, Matrisian LM. Matrix metalloproteinase inhibitors and cancer: trials and tribulations. Science 2002; 295: 2387-2392. 
37 Kessenbrock K, Plaks V, Werb Z. Matrix metalloproteinases: regulators of the tumor microenvironment. Cell 2010; 141: 52-67.

38 Artym V V, Zhang Y, Seillier-Moiseiwitsch F, Yamada KM, Mueller SC. Dynamic interactions of cortactin and membrane type 1 matrix metalloproteinase at invadopodia: defining the stages of invadopodia formation and function. Cancer Res 2006; 66: 3034-3043.

39 Blouw B, Seals DF, Pass I, Diaz B, Courtneidge SA. A role for the podosome/invadopodia scaffold protein Tks5 in tumor growth in vivo. Eur J Cell Biol 2008; 87: 555-567.

40 Crowley JL, Smith TC, Fang Z, Takizawa N, Luna EJ. Supervillin reorganizes the actin cytoskeleton and increases invadopodial efficiency. Mol Biol Cell 2009; 20: 948-962.

41 Clark ES, Whigham AS, Yarbrough WG, Weaver AM. Cortactin is an essential regulator of matrix metalloproteinase secretion and extracellular matrix degradation in invadopodia. Cancer Res 2007; 67: 4227-4235.

42 Li A, Dawson JC, Forero-Vargas M, Spence HJ, Yu X, Konig I et al. The actinbundling protein fascin stabilizes actin in invadopodia and potentiates protrusive invasion. Curr Biol 2010; 20: 339-345.

43 Clark ES, Brown B, Whigham AS, Kochaishvili A, Yarbrough WG, Weaver AM. Aggressiveness of HNSCC tumors depends on expression levels of cortactin, a gene in the 11q13 amplicon. Oncogene 2009; 28: 431-444.

44 Patel AS, Schechter GL, Wasilenko WJ, Somers KD. Overexpression of EMS1/cortactin in NIH3T3 fibroblasts causes increased cell motility and invasion in vitro. Oncogene 1998; 16.

45 Li A, Morton JP, Ma Y, Karim SA, Zhou Y, Faller WJ et al. Fascin is regulated by slug, promotes progression of pancreatic cancer in mice, and is associated with patient outcomes. Gastroenterology 2014; 146: 1386-96.e1-17.

46 Li Y, Tondravi M, Liu J, Smith E, Haudenschild CC, Kaczmarek M et al. Cortactin potentiates bone metastasis of breast cancer cells. Cancer Res 2001; 61: 69066911.

47 Leong HS, Robertson AE, Stoletov K, Leith SJ, Chin CA, Chien AE et al. Invadopodia Are Required for Cancer Cell Extravasation and Are a Therapeutic Target for Metastasis. Cell Rep 2014; 8: 1558-1570. 
48 Tokui N, Yoneyama MS, Hatakeyama S, Yamamoto H, Koie T, Saitoh H et al. Extravasation during bladder cancer metastasis requires cortactin-mediated invadopodia formation. Mol Med Rep 2014; 9: 1142-1146.

49 Walk EL, Weed SA. Recently identified biomarkers that promote lymph node metastasis in head and neck squamous cell carcinoma. Cancers (Basel) 2011; 3: 747-772. 
Appendix 
Review

cancers issN 2072-6694

www.mdpi.com/journal/cancers

\title{
Recently Identified Biomarkers That Promote Lymph Node Metastasis in Head and Neck Squamous Cell Carcinoma
}

\section{Elyse L. Walk and Scott A. Weed *}

Department of Neurobiology and Anatomy, Program in Cancer Cell Biology, Mary Babb Randolph Cancer Center, West Virginia University, Morgantown, WV 26506, USA; E-

Mail: ewalk@hsc.wvu.edu

* Author to whom correspondence should be addressed; E-Mail: sweed@hsc.wvu.edu; Tel.: +1-304-293-3016; Fax: +1-304-293-4667.

Received: 10 January 2011; in revised form: 9 February 2011 / Accepted: 17 February 2011 /

Published: 22 February 2011

\begin{abstract}
Head and neck squamous cell carcinoma (HNSCC) is a heterogeneous cancer that arises in the upper aerodigestive tract. Despite advances in knowledge and treatment of this disease, the five-year survival rate after diagnosis of advanced (stage 3 and 4) HNSCC remains approximately $50 \%$. One reason for the large degree of mortality associated with late stage HNSCC is the intrinsic ability of tumor cells to undergo locoregional invasion. Lymph nodes in the cervical region are the primary sites of metastasis for HNSCC, occurring before the formation of distant metastases. The presence of lymph node metastases is strongly associated with poor patient outcome, resulting in increased consideration being given to the development and implementation of anti-invasive strategies. In this review, we focus on select proteins that have been recently identified as promoters of lymph node metastasis in HNSCC. The discussed proteins are involved in a wide range of critical cellular functions, and offer a more comprehensive understanding of the factors involved in HNSCC metastasis while additionally providing increased options for consideration in the design of future therapeutic intervention strategies.
\end{abstract}

Keywords: head and neck cancer; lymph node; invasion; metastasis; biomarker 


\section{Introduction}

The main cause of cancer-related death is due to metastasis of primary tumors to secondary sites within the body. Advanced cases of head and neck squamous carcinoma (HNSCC) primarily spread locoregionally, where tumor cells infiltrate the lymphatic drainage and travel into cervical lymph nodes [1]. While incidence rates and overall disease-related deaths have dropped over recent years [2], the five-year survival rate for patients presenting with clinically advanced disease remains around 55\% [3]. Predicting the inherent metastatic potential of primary HNSCC tumors would serve to aid in enhancing approaches to treatment that would improve patient management. However, current diagnosing strategies rely in part on histological analyses of biopsy samples, which have largely proven inadequate due to the high frequency of patients with recurrent disease [4]. The presence of lymph node metastasis in HNSCC patients has long been established as a poor prognostic indicator [5-7], making earlier detection of tumors with the propensity to invade and spread through local lymphatics an important step in patient management towards a more promising outcome. The stepwise model of carcinoma progression involves changes at the molecular level that ultimately provide normal epithelia cells with the ability to invade surrounding tissue [8]. In HNSCC, efforts at identifying molecules associated with and responsible for driving nodal metastasis has revealed many potential biomarkers for this process over the past decade [4,9-11]. Some of the more notable markers associated with nodal metastasis are cell cycle and proliferation regulators such as p53, epidermal growth factor receptor (EGFR), p16, and cyclin D1. The roles of these proteins in HNSCC development and progression are well documented [4,11-13,13]. More recently, expression profiling through DNA microarray technology has been useful in identifying genes previously unrecognized in the field that also contribute to or are associated with lymph node metastasis [14-16]. In this review, we focus on various studies conducted within the past four years that have linked overexpression of specific proteins in HNSCC to lymph node metastasis, highlighting several new potential candidates (Table 1) that could prove useful in the prediction, detection and treatment determination of metastatic disease.

\section{Proteins Involved in Cell Cycle Regulation, Proliferation and Apoptosis}

Regulation of the cell cycle requires the coordination of many protein classes, creating a system of checks and balances that when dysregulated results in either cell proliferation or death. Mutations or altered expression of proteins important for proper governing of cell cycle initiation and coordination can set the system off balance, providing tumor cells with means to bypass normal cell cycle check points, evade apoptosis and over-proliferate. Several proteins involved in cell cycle regulation have recently been identified as markers with increased expression in HNSCC that correspond with lymph node metastasis. 
Table 1. Recently identified biomarkers involved in lymph node metastasis.

\begin{tabular}{|l|l|l|}
\hline Biomarker & \multicolumn{1}{|c|}{ Cellular Function } & Relevant References \\
\hline c-Met & Proliferation & {$[23]$} \\
\hline CEP55 & Cell cycle regulation, cytokinesis & {$[39,40]$} \\
\hline NBS1 & Cell cycle regulation, DNA double-strand break repair & {$[43,45]$} \\
\hline Survivin & Inhibitor of apoptosis & {$[51,55,61]$} \\
\hline RSK2 & Cell cycle regulation, proliferation, apoptosis & {$[65]$} \\
\hline Cortactin & Cell motility and invasion & {$[74-76,79]$} \\
\hline CD44 & Cell-cell and cell-matrix adhesions & {$[81-83]$} \\
\hline MMP-9 & ECM degradation & {$[81,88]$} \\
\hline MT1-MMP & ECM degradation & {$[90]$} \\
\hline CXCR4 & SDF-1 chemokine receptor, chemoattraction & {$[98-101]$} \\
\hline CCR7 & Chemokine receptor, chemoattraction & {$[100,101,103]$} \\
\hline VEGF/R & Angiogenesis & {$[110,115,117,119]$} \\
\hline NFkB & Proinflammatory TF & {$[126,127]$} \\
\hline Twist & TF, regulator of EMT & {$[101,138]$} \\
\hline Snail & TF, regulator of EMT & {$[138,141,142]$} \\
\hline Hif-1 $\alpha$ & TF, hypoxia & {$[138,146]$} \\
\hline p21 ${ }^{\text {WAF1/Cip1 }}$ & Cell cycle regulation, proliferation, apoptosis & {$[154,155]$} \\
\hline $\begin{array}{l}\text { MMP: matrix metalloproteinase; ECM: extracellular matrix; TF: } \\
\text { transcription factor; EMT: epithelial-mesenchymal transition. }\end{array}$ & \\
\hline
\end{tabular}

\section{1. $\mathrm{c}-\mathrm{Met}$}

The receptor tyrosine kinase c-Met is normally active during embryonic development and wound healing [17]. Activated c-Met promotes cellular proliferation by organizing an "invasive growth" program by which normal cells migrate to new sites to form polarized cells and functional 3D structures. [18]. The ligand for c-Met is hepatocyte growth factor (HGF). HGF is secreted by mesenchymal cells and upon binding to c-Met causes receptor homodimerization and phosphorylation/activation of the catalytic site, resulting in downstream signaling events that lead to cell transformation and invasion [17,19]. Expression of c-Met on epithelial cells enables them to receive signals from surrounding stromal cells through stromal cell HGF secretion. In transformed cells, c-Met activity is enhanced through several mechanisms, including increased ligand-based stimulation via elevated autocrine or paracrine HGF secretion, receptor overexpression or mutational activation of the c-Met kinase domain [17,19]. One notable function of c-Met is its interaction with the oncogenic tyrosine kinase c-Src, creating a 
mechanism to bypass inhibited EGFR signaling in breast cancer cell lines [20] as well as increasing resistance to c-Src inhibitory drugs in HNSCC [21]. Both c-Src and EGFR are overexpressed in HNSCC and are important in head and neck cancer development and progression [22]. A retrospective analysis of 61 surgically treated cases of HNSCC showed frequent expression of c-Met in tumors with higher T-stage classification [23]. Patients with lymph node metastasis have a significant increase in c-Met expression when compared with indolent cases

lacking metastasis. While HGF was found at elevated levels in over $60 \%$ of the cases, it was not a significant factor in this study; however when combined with c-Met overexpression there was a correlation with lymph node metastasis. Being a paracrine factor secreted by cells of mesenchymal origin, HGF may be more relevant as a serum biomarker, as shown in previous studies [24-26]. In these prospective studies, serum cytokine levels were measured in patients before and after treatment. High levels of serum HGF were found in patients before treatment, decreased after treatment, and were found to increase again with recurrence. These results suggest monitoring HGF levels may prove useful in determining response to treatment and recurrence. The HGF/c-Met pathway has been implicated in invasion and metastasis in HNSCC and other cancers, both in vitro and in vivo [27-31] and has been linked to resistance of EGFR inhibitors and cisplatin [20,32-35], making both c-Met and HGF attractive drug targets as well as determinants of treatment. Currently there are several clinical trials involving drugs that target c-Met or HGF specifically, although these trials have not gone past phase I/II [36].

\subsection{CEP55 (FLJ10540)}

The cytokinesis regulator CEP55, also known as FLJ10540, is a $55 \mathrm{kDa}$ protein that localizes to the centrosome of chromosomes in interphase and the midbody during cytokinesis, where it mediates the final stages of mitotic division into two daughter cells [37]. CEP55 is a recently identified downstream target of the oncogene FOXM1, which has been shown to be upregulated in pre-malignant HNSCC lesions [38]. Subsequently, CEP55 overexpression has been directly correlated with an increase in tumor aggressiveness in oral squamous cell carcinoma (OSCC) [39]. Retrospective immunohistochemistry (IHC) analysis revealed overexpression in patient tumor samples, which was linked to tumor and nodal stage as well as a poor prognosis [39]. There was also significantly higher expression in patients with advanced $\mathrm{T}$ stage ( 3 and 4) with lymph node metastasis when compared with node negative and stage 1-2 tumors. In vitro work has linked CEP55 expression to increased cell motility and invasion through regulation of FOXM1 and MMP-2 [39]. In another report, while CEP55 was shown to be significantly upregulated in dysplasias and HNSCC, upregulation within lymph node metastases was not significant, which the authors cite as being due to tissue heterogeneity [40]. Taken together, 
these results suggest CEP55 may prove useful in predicting disease progression. As cytokinesis is of obvious importance to highly proliferative cells, overexpression of CEP55 is therefore a logical candidate for potential use as an HNSCC metastatic biomarker in clinical settings.

\subsection{NBS1}

Nijmegen breakage syndrome (NBS) is a syndrome characterized by growth retardation, immunodeficiencies and predisposition to malignancies [41]. The only gene associated with this syndrome is NBS1, and its gene product plays an important cell cycle checkpoint role in double strand DNA break repair [41]. NBS1 is part of a complex including Mre11 and Rad5 (MRN complex) that is central to detection of DNA breakage, coordinating response programs for and catalyzing repair mechanisms of double-strand breaks [42]. A study analyzing OSCC samples revealed an increase in NBS1 mRNA expression that correlated to increased protein expression [43]. NBS1 overexpression was associated with advanced disease and recurrence/metastasis in OSCC, while non-oral HNSCC

samples with the same levels of expression were only associated with recurrence. An increase in NBS1 expression in HNSCC regardless of origin site was additionally associated with lymph node involvement [43]. In this same study, NBS1 was found to be a prognostic marker even with samples divided into subgroups based on tumor and nodal stage or treatment type. Earlier studies by the authors had linked NBS1 overexpression to more aggressive disease and worse prognosis in advanced HNSCC [44], and to lymph node and distant metastasis [45]. These studies also determined NBS1 expression to be involved in cellular transformation through activation of the PI3K/Akt pathway and induction of EMT [44,45]. One explanation for this association could be due to single nucleotide polymorphisms (SNPs) within the NBS1 gene. Several studies have linked genetic variations to development of cancers of the breast, lung, esophagus, non-Hodgkin's lymphoma and upper aerodigestive tract [46-48]. Identifying high risk patients through detection of NBS1 SNPs may be a useful tool in predicting patient outcome in OSCC and other HNSCC subtypes.

\subsection{Survivin}

An inhibitor of apoptosis (IAP) family member, survivin, suppresses apoptosis by directly binding to and inhibiting caspase family members, typically caspase 3 and caspase 7 , or by indirectly suppressing apoptosis through activation of caspase-associated cofactors [49,50]. Survivin overexpression has been identified in different cancer types, suggesting it may be a tumor marker and possible drug target [49,50]. There have been multiple studies linking survivin expression to HNSCC progression in recent years. In a retrospective study of 42 OSCC cases, individuals with lymph node metastasis had significantly high survivin expression compared to 
non-metastatic cases [51]. A correlation between expression and low survival rate was also concluded in this study. A significantly higher expression of survivin was found in another study of OSCC cases [52]. Premalignant lesions were also included, and survivin expression was elevated in these regions when compared to normal tissue. Survivin has been found to play different roles depending on location within the cell [49]. In the nucleus, survivin controls cell division by functioning as a subunit of the chromosomal passenger complex (CPC), while cytoplasmic survivin is cytoprotective, providing the cell with protection from cell death induced by radiation or chemotherapeutic drugs [53]. An examination of normal and HNSCC tissues by IHC showed nuclear and cytoplasmic staining, both which were significantly correlated to poor differentiation and lymph node metastasis [54]. There have been several other studies that investigated the prognostic role of cytoplasmic and nuclear survivin. Although no general consensus was found based on subcellular location, survivin expression has consistently been linked to unfavorable outcome and reduced disease-free survival. [55-57]. The anti-apoptotic effects of survivin may be linked to treatment failure as some in vitro studies have suggested [58-60]. In one particular model, HNSCC cells that escaped cellular senescence after treatment with the chemotherapeutic drug camptothecin were unable to escape senescence upon knockdown of survivin [61]. Another retrospective study analyzed OSCC cases and correlated survivin mRNA expression to tumor differentiation, stage and lymph node involvement. This study also found that down-regulation of survivin increased sensitivity of HNSCC cells to cisplatin [62]. While more studies are needed to firmly link survivin overexpression to lymph node metastasis, its role as a prognostic and drug resistance marker warrants further investigation as a potential therapeutic target.

\subsection{RSK2}

p90 ribosomal S6 kinase 2 (RSK2) is a serine/threonine kinase activated downstream in the MAPK pathway $[63,64]$. Numerous substrates have been identified for RSK2, including GSK3 $\beta$, c-Fos, p2 $7^{\mathrm{kip} 1}$, e1F4B, and p65, a subunit of NF- $\mathrm{BB}$. These substrates link RSK2 activity in mediating pathways central to cell proliferation, transcriptional and translational regulation, survival and apoptosis [63,64]. Retrospective IHC analysis has identified RSK2 overexpression in HNSCC tumor and lymph node patient samples [65]. Primary tumors from patients with lymph node metastases and matched lymph node specimens had a significantly higher expression of RSK2 than patients with non-metastatic primary HNSCC. Manipulation of RSK2 levels by RNA interference demonstrates a clear dependence of RSK2 expression levels in modulating invasion in Matrigel transwell assays. Similar results were obtained in a xenograft mouse model, where cells with stable knockdown of RSK2 had less metastatic potential than controls [65]. Previous in vitro work identified RSK2 as a critical regulator in cellular transformation [66] and though not extensively studied in head and neck cancer, the versatility of RSK2 makes it a worthwhile target for additional investigation. Multiple small 
molecule inhibitors specific to RSK family members have been identified [67] that may serve as viable platforms for further development of potential targeted anti-RSK2 therapeutic compounds.

\section{Cell Motility, Adhesion and Extracellular Matrix Degradation}

Without the ability to modify their surroundings and move to new areas, tumor cells would remain in their primary location, making them more manageable by conventional surgical and radiation-based treatment regimes. Overexpression of proteins involved in cell motility and extracellular matrix remodeling equips primary HNSCC cells with the ability to degrade and escape an encapsulating extracellular matrix and penetrate through the surrounding stroma, ultimately resulting in lymphatic intravasation and spread into regional lymph nodes.

\subsection{Cortactin}

Cortactin is an actin binding protein that plays roles in cell motility and invasion by promoting Arp $2 / 3$ complex actin nucleation and by stabilizing the newly formed actin branchpoints [68]. Located at chromosomal region 11q13, an area frequently amplified in HNSCC, cortactin has consistently been associated with more aggressive and invasive tumors, lymph node metastasis and poor clinical outcome in HNSCC [69-73]. Yamada et al. analyzed a series of OSCC patient biopsy samples, finding overexpression of cortactin more often in OSCC than in normal epithelium, as well as localization of cortactin at the invasive front [74]. Cortactin overexpression was also found more frequently in tumors with high $\mathrm{T}$ and $\mathrm{N}$ classification and significantly correlated to regional invasion in these patients [74]. A separate study looked at the relationship between CTTN gene amplification status, mRNA and protein expression in patients with pharyngeal or laryngeal SCC [75]. This study found that gene amplification correlated significantly to mRNA and protein expression, with cases containing strong cortactin staining significantly associated with lymph node metastasis. This group conducted an analysis of CTTN gene amplification, comparing amplification within epithelial hyperplastic/dysplastic lesions and high-grade dysplasias/carcinoma in situ, to determine timing of amplification. Consistent with studies of 11q13 gene amplification being a later stage event [4], CTTN was only detected in the higher grade lesions [75]. Cortactin expression was also studied along with EGFR status in a series of HNSCC samples of different origins [76]. Cortactin overexpression correlated to higher TNM stage, histologic grade and was associated with decreased overall survival and increased local recurrence. However, patients that had both cortactin and EGFR overexpression did not have a different survival rate than those with cortactin only. This is surprising due to evidence that cortactin overexpression contributes to sustained EGFR surface expression by preventing ligand-mediated receptor downregulation [77] suggesting cortactin overexpression can be uncoupled from EGFR as 
reported in a subsequent study [78]. Cortactin overexpression in HNSCC does enhance c-Met surface expression, providing an additional mechanism for sustained c-Met signaling [77]. Another study focusing on laryngeal SCC found cortactin expression to be linked to both lymph node and distant metastases, and was identified as a predictor of poor prognosis in this HNSCC subtype [79]. The collective results from these recent studies strongly indicate that cortactin gene amplification and/or protein overexpression increases HNSCC aggressiveness. Although a late stage player in HNSCC progression, monitoring cortactin expression in HNSCC may also be useful in predicting invasive carcinoma and tumor recurrence.

\section{2. $C D 44$}

Cell adhesion molecules (CAMs) are necessary for cell-cell or cell-extracellular matrix (ECM) contacts. The transmembrane glycoprotein CD44 is a CAM that binds hyaluronan (HA), a glycosaminoglycan component of the ECM and the primary ligand for CD44. The CD44 protein family consists of various isoforms that are the result of alternative splicing of exons 614 [80]. CD44 variants are often overexpressed in different cancer types, with overexpression correlating to poor patient outcome [80]. Standard CD44 (CD44s) and three variants, v3, v6 and v10, are overexpressed in HNSCC [81]. CD44s was overexpressed at a higher frequency in supraglottic laryngeal carcinomas of patients that were lymph node positive, although no significant differences were found between tumor stages and differentiation and CD44 expression [82]. The CD44 variants v3, v6 and v10 were identified in HNSCC samples from the oral cavity, oropharynx or larynx, with strong staining by IHC in both primary and lymph node metastases [81]. CD44 v3 and v6 were both associated with advanced T stage, while a strong v3 expression within primary tumors was related to lymph node metastasis and v10 expression related to distant metastases [81]. The same study also found CD44 mediated sensitivity to cisplatin in vitro and CD44 knockdown increased HNSCC cell death. Another interesting study analyzed blood for CD44 mRNA from patients with advanced HNSCC who had been treated with chemotherapy and radiotherapy to determine if there the presence of CD44 mRNA correlated with prognosis during the patient follow up period [83]. Quantitative RT-PCR detected mRNA in peripheral blood from patients and healthy volunteers, and elevated levels of CD44 mRNA in HNSCC patients correlated with the degree of lymph node involvement and recurrence. IHC analysis of tumor samples confirmed CD44 protein expression for all patients. These studies suggest a role for CD44 and specific splice variant isoforms in the regional and distant spread of HNSCC, with evidence for pre-treatment screening of CD44 being beneficial to determining prognosis and drug response. 


\subsection{Matrix Metalloproteinases}

Invasion and metastasis of tumor cells requires proteolysis of the basement membrane and surrounding ECM. Matrix metalloproteinases (MMPs) provide cells with a mechanism to modulate the microenvironment through the breakdown of ECM molecules present in basement membranes and stroma [84]. Twenty three different MMPs are expressed in humans, with MMP-9 and MMP-14 (MT1-MMP) accepted as playing critical roles in HNSCC invasion and metastasis. MMP-9 is a secreted proteinase that utilizes CD44 as a docking site, allowing for its retention on the cell surface $[84,85]$. CD44s expression in supraglottic laryngeal carcinoma samples correlates with MMP-9 expression in lymph node positive patients [82]. Similar results were obtained in a second study of OSCC, linking MMP-9 expression to lymph node metastasis [86]. Expression of MMP-9 was also found to co-localize to the invasive front with CD44 of HNSCC patient samples, while normal mucosa showed little to no MMP-9 labeling [87]. A prospective study investigated whether serum MMP-9 levels of 161 patients with OSCC could be correlated to clinicopathological parameters [88]. Pre-treatment serum MMP-9 levels correlated to clinical stage and were also significantly higher in patients with lymph node metastasis, while a significant decrease in levels was seen after surgery. Presurgery levels of MMP-9 in patients who died during the study were found to be significantly higher than those who survived, linking serum MMP-9 to patient outcome [88]. The results of this study are comparable to an earlier study from 2005, which also investigated serum levels of MMP-9 in HNSCC patients before surgery [89]. Transmembrane MMPs are also important for the activation of secreted MMPs through the cleavage of secreted MMP proforms to generate a functional extracellular enzyme. Studies on supraglottic HNSCC patients demonstrate increased MT1-MMP expression compared to normal tissue. In this study, the level of MT1-MMP overexpression correlated to the depth of invasion, presence of lymph node metastasis and advanced clinical stage [90]. Patients with high MT1-MMP expression also had a poor prognosis. Interestingly, cortactin overexpression has been reported to enhance MMP-9 secretion and promote MT1-MMP surface expression in HNSCC cell lines, resulting in enhanced ECM degradation at plasma membrane structures known as invadopodia [91,92]. The pro-invasive function of combined MMP activity in HNSCC and other tumor types makes them useful as prognostic markers as well as attractive and important therapeutic targets. Despite previous failed attempts at targeted drug therapy [93,94], development of new generation MMP inhibitors is being pursued, where improved drug and trial design may yet result in the production of selective and effective antiinvasive drugs [94].

\section{Tumor Microenvironment and Angiogenesis}


HNSCC and other tumor types frequently exploit signals generated from cellular and noncellular ECM components to promote tumor growth and dissemination. The process of new blood vessel formation (angiogenesis) is initiated in order to provide tumors with the means to supply nutrients to facilitate their growth, as well providing avenues for eventual metastasis through the vascular system.

\subsection{Chemokines}

Chemokines are small peptides that upon receptor binding act as chemoattractants, homing leukocytes to areas of inflammation [95,96]. Their roles in cell trafficking and angiogenesis help promote tumor growth, as evidenced by their overexpression in several different human cancers. The receptor CXCR4 and its ligand CXCL12 (also called SDF-1) is one chemokine pathway exploited by metastatic HNSCC [97]. A retrospective analysis by IHC of 30 patients with laryngeal and hypopharyngeal SCC showed a significant increase in CXCR4 expression in patients with positive lymph node and distant metastases compared to patients lacking metastatic disease [98]. This study also looked at CXCL12 expression and while higher in patients with metastasis, it was not statistically significant. Two other studies assessing the prognostic value of CXCR4 in OSCC also drew similar conclusions, finding a significant association of expression with lymph node metastasis $[86,99]$. One study examined expression of CXCR4 and another chemokine receptor, CCR7, which has been shown to activate the PI3K/Akt pathway in HNSCC, a pathway involved in cell growth, differentiation and survival [100]. Both chemokines were expressed at significantly higher levels in those patients with positive lymph node involvement compared with lymph node negative cases [100]. One notable difference was that CCR7 expression correlated to cases with advanced tumor stage, while CXCR4 was significantly higher in patients with distant metastases. A similar study also significantly associated CCR7 expression with lymph node metastasis, while CXCR4 expression was associated but not statistically significant [101]. CCR7 also positively associated with lymph node metastasis in patients with tonsillar SCC [102] and OSCC [103]. The influence of autocrine/paracrine activation of CCR7 was examined in another retrospective study of HNSCC and found higher mRNA expression of CCR7 and its ligands CCL19 and CCL21 in metastatic lymph nodes [104]. This study further concluded from additional in vitro and orthotopic mouse model studies that blockage of CCR7 impaired tumor cell proliferation and decreased resistance to cisplatin-induced apoptosis. The impact of chemokines and their receptors on HNSCC may be explained in part by their influence on MMPs [95,105]. CXCR4 increased HNSCC cellular invasion in vitro by upregulating expression of MMP-9 and MMP-13 [98,106]. High CXCR4 levels also correlate with high MMP-9 in OSCC patient samples [86]. CCR7 is typically involved in directing dendritic cells to peripheral lymph nodes [105]. The frequent expression of CCR7 in HNSCC and association with lymph node metastasis suggests that CCR7 
expression provides tumor cells with a mechanism for direct lymph node infiltration [95,96,107,108]. These results suggest overlapping roles for chemokine receptors in HNSCC progression to metastatic disease, a consideration that may need to be taken into account for any future therapeutic targeting strategies.

\section{2. $V E G F / R$}

Vascular endothelial growth factor (VEGF) is a cytokine expressed by tumors that plays a key role in angiogenesis. VEGF performs its function through binding to one of the VEGF receptor family members, with VEGFR2 serving as the major receptor subtype in several different neoplasms [109]. The importance of VEGF in cancer progression has been well documented [110-114], and recent studies further demonstrate VEGF as a valuable prognostic marker for HNSCC. As a growth factor, circulating VEGF can be a useful marker for detecting advanced disease since circulating serum levels of VEGF in HNSCC patients before treatment was significantly higher when compared with non-cancerous individuals [115]. Patients with advanced $\mathrm{T}$ stage, lymph node metastasis and advanced disease stage also had significantly higher serum VEGF levels [115]. Another study involving the prognostic value of serum VEGF levels in nasopharyngeal carcinoma found a significant relationship between higher levels of VEGF and several clinicopathologic parameters, including $\mathrm{T}$ and $\mathrm{N}$ stage and distant metastasis [116]. Similar results were obtained in another prospective serum analysis of OSCC patients before and after treatment [88]. In a separate retrospective study, OSCC cases were analyzed for VEGF-C and VEGF-D expression by IHC [117], where increased staining intensity for these ligands significantly corresponded with lymph node involvement. In addition, lymphatic vessel density (LVD) was also evaluated in this report, where high LVD correlated with VEGFC/VEGF-D expression. Another study evaluated the relationship between lymph node metastasis and VEGF. Positive IHC expression of VEGF and Notch1, a receptor capable of promoting transcription of genes involved in cellular proliferation [118] was observed in patients with early SCC of the tongue. High Notch1 expression was also more frequent in patients with lymph node involvement. Another analyzed variable in this study was the distance of tumor cell invasion from the surface mucosa. A greater invasion depth was found in patients with elevated VEGF expression compared with cases containing normal VEGF levels [110]. In a separate study focusing on the role of angiogenesis in early SCC of the tongue, VEGF expression was found in $74 \%$ of analyzed patient samples, where it correlated with increased tumor size, disease stage, lymph node invasion, tumor recurrence and distant metastases [119]. Retrospective mRNA analysis of VEGF-C and VEGFR3 in locoregionally relapsed HNSCC revealed a significant association of high mRNA levels and relapse beyond the primary tumor [120]. While the majority of studies on VEGF expression supports a pro-metastatic role, there have been some reports where such a correlation between VEGF expression and advanced tumor stage is not 
evident [121,122]. However, only laryngeal SCC was analyzed in one of these studies, with the data suggesting patients with advanced disease and lower VEGF expression would benefit the most from induction chemotherapy [121]. In a separate report, VEGF expression did not predict metastasis in early (T1 or 2) stage OSCC [122]. Collectively these studies suggest VEGF and/or VEGFR status is useful as a pro-metastatic marker in HNSCC, and may also serve to predict relapse and treatment response.

\section{Transcription Factors}

Transcription factors are required for normal cellular homeostasis. Dysregulation of transcription factor expression is a major contributor in initiating cancer and driving tumor progression. Several transcription factors have been found to regulate expression of target genes involved in promoting HNSCC lymph node metastasis. The pleiotropic effect of these transcriptional regulators on diverse signaling pathways makes them rational targets for therapeutic intervention in HNSCC and other cancer types.

\section{1. $N F-\kappa B$}

Nuclear factor-kappa B (NF- $\mathrm{KB}$ ) is part of a family of transcription factors that regulate genes needed for most aspects of neoplastic transformation [123,124]. Inflammation has been linked to cancer progression [125], and as a proinflammatory transcription factor NF- $\mathrm{kB}$ is often found expressed in most tumor types [124]. Specific to HNSCC, analysis of tumors from varying primary sites as well as matched lymph node metastases showed positive nuclear NF- $\mathrm{kB}$ expression, and was found with a greater significant frequency in primary tumors with metastasis [126]. NF- $\mathrm{BB}$ expression levels were highest in the nodal metastases evaluated in this study. A study of laryngeal cancer patients also reported a connection between NF- $\mathrm{kB}$ expression and lymph node metastasis, as well as T stage and overall survival [127]. A retrospective study of early-stage laryngeal cancer correlated NF- $\mathrm{KB}$ expression to local recurrence in patients resistant to radiotherapy [128]. In addition, patients with recurrence and positive NF- $\mathrm{KB}$ expression in pretreatment tumors showed enhanced expression in recurrent tumors, while those with recurrence but without expression before treatment became NF-kB-positive. NF$\kappa \mathrm{B}$ has been shown to regulate other proteins involved in HNSCC cellular proliferation and metastasis, such as survivin [55], Twist1 [129], Snail [130], VEGF and MMP-9 [126], as well as other targets in HSNCC $[123,124]$. It has also been demonstrated that NF- $\mathrm{KB}$ expression can be regulated by chemokines or interact with other transcriptional regulators (Hif-1 $\alpha$ ) [131-133], making NF- $\mathrm{KB}$ a central player in the development and spread of HNSCC. Therapeutic targeting of NF- $\mathrm{kB}$ would therefore potentially disrupt multiple pathways important in HSNCC.

\subsection{Regulators of EMT}


Epithelial-mesenchymal transition (EMT) is a process in which cells lose epithelial traits and obtain a mesenchymal phenotype. While a normal part of embryonic development, EMT is a major mechanism that drives cancer development and progression. Several proteins involved in the induction of EMT in cancer have been identified [134,135]. Among these are the transcription factors Twist and Snail. Twist belongs to the basic helix-loop-helix family of transcriptional regulatory proteins [136]. Upregulation of Twist expression has been shown to promote EMT in breast cancer, while downregulation suppresses metastasis [137]. In HNSCC, Twist has been correlated to lymph node metastasis through tissue microarray screening [101]. Higher Twist expression was also observed in metastatic samples when compared to primary tumors, significantly correlating with reduced survival [138]. Another study correlated high tumor grade to Twistl expression in HNSCC cases and while not statistically significant, Twist1 expression was associated with poor prognosis [139]. Several in vitro studies have implicated Twist expression in the acquisition of chemotherapeutic resistance for various cancer types $[90,129,140]$. One of these was nasopharyngeal carcinoma, where decreased Twist expression by RNAi enhances sensitivity to chemotherapeutic compounds such as taxol and cisplatin $[90,129,140]$.

The transcription factor Snail is a zinc-finger transcriptional repressor that induces EMT by suppressing expression of E-cadherin, a component of adherens junctions that maintains epithelial cell-cell adhesion [136]. Expression of Snail was also found at higher levels in metastatic HNSCC samples [138] and was positively associated with higher-grade tumors, lower survival rates $[141,142]$, increased invasion depth and development of metastases [142]. Additionally, another earlier retrospective study found higher Snail expression correlated with cervical lymph node and distant metastasis. When co-expressed with NBS1, Snail expression resulted in higher probability of metastasis and shorter survival periods [45]. Like Twist, Snail has also been associated with chemoresistance [143]. Snail promoted cisplatin resistance in HNSCC cell lines via upregulation of excision repair cross-complementation group 1 (ERCC1), a protein important in nucleotide excision. IHC analysis of HNSCC patients who had undergone cisplatin treatment revealed a higher risk of resistance with Snail expression. Twist 1 was also evaluated in this study and was correlated with greater resistance [143]. Given their function in HNSCC and other tumor types, Twist 1 and Snail expression levels are likely good candidates for monitoring the invasive and metastatic potential of primary HNSCC, and may be useful in predicting patient response to chemotherapy.

\subsection{Hif- $1 \alpha$}

In response to the low oxygen (hypoxic) environment present in primary tumors as they proliferate and increase in size, tumor cells activate hypoxia-inducible factor 1 (HIF-1) to upregulate proteins necessary for preventing cell death $[144,145]$. HIF-1 is a heterodimeric 
protein consisting of an alpha and a beta subunit [144]. The HIF-1 alpha subunit is needed for HIF-1 to function as a transcription factor, and responds to cellular oxygen levels by activating transcription of genes such as VEGF, platelet-derived growth factor (PDGF) and transforming growth factor- $\alpha$ (TGF- $\alpha$ ) to survive under hypoxic conditions [144]. In OSCC, high HIF-1 alpha expression was correlated to worse outcome in metastatic OSCC samples [138,146]. Overexpression of HIF-1 alpha was frequently observed in HNSCC patients with lymph node metastasis, and was significantly higher when compared with node-negative cases [146]. Hypoxic tumor cells are known to influence other factors required for HNSCC cell survival and growth including EMT, ECM invasion and angiogenesis [147]. HIF-1 alpha performs these functions through regulation of expression and/or activity of multiple proteins, including Twist, MMP-2, MMP-9, VEGF and CXCR4/SDF-1 [147,148]. Hypoxia and HIF-1 alpha have been cited as one of the major causes of drug resistance to anti-angiogenic therapies in many human cancers [149]. These studies suggest that HIF-1 alpha expression may be a potential candidate to serve as a pro-metastatic biomarker in HNSCC and also predict treatment response.

\section{HPV and HNSCC}

Increased risk of HNSCC has largely been attributed to tobacco exposure and alcohol use; however in recent years, studies have also implicated human papillomavirus (HPV) infection as an additional risk [4,150,151]. Approximately 20-25\% of HNSCC are HPV-positive, with the majority of these cases arising in the oropharynx [4,150,151]. The HPV proteins E6 and E7 are key players in carcinogenesis, causing the destabilization and degradation of cell cycle regulators p53 and $\mathrm{pRb}[150,151]$. As a result, deregulation of cell cycle checkpoints and downregulation of other cell cycle regulatory proteins occurs, leading to genomic instability and uncontrolled proliferation [150,151]. There are multiple differences between HPV-positive and HPVnegative HNSCC, making them clinically distinct and requiring different management strategies. In HPV-positive HNSCC cases, genome-wide alterations in DNA copy number that are frequent in HPV-negative tumors are fewer in number; there are also fewer

TP53 mutations, and epigenetic changes such as $\mathrm{p} 16^{\mathrm{INK} 4 \mathrm{~A}}$ gene silencing due to downstream $\mathrm{Rb}$ degradation [4,151]. Another major difference is in cell cycle regulatory pathways, with upregulation of cyclins D and E being a common occurrence in HPV-positive tumors. An important distinction to note is the expression of $\mathrm{p} 21^{\mathrm{WAF} 1 / \mathrm{Cip} 1}$, a cell cycle regulator that normally functions to promote cell cycle arrest through binding and interfering with cyclin-dependent kinases (CDKs) 1 and 2, as well as proliferating cell nuclear antigen (PCNA) [152] to produce cell senescence. p21 WAF1/Cip1 also promotes resistance to apoptosis [153] and is either up or down regulated depending on cancer type, giving it dual oncogenic and tumor suppressor properties [152]. In a retrospective study involving 117 patient samples, p21 $1^{\text {WAF1/Cip1 }}$ was overexpressed in HNSCC samples from pharynx and larynx, and its increased expression was correlated with lymph node metastasis, locoregional relapse and decreased survival rate 
[154]. HPV status was not determined in this report. In a more definitive study of HPVpositive HNSCC, p21 $1^{\text {WAF1/Cip1 }}$ overexpression was associated with favorable outcome [155]. In general, HPV-positive cancers have better prognosis and response to radio- and chemotherapies, with fewer distant metastases when there has been no tobacco exposure $[4,151,156]$. For these reasons, HPV-positive HNSCC should be treated as a separate subtype with specific biomarkers and warrants determination of HPV as standard practice in order to accurately format appropriate treatment strategies.

\section{Conclusions}

Development of lymph node metastases remains a major prognostic factor in HNSCC. Many patients present with clinically advanced disease, where surgery, radiation and chemotherapy are the standard of care. Given the highly disfigurative nature of HNSCC surgical treatment and typically repeated exposure to high-dose radiation, identification of primary HNSCC tumors with enhanced metastatic potential by molecular means can aid clinicians in tailoring appropriate treatment strategies, especially in cases that have no apparent nodal involvement. Current histological procedures can be limited in their ability to detect nodal metastasis, highlighting a need for detailed, accurate molecular analysis of individual HNSCC tumors to determine specific deleterious protein expression patterns. Such a molecular analysis would theoretically result in an increased ability to identify patients with a greater risk for metastasis formation, allowing for rational treatment design to be tailored for the best possible patient outcome [157].

Early detection of oral premalignant lesions is one route to improving patient prognosis. Markers predicting progression of these lesions to cancer have not been extensively studied, however a recent gene expression profiling study revealed a signature useful in predicting OSCC development [158]. The biomarkers of focus here have been more extensively characterized in tumor spread beyond the primary site, however it would be interesting to find out if they could also be useful in identifying precancerous lesions at risk for progression to carcinoma. Some of these proteins are more useful in later stages of HNSCC. Expression of cortactin, CD44, NBS1, CXCR4, Snail and VEGF in patients with metastatic disease has been correlated to the development of distant metastases. These patients may benefit from induction and maintenance therapy in order to prevent spread below the clavicles. Monitoring serum levels of HGF, MMPs and VEGF has also been shown to be beneficial in predicting patient outcome, and further studies involving prospective analyses could provide an easier route to identification of patients at higher risk for metastasis.

HNSCC invasion and nodal metastasis is a complex process involving multiple signaling pathways and protein components. As reviewed here, several proteins have recently been characterized that give insight into HNSCC progression that have been documented to interact in signaling pathways ultimately resulting in lymph node metastasis. Figure 1 summarizes the potential interactions between these signaling pathways. Combinations of 
multiple protein expression patterns may potentially produce an accurate lymph node metastasis signature that could serve as a predictive tool for analyzing patient tumors. While the implementation of such a signature would require further validation in both experimental and clinical settings, the outcome of such work would provide an improved understanding of HNSCC as a disease, with the combined goal of enhancing overall patient quality of life. 
Figure 1. Potential interactions between recently identified biomarkers involved in HNSCC lymph node metastasis. (A) Putative interactions between proteins involved in cell cycle regulation, cell proliferation and apoptosis. (B) Potential interactions highlighted for mediators of cell motility, adhesion, ECM degradation and tumor microenvironment.

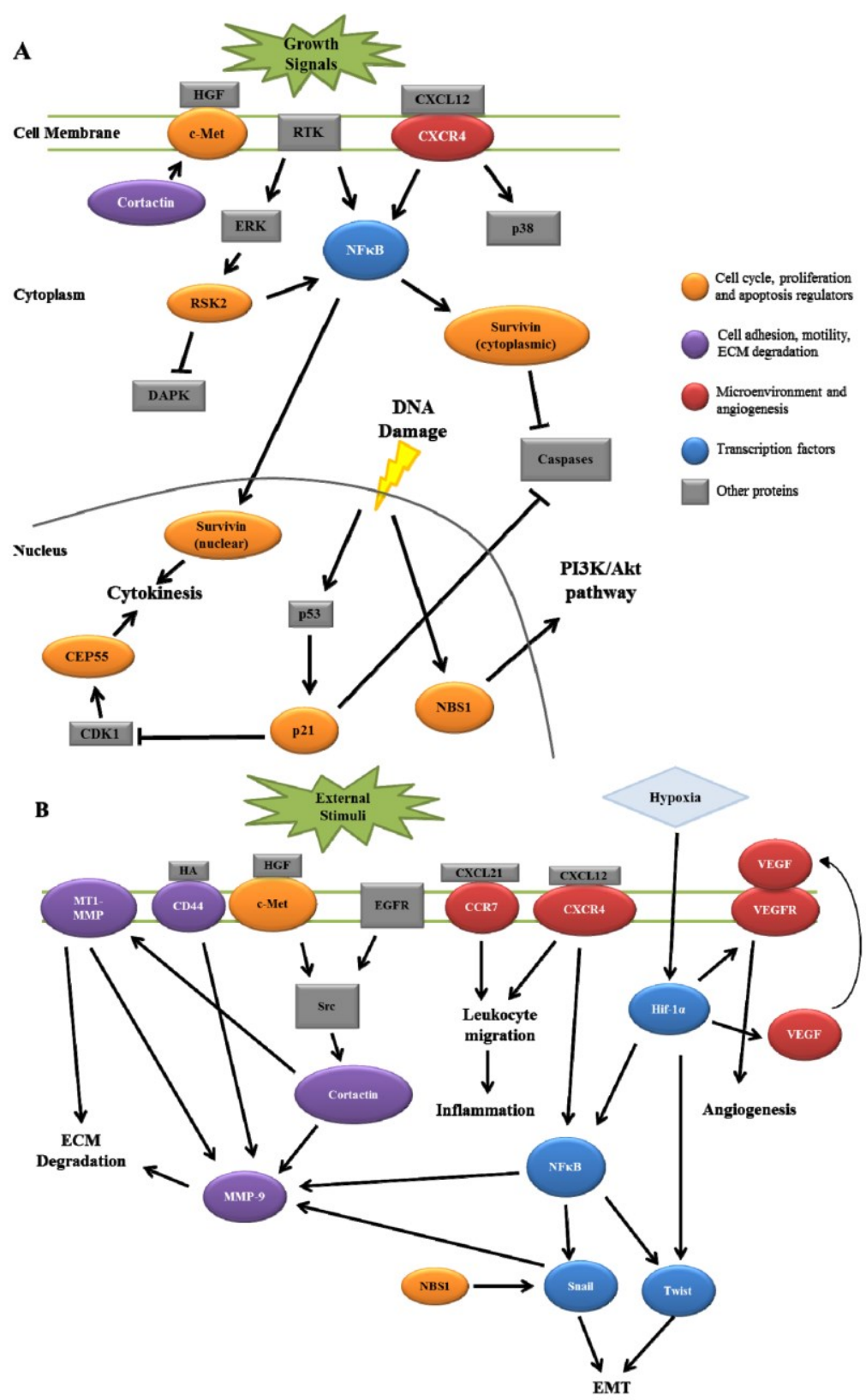




\section{Acknowledgements}

This work was supported by a subproject of National Institute of Health grant RR16440 to

SAW and by the West Virginia University Office of Research and Graduate Education (ELW).

\section{References}

1. Leemans, C.R.; Tiwari, R.; Nauta, J.J.; van der Waal, I.; Snow, G.B. Regional Lymph Node Involvement and its Significance in the Development of Distant Metastases in Head and Neck Carcinoma. Cancer 1993, 71, 452-456.

2. Jemal, A.; Siegel, R.; Xu, J.; Ward, E. Cancer Statistics, 2010. CA Cancer J. Clin. 2010, 60, 277-300.

3. Altekruse, S.F.; Kosary, C.L.; Krapcho, M.; Neyman, N.; Aminou, R.; Waldron, W.; Ruhl, J.; Howlader, N.; Tatalovich, Z.; Cho, H.; et al. SEER Cancer Statistics Review, 1975-2007; National Cancer Institute: Bethesda, MD, USA, 2010. Available online: http://seer.Cancer.gov/csr/1975_2007/ (Based on November 2009 SEER Data Submission, Posted to the SEER Web Site, 2010).

4. Pai, S.I.; Westra, W.H. Molecular Pathology of Head and Neck Cancer: Implications for Diagnosis, Prognosis, and Treatment. Annu. Rev. Pathol. 2009, 4, 49-70.

5. Le Tourneau, C.; Velten, M.; Jung, G.M.; Bronner, G.; Flesch, H.; Borel, C. Prognostic Indicators for Survival in Head and Neck Squamous Cell Carcinomas: Analysis of a Series of 621 Cases. Head Neck 2005, 27, 801-808.

6. Dunne, A.A.; Muller, H.H.; Eisele, D.W.; Kessel, K.; Moll, R.; Werner, J.A. MetaAnalysis of the Prognostic Significance of Perinodal Spread in Head and Neck Squamous Cell Carcinomas (HNSCC) Patients. Eur. J. Cancer 2006, 42, 1863-1868.

7. Liu, M.; Weynand, B.; Delos, M.; Marbaix, E. Prognostic Factors in Squamous Cell Carcinomas of the Head and Neck. Acta Otorhinolaryngol. Belg. 1999, 53, 155-160.

8. Hanahan, D.; Weinberg, R.A. The Hallmarks of Cancer. Cell 2000, 100, 57-70.

9. Cortesina, G.; Martone, T. Molecular Metastases Markers in Head and Neck Squamous Cell Carcinoma: Review of the Literature. Acta Otorhinolaryngol. Ital. 2006, 26, 317-325.

10. El-Naggar, A.K. Pathobiology of Head and Neck Squamous Tumorigenesis. Curr. Cancer Drug Targets 2007, 7, 606-612.

11. Takes, R.P.; Rinaldo, A.; Rodrigo, J.P.; Devaney, K.O.; Fagan, J.J.; Ferlito, A. Can Biomarkers Play a Role in the Decision about Treatment of the Clinically Negative Neck in Patients with Head and Neck Cancer? Head Neck 2008, 30, 525-538.

12. Molinolo, A.A.; Amornphimoltham, P.; Squarize, C.H.; Castilho, R.M.; Patel, V.; Gutkind, J.S. Dysregulated Molecular Networks in Head and Neck Carcinogenesis. Oral Oncol. 2009, 45, 324-334. 
13. Thomas, G.R.; Nadiminti, H.; Regalado, J. Molecular Predictors of Clinical Outcome in Patients with Head and Neck Squamous Cell Carcinoma. Int. J. Exp. Pathol. 2005, 86, 347363.

14. Hensen, E.F.; De Herdt, M.J.; Goeman, J.J.; Oosting, J.; Smit, V.T.; Cornelisse, C.J.; Baatenburg de Jong, R.J. Gene-Expression of Metastasized Versus Non-Metastasized Primary Head and Neck Squamous Cell Carcinomas: A Pathway-Based Analysis. BMC Cancer 2008, 8, 168.

15. Rickman, D.S.; Millon, R.; De Reynies, A.; Thomas, E.; Wasylyk, C.; Muller, D.; Abecassis, J.; Wasylyk, B. Prediction of Future Metastasis and Molecular Characterization of Head and Neck Squamous-Cell Carcinoma Based on Transcriptome and Genome Analysis by Microarrays. Oncogene 2008, 27, 6607-6622.

16. Roepman, P.; de Jager, A.; Groot Koerkamp, M.J.; Kummer, J.A.; Slootweg, P.J.; Holstege, F.C. Maintenance of Head and Neck Tumor Gene Expression Profiles upon Lymph Node Metastasis. Cancer Res. 2006, 66, 11110-11114.

17. Gentile, A.; Trusolino, L.; Comoglio, P.M. The Met Tyrosine Kinase Receptor in Development and Cancer. Cancer Metastasis Rev. 2008, 27, 85-94.

18. Comoglio, P.M.; Trusolino, L. Invasive Growth: From Development to Metastasis. $J$. Clin. Invest. 2002, 109, 857-862.

19. Benvenuti, S.; Comoglio, P.M. The MET Receptor Tyrosine Kinase in Invasion and Metastasis. J. Cell. Physiol. 2007, 213, 316-325.

20. Mueller, K.L.; Hunter, L.A.; Ethier, S.P.; Boerner, J.L. Met and c-Src Cooperate to Compensate for Loss of Epidermal Growth Factor Receptor Kinase Activity in Breast Cancer Cells. Cancer Res. 2008, 68, 3314-3322.

21. Sen, B.; Peng, S.H.; Saigal, B.; Williams, M.D.; Johnson, F.M. Distinct Interactions between c-Src and c-Met in Mediating Resistance to c-Src Inhibition in Head and Neck Cancer. Clin. Cancer Res. 2010, doi: 10.1158/1078-0432.CCR-10-1617.

22. Egloff, A.M.; Grandis, J.R. Targeting Epidermal Growth Factor Receptor and SRC Pathways in Head and Neck Cancer. Semin. Oncol. 2008, 35, 286-297.

23. Kim, C.H.; Koh, Y.W.; Han, J.H.; Kim, J.W.; Lee, J.S.; Baek, S.J.; Hwang, H.S.; Choi, E.C. C-Met Expression as an Indicator of Survival Outcome in Patients with Oral Tongue Carcinoma. Head Neck 2010, 32, 1655-1664.

24. Kim, C.H.; Lee, J.S.; Kang, S.O.; Bae, J.H.; Hong, S.P.; Kahng, H. Serum Hepatocyte Growth Factor as a Marker of Tumor Activity in Head and Neck Squamous Cell Carcinoma. Oral Oncol. 2007, 43, 1021-1025.

25. Druzgal, C.H.; Chen, Z.; Yeh, N.T.; Thomas, G.R.; Ondrey, F.G.; Duffey, D.C.; Vilela, R.J.; Ende, K.; McCullagh, L.; Rudy, S.F. et al. A Pilot Study of Longitudinal Serum Cytokine and Angiogenesis Factor Levels as Markers of Therapeutic Response and 
Survival in Patients with Head and Neck Squamous Cell Carcinoma. Head Neck 2005, 27, 771-784.

26. Allen, C.; Duffy, S.; Teknos, T.; Islam, M.; Chen, Z.; Albert, P.S.; Wolf, G.; Van Waes, C. Nuclear Factor-kappaB-Related Serum Factors as Longitudinal Biomarkers of Response and Survival in Advanced Oropharyngeal Carcinoma. Clin. Cancer Res. 2007, 13, 3182-3190.

27. Kim, C.H.; Moon, S.K.; Bae, J.H.; Lee, J.H.; Han, J.H.; Kim, K.; Choi, E.C. Expression of Hepatocyte Growth Factor and c-Met in Hypopharyngeal Squamous Cell Carcinoma. Acta Otolaryngol. 2006, 126, 88-94.

28. Uchida, D.; Kawamata, H.; Omotehara, F.; Nakashiro, K.; Kimura-Yanagawa, T.; Hino, S.; Begum, N.M.; Hoque, M.O.; Yoshida, H.; Sato, M. et al. Role of HGF/c-Met System in Invasion and Metastasis of Oral Squamous Cell Carcinoma Cells in vitro and its Clinical Significance. Int. J. Cancer 2001, 93, 489-496.

29. Marshall, D.D.; Kornberg, L.J. Overexpression of Scatter Factor and its Receptor (c-Met) in Oral Squamous Cell Carcinoma. Laryngoscope 1998, 108, 1413-1417.

30. Galeazzi, E.; Olivero, M.; Gervasio, F.C.; De Stefani, A.; Valente, G.; Comoglio, P.M.; Di Renzo, M.F.; Cortesina, G. Detection of MET oncogene/hepatocyte Growth Factor Receptor in Lymph Node Metastases from Head and Neck Squamous Cell Carcinomas. Eur. Arch. Otorhinolaryngol. 1997, 254 (Suppl. 1), S138-S143.

31. Bishop, E.A.; Lengyel, E.R.; Yamada, S.D.; Montag, A.; Temkin, S.M. The Expression of Hepatocyte Growth Factor (HGF) and c-Met in Uterine Serous Carcinoma. Gynecol. Oncol. 2010, doi: doi:10.1016/j.ygyno.2010.11.031.

32. Zucali, P.A.; Ruiz, M.G.; Giovannetti, E.; Destro, A.; Varella-Garcia, M.; Floor, K.; Ceresoli, G.L.; Rodriguez, J.A.; Garassino, I.; Comoglio, P. et al. Role of cMET Expression in Non-Small- Cell Lung Cancer Patients Treated with EGFR Tyrosine Kinase Inhibitors. Ann. Oncol. 2008, 19, 1605-1612.

33. Mueller, K.L.; Yang, Z.Q.; Haddad, R.; Ethier, S.P.; Boerner, J.L. EGFR/Met Association Regulates EGFR TKI Resistance in Breast Cancer. J. Mol. Signal. 2010, 5, 8.

34. Liska, D.; Chen, C.T.; Bachleitner-Hofmann, T.; Christensen, J.G.; Weiser, M.R. HGF Rescues Colorectal Cancer Cells from EGFR Inhibition Via MET Activation. Clin. Cancer Res. 2010, 17, 472-482.

35. Kasahara, K.; Arao, T.; Sakai, K.; Matsumoto, K.; Sakai, A.; Kimura, H.; Sone, T.; Horiike, A.; Nishio, M.; Ohira, T. et al. Impact of Serum Hepatocyte Growth Factor on Treatment Response to Epidermal Growth Factor Receptor Tyrosine Kinase Inhibitors in Patients with Non-Small Cell Lung Adenocarcinoma. Clin. Cancer Res. 2010, 16, 46164624. 
36. Eder, J.P.; Vande Woude, G.F.; Boerner, S.A.; LoRusso, P.M. Novel Therapeutic Inhibitors of the c-Met Signaling Pathway in Cancer. Clin. Cancer Res. 2009, 15, 22072214.

37. Fabbro, M.; Zhou, B.B.; Takahashi, M.; Sarcevic, B.; Lal, P.; Graham, M.E.; Gabrielli, B.G.; Robinson, P.J.; Nigg, E.A.; Ono, Y. et al. Cdk1/Erk2- and Plk1-Dependent Phosphorylation of a Centrosome Protein, Cep55, is Required for its Recruitment to Midbody and Cytokinesis. Dev. Cell. 2005, 9, 477-488.

38. Gemenetzidis, E.; Bose, A.; Riaz, A.M.; Chaplin, T.; Young, B.D.; Ali, M.; Sugden, D.; Thurlow, J.K.; Cheong, S.C.; Teo, S.H. et al. FOXM1 Upregulation is an Early Event in Human Squamous Cell Carcinoma and it is Enhanced by Nicotine during Malignant Transformation. PLoS One 2009, 4, e4849.

39. Chen, C.H.; Chien, C.Y.; Huang, C.C.; Hwang, C.F.; Chuang, H.C.; Fang, F.M.; Huang, H.Y.; Chen, C.M.; Liu, H.L.; Huang, C.Y. Expression of FLJ10540 is Correlated with Aggressiveness of Oral Cavity Squamous Cell Carcinoma by Stimulating Cell Migration and Invasion through Increased FOXM1 and MMP-2 Activity. Oncogene 2009, 28, 27232737.

40. Waseem, A.; Ali, M.; Odell, E.W.; Fortune, F.; Teh, M.T. Downstream Targets of FOXM1: CEP55 and HELLS are Cancer Progression Markers of Head and Neck Squamous Cell Carcinoma. Oral Oncol. 2010, 46, 536-542.

41. Antoccia, A.; Kobayashi, J.; Tauchi, H.; Matsuura, S.; Komatsu, K. Nijmegen Breakage Syndrome and Functions of the Responsible Protein, NBS1. Genome Dyn. 2006, 1, 191-205.

42. Lamarche, B.J.; Orazio, N.I.; Weitzman, M.D. The MRN Complex in Double-Strand Break Repair and Telomere Maintenance. FEBS Lett. 2010, 584, 3682-3695.

43. Hsu, D.S.; Chang, S.Y.; Liu, C.J.; Tzeng, C.H.; Wu, K.J.; Kao, J.Y.; Yang, M.H. Identification of Increased NBS1 Expression as a Prognostic Marker of Squamous Cell Carcinoma of the Oral Cavity. Cancer Sci. 2010, 101, 1029-1037.

44. Yang, M.H.; Chiang, W.C.; Chou, T.Y.; Chang, S.Y.; Chen, P.M.; Teng, S.C.; Wu, K.J. Increased NBS1 Expression is a Marker of Aggressive Head and Neck Cancer and Overexpression of NBS1 Contributes to Transformation. Clin. Cancer Res. 2006, 12, 507-515.

45. Yang, M.H.; Chang, S.Y.; Chiou, S.H.; Liu, C.J.; Chi, C.W.; Chen, P.M.; Teng, S.C.; $\mathrm{Wu}$, K.J. Overexpression of NBS1 Induces Epithelial-Mesenchymal Transition and Co-Expression of NBS1 and Snail Predicts Metastasis of Head and Neck Cancer. Oncogene 2007, 26, 1459-1467.

46. Park, S.L.; Bastani, D.; Goldstein, B.Y.; Chang, S.C.; Cozen, W.; Cai, L.; CordonCardo, C.; Ding, B.; Greenland, S.; He, N. et al. Associations between NBS1 
Polymorphisms, Haplotypes and Smoking-Related Cancers. Carcinogenesis 2010, 31, 1264-1271.

47. Schuetz, J.M.; MaCarthur, A.C.; Leach, S.; Lai, A.S.; Gallagher, R.P.; Connors, J.M.; Gascoyne, R.D.; Spinelli, J.J.; Brooks-Wilson, A.R. Genetic Variation in the NBS1, MRE11, RAD50 and BLM Genes and Susceptibility to Non-Hodgkin Lymphoma. BMC Med. Genet. 2009, 10, 117.

48. di Masi, A.; Antoccia, A. NBS1 Heterozygosity and Cancer Risk. Curr. Genomics 2008, 9 , 275-281.

49. Duffy, M.J.; O'Donovan, N.; Brennan, D.J.; Gallagher, W.M.; Ryan, B.M. Survivin: A Promising Tumor Biomarker. Cancer Lett. 2007, 249, 49-60.

50. Guha, M.; Altieri, D.C. Survivin as a Global Target of Intrinsic Tumor Suppression Networks. Cell Cycle 2009, 8, 2708-2710.

51. Kim, Y.H.; Kim, S.M.; Kim, Y.K.; Hong, S.P.; Kim, M.J.; Myoung, H. Evaluation of Survivin as a Prognostic Marker in Oral Squamous Cell Carcinoma. J. Oral Pathol. Med. 2010, 39, 368-375.

52. Khan, Z.; Tiwari, R.P.; Mulherkar, R.; Sah, N.K.; Prasad, G.B.; Shrivastava, B.R.; Bisen, P.S. Detection of Survivin and p53 in Human Oral Cancer: Correlation with Clinicopathologic Findings. Head Neck 2009, 31, 1039-1048.

53. Lippert, B.M.; Knauer, S.K.; Fetz, V.; Mann, W.; Stauber, R.H. Dynamic Survivin in Head and Neck Cancer: Molecular Mechanism and Therapeutic Potential. Int. J. Cancer 2007, 121, 1169-1174.

54. Qi, G.; Kudo, Y.; Ando, T.; Tsunematsu, T.; Shimizu, N.; Siriwardena, S.B.; Yoshida, M.; Keikhaee, M.R.; Ogawa, I.; Takata, T. Nuclear Survivin Expression is Correlated with Malignant Behaviors of Head and Neck Cancer Together with Aurora-B. Oral Oncol. 2010, 46, 263-270.

55. Lin, J.; Guan, Z.; Wang, C.; Feng, L.; Zheng, Y.; Caicedo, E.; Bearth, E.; Peng, J.R.; Gaffney, P.; Ondrey, F.G. Inhibitor of Differentiation 1 Contributes to Head and Neck Squamous Cell Carcinoma Survival Via the NF-kappaB/survivin and Phosphoinositide 3-kinase/Akt Signaling Pathways. Clin. Cancer Res. 2010, 16, 77-87.

56. Preuss, S.F.; Weinell, A.; Molitor, M.; Semrau, R.; Stenner, M.; Drebber, U.; Wedemeyer, I.; Hoffmann, T.K.; Guntinas-Lichius, O.; Klussmann, J.P. Survivin and Epidermal Growth Factor Receptor Expression in Surgically Treated Oropharyngeal Squamous Cell Carcinoma. Head Neck 2008b, 30, 1318-1324.

57. Preuss, S.F.; Weinell, A.; Molitor, M.; Stenner, M.; Semrau, R.; Drebber, U.; Weissenborn, S.J.; Speel, E.J.; Wittekindt, C.; Guntinas-Lichius, O. et al. Nuclear Survivin Expression is Associated with HPV-Independent Carcinogenesis and is an Indicator of Poor Prognosis in Oropharyngeal Cancer. Br. J. Cancer 2008a, 98, 627-632. 
58. Fetz, V.; Bier, C.; Habtemichael, N.; Schuon, R.; Schweitzer, A.; Kunkel, M.; Engels, K.; Kovacs, A.F.; Schneider, S.; Mann, W. et al. Inducible NO Synthase Confers Chemoresistance in Head and Neck Cancer by Modulating Survivin. Int. J. Cancer 2009, 124, 2033-2041.

59. Wang, S.; Huang, X.; Lee, C.K.; Liu, B. Elevated Expression of erbB3 Confers Paclitaxel Resistance in erbB2-Overexpressing Breast Cancer Cells Via Upregulation of Survivin. Oncogene 2010, 29, 4225-4236.

60. Promkan, M.; Liu, G.; Patmasiriwat, P.; Chakrabarty, S. BRCA1 Modulates Malignant Cell Behavior, the Expression of Survivin and Chemosensitivity in Human Breast Cancer Cells. Int. J. Cancer 2009, 125, 2820-2828.

61. Wang, Q.; Wu, P.C.; Roberson, R.S.; Luk, B.V.; Ivanova, I.; Chu, E.; Wu, D.Y. Survivin and Escaping in Therapy-Induced Cellular Senescence. Int. J. Cancer 2010, doi: 10.1002/ijc.25482.

62. Su, L.; Wang, Y.; Xiao, M.; Lin, Y.; Yu, L. Up-Regulation of Survivin in Oral Squamous Cell Carcinoma Correlates with Poor Prognosis and Chemoresistance. Oral Surg. Oral Med. Oral Pathol. Oral Radiol. Endod. 2010, 110, 484-491.

63. Carriere, A.; Ray, H.; Blenis, J.; Roux, P.P. The RSK Factors of Activating the Ras/MAPK Signaling Cascade. Front. Biosci. 2008, 13, 4258-4275.

64. Anjum, R.; Blenis, J. The RSK Family of Kinases: Emerging Roles in Cellular Signalling. Nat. Rev. Mol. Cell Biol. 2008, 9, 747-758.

65. Kang, S.; Elf, S.; Lythgoe, K.; Hitosugi, T.; Taunton, J.; Zhou, W.; Xiong, L.; Wang, D.; Muller, S.; Fan, S. et al. P90 Ribosomal S6 Kinase 2 Promotes Invasion and Metastasis of Human Head and Neck Squamous Cell Carcinoma Cells. J. Clin. Invest. 2010, 120, 1165-1177.

66. Cho, Y.Y.; Yao, K.; Kim, H.G.; Kang, B.S.; Zheng, D.; Bode, A.M.; Dong, Z. Ribosomal S6 Kinase 2 is a Key Regulator in Tumor Promoter Induced Cell Transformation. Cancer Res. 2007, 67, 8104-8112.

67. Nguyen, T.L. Targeting RSK: An Overview of Small Molecule Inhibitors. Anticancer Agents Med. Chem. 2008, 8, 710-716.

68. Ammer, A.G.; Weed, S.A. Cortactin Branches Out: Roles in Regulating Protrusive Actin Dynamics. Cell Motil. Cytoskeleton 2008, 65, 687-707.

69. Rodrigo, J.P.; Garcia, L.A.; Ramos, S.; Lazo, P.S.; Suarez, C. EMS1 Gene Amplification Correlates with Poor Prognosis in Squamous Cell Carcinomas of the Head and Neck. Clin. Cancer Res. 2000, 6, 3177-3182.

70. Rothschild, B.L.; Shim, A.H.; Ammer, A.G.; Kelley, L.C.; Irby, K.B.; Head, J.A.; Chen, L.; Varella-Garcia, M.; Sacks, P.G.; Frederick, B. et al. Cortactin Overexpression Regulates Actin- Related Protein 2/3 Complex Activity, Motility, and Invasion in Carcinomas with Chromosome 11q13 Amplification. Cancer Res. 2006, 66, 8017-8025. 
71. Meredith, S.D.; Levine, P.A.; Burns, J.A.; Gaffey, M.J.; Boyd, J.C.; Weiss, L.M.; Erickson, N.L.; Williams, M.E. Chromosome 11q13 Amplification in Head and Neck Squamous Cell Carcinoma. Association with Poor Prognosis. Arch. Otolaryngol. Head. Neck. Surg. 1995, 121, 790-794.

72. Williams, M.E.; Gaffey, M.J.; Weiss, L.M.; Wilczynski, S.P.; Schuuring, E.; Levine, P.A. Chromosome 11Q13 Amplification in Head and Neck Squamous Cell Carcinoma. Arch. Otolaryngol. Head. Neck. Surg. 1993, 119, 1238-1243.

73. Luo, M.L.; Shen, X.M.; Zhang, Y.; Wei, F.; Xu, X.; Cai, Y.; Zhang, X.; Sun, Y.T.; Zhan, Q.M.; Wu, M. et al. Amplification and Overexpression of CTTN (EMS1) Contribute to the Metastasis of Esophageal Squamous Cell Carcinoma by Promoting Cell Migration and Anoikis Resistance. Cancer Res. 2006, 66, 11690-11699.

74. Yamada, S.I.; Yanamoto, S.; Kawasaki, G.; Mizuno, A.; Nemoto, T.K. Overexpression of Cortactin Increases Invasion Potential in Oral Squamous Cell Carcinoma. Pathol. Oncol. Res. 2010, 4, 523-531.

75. Rodrigo, J.P.; Garcia-Carracedo, D.; Garcia, L.A.; Menendez, S.; Allonca, E.; Gonzalez, M.V.; Fresno, M.F.; Suarez, C.; Garcia-Pedrero, J.M. Distinctive Clinicopathological Associations of Amplification of the Cortactin Gene at 11q13 in Head and Neck Squamous Cell Carcinomas. J. Pathol. 2009, 217, 516-523.

76. Hofman, P.; Butori, C.; Havet, K.; Hofman, V.; Selva, E.; Guevara, N.; Santini, J.; Van Obberghen-Schilling, E. Prognostic Significance of Cortactin Levels in Head and Neck Squamous Cell Carcinoma: Comparison with Epidermal Growth Factor Receptor Status. Br. J. Cancer 2008, 98, 956-964.

77. Timpson, P.; Wilson, A.S.; Lehrbach, G.M.; Sutherland, R.L.; Musgrove, E.A.; Daly, R.J. Aberrant Expression of Cortactin in Head and Neck Squamous Cell Carcinoma Cells is Associated with Enhanced Cell Proliferation and Resistance to the Epidermal Growth Factor Receptor Inhibitor Gefitinib. Cancer Res. 2007, 67, 9304-9314.

78. Fantozzi, I.; Grall, D.; Cagnol, S.; Stanchi, F.; Sudaka, A.; Brunstein, M.C.; Bozec, A.; Fischel, J.L.; Milano, G.; Van Obberghen-Schilling, E. Overexpression of Cortactin in Head and Neck Squamous Cell Carcinomas can be Uncoupled from Augmented EGF Receptor Expression. Acta Oncol. 2008, 47, 1502-1512.

79. Gibcus, J.H.; Mastik, M.F.; Menkema, L.; de Bock, G.H.; Kluin, P.M.; Schuuring, E.; van der Wal, J.E. Cortactin Expression Predicts Poor Survival in Laryngeal Carcinoma. Br. J. Cancer 2008, 98, 950-955.

80. Orian-Rousseau, V. CD44, a Therapeutic Target for Metastasising Tumours. Eur. J. Cancer 2010, 46, 1271-1277.

81. Wang, S.J.; Wong, G.; de Heer, A.M.; Xia, W.; Bourguignon, L.Y. CD44 Variant Isoforms in Head and Neck Squamous Cell Carcinoma Progression. Laryngoscope 2009, $119,1518-1530$. 
82. Yuce, I.; Bayram, A.; Cagli, S.; Canoz, O.; Bayram, S.; Guney, E. The Role of CD44 and Matrix Metalloproteinase-9 Expression in Predicting Neck Metastasis of Supraglottic Laryngeal Carcinoma. Am. J. Otolaryngol. 2010, doi:10.1016/j.amjoto.2010.01.001.

83. Lin, J.T.; Chang, T.H.; Chang, C.S.; Wang, W.H.; Su, B.W.; Lee, K.D.; Chang, P.J. Prognostic Value of Pretreatment CD44 mRNA in Peripheral Blood of Patients with Locally Advanced Head and Neck Cancer. Oral Oncol. 2010, 46, e29-e33.

84. Kessenbrock, K.; Plaks, V.; Werb, Z. Matrix Metalloproteinases: Regulators of the Tumor Microenvironment. Cell 2010, 141, 52-67.

85. Yu, Q.; Stamenkovic, I. Cell Surface-Localized Matrix Metalloproteinase-9 Proteolytically Activates TGF-Beta and Promotes Tumor Invasion and Angiogenesis. Genes Dev. 2000, 14, 163-176.

86. Lee, J.I.; Jin, B.H.; Kim, M.A.; Yoon, H.J.; Hong, S.P.; Hong, S.D. Prognostic Significance of CXCR-4 Expression in Oral Squamous Cell Carcinoma. Oral Surg. Oral Med. Oral Pathol. Oral Radiol. Endod. 2009, 107, 678-684.

87. Sterz, C.M.; Kulle, C.; Dakic, B.; Makarova, G.; Bottcher, M.C.; Bette, M.; Werner, J.A.; Mandic, R. A Basal-Cell-Like Compartment in Head and Neck Squamous Cell Carcinomas Represents the Invasive Front of the Tumor and is Expressing MMP-9. Oral Oncol. 2010, 46, 116-122.

88. Liu, C.J.; Chang, K.W.; Lin, S.C.; Cheng, H.W. Presurgical Serum Levels of Matrix Metalloproteinase-9 and Vascular Endothelial Growth Factor in Oral Squamous Cell Carcinoma. Oral Oncol. 2009, 45, 920-925.

89. Ruokolainen, H.; Paakko, P.; Turpeenniemi-Hujanen, T. Serum Matrix Metalloproteinase-9 in Head and Neck Squamous Cell Carcinoma is a Prognostic Marker. Int. J. Cancer 2005, 116, 422- 427.

90. Zhang, H.; Liu, M.; Sun, Y.; Lu, J. MMP-14 can Serve as a Prognostic Marker in Patients with Supraglottic Cancer. Eur. Arch. Otorhinolaryngol. 2009, 266, 1427-1434.

91. Clark, E.S.; Whigham, A.S.; Yarbrough, W.G.; Weaver, A.M. Cortactin is an Essential Regulator of Matrix Metalloproteinase Secretion and Extracellular Matrix Degradation in Invadopodia. Cancer Res. 2007, 67, 4227-4235.

92. Clark, E.S.; Weaver, A.M. A New Role for Cortactin in Invadopodia: Regulation of Protease Secretion. Eur. J. Cell Biol. 2008, 87, 581-590.

93. Coussens, L.M.; Fingleton, B.; Matrisian, L.M. Matrix Metalloproteinase Inhibitors and Cancer: Trials and Tribulations. Science 2002, 295, 2387-2392.

94. Dorman, G.; Cseh, S.; Hajdu, I.; Barna, L.; Konya, D.; Kupai, K.; Kovacs, L.; Ferdinandy, P. Matrix Metalloproteinase Inhibitors: A Critical Appraisal of Design Principles and Proposed Therapeutic Utility. Drugs 2010, 70, 949-964.

95. Kakinuma, T.; Hwang, S.T. Chemokines, Chemokine Receptors, and Cancer Metastasis. J. Leukoc. Biol. 2006, 79, 639-651. 
96. Ben-Baruch, A. Site-Specific Metastasis Formation: Chemokines as Regulators of Tumor Cell Adhesion, Motility and Invasion. Cell. Adh Migr. 2009, 3, 328-333.

97. Teicher, B.A.; Fricker, S.P. CXCL12 (SDF-1)/CXCR4 Pathway in Cancer. Clin. Cancer Res. 2010, 16, 2927-2931.

98. Tan, C.T.; Chu, C.Y.; Lu, Y.C.; Chang, C.C.; Lin, B.R.; Wu, H.H.; Liu, H.L.; Cha, S.T.; Prakash, E.; Ko, J.Y. et al. CXCL12/CXCR4 Promotes Laryngeal and Hypopharyngeal Squamous Cell Carcinoma Metastasis through MMP-13-Dependent Invasion Via the ERK1/2/AP-1 Pathway. Carcinogenesis 2008, 29, 1519-1527.

99. Meng, X.; Wuyi, L.; Yuhong, X.; Xinming, C. Expression of CXCR4 in Oral Squamous Cell Carcinoma: Correlations with Clinicopathology and Pivotal Role of Proliferation. $J$. Oral Pathol. Med. 2010, 39, 63-68.

100. Ueda, M.; Shimada, T.; Goto, Y.; Tei, K.; Nakai, S.; Hisa, Y.; Kannagi, R. Expression of CC-Chemokine Receptor 7 (CCR7) and CXC-Chemokine Receptor 4 (CXCR4) in Head and Neck Squamous Cell Carcinoma. Auris Nasus Larynx 2010, 37, 488-495.

101. Ou, D.L.; Chien, H.F.; Chen, C.L.; Lin, T.C.; Lin, L.I. Role of Twist in Head and Neck Carcinoma with Lymph Node Metastasis. Anticancer Res. 2008, 28, 1355-1359.

102. Pitkin, L.; Luangdilok, S.; Corbishley, C.; Wilson, P.O.; Dalton, P.; Bray, D.; Mady, S.; Williamson, P.; Odutoye, T.; Rhys Evans, P. et al. Expression of CC Chemokine Receptor 7 in Tonsillar Cancer Predicts Cervical Nodal Metastasis, Systemic Relapse and Survival. Br. J. Cancer 2007, 97, 670-677.

103. Shang, Z.J.; Liu, K.; Shao, Z. Expression of Chemokine Receptor CCR7 is Associated with Cervical Lymph Node Metastasis of Oral Squamous Cell Carcinoma. Oral Oncol. 2009, 45, 480-485.

104. Wang, J.; Seethala, R.R.; Zhang, Q.; Gooding, W.; van Waes, C.; Hasegawa, H.; Ferris, R.L. Autocrine and Paracrine Chemokine Receptor 7 Activation in Head and Neck Cancer: Implications for Therapy. J. Natl. Cancer Inst. 2008, 100, 502-512.

105. Wolf, M.; Albrecht, S.; Marki, C. Proteolytic Processing of Chemokines: Implications in Physiological and Pathological Conditions. Int. J. Biochem. Cell Biol. 2008, 40, 11851198.

106. Yu, T.; Wu, Y.; Helman, J.I.; Wen, Y.; Wang, C.; Li, L. CXCR4 Promotes Oral Squamous Cell Carcinoma Migration and Invasion through Inducing Expression of MMP-9, 13 Via the ERK Signaling Pathway. Mol. Cancer. Res. 2011, doi: 10.1158/1541-7786.MCR10-0386.

107. Raman, D.; Baugher, P.J.; Thu, Y.M.; Richmond, A. Role of Chemokines in Tumor Growth. Cancer Lett. 2007, 256, 137-165.

108. Wang, J.; Xi, L.; Hunt, J.L.; Gooding, W.; Whiteside, T.L.; Chen, Z.; Godfrey, T.E.; Ferris, R.L. Expression Pattern of Chemokine Receptor 6 (CCR6) and CCR7 in Squamous Cell 
Carcinoma of the Head and Neck Identifies a Novel Metastatic Phenotype. Cancer Res. 2004, 64, 1861-1866.

109. Margaritescu, C.; Pirici, D.; Simionescu, C.; Mogoanta, L.; Raica, M.; Stinga, A.; Ciurea, R.; Stepan, A.; Stinga, A.; Ribatti, D. VEGF and VEGFRs Expression in Oral Squamous Cell Carcinoma. Rom. J. Morphol. Embryol. 2009, 50, 527-548.

110. Joo, Y.H.; Jung, C.K.; Kim, M.S.; Sun, D.I. Relationship between Vascular Endothelial Growth Factor and Notch1 Expression and Lymphatic Metastasis in Tongue Cancer. Otolaryngol. Head. Neck. Surg. 2009, 140, 512-518.

111. Hicklin, D.J.; Ellis, L.M. Role of the Vascular Endothelial Growth Factor Pathway in Tumor Growth and Angiogenesis. J. Clin. Oncol. 2005, 23, 1011-1027.

112. Winder, T.; Lenz, H.J. Vascular Endothelial Growth Factor and Epidermal Growth Factor Signaling Pathways as Therapeutic Targets for Colorectal Cancer. Gastroenterology 2010, 138, 2163-2176.

113. Guo, S.; Colbert, L.S.; Fuller, M.; Zhang, Y.; Gonzalez-Perez, R.R. Vascular Endothelial Growth Factor Receptor-2 in Breast Cancer. Biochim. Biophys. Acta 2010, 1806, 108-121.

114. Delli Carpini, J.; Karam, A.K.; Montgomery, L. Vascular Endothelial Growth Factor and its Relationship to the Prognosis and Treatment of Breast, Ovarian, and Cervical Cancer. Angiogenesis 2010, 13, 43-58.

115. Hong, D.Y.; Lee, B.J.; Lee, J.C.; Choi, J.S.; Wang, S.G.; Ro, J.H. Expression of VEGF, HGF, IL-6, IL-8, MMP-9, Telomerase in Peripheral Blood of Patients with Head and Neck Squamous Cell Carcinoma. Clin. Exp. Otorhinolaryngol. 2009, 2, 186-192.

116. Lv, X.; Xiang, Y.Q.; Cao, S.M.; Qian, C.N.; Li, N.W.; Guo, L.; Mai, H.Q.; Chen, Q.Y.; Huang, P.Y.; Luo, D. et al. Prospective Validation of the Prognostic Value of Elevated Serum Vascular Endothelial Growth Factor in Patients with Nasopharyngeal Carcinoma: More Distant Metastases and Shorter overall Survival After Treatment. Head Neck 2010, doi: $10.1002 /$ hed.21541.

117. Sugiura, T.; Inoue, Y.; Matsuki, R.; Ishii, K.; Takahashi, M.; Abe, M.; Shirasuna, K. VEGF-C and VEGF-D Expression is Correlated with Lymphatic Vessel Density and Lymph Node Metastasis in Oral Squamous Cell Carcinoma: Implications for use as a Prognostic Marker. Int. J. Oncol. 2009, 34, 673-680.

118. Borggrefe, T.; Oswald, F. The Notch Signaling Pathway: Transcriptional Regulation at Notch Target Genes. Cell Mol. Life Sci. 2009, 66, 1631-1646.

119. Shao, Z.; Zhang, W.F.; Chen, X.M.; Shang, Z.J. Expression of EphA2 and VEGF in Squamous Cell Carcinoma of the Tongue: Correlation with the Angiogenesis and Clinical Outcome. Oral Oncol. 2008, 44, 1110-1117.

120. Pentheroudakis, G.; Angouridakis, N.; Wirtz, R.; Nikolaou, A.; Kalogeras, K.T.; Pavlidis, N.; Fountzilas, G. Transcriptional Activity of Human Epidermal Growth Factor Receptor Family and Angiogenesis Effectors in Locoregionally Recurrent Head and Neck 
Squamous Cell Carcinoma and Correlation with Patient Outcome. J. Oncol. 2009, 2009, 854127.

121. Rueda, A.; Cazorla, O.; Perez, L.; Alvarez, M.; Redondo, M.; Gallego, E.; Saez, M.; Medina, J.A.; Solano, J.; Matilla, A. Vascular Endothelial Growth Factor and Vascular Endothelial Growth Factor Receptor-2 Tumor Expression in Patients with Advanced Laryngeal Cancer After Induction Chemotherapy for Organ Preservation. Head Neck 2010, doi: 10.1002/hed.21551.

122. Faustino, S.E.; Oliveira, D.T.; Nonogaki, S.; Landman, G.; Carvalho, A.L.; Kowalski, L.P. Expression of Vascular Endothelial Growth Factor-C does Not Predict Occult Lymph-Node Metastasis in Early Oral Squamous Cell Carcinoma. Int. J. Oral Maxillofac. Surg. 2008, 37, 372-378.

123. Luqman, S.; Pezzuto, J.M. NFkappaB: A Promising Target for Natural Products in Cancer Chemoprevention. Phytother. Res. 2010, 24, 949-963.

124. Aggarwal, B.B. Nuclear Factor-kappaB: The Enemy within Cancer. Cell 2004, 6, 203-208.

125. Mantovani, A.; Allavena, P.; Sica, A.; Balkwill, F. Cancer-Related Inflammation. Nature 2008, 454, 436-444.

126. Yan, M.; Xu, Q.; Zhang, P.; Zhou, X.J.; Zhang, Z.Y.; Chen, W.T. Correlation of NFkappaB Signal Pathway with Tumor Metastasis of Human Head and Neck Squamous Cell Carcinoma. BMC Cancer 2010, 10, 437.

127. Huang, C.; Huang, K.; Wang, C.; Jiang, Z.D.; Li, X.X.; Wang, H.P.; Chen, H.Y. Overexpression of Mitogen-Activated Protein Kinase Kinase 4 and Nuclear FactorkappaB in Laryngeal Squamous Cell Carcinoma: A Potential Indicator for Poor Prognosis. Oncol. Rep. 2009, 22, 89-95.

128. Yoshida, K.; Sasaki, R.; Nishimura, H.; Okamoto, Y.; Suzuki, Y.; Kawabe, T.; Saito, M.; Otsuki, N.; Hayashi, Y.; Soejima, T. et al. Nuclear Factor-kappaB Expression as a Novel Marker of Radioresistance in Early-Stage Laryngeal Cancer. Head Neck 2010, 32, 646-655.

129. Pham, C.G.; Bubici, C.; Zazzeroni, F.; Knabb, J.R.; Papa, S.; Kuntzen, C.; Franzoso, G. Upregulation of Twist-1 by NF-kappaB Blocks Cytotoxicity Induced by Chemotherapeutic Drugs. Mol. Cell. Biol. 2007, 27, 3920-3935.

130. Julien, S.; Puig, I.; Caretti, E.; Bonaventure, J.; Nelles, L.; van Roy, F.; Dargemont, C.; de Herreros, A.G.; Bellacosa, A.; Larue, L. Activation of NF-kappaB by Akt Upregulates Snail Expression and Induces Epithelium Mesenchyme Transition. Oncogene 2007, 26, 7445-7456.

131. Rehman, A.O.; Wang, C.Y. SDF-1alpha Promotes Invasion of Head and Neck Squamous Cell Carcinoma by Activating NF-kappaB. J. Biol. Chem. 2008, 283, 19888-19894. 
132. Chaturvedi, M.M.; Sung, B.; Yadav, V.R.; Kannappan, R.; Aggarwal, B.B. NFkappaB Addiction and its Role in Cancer: 'One Size does Not Fit all'. Oncogene 2010, doi:10.1038/onc.2010.566.

133. Liu, F.Y.; Zhao, Z.J.; Li, P.; Ding, X.; Guo, N.; Yang, L.L.; Zong, Z.H.; Sun, C.F. NFkappaB Participates in Chemokine Receptor 7-Mediated Cell Survival in Metastatic Squamous Cell Carcinoma of the Head and Neck. Oncol. Rep. 2011, 25, 383-391.

134. Iwatsuki, M.; Mimori, K.; Yokobori, T.; Ishi, H.; Beppu, T.; Nakamori, S.; Baba, H.; Mori, M. Epithelial-Mesenchymal Transition in Cancer Development and its Clinical Significance. Cancer Sci. 2010, 101, 293-299.

135. Yilmaz, M.; Christofori, G. EMT, the Cytoskeleton, and Cancer Cell Invasion. Cancer Metastasis Rev. 2009, 28, 15-33.

136. Ouyang, G.; Wang, Z.; Fang, X.; Liu, J.; Yang, C.J. Molecular Signaling of the Epithelial to Mesenchymal Transition in Generating and Maintaining Cancer Stem Cells. Cell Mol. Life Sci. 2010, 67, 2605-2618.

137. Yang, J.; Mani, S.A.; Donaher, J.L.; Ramaswamy, S.; Itzykson, R.A.; Come, C.; Savagner, P.; Gitelman, I.; Richardson, A.; Weinberg, R.A. Twist, a Master Regulator of Morphogenesis, Plays an Essential Role in Tumor Metastasis. Cell 2004, 117, 927-939.

138. Yang, M.H.; Wu, M.Z.; Chiou, S.H.; Chen, P.M.; Chang, S.Y.; Liu, C.J.; Teng, S.C.; Wu, K.J. Direct Regulation of TWIST by HIF-1alpha Promotes Metastasis. Nat. Cell Biol. 2008, 10, 295-305.

139. Yang, M.H.; Hsu, D.S.; Wang, H.W.; Wang, H.J.; Lan, H.Y.; Yang, W.H.; Huang, C.H.; Kao, S.Y.; Tzeng, C.H.; Tai, S.K. et al. Bmil is Essential in Twist1-Induced EpithelialMesenchymal Transition. Nat. Cell Biol. 2010, 12, 982-992.

140. Shiota, M.; Izumi, H.; Onitsuka, T.; Miyamoto, N.; Kashiwagi, E.; Kidani, A.; Yokomizo, A.; Naito, S.; Kohno, K. Twist Promotes Tumor Cell Growth through YB-1 Expression. Cancer Res. 2008, 68, 98-105.

141. Yu, C.C.; Lo, W.L.; Chen, Y.W.; Huang, P.I.; Hsu, H.S.; Tseng, L.M.; Hung, S.C.; Kao, S.Y.; Chang, C.J.; Chiou, S.H. Bmi-1 Regulates Snail Expression and Promotes Metastasis Ability in Head and Neck Squamous Cancer-Derived ALDH1 Positive Cells. J. Oncol. 2011, 2011, doi:10.1155/2011/609259.

142. Hayry, V.; Makinen, L.K.; Atula, T.; Sariola, H.; Makitie, A.; Leivo, I.; Keski-Santti, H.; Lundin, J.; Haglund, C.; Hagstrom, J. Bmi-1 Expression Predicts Prognosis in Squamous Cell Carcinoma of the Tongue. Br. J. Cancer 2010, 102, 892-897.

143. Hsu, D.S.; Lan, H.Y.; Huang, C.H.; Tai, S.K.; Chang, S.Y.; Tsai, T.L.; Chang, C.C.; Tzeng, C.H.; Wu, K.J.; Kao, J.Y. et al. Regulation of Excision Repair CrossComplementation Group 1 by Snail Contributes to Cisplatin Resistance in Head and Neck Cancer. Clin. Cancer Res. 2010, 16, 4561-4571. 
144. Semenza, G.L. Defining the Role of Hypoxia-Inducible Factor 1 in Cancer Biology and Therapeutics. Oncogene 2010, 29, 625-634.

145. Mizukami, Y.; Kohgo, Y.; Chung, D.C. Hypoxia Inducible Factor-1 Independent Pathways in Tumor Angiogenesis. Clin. Cancer Res. 2007, 13, 5670-5674.

146. Uehara, M.; Sano, K.; Ikeda, H.; Nonaka, M.; Asahina, I. Hypoxia-Inducible Factor 1 Alpha in Oral Squamous Cell Carcinoma and its Relation to Prognosis. Oral Oncol. 2009, 45, 241-246.

147. Gort, E.H.; Groot, A.J.; van der Wall, E.; van Diest, P.J.; Vooijs, M.A. Hypoxic Regulation of Metastasis Via Hypoxia-Inducible Factors. Curr. Mol. Med. 2008, 8, 60-67.

148. Yang, M.H.; Wu, K.J. TWIST Activation by Hypoxia Inducible Factor-1 (HIF-1): Implications in Metastasis and Development. Cell Cycle 2008, 7, 2090-2096.

149. Rapisarda, A.; Melillo, G. Role of the Hypoxic Tumor Microenvironment in the Resistance to Anti-Angiogenic Therapies. Drug Resist. Updat. 2009, 12, 74-80.

150. Goon, P.K.; Stanley, M.A.; Ebmeyer, J.; Steinstrasser, L.; Upile, T.; Jerjes, W.; BernalSprekelsen, M.; Gorner, M.; Sudhoff, H.H. HPV \& Head and Neck Cancer: A Descriptive Update. Head Neck Oncol. 2009, 1, 36.

151. Chung, C.H.; Gillison, M.L. Human Papillomavirus in Head and Neck Cancer: Its Role in Pathogenesis and Clinical Implications. Clin. Cancer Res. 2009, 15, 6758-6762.

152. Abbas, T.; Dutta, A. P21 in Cancer: Intricate Networks and Multiple Activities. Nat. Rev. Cancer. 2009, 9, 400-414.

153. Roninson, I.B. Oncogenic Functions of Tumour Suppressor p21(Waf1/Cip1/Sdil): Association with Cell Senescence and Tumour-Promoting Activities of Stromal Fibroblasts. Cancer Lett. 2002, 179, 1-14.

154. Fischer, C.A.; Jung, M.; Zlobec, I.; Green, E.; Storck, C.; Tornillo, L.; Lugli, A.; Wolfensberger, M.; Terracciano, L.M. Co-Overexpression of p21 and Ki-67 in Head and Neck Squamous Cell Carcinoma Relative to a significantly Poor Prognosis. Head Neck 2010, 33, 267-273.

155. Hafkamp, H.C.; Mooren, J.J.; Claessen, S.M.; Klingenberg, B.; Voogd, A.C.; Bot, F.J.; Klussmann, J.P.; Hopman, A.H.; Manni, J.J.; Kremer, B. et al. P21 Cip1/WAF1 Expression is Strongly Associated with HPV-Positive Tonsillar Carcinoma and a Favorable Prognosis. Mod. Pathol. 2009, 22, 686-698.

156. Maxwell, J.H.; Kumar, B.; Feng, F.Y.; Worden, F.P.; Lee, J.S.; Eisbruch, A.; Wolf, G.T.; Prince, M.E.; Moyer, J.S.; Teknos, T.N. et al. Tobacco use in Human PapillomavirusPositive Advanced Oropharynx Cancer Patients Related to Increased Risk of Distant Metastases and Tumor Recurrence. Clin. Cancer Res. 2010, 16, 1226-1235.

157. McDermott, U.; Downing, J.R.; Stratton, M.R. Genomics and the Continuum of Cancer Care. N. Engl. J. Med. 2011, 364, 340-350. 
158. Saintigny, P.; Zhang, L.; Fan, Y.H.; El-Naggar, A.K.; Papadimitrakopoulou, V.A.; Feng, L.; Lee, J.J.; Kim, E.S.; Hong, W.K.; Mao, L. Gene Expression Profiling Predicts the Development of Oral Cancer. Cancer Prev. Res. 2011, 4, 218.

(C) 2011 by the authors; licensee MDPI, Basel, Switzerland. This article is an open access article distributed under the terms and conditions of the Creative Commons Attribution license (http://creativecommons.org/licenses/by/3.0/). 


\title{
Video Article \\ Quantitative Measurement of Invadopodia-mediated Extracellular Matrix Proteolysis in Single and Multicellular Contexts
}

\author{
Karen H. Martin, Karen E. Hayes, Elyse L. Walk, Amanda Gatesman Ammer, Steven M. Markwell, Scott A. Weed \\ Department of Neurobiology and Anatomy, Program in Cancer Cell Biology, Mary Babb Randolph Cancer Center, West Virginia University
}

Correspondence to: Scott A. Weed at scweed@hsc.wvu.edu

URL:

http://www.jov

e.com/video/4

119/ DOI:

$10.3791 / 4119$

Keywords: Cellular Biology, Issue 66, Cancer Biology, Anatomy, Molecular Biology, Biochemistry, invadopodia, extracellular matrix, gelatin, confocal microscopy, quantification, oregon green

Date Published: 8/27/2012

Citation: Martin, K.H., Hayes, K.E., Walk, E.L., Ammer, A.G., Markwell, S.M., Weed, S.A. Quantitative Measurement of Invadopodia-mediated

Extracellular Matrix Proteolysis in Single and Multicellular Contexts. J. Vis. Exp. (66), e4119 10.3791/4119, DOI : $10.3791 / 4119$ (2012).

\section{Abstract}

Cellular invasion into local tissues is a process important in development and homeostasis. Malregulated invasion and subsequent cell movement is characteristic of multiple pathological processes, including inflammation, cardiovascular disease and tumor cell metastasis ${ }^{1}$. Focalized proteolytic degradation of extracellular matrix (ECM) components in the epithelial or endothelial basement membrane is a critical step in initiating cellular invasion. In tumor cells, extensive in vitro analysis has determined that ECM degradation is accomplished by ventral actin-richmembrane protrusive structures termed invadopodia ${ }^{2,3}$. Invadopodia form in close apposition to the ECM, where they moderate ECM breakdown through the action of matrix metalloproteinases (MMPs). The ability of tumor cells to form invadopodia directly correlates with the ability to invade into local stroma and associated vascular components ${ }^{3}$.

Visualization of invadopodia-mediated ECM degradation of cells by fluorescent microscopy using dye-labeled matrix proteins coated onto glass coverslips has emerged as the most prevalent technique for evaluating the degree of matrix proteolysis and cellular invasive potential ${ }^{4,5}$. Here we describe a version of the standard method for generating fluorescently-labeled glass coverslips utilizing a commercially available Oregon Green-488 gelatin conjugate. This method is easily scaled to rapidly produce large numbers of coated coverslips. We show some of the common microscopic artifacts that are often encountered during this procedure and how these can be avoided. Finally, we describe standardized methods using readily available computer software to allow quantification of labeled gelatin matrix degradation mediated by individual cells and by entire cellular populations. The described procedures provide the ability to accurately and reproducibly monitor invadopodia activity, and can also serve as a platform for evaluating the efficacy of modulating protein expression or testing of anti-invasive compounds on extracellular matrix degradation in single and multicellular settings.

\section{Video Link}

The video component of this article can be found at http://www.jove.com/video/4119/

Protocol

\section{Production of Oregon Green 488-gelatin Coated Coverslips}

1. Prepare an unlabeled $5 \%(\mathrm{w} / \mathrm{w})$ stock gelatin/sucrose solution by adding $1.25 \mathrm{~g}$ gelatin and $1.25 \mathrm{~g}$ sucrose in PBS to a final volume of $50 \mathrm{ml}$.

Warm the stock gelatin solution to $37^{\circ} \mathrm{C}$ and ensure it is entirely melted before use. Store the final mixture at $4{ }^{\circ} \mathrm{C}$.

2. Clean $13 \mathrm{~mm}$ diameter \#1 glass coverslips by placing an individual coverslip into each well of a 24 well plastic tissue culture plate. Add $500 \mu \mathrm{l}$ of $20 \%$ nitric acid to each well and incubate for $30 \mathrm{~min}$. Aspirate the nitric acid solution and wash coverslips three times with deionized water. 
3. Coat coverslips with $500 \mu \mathrm{l}$ of $50 \mu \mathrm{g} / \mathrm{ml}$ poly-L-lysine (prepared from $0.1 \%$ stock solution and diluted in deionized water) to each well for $20 \mathrm{~min}$ at room temperature. Aspirate the solution and wash three times with PBS. Poly-L-lysine coating facilitates even coating and bonding of the overlying labeled gelatin.

4. Add $500 \mu \mathrm{l}$ of $0.5 \%$ glutaraldehyde (made fresh before use) to each well and incubate the 24 well plates on ice for $15 \mathrm{~min}$. Aspirate and wash three times with cold PBS. Be sure to remove all traces of PBS prior to gelatin coating. Keep plates on ice during all washes until gelatin is added.

5. Reconstitute the Oregon Green 488-conjugated gelatin as per manufacturer's protocol and warm it and the unlabeled $5 \%$ gelatin/sucrose solution from (1.1) to $37^{\circ} \mathrm{C}$. Dilute one part Oregon Green 488 gelatin into eight parts of unlabeled gelatin/sucrose (i.e.; $500 \mu \mathrm{l}$ of Oregon Green 488 gelatin into $4 \mathrm{ml}$ of $5 \%$ gelatin mixture). Pipet $100 \mu \mathrm{l}$ of the diluted $488-$ gelatin mixture (kept at $37^{\circ} \mathrm{C}$ ) onto each coverslip, using enough gelatin to coat the coverslip without manual spreading (which can lead to uneven coverslip coating as shown in Figure 3B). It is important to keep the diluted 488-gelatin mixture at $37^{\circ} \mathrm{C}$ during the coating procedure to prevent premature solidification. From this step forward the coverslips should be kept in the dark as much as possible to avoid potential photobleaching. Other ECM proteins conjugated to different fluorophores can be substituted for Oregon Green 488 gelatin (see Discussion).

6. Once all coverslips are coated in a single plate, hold the 24 well plate at an angle and remove excess gelatin from each well by vacuum aspiration. Incubate coated coverslips in the dark for $10 \mathrm{~min}$ at room temperature.

7. Wash the coverslips three times with PBS, then add $500 \mu \mathrm{l}$ of freshly made $5 \mathrm{mg} / \mathrm{ml}$ sodium borohydride $\left(\mathrm{NaBH}_{4}\right)$ for 15 min at room temperature to reduce and inactivate residual glutaraldehyde. Sodium borohydride is effervescent, and small bubbles will be evident on and around each coverslip.

8. Remove the $\mathrm{NaBH}_{4}$ solution by vacuum aspiration with a quick sweeping motion around the outside of each well. Take care not to pick up any floating coverslips that became detached from the bottom of the tissue culture plate during $\mathrm{NaBH}_{4}$ treatment. Detached coverslips that float to the top may be gently pushed back down to the well bottom, but care must be taken to avoid damaging the protein coating. Wash each well three times with PBS and then incubate coverslips in $70 \%$ ethanol for $30 \mathrm{~min}$ at room temperature.

9. Using sterile technique, transfer the coverslip-containing plates to a type IIA/B cell culture laminar flow hood and rinse coverslips three times with sterile PBS. At this point coverslips can be stored in PBS protected from light at $4{ }^{\circ} \mathrm{C}$ for at least two months.

10. Transfer coverslips to be used for degradation assays to an empty well of a new 24 well plate by careful removal using a sterile needle and forceps. Equilibrate coverslips for 1-24 hr with complete media appropriate to the specific cell type being assayed. Care must be taken not to invert the coverslip or scratch the gelatin coating (see Figure 3B).

\section{Plating and Processing of Cells on Oregon Green 488-gelatin Coated Coverslips to Assay ECM Degradation}

1. Seed $3-5 \times 10^{4}$ cells onto a coverslip within each well of the 24 well plate.

2. Conduct a time course study to determine optimal times required for invadopodia degradation activity for the particular cell line/type of interest. Most invasive cells require a time between 4-24 h for degradation to become apparent, although this range can vary widely and should be empirically determined. To synchronize invadopodia activity, cells can be treated with MMP inhibitors (e.g., GM 6001) for a desired time period, then wash out the inhibitor to allow invadopodia activity to proceed (for example, see ${ }^{6}$ ).

3. Rinse coverslips three times with PBS, then fix cells with $500 \mu \mathrm{l}$ of $10 \%$ buffered formalin phosphate for 15 min. Rinse three times with PBS and permeabilize for 4 min with $0.4 \%$ Triton X-100 in PBS. Rinse three times with PBS to remove the Triton $\mathrm{X} 100$.

4. Label cells using any standard protocol for immunofluorescence staining (see ${ }^{7}$ for example) by co-labeling cells with fluorescent conjugated phalloidin to visualize actin filaments (F-actin) and for a known marker protein that localizes to invadopodia (e.g; cortactin ${ }^{5}, \mathrm{TKS}^{8}$, or $\mathrm{N}-\mathrm{WASp}^{9}$ ). Remember to avoid using 488-labeled secondary antibodies or GFPlabeled proteins if using Oregon Green 488 or FITC-labeled gelatin to prevent signal interference.

5. Mount stained coverslips onto glass microscope slides by carefully inverting the coverslip and placing it on a drop of ProLong Gold antifade or similar reagent.

6. To assess matrix degradation, image cells in appropriate channels using a conventional fluorescent or confocal microscope. Gelatin degradation is visualized as darker areas on the coverslip due to proteolytic removal of the fluorescent gelatin (Figure 4A). Labeling of cells for actin and an invadopodia marker protein allows for confirmation of invadopodia at sites of matrix degradation in merged images (Figure 4A).

7. Degradation activity can also be monitored in real time by live cell imaging with fluorescent-tagged recombinant proteins to track invadopodia formation and matrix degradation ${ }^{5,10,11}$.

\section{Quantification of Fluorescent Gelatin Degradation by Measuring Normalized Matrix Degradation}

This analysis provides the normalized area of matrix degradation relative to the area of the cells or the number of cells. It is useful for analyzing entire microscopic fields of view where multiple cells are present that have been collectively treated with siRNA, growth factors or therapeutic agents. For this analysis, images collected at lower magnification are sufficient to efficiently collect information about populations of cells. 
1. Open the images in Image ${ }^{12}$. ImageJ for microscopy can be downloaded from http://www.macbiophotonics.ca/imagej/.

2. Check the scale information by choosing the menu command "Analyze/Set Scale." This information will import automatically with many file formats, but can be entered manually if required. Proper scaling is necessary to report measurements in microns rather than pixels.

3. Select the appropriate measurements to track by choosing "Analyze/Set Measurements." Check Area and Limit to Threshold.

4. Calculate the area of degradation using the fluorescent gelatin image (Figure 5A).

5. Threshold the image ("Image/Adjust/Threshold") to set the upper and lower pixel intensity values to select the areas of degradation (highlighted in red; Figure 5B). In subsequent images, use the Set button in the Threshold window to set the same threshold for all images as an objective means to select degradation area.

6. In some cases, the coverslip may not be perfectly flat when images are acquired. This causes the intensity of the gelatin to change across the image. If this variation creates problems when thresholding the image, correct for uneven illumination across the gelatin by subtracting the background ("Process/Subtract Background") or by filtering with a bandpass filter ("Process/FFT/Bandpass Filter") or a pseudo flatfield filter ("Process/Filters/Pseudo Flatfield") until the background intensity is uniform.

7. Measure the area of matrix degradation ("Analyze/Analyze Particles"). In the Analyze Particles window, choose a particle size $>0$ to remove noise from the selection. Show Outlines to identify regions of interest (ROls). Check Display Results and Summarize to show measurements. If the drawing has specifically outlined all of the areas of degradation (Figure 5C), copy the Total Area measurement into a spreadsheet. If other objects were selected (such as debris), record only the areas of the relevant ROIs.

8. Calculate the cell area using the phalloidin stained (F-actin) image (Figure 5D).

9. Threshold the image ("Image/Adjust/Threshold") to set the upper and lower pixel intensity values so that the edges of the cells are selected (highlighted in red; Figure 5E). In subsequent images, use the Set button in the Threshold window to set the same threshold for all images as an objective means to select cell area.

10. Measure the area of the cells ("Analyze/Analyze Particles"). In the Analyze Particles window, choose a particle size $>0$ to remove noise from the selection. Show Outlines to identify regions for analysis (Figure 5F). Check Display Results and Summarize to show area measurements. Do not check Include Holes if there are spaces between cells in a cluster so the non-selected pixels within the cluster will not be included in the cell area calculation. Choose $O K$.

11. Copy the Area results for relevant ROls into a spreadsheet.

12. Calculate the area of gelatin degradation per total area of cells ${ }^{13}$

13. An alternative approach would be to report the area of degradation per number of cells from counting nuclei (Figure 5G). This is necessary if manipulations alter the cell area between different compared treatment groups. Automatic counting works best if nuclei are well separated, uniform in intensity and round. Automatically count nuclei ("Plugins/Particle Analysis/Nucleus Counter"). Choose Smallest and Largest Particle Size, a Threshold Method and a Smoothing Method. Check Subtract Background, Watershed Filter, Add Particles to ROI Manager and Show Summary (Figure 5H).

14. If nuclei overlap extensively or have an irregular shape or texture, automatic counting may not produce an accurate count (Figure 5H, arrows on right). In this case, manual counting can be facilitated using the cell counter tool ("Plugins/Particle Analysis/Cell Counter"). This will keep count as cells are marked during a manual count (Figure 5I).

15. Copy the number of cells (nuclei) into a spreadsheet. Calculate the area of gelatin degradation per total number of cells.

\section{Quantification of Fluorescent Gelatin Degradation by Individual Cells in a Mixed Cellular Population}

To evaluate matrix degradation resulting from specific cells in a population apart from other cells within the field (e.g., transfected versus non- transfected cells), the procedure in section 3 can be modified to measure the area of degradation under individual cells. An additional fluorescent channel is needed to mark transfected cells. In this instance, higher magnification images and well-separated cells are easier to quantitate.

1. Check the scale information by choosing the menu command "Analyze/Set Scale." Select the appropriate measurements to track by choosing "Analyze/Set Measurements." Check Area and Limit to Threshold.

2. For individual cells that are not touching, identify each cell using the F-actin image (Figure 6A). Threshold the image (see 3.9) (Figure 6B). It is important to capture the edges of the cells, but there can be holes inside that are not included in the threshold. Use the same intensity values across images to select cell boundaries.

3. To measure the area of the cells, use "Analyze/Analyze Particles. "In the Analyze Particles window, choose a Size >0 (to eliminate noise), Show Outlines, and check Display Results, Add to Manager and Include Holes (to record the entire area inside the outline). Choose $O K$ and record the Area for each cell from the Results window.

4. Identify which cells are transfected (Figure 6C).

5. Identify the areas of degradation using the fluorescent gelatin image (Figure 6D). If needed, filter the gelatin image to even background intensity (see 3.6). Threshold to select the areas of degradation, making note of the threshold settings (Figure 6E). On subsequent images, use these same upper and lower intensity values (using the Set button in the Threshold window) for an objective selection of areas of degradation.

6. Measure the areas of degradation under the cells. On the thresholded fluorescent gelatin image, show an outline of the cells by selecting ROIs in the ROI Manager window and selecting Measure (Figure 6F). Record the results and calculate the normalized area of degradation/ cell or cell area. 


\section{Representative Results}

The overall schematic for the procedure is shown in Figure 1. The procedure entails preparation of glass coverslips and coating with fluorescently-conjugated gelatin, plating of cells onto the coated coverslips to allow cells to degrade the gelatin, fixing and labeling of cells for fluorescence microscopic analysis, imaging the fluorescent matrix to assess the matrix integrity, and objectively quantifying the degree of gelatin matrix degradation using computer software. 


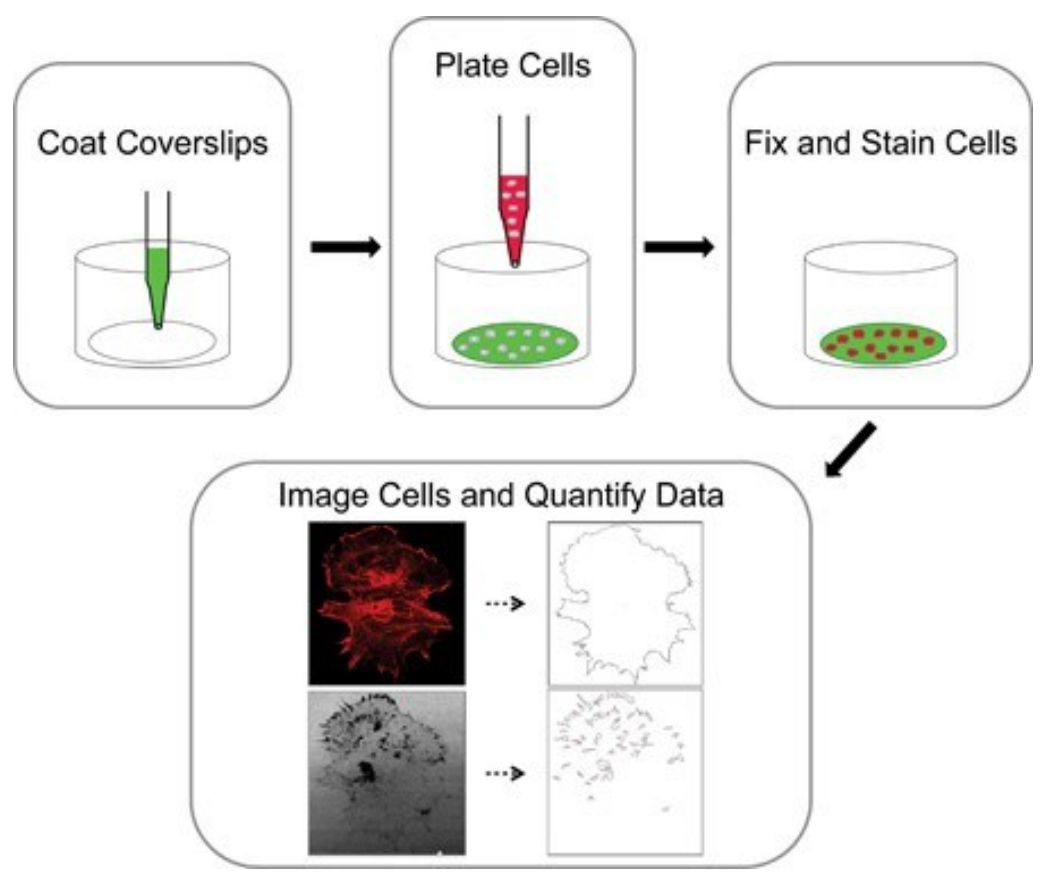

Figure 1. Overall schematic highlighting the key steps involved in fluorescent gelatin coating, cell plating, fixing and immunolabeling, and evaluating matrix proteolysis.

The key procedural steps involved in preparing and coating glass coverslips are outlined in Figure 2.

Prior to gelatin coating

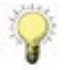

Coating
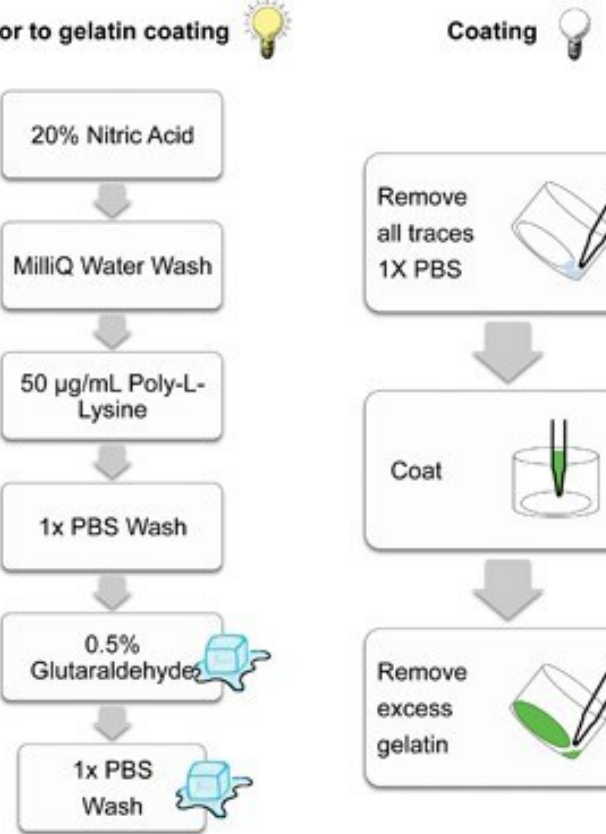

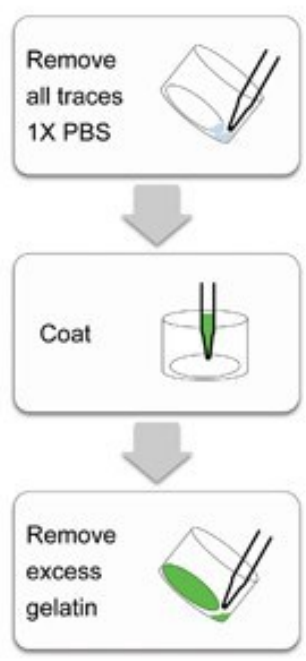

After Coating

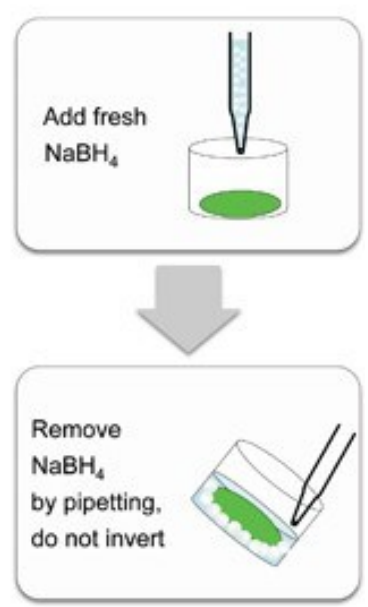

Figure 2. Schematic demonstrating the individual steps involved in preparing glass coverslips for gelatin matrix coating Steps conducted in the light (lit bulb), on ice (cubes) and in the dark (non-illuminated bulb) are cartoon indicated. Steps conducted in the dark help prevent photobleaching of the fluorescent matrices.

When properly performed, coverslips are evenly coated with Oregon Green 488-conjugated gelatin, displaying homogenous fluorescence when visualized by microscopy (Figure 3A). Typical artifacts that can arise due to improper coating, handling, storage and usage of coated coverslips are shown in Figure 3B. 
A

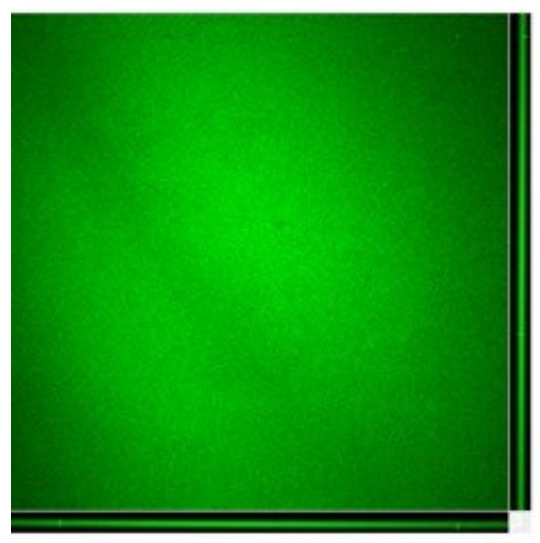

B

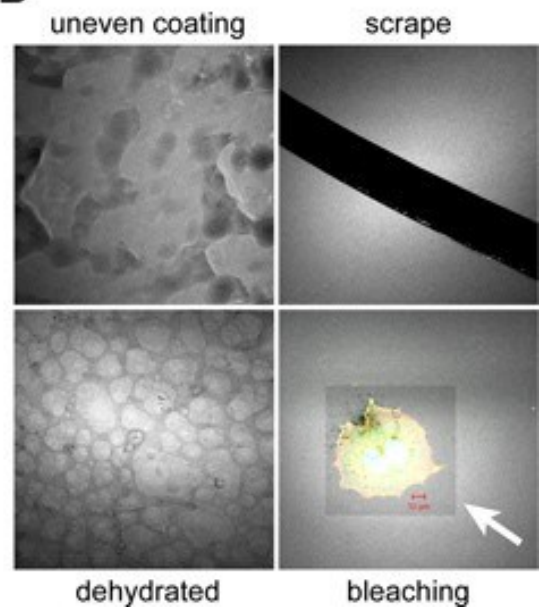

Figure 3. Examples of artifacts encountered during gelatin coated coverslip preparation and handling. A. Orthogonal view of a confocal z-stack showing the typical color and consistency of an Oregon Green 488-conjugated gelatin coated coverslip produced using the prescribed protocol. Coverslips should have a homogenous coating $\sim 1-2 \mu \mathrm{m}$ thick as shown in the $X-Z$ (bottom) and Y-Z (right) confocal planes. B. Artifacts that

can occur during the coating and processing of gelatin-coated coverslips include: Improper covering of the coverslip during the coating process due to poor mixing, manual spreading or partial solidification of the gelatin mixture (uneven coating), removal of the coated matrix by scoring with needles or forceps during handling (scrape), drying of the coverslip surface during prolonged storage periods, resulting in a "cobblestone" appearance (dehydrated) and photobleaching of the fluorescent gelatin surface during imaging due to prolonged or high intensity light exposure (bleaching). White arrow indicates bleached area encompassing a plated OSC19 head and neck squamous carcinoma cell. The Oregon Green 488-conjugated gelatin is pseudocolored white to enhance image contrast. Bar, $10 \mu \mathrm{m}$.

The resulting thin matrices produced during this procedure provide a sensitive means to evaluate the ability of cells to degrade ECM. Figure 4 demonstrates an example of invadopodia activity from an OSC19 cell plated on an Oregon Green488 conjugated gelatin coverslip and imaged by conventional confocal microscopy as well as by volume-fill image rendering following three dimensional deconvolution. 
A
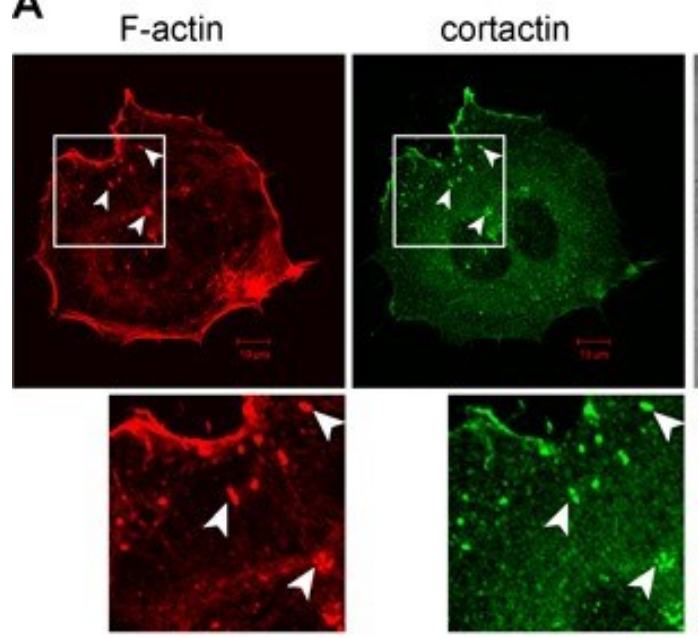

B
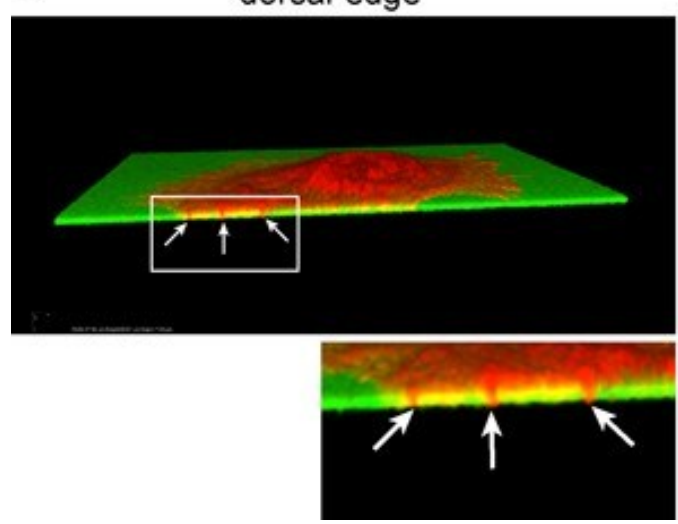

\section{OG 488-gelatin}
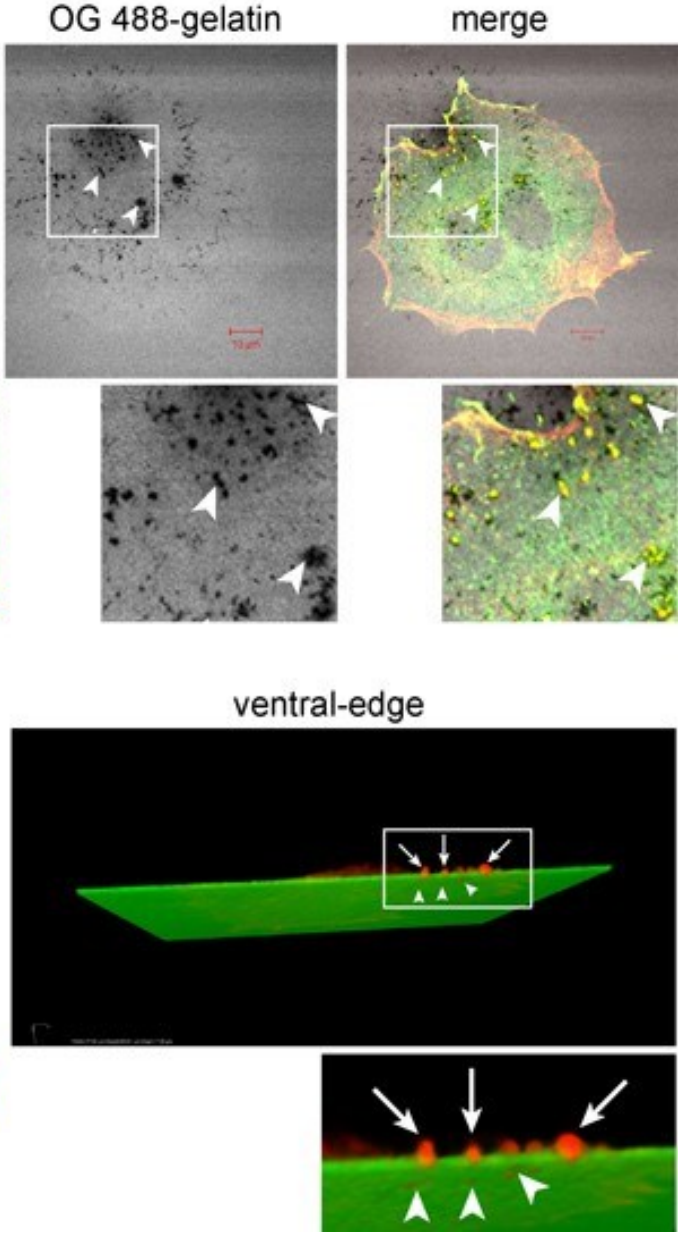

Figure 4. Representative examples of invadopodia matrix degradation activity. A. Visualization of invadopodia and corresponding gelatin matrix proteolysis. OSC19 cells plated on Oregon Green 488-conjugated gelatin coverslips for $10 \mathrm{hr}$ were fixed and labeled with rhodamine-conjugated phalloidin (F-actin) and anti-cortactin antibodies (visualized with an Alexa Fluor 647 secondary antibody and pseudocolored green). Invadopodia are evident as focal cytoplasmic concentrations of F-actin and cortactin that overlap with areas of gelatin clearing (dark holes in the matrix) within the merged image. Boxed regions containing arrowheads indicate individual invadopodia and areas of focal matrix proteolysis as shown in the enlarged regions below. Bar, $10 \mu \mathrm{m}$. B. Volume fill visualization of invadopodia penetration into the ECM. OSC 19 cells plated and stained as in (A) were visually rendered by obtaining 23 successive $0.32 \mu \mathrm{m}$ optical z-slices totaling $7.04 \mu \mathrm{m}$ for rhodamine-conjugated phalloidin and Oregon Green 488-conjugated gelatin. The native LSM file set for each channel was opened in AutoQuant X2.2 software and a 3D blind deconvolution

of each image stack was performed using the recommended settings (10 iterations, medium noise). The processed images were saved as TIFF stacks that were then opened in NIS Elements and rendered as a volume view with alpha blending. The LUTs were adjusted, and a subvolume was created to show an edge inside the cell where invadopodia are present. Dorsal-edge view demonstrates invadopodia (red, arrows) inserted into the underlying gelatin (green). Ventral-edge view shows protrusive invadopodia and areas of gelatin degradation underneath the coverslip as regions of red present in the green matrix (arrowheads). The total image field presented is cropped to $77 \times 65 \mu \mathrm{m}$; the cell is $60 \times 40 \mu \mathrm{m}$.

Figure 5 shows some of the important steps for quantification of normalized gelatin matrix degradation as described in step 3 of the protocol. This procedure is designed to allow for unbiased quantitation of gelatin degradation in an entire field of view, and is suitable for matrix degradation attributed to many cells within the field. 

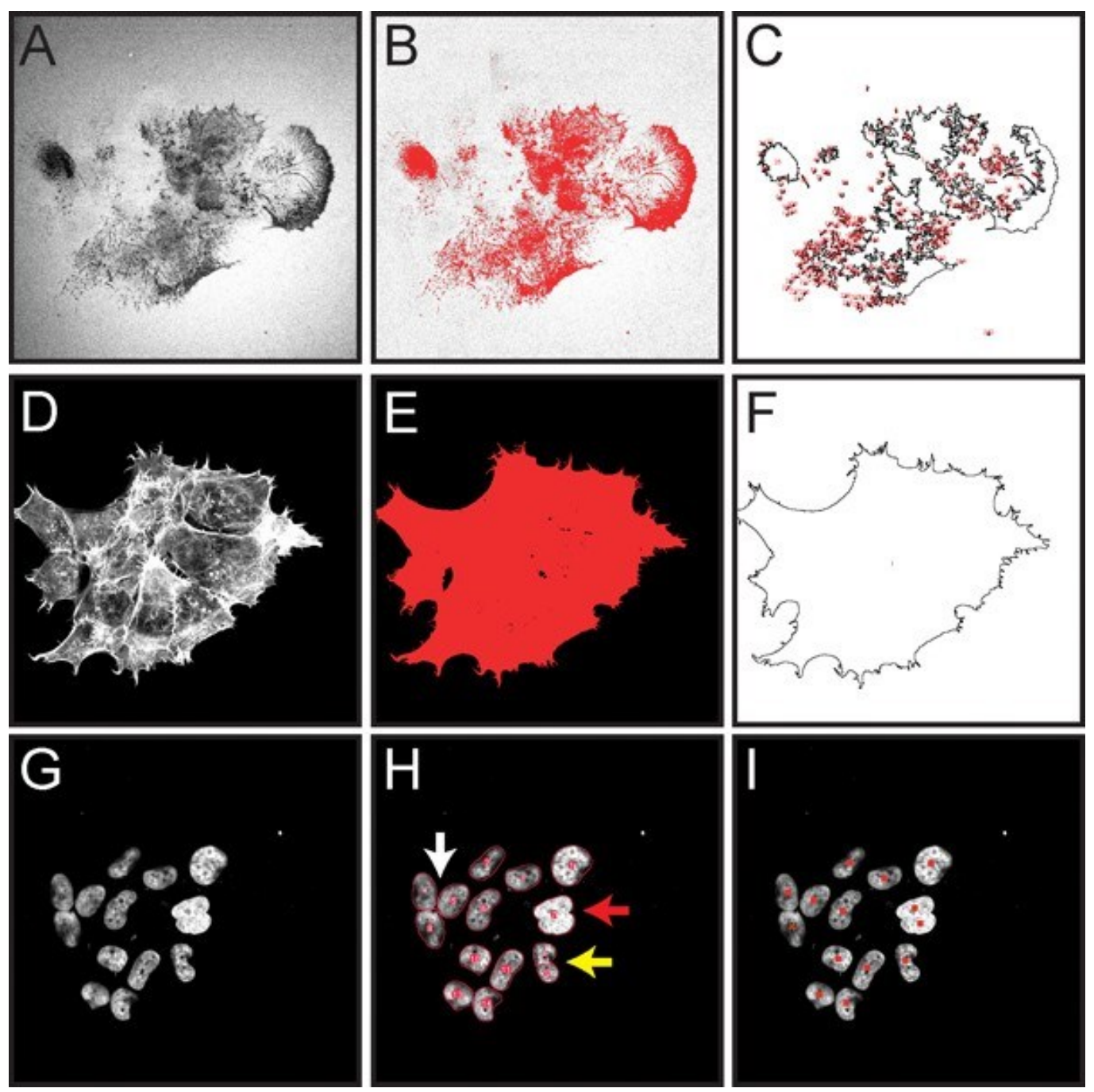

Figure 5. Screen capture images demonstrating key steps in computational-assisted quantification of normalized gelatin degradation for cells within an entire microscopic image as described in protocol step 3. All fluorescent images have been converted to grayscale to better display the red thresholding and ROI markings. A. Image of Oregon Green 488-conjugated gelatin, showing dark areas ("holes") where degradation has occurred (step 3.4). B. Thresholded gelatin image highlighting areas of degradation in red (step 3.5). C. Drawing showing ROls measured for area of degradation (step 3.7). D. Rhodamine phalloidin staining of F-actin (step 3.8). E. Thresholded actin image highlighting total cell area in red (step 3.9). F. Drawing showing cell areas to be measured (step 3.10). G. Image of DAPI-stained cell nuclei (step 3.13). H. Red outlines show results from automatic nuclei counting (step 3.13). The Watershed filter has the potential to separate nuclei that are touching (white arrow). If nuclei overlap extensively, they may not be separated into individual objects (red arrow). If a nucleus has an irregular shape, it may be separated into multiple objects (yellow arrow). I. Results from marking nuclei during a manual count using the cell counter tool (step 3.14).

Figure 6. demonstrates select steps involved in quantifying fluorescent gelatin degradation by individual cells within a mixed cellular population as described in protocol step 4 . Here, matrix degradation by transfected cells can be analyzed within a mixed population of transfected and non- transfected cells. 

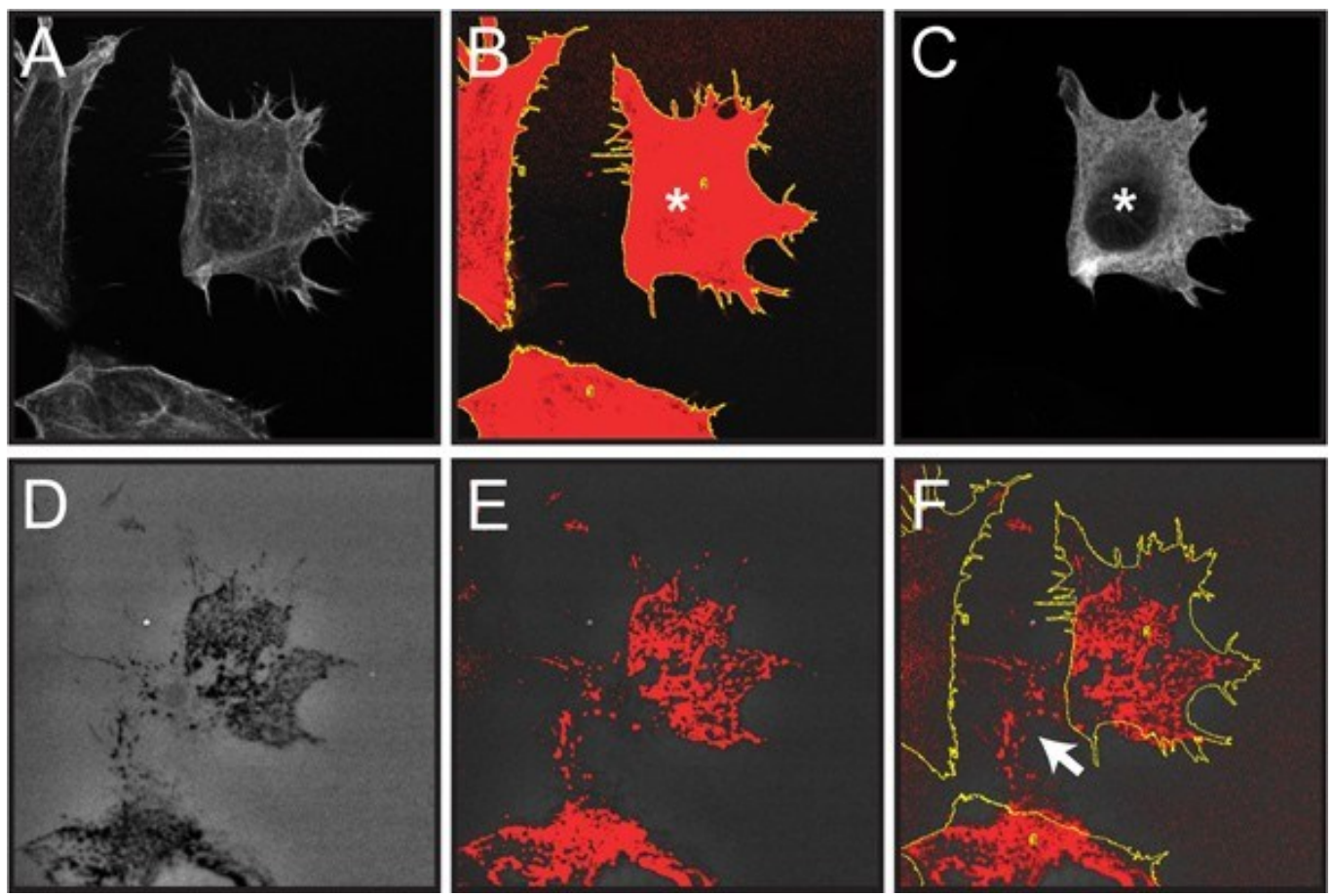

Figure 6. Screen capture images of steps involved in quantifying gelatin degradation from individual transfected cells within a cell population. Quantification of a single transfected OSC19 cell overexpressing recombinant cortactin fused to the FLAG epitope tag is shown as an example. All fluorescent images have been converted to grayscale to better display the red thresholding and yellow ROI markings. A. Confocal image

of three cells labeled with rhodamine-phalloidin (step 4.2). B. Drawing of total cell area based on F-actin staining following application of the Threshold and Analyze Particles functions (step 4.2-3). C. Confocal image of anti-FLAG immunolabeling of the cell population demonstrating a single cell expressing FLAG-tagged cortactin (marked with *) (step 4.4). D. Image of Oregon Green 488-conjugated gelatin, showing dark areas ("holes") where degradation has occurred (step 4.5) E. Thresholded gelatin image highlighting dark areas of degradation in red (step 4.5). F. Thresholded gelatin image overlaid with cell outlines from panel B (step 4.6). Note that only the thresholded pixels within the cell outlines are counted in the analysis. Areas of degradation outside the current cell location (white arrow) result from cell migration across the gelatin over time and are not included in the analysis.

\section{Discussion}

The ability to visualize cells degrading the extracellular matrix has aided in discovering the molecular mechanisms employed in the early steps

of cell invasion. Pioneered by Wen-Tien Chen in the early $1980^{\prime} \mathrm{s}^{4,14,15}$, coating fluorescently labeled extracellular proteins on glass coverslips for subsequent microscopic analysis has emerged as the primary technique in evaluating invadopodia function across a wide range of cell types. The prescribed protocol demonstrates the basic method used for preparing gelatin-coated coverslips that form a collagenous layer less than

$2 \mu \mathrm{m}$ thick suitable for detection of extracellular matrix degradation by cells in most conventional fluorescent and confocal microscopes ${ }^{11,16-18}$, similar to what has been previously described ${ }^{19-21}$. These properties allow for rapid production of coated coverslips capable of detecting the initial onset of matrix degradation. The sensitivity afforded by the resulting thin gelatin matrix on the underlying hard glass surface likely aids in promoting invadopodia formation as a response to the high inherent stiffness of the overall matrix environment ${ }^{22}$. However, these matrices are not well suited for analysis of invadopodia elongation or additional morphological evaluation that has been achieved using thicker $(30-100 \mu \mathrm{m})$ gelatin layers with similar methodology, coated transwells or electron microscopy ${ }^{20,23,24}$

We have found that pre-conjugated commercially produced Oregon Green 488 gelatin allows for rapid experimental set up and consistent, reproducible results. However, alkaline borate conjugation of fluorescein isothiocyanate (FITC) to unlabeled gelatin remains a popular and inexpensive method for producing fluorescent gelatin conjugates ${ }^{20}$. Fibronectin is also used as an alternative matrix protein for labeling and coverslip coating ${ }^{4,9}$, and in some cases investigators have used labeled fibronectin layered onto unlabeled gelatin coated coverslips to create denser matrices ${ }^{11,25}$. Other matrices could be used, depending on the specifics of the cell type. In addition to dyes in the green $488 \mathrm{~nm}$ spectrum, a wide range of fluorophores have also been used with manual coupling methods to generate coverslips with different fluorescence spectra, including rhodamine ${ }^{21,26}$, Alexa Fluor 
$350^{24}, 546^{21}, 568^{5,11}, 594^{27}$ and $647^{5}$ dyes. Such conjugates are easily adaptable for use in the prescribed protocol, providing the flexibility for utilizing specific ECM protein-dye combinations suitable for most any imaging filter set.

The techniques described herein provide the necessary detailed steps for utilizing ImageJ to quantify gelatin matrix degradation attributed to individual cells in a heterogeneous population or to entire cell groups as published previously ${ }^{6,28}$. Proprietary software has also been successfully employed for the same purpose $e^{5,25}$. In this protocol, the area of matrix degradation is normalized to either the total area of the cells or the

total number of cells (nuclei) in the field. Generally, both options for normalization will give the same result (ELW, data not shown). However, if

different cell lines having different sized cells are being compared or if the experimental treatment causes cells to change size, then it may be

more accurate to normalize to cell number. On the other hand, many cancer cell lines have a high percentage of multi-nucleated cells, in which case total cell area may be a more accurate parameter for normalization. Also, if only part of a cell is captured in an image (Figure 6), it may

be better to normalize to cell area rather than underestimate the degradation potential for an individual cell. It is important to optimize the image analysis to best suit the characteristics and nuances of the specific experimental setup.

For determining cell numbers in a crowded field, counting nuclei is often the method of choice. ImageJ has a nucleus counter plugin for automatic counting. One option in this tool is the Watershed filter. This filter will help separate nuclei that are touching by segregating them into individual objects (Figure $\mathbf{5 H}$, white arrow). However, this filter may not be able to separate nuclei that overlap extensively (Figure $\mathbf{5 H}$, red arrow). In addition, if a nucleus has an irregular shape and large variations in intensity, the filter may separate a single nucleus into multiple objects (Figure $\mathbf{5 H}$, yellow arrow). Therefore, it is important to try different thresholding and smoothing methods in this plugin to determine the

best parameters for analysis. If the automatic counting does not produce accurate numbers, the cell counter plugin can facilitate manual counting of cells or nuclei.

In cases utilizing transient transfection, images will often contain a mixture of cells expressing or not expressing a protein of interest (Figure

6). In this scenario, it is not always apparent which cells were responsible for creating areas of matrix degradation. This is especially true if the cells are migrating across the gelatin. To be consistent in the analysis, it is important to only measure the degraded areas directly underneath each cell. By thresholding to select the dark areas in the matrix and using the actin to generate cell outlines, only the degraded areas under the cells will be quantitated. This procedure will exclude degraded areas outside of cell boundaries from analysis (Figure $6 \mathrm{~F}$, arrow). The assay may require optimization to select a time point that allows sufficient time for degradation before the cells have had a chance to move.

Numerous methods have been developed to quantitate invadopodia formation and function. In addition to matrix degradation, other frequently reported parameters include determining the number of invadopodia per cell, the percentage of cells displaying invadopodia within a given population, and the number of "immature" or "pre" non-degrading invadopodia compared to "mature" invadopodia capable of degrading the ECM ${ }^{11,13,25,26}$. The method(s) of choice for invadopodia evaluation depend on inherent characteristics of each cell type. For instance, counting the number of invadopodia per cell or determining the percentage of cells containing invadopodia is a straightforward approach that works well if the analyzed cells contain just a few prominent invadopodia, but becomes more difficult in cells that have dozens of invadopodia or where invadopodia may be small and difficult to detect. Using the degradation assay makes it possible to calculate the percentage of pre-invadopodia vs. mature invadopodia in single cells or in a population by comparing the total number of cells with invadopodia to the percentage that are degrading matrix. If there is a discrepancy where fewer cells are degrading matrix compared to cells displaying invadopodia, it may indicate that

these cells are forming pre-invadopodia that were incapable of matrix degradation at the time the cells were fixed.

Whatever method combination is chosen for analysis, it is important to quantify the desired invadopodia characteristics as objectively as possible. When collecting images on the microscope, choose fields by looking at cells (actin), rather than the fluorescent matrix, to avoid bias from preferentially selecting areas with high levels of degradation. Multiple images should be acquired to ensure a fair representation of the cell population. Images should also be acquired at an appropriate magnification. For uniform populations of cells, lower magnification can be used to collect more cells as long as the areas of degradation can still be resolved. Higher magnification images are preferred to measure areas under individual cells and to resolve individual invadopodia. When areas are being quantitated, thresholding images based on intensity is more objective than manually choosing the area of the matrix to measure. In all cases, a sufficient number of cells from multiple independent experiments should be analyzed to give statistically meaningful, reproducible results.

\section{Disclosures}

No conflicts of interest declared. 
This work was supported by endowment funds from the West Virginia University Mary Babb Randolph Cancer Center. We thank Susette Mueller (Georgetown University) and Laura Kelley for early advice and assistance. The use of the West Virginia University Microscopy Imaging Facility (supported by the Mary Babb Randolph Cancer Center and, NIH grants P20 RR16440, P30 RR032138 and P30 GM103488) is gratefully acknowledged.

\section{References}

1. Ridley, A.J. Life at the leading edge. Cell. 145, 1012-1022, [pii] S0092-8674(11)00652-0 doi:10.1016/j.cell.2011.06.010 (2011).

2. Murphy, D.A. \& Courtneidge, S.A. The 'ins' and 'outs' of podosomes and invadopodia: characteristics, formation and function. Nat. Rev. Mol. Cell Biol. 12, 413-426, [pii] nrm3141 doi:10.1038/nrm3141 (2011).

3. Linder, S., Wiesner, C., \& Himmel, M. Degrading Devices: Invadosomes in Proteolytic Cell Invasion. Annu. Rev. Cell. Dev. Biol., doi:10.1146/annurev-cellbio-092910-154216 (2010).

4. Chen, W.T., Chen, J.M., Parsons, S.J., \& Parsons, J.T. Local degradation of fibronectin at sites of expression of the transforming gene product pp60src. Nature. 316, 156-158 (1985).

5. Artym, V.V., Zhang, Y., Seillier-Moiseiwitsch, F., Yamada, K.M., \& Mueller, S.C. Dynamic interactions of cortactin and membrane type 1 matrix metalloproteinase at invadopodia: defining the stages of invadopodia formation and function. Cancer Res. 66, 3034-3043, [pii] 66/6/3034 doi:10.1158/0008-5472.CAN-05-2177 (2006).

6. Ayala, I., et al. Multiple regulatory inputs converge on cortactin to control invadopodia biogenesis and extracellular matrix degradation. J. Cell Sci., (2008).

7. Ammer, A.G., et al. Saracatinib impairs head and neck squamous cell carcinoma invasion by disrupting invadopodia function. J. Cancer Sci. Ther. 1, 52-61, doi:10.4172/1948-5956.1000009 (2009).

8. Seals, D.F., et al. The adaptor protein Tks5/Fish is required for podosome formation and function, and for the protease-driven invasion of cancer cells. Cancer Cell. 7, 155-165 (2005).

9. Yamaguchi, H., et al. Molecular mechanisms of invadopodium formation: the role of the N-WASP-Arp2/3 complex pathway and cofilin. J. Cell Biol. 168, 441-452 (2005).

10. Kopp, P., et al. The kinesin KIF1C and microtubule plus ends regulate podosome dynamics in macrophages. Mol. Biol. Cell. 17, 2811-2823, [pii] E05-11-1010 doi:10.1091/mbc.E05-11-1010 (2006).

11. Oser, M., et al. Cortactin regulates cofilin and N-WASp activities to control the stages of invadopodium assembly and maturation. J. Cell. Biol. 186, 571-587 (2009).

12. Rasband, W.S. ImageJ. U.S. National Institutes of Health., (1997-2011).

13. Kelley, L.C., et al. Oncogenic Src requires a wild-type counterpart to regulate invadopodia maturation. J. Cell Sci. 123, 39233932, [pii] jcs.075200 doi:10.1242/jcs.075200(2010).

14. Chen, W.T. \& Singer, S.J. Fibronectin is not present in the focal adhesions formed between normal cultured fibroblasts and their substrata. Proc. Natl. Acad. Sci. U.S.A. 77, 7318-7322 (1980).

15. Chen, W.T., Olden, K., Bernard, B.A., \& Chu, F.F. Expression of transformation-associated protease(s) that degrade fibronectin at cell contact sites. J. Cell Biol. 98, 1546-1555 (1984).

16. Bharti, S., et al. Src-dependent phosphorylation of ASAP1 regulates podosomes. Mol. Cell Biol. 27, 8271-8283 (2007)

17. Albrechtsen, R., Stautz, D., Sanjay, A., Kveiborg, M., \& Wewer, U. M. Extracellular engagement of ADAM12 induces clusters of invadopodia with localized ectodomain shedding activity. Exp. Cell Res. 317, 195-209, [pii] S0014-4827(10)00457-X doi:10.1016/j.yexcr.2010.10.003 (2011).

18. Scott, R.W., et al. LIM kinases are required for invasive path generation by tumor and tumor-associated stromal cells. J. Cell Biol. 191, 169-185, [pii] jcb.201002041 doi:10.1083/jcb.201002041 (2010).

19. Mueller, S.C., Yeh, Y., \& Chen, W.T. Tyrosine phosphorylation of membrane proteins mediates cellular invasion by transformed cells. J. Cell. Biol. 119, 1309-1325 (1992).

20. Bowden, E.T., Coopman, P.J., \& Mueller, S.C. Invadopodia: unique methods for measurement of extracellular matrix degradation in vitro. Methods Cell Biol. 63, 613-627 (2001).

21. Baldassarre, M., et al. Dynamin participates in focal extracellular matrix degradation by invasive cells. Mol. Biol. Cell. 14, 1074$1084(2003)$

22. Alexander, N.R., et al. Extracellular matrix rigidity promotes invadopodia activity. Curr. Biol. 18, 1295-1299, [pii] S09609822(08)01035-X doi:10.1016/j.cub.2008.07.090 (2008).

23. Artym, V.V., Yamada, K.M., \& Mueller, S.C. ECM degradation assays for analyzing local cell invasion. Methods Mol. Biol. 522, 211-219, doi:10.1007/978-1-59745-413-1_15 (2009).

24. Schoumacher, M., Goldman, R.D., Louvard, D., \& Vignjevic, D.M. Actin, microtubules, and vimentin intermediate filaments cooperate for elongation of invadopodia. J. Cell Biol. 189, 541-556, [pii] jcb.200909113 doi:10.1083/jcb.200909113 (2010).

25. Clark, E.S., Whigham, A.S., Yarbrough, W.G., \& Weaver, A.M. Cortactin is an essential regulator of matrix metalloproteinase secretion and extracellular matrix degradation in invadopodia. Cancer Res. 67, 4227-4235, [pii] 67/9/4227 doi:10.1158/00085472.CAN-06-3928 (2007).

26. Yamaguchi, H., et al. Phosphoinositide 3-kinase signaling pathway mediated by $\mathrm{p} 110$ alpha regulates invadopodia formation. $J$. Cell Biol. 193,1275-1288, [pii] jcb.201009126 doi:10.1083/jcb.201009126 (2011).

27. Li, A., et al. The actin-bundling protein fascin stabilizes actin in invadopodia and potentiates protrusive invasion. Curr. Biol. 20, 339-345, [pii] S0960-9822(09)02159-9 doi:10.1016/j.cub.2009.12.035 (2010).

28. Yamaguchi, H., et al. Phosphatidylinositol 4,5-bisphosphate and PIP5-kinase lalpha are required for invadopodia formation in human breast cancer cells. Cancer Sci. [pii] CAS1574 doi:10.1111/j.1349-7006.2010.01574.x (2010). 
High Frequency Ultrasound Imaging of Mouse Cervical Lymph Nodes

\section{Authors:}

Elyse L. Walk*, Sarah L. McLaughlin* and Scott A. Weed

Elyse L. Walk

Department of Neurobiology and Anatomy

Program in Cancer Cell Biology

Mary Babb Randolph Cancer

Center West Virginia University

ewalk@hsc.wvu.edu

Sarah L. McLaughlin

Animal Models and Imaging

Facility Mary Babb Randolph

Cancer Center West Virginia

University

smclaughlin@hsc.wvu.edu

Scott A. Weed

Department of Neurobiology and Anatomy

Program in Cancer Cell Biology

Mary Babb Randolph Cancer

Center West Virginia University

scweed@hsc.wvu.edu

${ }^{*}$ Denotes equal

contribution

Corresponding

author: Scott A. Weed

Keywords

Ultrasound, cervical lymph node, mouse, imaging, animal model, anatomy, mapping 


\section{Short Abstract}

This protocol describes the application of high frequency ultrasound (HF US) for imaging mouse cervical lymph nodes. This technique optimizes visualization and quantification of cervical lymph node morphology, volume and blood flow. Image-guided biopsy of cervical lymph nodes and processing of lymph tissue for histological evaluation is also demonstrated. 


\section{Long Abstract}

High frequency ultrasound (HF US) is widely employed as a non-invasive method for imaging internal anatomic structures in experimental animal systems. HF US has the ability to detect structures as small as $30 \mu \mathrm{m}$, a property that has been exploited for visualizing superficial lymph nodes in rodents in brightness (B)-mode. Combining power Doppler with B-mode imaging allows for measuring circulatory blood flow within lymph nodes and other vessel-containing organs. While HF US has been utilized for lymph node imaging in a number of mouse model systems, a detailed protocol describing HF US imaging and characterization of the supraclavicular lymph nodes in mice has not been reported. Here, we show that HF US can be adapted to detect and characterize cervical lymph nodes in mice. Combined B-mode and power Doppler imaging can be used to detect increases in blood flow in immunologically-enlarged cervical nodes. We also describe the use of B-mode imaging to conduct fine needle biopsies of cervical lymph nodes to retrieve lymph tissue for histological analysis. Finally, software-aided steps are described to calculate changes in lymph node volume and to visualize changes in lymph node morphology following image reconstruction. The ability to visually monitor changes in cervical lymph node biology over time provides a simple and powerful technique for the non-invasive monitoring of cervical lymph node alterations in preclinical mouse models of oral cavity disease. 


\section{Introduction}

Lymph drainage of interstitial tissue fluid is the main method of dissemination for infectious microorganisms and cancers arising in the oral and maxillofacial region ${ }^{1,2}$. Clinical evaluation of cervical lymph nodes is a common diagnostic practice used to determine the presence or progression of diseases that originate in the oral cavity. This underscores the importance of the collecting supraclavicular lymph nodes as valuable anatomic sites for oral disease diagnosis ${ }^{3}$. Several specialized imaging methodologies are clinically utilized for identifying diseased cervical lymph nodes. These include positron emission tomography (PET), computed tomography (CT) and magnetic resonance imaging (MRI). While highly valuable, these methods all require extensive patient preparation, highly specialized equipment and/or chemical infusion into the circulation to enable or enhance the imaging process.

Sonographic imaging (ultrasound; US) is a commonly applied technique used to image cervical lymph nodes presenting with lymphadenopathy due to infection or metastatic involvement ${ }^{4-6}$. US is often combined with PET-CT and MRI imaging to provide a comprehensive representation of patient lymph node status, helping to determine tumor staging and necessity for surgical excision ${ }^{7}$. The non-invasive nature of US also has additional inherent advantages over other imaging modalities, including ease of use, low cost, minimal patient discomfort and preparation. The superficial subcutaneous location of most cervical lymph nodes allows for US to guide minimally invasive fine needle aspiration biopsies with increased precision, improving diagnostic accuracy ${ }^{8}$.

Commercial high frequency (HF) US provides detailed resolution of internal anatomic structures to $30 \mu \mathrm{m}^{9}$. When combined with suitably sized transducers, HF US has been readily applied to a variety of experimental rodent systems to allow real-time imaging of internal organs in vivo. HF US has been adapted for visualization of tumor formation in conventional brightness (B)-mode, as well as with a number of general and specialized contrast enhancement agents ${ }^{9}$. Using power Doppler with HF US provides the ability to monitor blood flow within mouse tumors, allowing a comprehensive assessment of angiogenic perfusion in live mice ${ }^{10,11}$. The resolution capability of HF US has been used to visualize diseased mouse lymph nodes within the main body cavity, demonstrating parallel utility of this technology to clinical practice. In particular, inflammatory and metastatic visceral lymph node alterations have been observed in mouse models of cancer harboring breast ${ }^{12,13}$, pancreatic ${ }^{14}$, colorectal ${ }^{15}$ and lung ${ }^{16}$ tumors, as well as fibrous histocytomas ${ }^{17}$. These examples solidify the value of HF US as a powerful investigative tool for tumor-induced lymphadenopathy in a wide variety of rodent systems.

Several models of bacterial infection ${ }^{18,19}$ and head and neck squamous cell carcinoma (HNSCC) ${ }^{20,21}$ have been developed to study these diseases in the preclinical setting. In contrast to humans, mice contain three supraclavicular lymph nodes that survey lymph from oral cavity tissues (mandibular, accessory mandibular and superficial parotid: ${ }^{22}$ ). Recently, we reported the use of HF US to map the location and morphology of these lymph nodes, monitoring changes in lymph node volume and blood flow in a 
carcinogen-induced mouse model of $\mathrm{HNSCC}^{23}$. Here, we provide a detailed protocol for the use of HF US for identifying, imaging and analyzing cervical lymph nodes in living mice. This protocol also demonstrates the feasibility of using HF US to conduct imageguided fine needle biopsy of enlarged mouse cervical lymph nodes, allowing histological monitoring of changes in cervical lymph node content and pathologies over time in the same animal. This protocol is readily adaptable to allow for the detailed study of cervical lymph node pathologies resultant from any invasive oral cavity disease in mice. 


\section{Protocol}

All animal procedures demonstrated in this protocol have been reviewed and approved by the West Virginia University Animal Care and Use Committee under protocols 110412 and 14-0514.

\section{Animal Preparation}

1.1 Anesthetize a single mouse in an induction chamber using $3 \%$ isofluorane mixed with $1.5 \mathrm{~L} / \mathrm{min} 100 \%$ oxygen. Remove the animal from the induction chamber and place in a supine position on the imaging platform preheated to $40{ }^{\circ} \mathrm{C}$ and maintained between $37-42^{\circ} \mathrm{C}$ (Figure $2 \mathrm{~A}$ ).

1.2 Position the mouse snout within the nosecone connected to the anesthesia system. Apply anesthesia to maintain steady state sedation (1.5\% isofluorane mixed with 1.5 L/min $100 \%$ oxygen).

1.3 Apply eye lubricant the each eye to prevent drying. Apply electrode gel to the electrodes and use tape to secure each of the four paws to the corresponding electrode. Lubricate and insert the rectal temperature probe for continuous monitoring of body temperature.

1.4 Use depilatory cream to remove the fur from the neck of the mouse. Rinse the neck region with water to remove hair and excess depilatory cream. A second depilatory application may be needed to remove any remaining body hair (Figure 1B).

\section{Identification and Image Acquisition of Mouse Cervical Lymph Nodes using HF US}

2.1 To begin, apply a layer of ultrasound gel to the neck area devoid of fur. A liberal application of gel is required for optimal image quality (Figure 1C). Avoid introducing air bubbles in the gel during application, which can interfere with ultrasonic imaging.

2.2 Adjust the imaging platform so the mouse is positioned with the head slightly elevated. Place the $40 \mathrm{MHz}$ transducer in the adjustable clamp and carefully lower it until the front of the transducer scanhead is immersed in the ultrasound gel (Figure 1C).

2.3 Adjust the brightness (B-)mode settings to the following parameters: Gain $22 \mathrm{~dB}$, depth $10.00 \mathrm{~mm}$, width $14.08 \mathrm{~mm}$. These settings are a suggested starting point, and may require slight adjusting for optimal image acquisition between different applications. Cervical lymph nodes typically appear as bean-shaped hypoechoic structures near the skin surface within a surrounding hyperechoic field. The following steps are used to systematically image all lymph nodes within the neck region:

2.3.1 Use the Y-axis to scan the neck in a cranial to caudal manner towards to thoracic region. Use $\mathrm{X}$-axis to center the image. 
2.3.2 Identify major landmarks: cheek pouch, tongue, and thyroid gland (Figures $3 \mathrm{~A}, \mathrm{~B}$ and $\mathrm{C}$; respectively); tilt the imaging stage to flatten the image, making both sides of the neck appear even in the B-mode image. The amount of tilting depends upon the physiology of each individual mouse.

2.4 Conduct a 3D scan of the entire neck region

2.4.1 Locate the tongue/cheek pouch region (Figure $3 \mathrm{~A}$ ) and note the numerical location on the $\mathrm{Y}$ scale.

2.4.2 Locate thyroid gland (Figure $3 \mathrm{C}$ ) and note the numerical location on the $\mathrm{Y}$ scale.

2.4.3 Calculate the difference between the obtained values in (2.4.1) and (2.4.2) to determine the total length in millimeters for the imaged neck region.

2.4.4 Center the transducer on the midpoint of the determined total length.

2.4.5 Press "3D". Enter the total length. For 3D step size, use $0.076 \mathrm{~mm}$ to acquire the image series stack for the entire neck region.

2.5 Once scanning is complete, select the right or left side of the neck and center the transducer on an individual lymph node of interest, then raise the $40 \mathrm{MHz}$ transducer off the mouse. Remove the $40 \mathrm{MHz}$ transducer and replace with a $50 \mathrm{MHz}$ microscan transducer to obtain higher-resolution images. Replenish the ultrasound gel on the mouse neck and lower the $50 \mathrm{MHz}$ transducer into the ultrasound gel.

2.6 Conduct 3D scans of individual cervical lymph nodes as follows:

2.6.1 Press the Power button on the system keyboard to acquire power Dopper and adjust the following power-mode settings: PRF $4 \mathrm{KHz}$, Doppler gain $34 \mathrm{~dB}$, 2D gain $30 \mathrm{~dB}$, depth $5.00 \mathrm{~mm}$, width $4.73 \mathrm{~mm}$. As before, these settings are a suggested starting point and may need to be modified as needed for optimal image acquisition in various models.

2.6.2 Locate the cranial-most point of the lymph node of interest and note the location on the $\mathrm{Y}$ scale.

2.6.3 Locate the most caudal point of the same node and note the location on the $\mathrm{Y}$ scale.

2.6.4 Calculate the distance difference to determine the total length of the lymph node. 
2.6.5 Center the transducer on the midpoint of the determined total length.

2.6.6 Press "3D" and enter total lymph node length. Use $0.051 \mathrm{~mm}$ for the step size.

2.6.7 Due to the proximity of the transducer to the chest region, the $50 \mathrm{MHz}$ transducer may result in an unstable Doppler image due to detection of normal respiratory motion. This can be eliminated by using the "Respiration Gating" option available under the "Physiological" tab.

2.6.8 Surround the selected lymph node with the yellow box that designates the region to be analyzed by power Doppler and select "3D scan" to acquire images. Raise the transducer off of the mouse and move it to the opposite side of the neck. Lower the transducer onto the mouse and repeat the steps described above to image lymph nodes on this side of the neck.

2.7 Save image sets for subsequent analysis.

\section{Cervical Lymph Node Biopsy}

3.1 Select the desired lymph node for biopsy and maintain HF US imaging with the 50 $\mathrm{MHz}$ transducer. We chose the largest visible cervical lymph node in each side of the mouse neck. Lymph node enlargement typically indicates an inflammatory response, and therefore such nodes are ideal candidates for biopsy. In addition, we have found it is very difficult to conduct biopsies on cervical nodes smaller than $10 \mathrm{~mm}^{3}$. Prepare the needle and syringe for biopsy by placing a $1 \mathrm{ml}$ syringe with an attached $27 \mathrm{G}, 0.5$ inch needle into the syringe holder. Adjust the needle holder to orient the needle 90 degrees to the mouse neck (Figure 4A).

3.2 Prepare the stage by elevating the entire mouse platform to the level of the needle. This can be achieved by removing the 3D motor and switching to a taller platform, or by placing a solid object of suitable height under the provided short platform. A plastic microfuge tube rack is suitable for this purpose. If necessary, rotate the stage 180 degrees to biopsy nodes located on the side of the neck opposite to the needle apparatus.

3.3 Adjust the acquisition settings by selecting "Preferences", then choosing "Max \& Extended buffer". Enlarge the field of view to a depth of $8.00 \mathrm{~mm}$ and width of $9.73 \mathrm{~mm}$. Turn on the needle guide using the Screen Keys dial.

3.4 Ensure that the lymph node remains constantly in view by centering the lymph node in the middle or slightly to the left of center in the screen (Figure 4B). To obtain the entire cine loop of the procedure, press Pre-trigger on the system keyboard before beginning the biopsy.

3.5 Adjust the needle holder until the needle tip comes into view and contacts the skin (Figure 4B). Advance the needle with a firm, fast push to puncture the skin. Continue 
to advance the needle until the tip also punctures the capsule (Figure 4C) and is visible within the medulla (Figure 4D).

3.6 Once the needle is properly located within the node, gently pull the syringe plunger back between the 200-300 $\mu \mathrm{l}$ demarcations to conduct the biopsy (Figure 4D and 4E). Note that biopsy material is typically not visible within the syringe.

3.7 Gently remove the needle from the mouse neck. Expel the syringe contents into a1.5 $\mathrm{ml}$ microfuge tube. Remove the needle from the syringe, leaving the needle in the tube. Collect $1 \mathrm{~mL}$ of biopsy media with the same syringe, and then reattach the needle to the syringe while keeping the needle in the tube. Rinse the syringe and needle with the biopsy media by expelling the biopsy media into the tube. Do not pull back on the plunger while the needle is attached at any point after the biopsy. This reduces the risk of losing the biopsy material due to the small sample size.

3.8 Confirm lymph node content by histological means (Figure 4F) and analyze by additional methods (histochemistry, flow cytometry, etc.) as appropriate.

3.9 Once biopsy is complete, turn off the anesthesia and remove the rectal temperature probe. Remove excess ultrasound gel from mouse with gauze and remove the tape from each paw.

3.10 Remove the mouse from the imaging platform and return to a cage. Minimal bleeding from injection site will occur, but this stops without intervention. Monitor the mouse during recovery until full activity is resumed.

\section{Image Analysis of Cervical Lymph Nodes}

4.1 In the ultrasound software, select the image for analysis and navigate to the "Image Processing" tab. Choose "Load into 3D".

4.2 Select "3D Reconstructed Image" in top left corner, clicking on the "Display Single Pane" button. Use the zoom function to enlarge the image if desired. Toggle "Display Layout" to view the image only in B-mode, which removes the power Doppler overlay from view. This makes it easier to see the edges of the lymph node during subsequent 3-D analysis. Scroll through the image series to locate the beginning of the lymph node.

4.3 To circumscribe the lymph node, navigate to the "3D Settings" tab. Select "volume", then the "Start" button next to "Parallel".

4.4 Draw contours around the area of interest within each image by scrolling through the image stack with the computer mouse wheel. Continue until the all images that encompass the entire lymph node are marked. Choose "Finish" to complete the analysis.

4.5 At the bottom of the image, 3D volume and \% vascularity will be automatically displayed. 3D volume corresponds to the lymph node volume, and $\%$ vascularity represents the percentage of the lymph node positive for blood flow by power Doppler. 
4.6 Toggle "Display Layout" to view the power Doppler imaging as an overlay on the Bmode image. The surface view shows a net view of the volume area of interest.

Images can be exported in tagged image file (TIF) format or 3D scans as movies (.avi) for further use. 


\section{Representative Results}

The overall schematic for the imaging and biopsy procedures is shown in Figure 1. The key steps in the procedure include proper preparation of the mouse for imaging, identification of the cervical lymph nodes, correct preparation and conducting of the needle biopsy, and analysis of B-mode and Doppler images to measure volume and the amount of vascularity within each selected node using computer software.

HF US imaging of mouse cervical lymph nodes requires applying and maintaining proper anesthesia throughout the imaging period (Figure 2A), as well as complete removal of the hair covering the entire neck area (Figure 2B). The liberal application of ultrasound gel to the depilated region ensures a clear HF US signal during the procedure (Figure $\mathbf{2 C}$ ).

HF US imaging of the neck region is aided by the visualization of cervical anatomical landmarks that produce characteristic sonographic images. Figure $\mathbf{3}$ shows examples of the key organs (Figure 3A-C), imaged cervical lymph nodes in B-mode (Figure 3D) and in power Doppler mode (Figure 3E).

Real-time HF US imaging in anesthetized mice allows for guided fine needle biopsy of cervical nodes similar to what is conducted in clinical practice. Placement of the biopsy needle and attached collection syringe to the controlling microinjector equipment is shown in Figure 4A. Subsequent B-mode sonographic images show ideal needle placement prior to biopsy (Figure 4B), needle tip entry into a cervical lymph node (Figure 4C), and needle position during biopsy (Figure 4D). Close-up image shows the needle tip within the medulla of the lymph node (Figure 4E). Processing of the biopsy components by cytospin reveals abundant lymphoid cell clusters and associated connective tissue, verifying successful lymph node biopsy (Figure 4F).

Computational-based analysis of HF US images allows for detailed information to be obtained regarding lymph node architecture, volume and vascular flow. Using power Doppler mode and 3D volume measurements, percent vascularity (PV) can be calculated from image series encompassing entire nodes (Figure 5A). Additionally, 3D imaging allows for virtual lymph node reconstruction, revealing overall lymph node topography (Figure 5B). 


\section{Figure Legends}

Figure 1. Overview schematic of the steps involved in diagnostic HF US cervical lymph node imaging in mice. The key steps include 1: Preparing the mouse for HF US imaging and obtaining 40 and $50 \mathrm{MHz}$ resolution images of the neck region containing the three mouse cervical lymph nodes. 2: Fine needle image-guided biopsy of cervical lymph nodes and subsequent histological analysis of biopsied material and 3: Computer-aided image analysis and 3D reconstruction of lymph node images obtained in B-mode and Doppler to determine the respective lymph node volume and percent $(\%)$ of vascular flow.

Figure 2. Overview of the high resolution in vivo micro-imaging system for cervical lymph node assessment and biopsy. A. The HF US system is shown with an anesthetized mouse prepared for cervical lymph node imaging. Also shown is the microinjector (MI) and 3D-motor stage (3D MS) accessory equipment. B. Close up view of an anesthetized mouse prepared for HF US imaging with hair removed in neck region. C. The same mouse with the $50 \mathrm{MHz}$ transducer in place on the neck. Note the extra ultrasound gel used to facilitate neck region imaging.

Figure 3. Representative HF US cervical anatomy images in B-mode and power Doppler. A,B. B-mode images of the oral cavity, showing the cheek pouch (CP) and tongue $(T)$ visualized by imaging closest to the mouse snout. Three cervical lymph nodes are found on each side of the neck (LN), occasionally appearing as a group of hypoechoic structures in a single imaging plane (B). C. The thyroid gland (Th) is visualized in the upper thoracic region, appearing as a solid, echogenic butterfly- shaped structure. Images A-C were visualized with a $40 \mathrm{MHz}$ transducer, scale bar $=1 \mathrm{~mm}$. D,E. Representative images of normal (D) and enlarged (E) cervical lymph nodes with B-mode and power Doppler (red). Dotted lines outline individual lymph nodes. Scale bar $=0.5$ $\mathrm{mm}$.

Figure 4. Cervical lymph node biopsy set-up, imaging and cytospin analysis of biopsy material. A. The imaging platform showing the micro- injector and needle placement near the mouse neck. A wide microcentrifuge tube rack is used to slightly raise the platform (orange block), enabling proper needle placement while still allowing space for the 3D-motor stage. This arrangement minimizes time spent removing the motor stage for each mouse. B-D. Whole neck HF US images taken from a video of a cervical lymph node biopsy using the $50 \mathrm{MHz}$ transducer. B. HF US B- mode image showing the needle positioned to the side of the neck prior to biopsy. The needle tip is the hyperechoic structure just below the position of the needle guide (green dotted line) superimposed during imaging to denote the needle trajectory. The lymph node is in the center of the image. Scale bar $=1 \mathrm{~mm}$. C. Needle entry into the lymph node. D. Biopsy of the cervical lymph node. E. Zoomed biopsy of cervical lymph node. Scale bar $=0.5 \mathrm{~mm}$. F. Cytospin analysis of representative biopsy lymph material confirming successful biopsy. Scale bar $=100 \mu \mathrm{m}$.

Figure 5. Computer analysis of 3D cervical lymph node images. A. Representative screenshot of a lymph node analyzed using computer software. The node is circumscribed 
in blue; analysis results show 3D Volume and percent vascularity (PV) as indicated. B. A surface view image of the same node after $3 D$ analysis. Renders entire volume of lymph node based on measurements taken in $A$. 


\section{Discussion}

The described protocol allows for the visualization and in situ evaluation of murine cervical lymph nodes using non-invasive HF US imaging. The use of B-mode and power Doppler imaging to visualize cervical lymph node morphology, volume and lymph node blood flow provides for an experimental analysis of preclinical mouse model systems similar to that used for the characterization of cervical patient nodes in clinical practice. The ability to monitor the supraclavicular lymph nodes via fine needle biopsy also provides a useful technique for detecting immune cell alterations and the presence of foreign cell types or bacteria during oral cavity disease-induced lymphadenopathies in mice. The ease of use of use and low cost associated with HF US allows for the rapid screening of cervical lymph node status in a wide variety of animal models.

A critical step in this protocol is the initial successful identification of the cervical lymph nodes in HF US images. Use of oral cavity and thyroid as imaging landmarks greatly aids in orienting the user to the proper region where the lymph nodes are localized. The characteristic bean-shape, hypoechoic nature and superficial location close to the skin surface allows for rapid confirmatory identification of the cervical lymph nodes within the proper neck region. While all three nodes may be visible in a single imaging plane (Figure 3B), typically one or two nodes are captured during imaging. Minor adjustments of the transducer position can be conducted to render different imaging planes visible, allowing visualization of all nodes on a single side of the neck.

The superficial nature of mouse cervical lymph nodes confers excessive mobility when even slight pressure is applied to the skin via the transducer head. This can be counteracted by slowly applying the transducer head into the ultrasound gel on the mouse neck until the landmark images are identified. Lymph node mobility can also complicate the fine needle biopsy, especially when using transducers in the higher resolution $(50 \mathrm{MHz})$ range. Centered images of lymph nodes for biopsy are typically pushed out of the field of view due to the force of the biopsy needle needed to puncture the overlying skin and capsule. This can be remedied by the off-center positioning of the lymph node towards the direction of needle entry, providing space for the lymph node to be pushed across but still remain within the field of view during biopsy.

HF US has been used to successfully visualize orthotopic HNSCC tumors ${ }^{24}$, and has the potential to monitor cervical node metastasis in mice with oral tumors ${ }^{23}$. In addition to ultrasound, bioluminescence imaging has also been used to visualize orthotopic oral tumor formation and cervical lymph node metastasis in live mice ${ }^{25,26}$. Bioluminescence imaging has a distinct advantage in being able to directly quantify tumor progression and metastatic burden over time in the same animal. While undeniably useful, bioluminescence imaging is unable to measure many of the parameters visualized by HF US, including lymph node morphology, nodal volumes or blood flow. Bioluminescence imaging also requires specialized dark boxes to maintain mice during imaging, rendering this technique unsuitable for adaptation for fine needle biopsy.

Furthermore, bioluminescence imaging requires production of tumor cells that stably express the luciferase enzyme, allowing this technique to be used only in cases of 
orthotopic xenografts with luciferase-transfected tumor cells in immunocompromised mice, or with inducible tissue-specific transgenic systems that restrict luciferase expression in a spatio-temporal manner specific to the tissue of tumor origin. In contrast, HF US can be used in conjunction with bioluminescence images in these models, as well as being capable of imaging cervical lymph nodes in models of carcinogen-induced oral tumors in mice with complete immune systems ${ }^{27,28}$. While HF US may be more adaptable to most mouse models of oral cancer, the combined information that can be obtained from bioluminescence and HF US imaging in systems where tumor cells express luciferase can provide a more complete picture of cervical lymph node involvement than either imaging modality alone.

The ability to identify and detect mouse cervical lymph nodes in real time allows for this technique to be used in most models of oral disease that result in inflammatory lymphadenopathy where the animal can be maintained in an inverted position under shortterm anesthesia. Detection of lymph node metastasis or bacterial infection and the concomitant impact on lymph node morphology in living animals presents a significant benefit over traditional methods that require lymph nodes to be removed from dead animals for histological processing. Combining HF US with fine needle biopsy allows a means for conducting routine pathological analysis of cervical lymph nodes, similar to what is conducted in the clinic, providing an improved method for monitoring disease progression in most current mouse models of oral cavity diseases. 


\section{Acknowledgements}

This work was supported by Dorothy D. Radford Endowment fund from the West Virginia University Mary Babb Randolph Cancer Center. The use of the West Virginia University Animal Models and Imaging Facility (AMIF) and Microscopy Imaging Facility (MIF) (supported by the Mary Babb Randolph Cancer Center and NIH grants P20 RR16440, P30 RR032138/GM103488 and S10 RR026378) is gratefully acknowledged. 


\section{Disclosures}

No conflicts of interest declared 


\section{References}

1 Montone, K. T. Infectious diseases of the head and neck: a review. Am J Clin Pathol 128, 35-67, doi:C05837U7J27221QM [pii]10.1309/6BBT12WGNK77N4EH (2007).

2 Bryson, T. C., Shah, G. V., Srinivasan, A. \& Mukherji, S. K. Cervical lymph node evaluation and diagnosis. Otolaryngol Clin North Am 45, 1363-1383, doi:S00306665(12)00121-1 [pii] 10.1016/j.otc.2012.08.007 (2012).

3 Joshi, P. S., Pol, J. \& Sudesh, A. S. Ultrasonography - A diagnostic modality for oral and maxillofacial diseases. Contemp Clin Dent 5, 345-351, doi:10.4103/0976237X.137942CCD-5-345 [pii] (2014).

$4 \mathrm{Oz}, \mathrm{F}$. et al. Evaluation of clinical and sonographic features in 55 children with tularemia. Vector Borne Zoonotic Dis 14, 571-575, doi:10.1089/vbz.2013.1517 (2014).

5 Niedzielska, G., Kotowski, M., Niedzielski, A., Dybiec, E. \& Wieczorek, P. Cervical lymphadenopathy in children--incidence and diagnostic management. Int J Pediatr Otorhinolaryngol $\mathbf{7 1}, \quad 51-56, \quad$ doi:S0165-5876(06)00342-9 [pii] 10.1016/j.ijporl.2006.08.024 (2007).

6 Ying, M., Bhatia, K. S., Lee, Y. P., Yuen, H. Y. \& Ahuja, A. T. Review of ultrasonography of malignant neck nodes: greyscale, Doppler, contrast enhancement and elastography. Cancer Imaging 13, 658-669, doi:10.1102/1470-7330.2013.0056 (2013).

7 Stoeckli, S. J. et al. Initial staging of the neck in head and neck squamous cell carcinoma: a comparison of CT, PET/CT, and ultrasound-guided fine-needle aspiration cytology. Head Neck 34, 469-476, doi:10.1002/hed.21764 (2012).

8 Rottey, S. et al. Evaluation of metastatic lymph nodes in head and neck cancer: a comparative study between palpation, ultrasonography, ultrasound-guided fine needle aspiration cytology and computed tomography. Acta Clin Belg 61, 236-241, doi:10.1179/acb.2006.039 (2006).

9 Greco, A. et al. Ultrasound biomicroscopy in small animal research: applications in molecular and preclinical imaging. J Biomed Biotechnol 2012, 519238, doi:10.1155/2012/519238 (2012).

10 Chen, J. J., Fu, S. Y., Chiang, C. S., Hong, J. H. \& Yeh, C. K. Characterization of tumor vasculature distributions in central and peripheral regions based on Doppler ultrasound. Med Phys 39, 7490-7498, doi:10.1118/1.4762683 (2012). 
11 El Kaffas, A., Giles, A. \& Czarnota, G. J. Dose-dependent response of tumor vasculature to radiation therapy in combination with Sunitinib depicted by threedimensional high-frequency power Doppler ultrasound. Angiogenesis 16, 443-454, doi:10.1007/s10456-012-9329-2 (2013).

12 Bachawal, S. V. et al. Earlier detection of breast cancer with ultrasound molecular imaging in a transgenic mouse model. Cancer Res 73, 1689-1698, doi:00085472.CAN-12-3391 [pii] 10.1158/0008-5472.CAN-12-3391 (2013).

13 Loveless, M. E. et al. A method for assessing the microvasculature in a murine tumor model using contrast-enhanced ultrasonography. J Ultrasound Med 27,1699-1709, doi:27/12/1699 [pii] (2008).

14 Snyder, C. S. et al. Complementarity of ultrasound and fluorescence imaging in an orthotopic mouse model of pancreatic cancer. BMC Cancer 9, 106, doi:1471-2407-9106 [pii] 10.1186/1471-2407-9-106 (2009).

15 Kodama, T. et al. Volumetric and angiogenic evaluation of antitumor effects with acoustic liposome and high-frequency ultrasound. Cancer Res 71, 6957-6964, doi:0008-5472.CAN-11-2389 [pii] 10.1158/0008-5472.CAN-11-2389 (2011).

16 Hwang, M., Hariri, G., Lyshchik, A., Hallahan, D. E. \& Fleischer, A. C. Correlation of quantified contrast-enhanced sonography with in vivo tumor response. $J$ Ultrasound Med 29, 597-607, doi:29/4/597 [pii] (2010).

17 Li, L., Mori, S., Sakamoto, M., Takahashi, S. \& Kodama, T. Mouse model of lymph node metastasis via afferent lymphatic vessels for development of imaging modalities. PLoS One 8, e55797, doi:10.1371/journal.pone.0055797PONE-D-12-17343 [pii] (2013).

18 Papadopoulos, G. et al. A Mouse Model for Pathogen-induced Chronic Inflammation at Local and Systemic Sites. J Vis Exp, doi:10.3791/51556 (2014).

19 Vulcano, A. B. et al. Oral infection with enteropathogenic Escherichia coli triggers immune response and intestinal histological alterations in mice selected for their minimal acute inflammatory responses. Microbiol Immunol 58, 352-359, doi:10.1111/1348-0421.12153 (2014).

20 Myers, J. N., Holsinger, F. C., Jasser, S. A., Bekele, B. N. \& Fidler, I. J. An orthotopic nude mouse model of oral tongue squamous cell carcinoma. Clin Cancer Res 8, 293298 (2002).

21 Kanojia, D. \& Vaidya, M. M. 4-nitroquinoline-1-oxide induced experimental oral carcinogenesis. Oral Oncol 42, 655-667 (2006). 
22 Van den Broeck, W., Derore, A. \& Simoens, P. Anatomy and nomenclature of murine lymph nodes: Descriptive study and nomenclatory standardization in BALB/cAnNCrl mice. J Immunol Methods 312, 12-19, doi:S0022-1759(06)00064-0 [pii] 10.1016/j.jim.2006.01.022 (2006).

23 Walk, E. L., McLaughlin, S., Coad, J. \& Weed, S. A. Use of high frequency ultrasound to monitor cervical lymph node alterations in mice. PLoS One 9, e100185, doi:10.1371/journal.pone.0100185PONE-D-13-52241 [pii] (2014).

24 Pezold, J. C., Zinn, K., Talbert, M. A., Desmond, R. \& Rosenthal, E. L. Validation of ultrasonography to evaluate murine orthotopic oral cavity tumors. ORL J Otorhinolaryngol Relat Spec 68, 159-163, doi:91324 [pii] 10.1159/000091324 (2006).

25 Sano, D. \& Myers, J. N. Metastasis of squamous cell carcinoma of the oral tongue. Cancer Metastasis Rev 26, 645-662 (2007).

26 Sano, D. et al. The effect of combination anti-endothelial growth factor receptor and anti-vascular endothelial growth factor receptor 2 targeted therapy on lymph node metastasis: a study in an orthotopic nude mouse model of squamous cell carcinoma of the oral tongue. Arch Otolaryngol Head Neck Surg 135, 411-420, doi:135/4/411 [pii] 10.1001/archoto.2009.14 (2009).

27 Tang, X. H., Knudsen, B., Bemis, D., Tickoo, S. \& Gudas, L. J. Oral cavity and esophageal carcinogenesis modeled in carcinogen-treated mice. Clin Cancer Res 10, 301-313 (2004).

28 Vitale-Cross, L. et al. Chemical carcinogenesis models for evaluating moleculartargeted prevention and treatment of oral cancer. Cancer Prev Res (Phila) 2, 419-422, doi:1940-6207.CAPR-09-0058 [pii] 10.1158/1940-6207.CAPR-09-0058 (2009). 
1. Prepare and image mouse
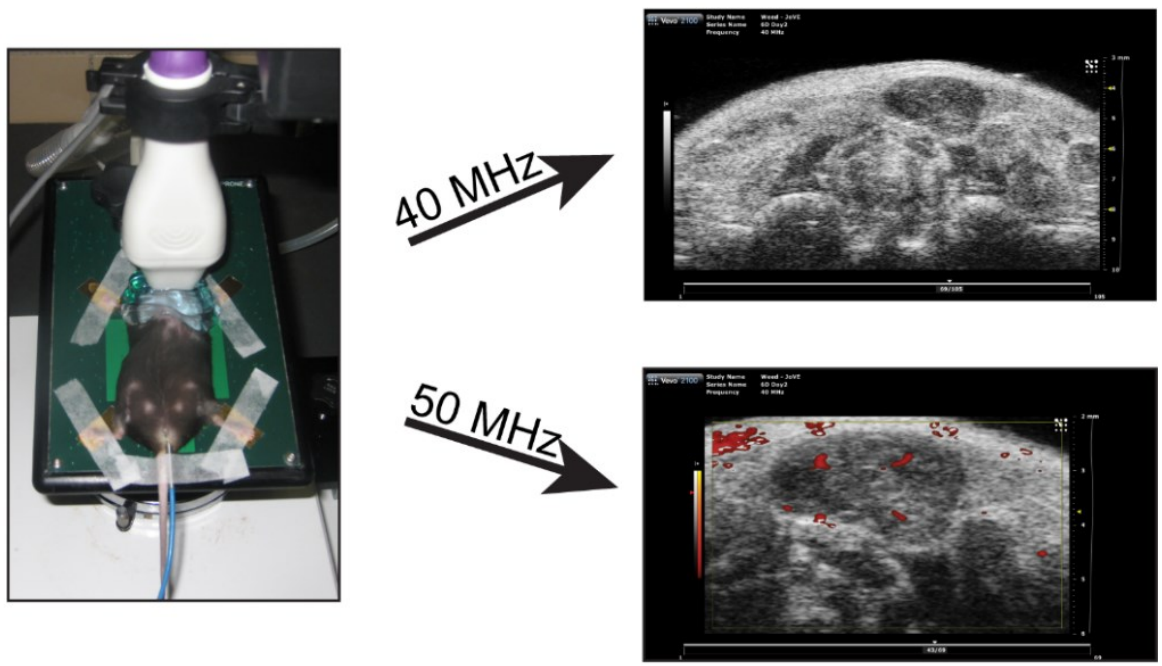

2. Biopsy
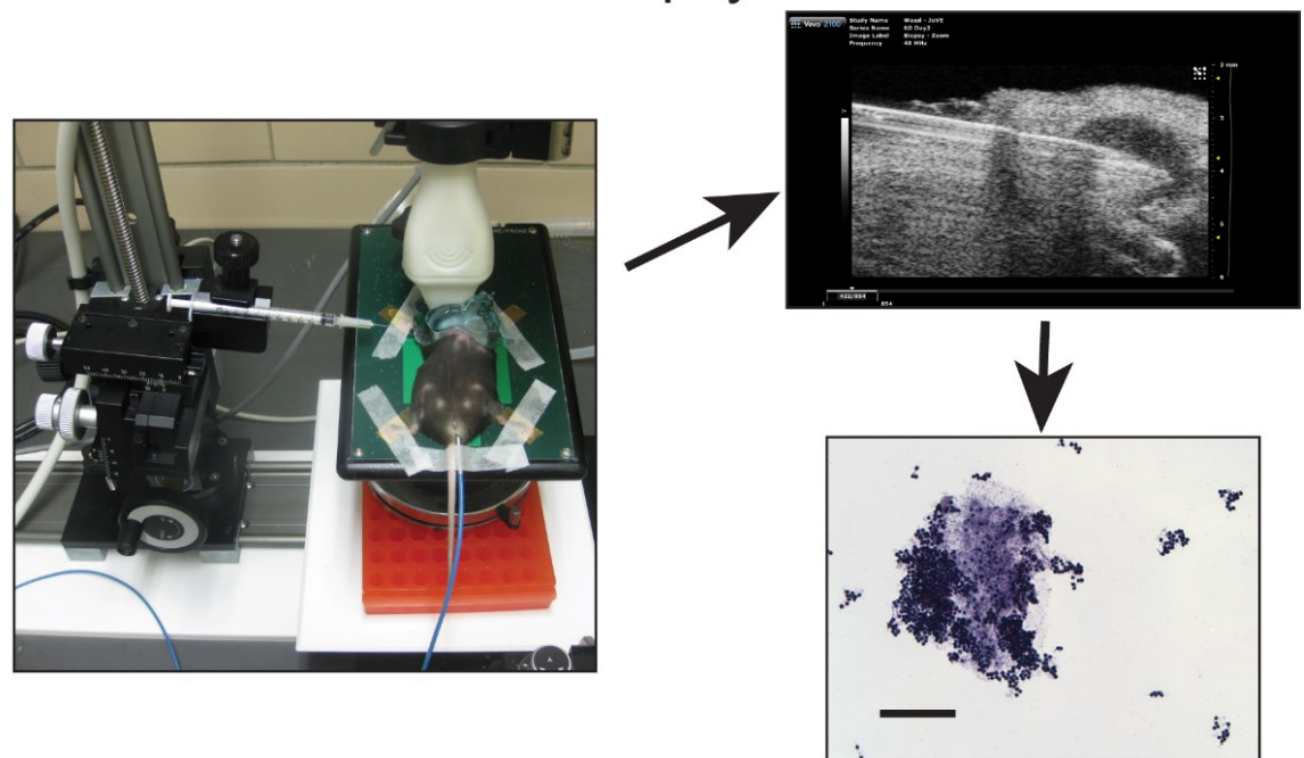

3. Image analysis
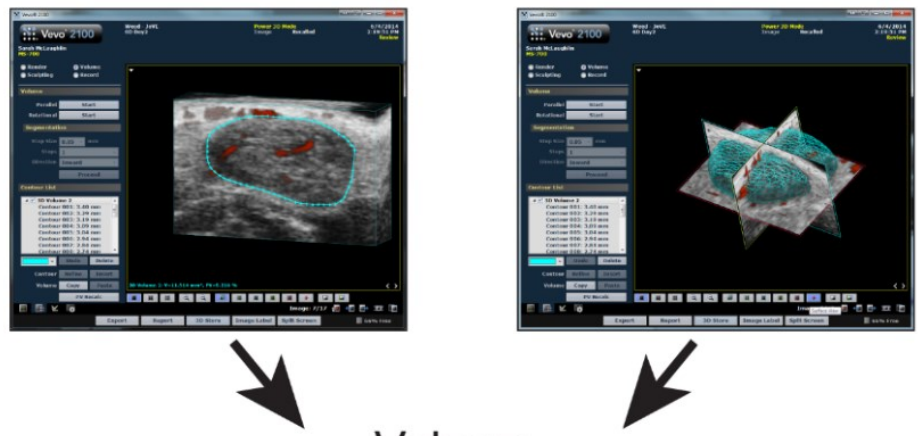

Volume

$\%$ Vascularity

Figure 1 Walk et al. 

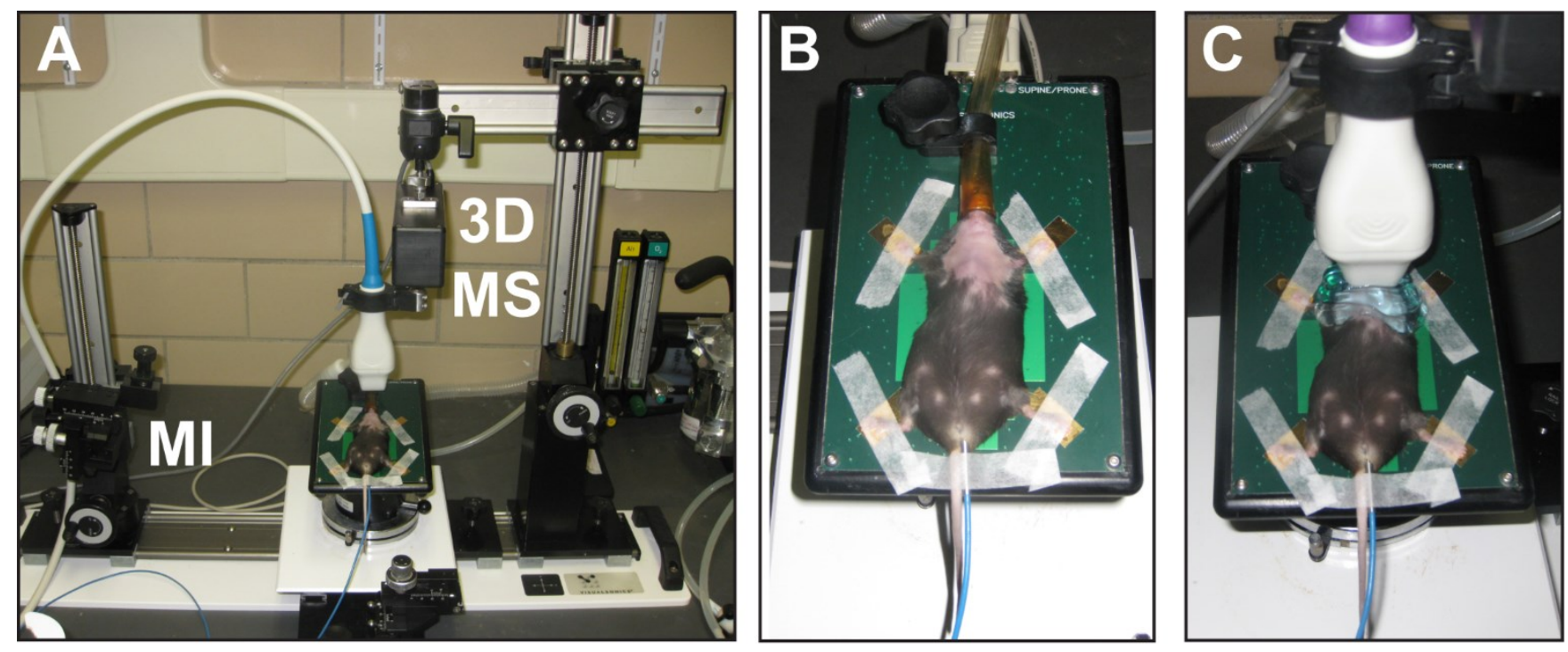

Figure 2 Walk et al. 


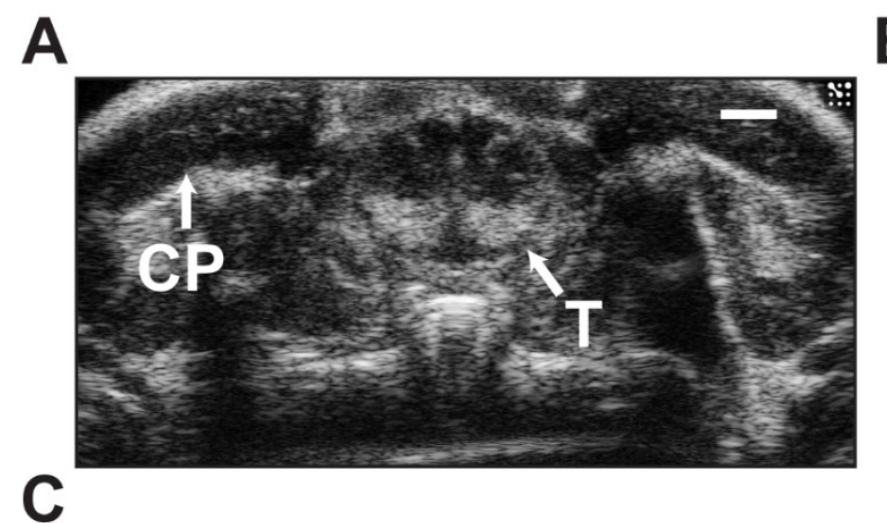

B
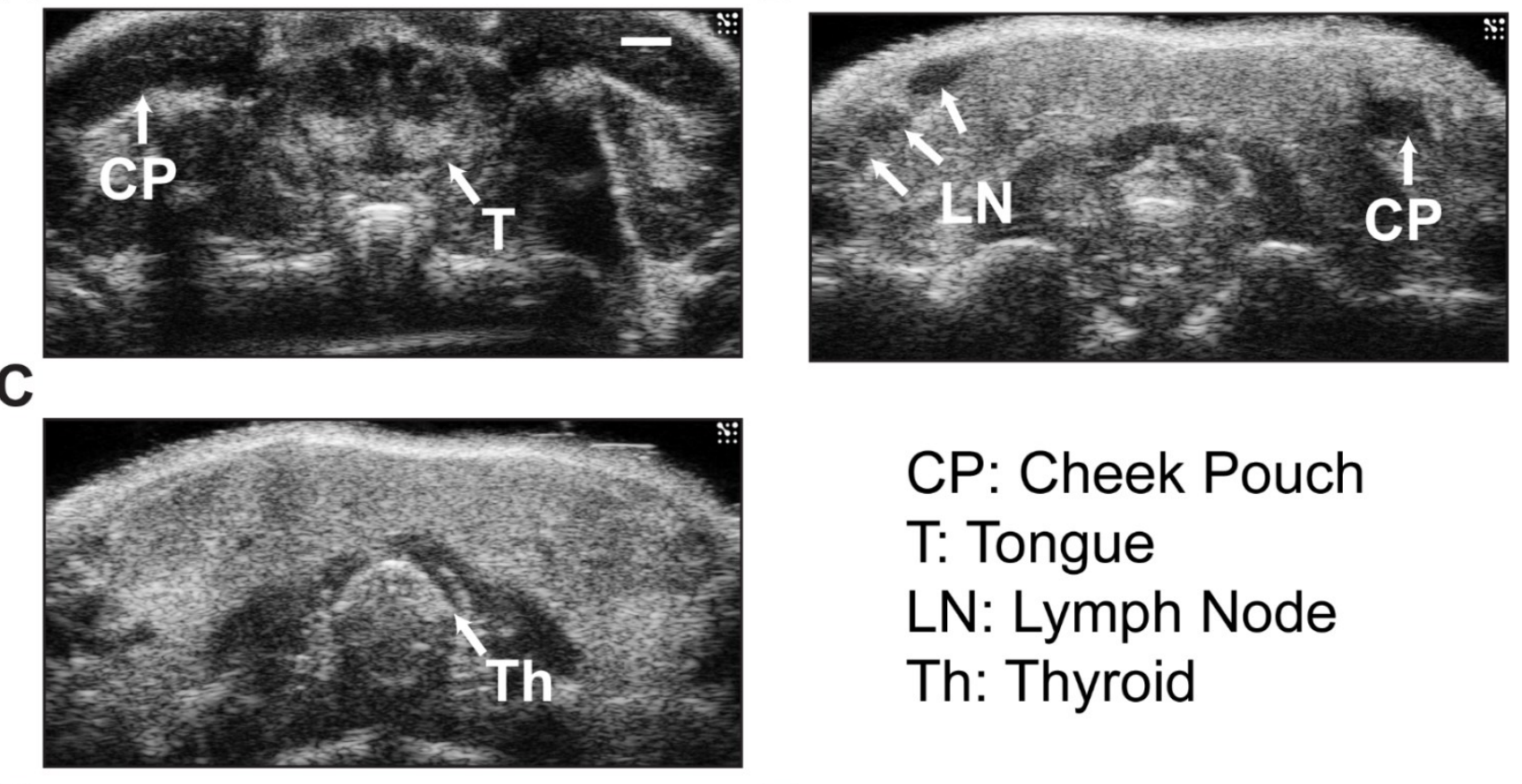

\section{CP: Cheek Pouch}

$\mathrm{T}$ : Tongue

LN: Lymph Node

Th: Thyroid
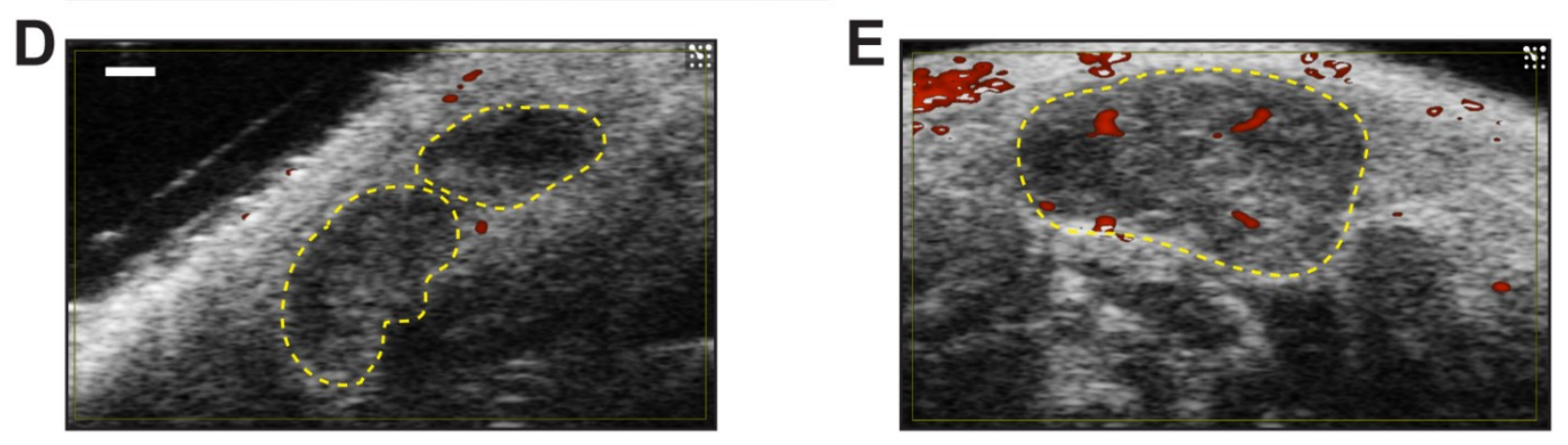

Figure 3 Walk et al. 
A

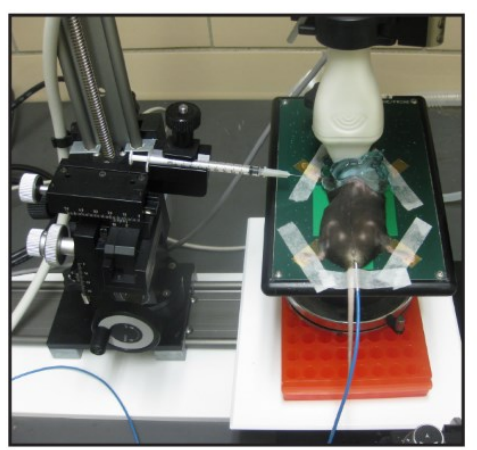

D

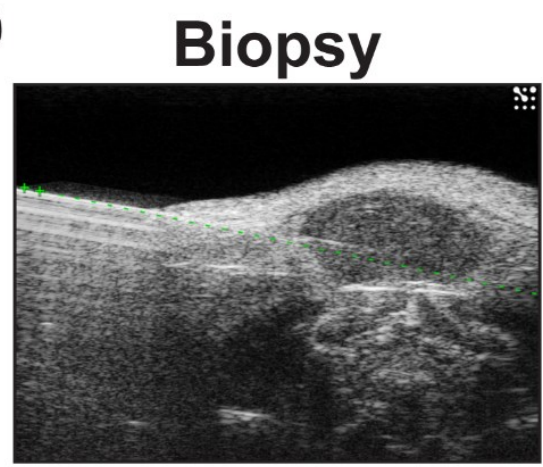

B Needle Position

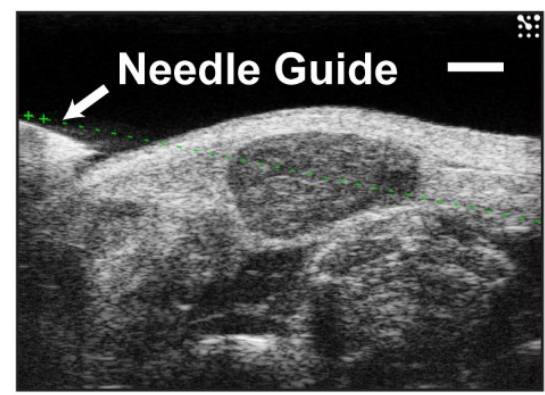

E Biopsy Zoom

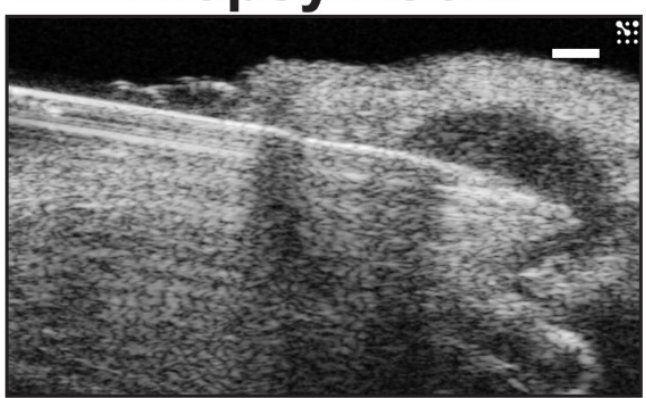

C Needle Entry

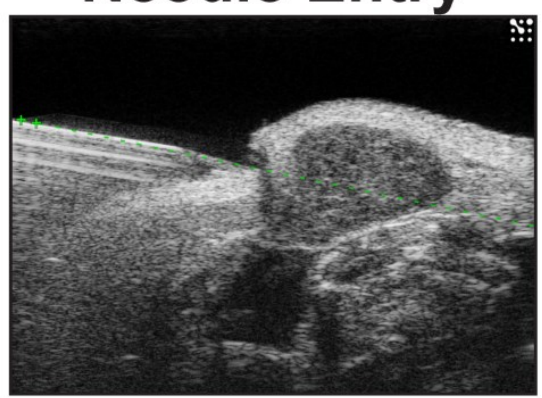

F Cytospin

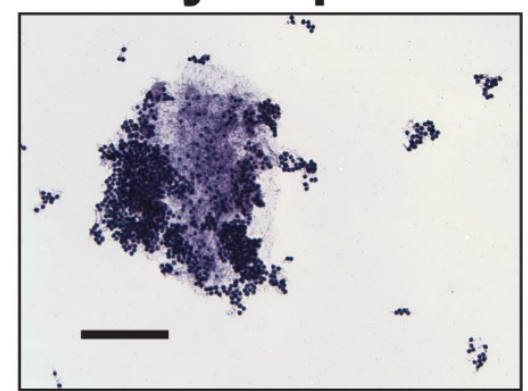

Figure 4 Walk et al.

A

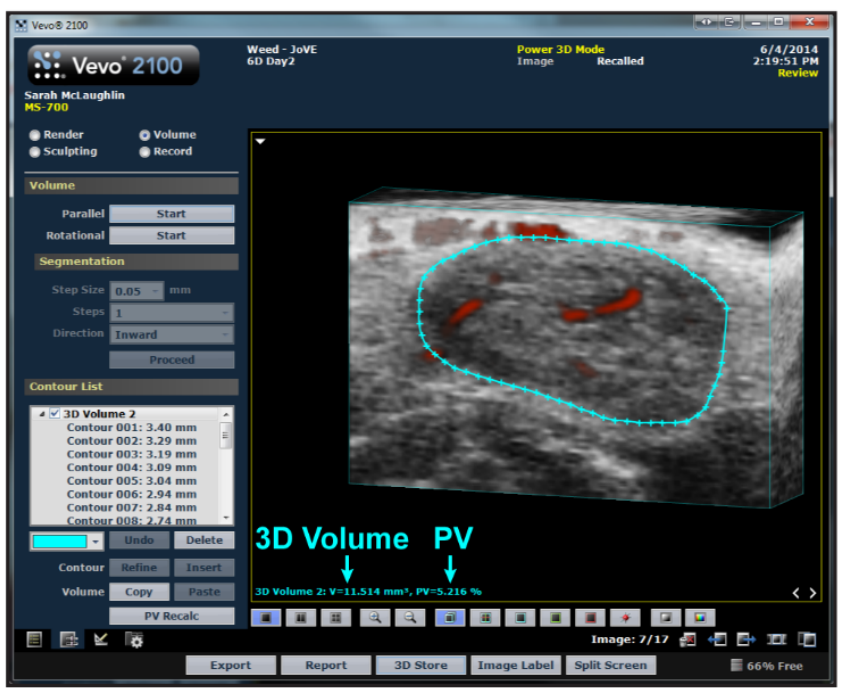

B

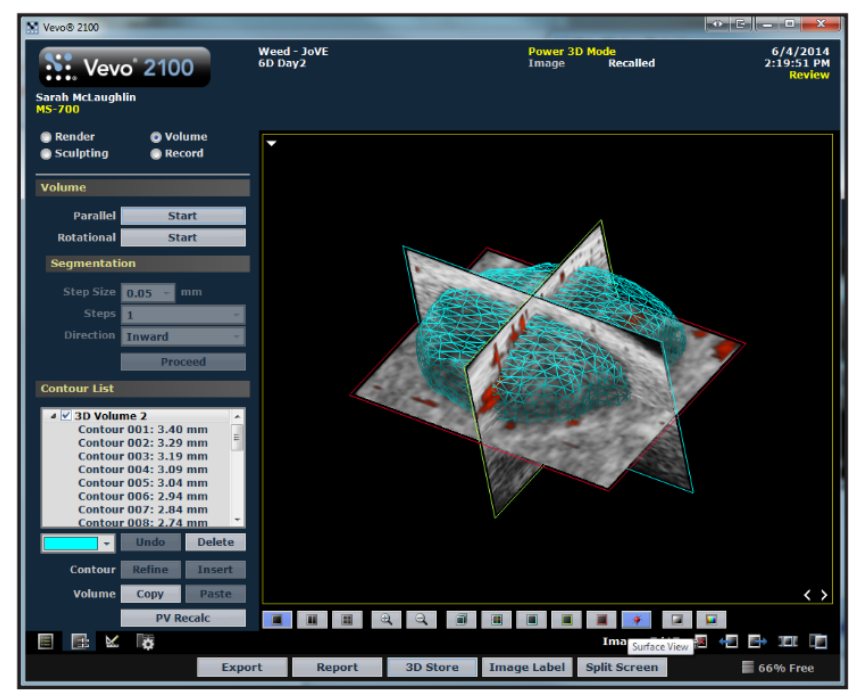

Figure 5 Walk et al. 


\section{Elyse L. Walk}

Curriculum vitae

\section{EDUCATION}

PhD. Biomedical Sciences, Program in Cancer Cell Biology, West Virginia University, Morgantown, WV. October 24, 2014

BS, Biology, George Mason University, Fairfax, VA. Degree conferral: January 15, 2005

\section{PROFESSIONAL WORK HISTORY}

August, 2008-Present

PhD Candidate, West Virginia University, Mary Babb Randolph Cancer Center, in the Lab of Scott Weed, PhD, Morgantown, WV Research involves mechanisms head and neck cancer cell invasion and metastasis.

August 2006-July 2007

Research Assistant I, Immunochemistry Services, Covance, Vienna, VA.

A production environment, performed immunoassays for clients in a Good Laboratory Practice environment.

May 2004-August 2006

Post-Baccalaureate Research Training Award Fellow, Genetics Branch, Center for Cancer Research, National Institutes of Health/National Cancer Institute, Bethesda, MD.

Advisor: Karen Woodson

Research involved using gene methylation as a cancer screening biomarker for breast and prostate cancers

\section{RELEVANT TECHNICAL ABILITIES}

- Small animal models: General mouse handling and colony maintenance, genotyping, intraperitoneal injections, chemical carcinogenesis, transgenic/conditional/Cre-mediated gene knock-out, ultrasound imaging, dissections

- Cellular adhesion, migration and invasion assays: ECIS, Boyden chamber migration, invadopodia-based gelatin degradation, 3D spheroid and organotypic invasion models

- Nucleic acid analysis: Tissue extractions, genomic DNA primer design, standard PCR and gel electrophoresis, real-time PCR, promoter bisulfite modifications, pyrosequencing, laser capture microdissection

- DNA subcloning for mammalian expression

- Protein analysis: Western blotting, immunoprecipitation, ELISA/ECL, SDS-PAGE

- Tissue/Cell Culture techniques: Maintaining cell lines, cellular transfection, lentivirus preparation and subsequent cellular infection, 3D cultures 
- Cell and tissue preparation for immunofluorescence/immunohistochemistry

- Systems: Fluorescent, laser scanning confocal and brightfield microscopy: Olympus AZ70 epifluorescent/transmitted light microscope, Zeiss LSM 510 laser scanning confocal, Zeiss Axiovert 200M, Vevo 2100 High-Frequency Ultrasound

- Software: Paint.net, Adobe Photoshop, Adobe Illustrator, ImageJ, Zeiss AxioVision and LSM, Microsoft PowerPoint and Excel, Vevo and VevoCQ, Stereo Investigator

\section{PROFESSIONAL DEVELOPMENT}

\section{Courses}

- $18^{\text {th }}$ Annual Short Course on Experimental Models of Human Cancer, Jackson Labs, Bar Harbor, ME. August 21-30, 2009

- Received a scholarship from Jackson Labs to attend; poster presentation

- Foundation for Advanced Education in the Sciences at the National Institutes of Health, Bethesda, MD. TRAC12: Transgenic Technology: Methods and Application. January 913, 2012

- Received WVU Biomedical Sciences graduate student travel award

\section{Conferences}

- The American Association of Cancer Research 102 ${ }^{\text {nd }}$ Annual Meeting, April 2-6, 2011

- Mini-Symposium Presentation: Mechanisms Regulating Migration and Invasion In vivo. "Cortactin and coronin 1B cooperate to promote tumor cell invasion in head and neck squamous cell carcinoma."

- $4^{\text {th }}$ Biennial IDeA Symposium, Washington DC, June 25-27, 2012

- Featured Poster

- Appalachia Regional Cell Conference, Student-run meeting sponsored by ASCB, October 26, 2013

- Oral presentation: "Detection of Pre-cancerous Cervical Lymph Node T-cell Expansion by High frequency Ultrasound in 4-NQO Treated Mice"

- Southeast Regional IDeA Meeting, November 15-17, 2013

- Oral presentation: "Detection of Pre-cancerous Cervical Lymph Node T-cell Expansion by High frequency Ultrasound in 4-NQO Treated Mice"

- The American Society for Cell Biology Annual Meeting, December 14-18, 2013

- Poster presentation: "Detection of Pre-cancerous Cervical Lymph Node T-cell Expansion by High frequency Ultrasound in 4-NQO Treated Mice"

- Received travel award

Other 
- Fujifilm VisualSonics-JoVE North and South America contest winner for abstract "Detection of Pre-cancerous Cervical Lymph Node T-cell Expansion by High frequency Ultrasound in 4-NQO Treated Mice" 2014. http://www.visualsonics.com/jove-grant-awardcontest-winners

\section{LEADERSHIP/TEACHING/TRAINING EXPERIENCE}

- Laboratory management: Responsible for ordering, obtaining quotes and interacting with sales representatives. Maintained and updated databases to keep track of lab resources.

- Trained several INBRE and COBRE summer students and undergraduate honors students in how to perform various laboratory techniques, and collect and interpret data.

- Contributed to organization of Cell Methods course provided to first-year Biomedical Science students in order to familiarize students new to laboratory research with techniques; taught Animal Models lecture, Fall 2011 and 2012.

- Biomedical Science Program representative for the WVU Health Sciences Center Student Advisory Board, Fall 2011-2013. Representatives listen to concerns of students and bring up issues at monthly meetings to the chancellor. The board also holds a fundraiser each spring for a local charity.

- Expanding Your Horizons Conference Presenter, Morgantown, WV. April 20, 2013

- Conference held to introduce young girls and women to STEM careers. Held a "Genetic Traits Bingo" workshop with another volunteer to teach about the basics of genetics to middle school-aged girls

\section{PROFESSIONAL MEMBERSHIPS}

- The American Society for Cell Biology

- The American Association for Cancer Research

- The Association for Women in Science

\section{SCHOLARLY ACTIVITIES}

- Cell Biology Training Program: A program to provide an interactive research environment for students and faculty with a focus on cell biology, and provide training in different stateof-the-art approaches to research in cell biology.

- Journal Club: Weekly discussion and analysis of the most current topics in cancer biology/therapeutics.

- Cancer Cell Biology Student Research Meeting: A bi-weekly, informal, student-based meeting focused on discussing and troubleshooting thesis projects, as well as encouraging networking between graduate students of different labs.

- Van Liere Research Day: West Virginia University's yearly celebration of the biomedical research being conducted at its Health Sciences Center campus. Poster presented in 2010, 2012 and 2014. 
- Student Seminar Presentations: Formal seminars given annually that are designed to allow students to present their research and to equip them with the fundamentals of scientific speaking in front of faculty and peers.

\section{PUBLICATIONS}

Walk EL, McLaughlin S, Coad J, Weed SA. Use of High Frequency Ultrasound to Monitor Cervical Lymph Node Alterations in Mice. PLoS One (23 Jun 2014). 10.1371/journal.pone.0100185

Hayes KE, Walk EL, Ammer AG, Kelley LC, Martin KH, Weed SA. Ableson kinases negatively regulate invadopodia function and invasion in head and neck squamous cell carcinoma by inhibiting an HB-EGF autocrine loop. Oncogene (2013) 32, 4766-4777.

Martin KH, Hayes KE, Walk EL, Ammer AG, Markwell SM, Weed SA. Quantitative measurement of invadopodia-mediated extracellular matrix proteolysis in single and multicellular contexts. $J$ Vis Exp. 2012 Aug 27;(66):e4119.

Walk, EL; Weed, SA Recently Identified Biomarkers That Promote Lymph Node Metastasis in Head and Neck Squamous Cell Carcinoma. Cancers 2011, 3, 747-772.

Woodson K, O'Reilly KJ, Hanson JC, Nelson D, Walk EL, Tangrea JA. The usefulness of the detection of GSTP1 methylation in urine as a biomarker in the diagnosis of prostate cancer. $J$ Urol. 2008 Feb;179(2):508-11; discussion 511-2.

Savage SA, Woodson K, Walk E, Modi W, Liao J, Douglass C, Hoover RN, Chanock SJ; National Osteosarcoma Etiology Study Group. Analysis of genes critical for growth regulation identifies Insulin-like Growth Factor 2 Receptor variations with possible functional significance as risk factors for osteosarcoma.. Cancer Epidemiol Biomarkers Prev. 2007 Aug;16(8):1667-74.

Woodson K, O'Reilly KJ, Ward DE, Walter J, Hanson J, Walk EL, Tangrea JA. CD44 and PTGS2 methylation are independent prognostic markers for biochemical recurrence among prostate cancer patients with clinically localized disease. Epigenetics. 2006 Oct-Dec;1(4):183-6. 